\title{
Introducing Financial Frictions and Unemployment into a Small Open Economy Model*
}

\author{
Lawrence J. Christiano $^{\dagger} \quad$ Mathias Trabandt Karl Walentin $^{\S}$ \\ January 6, 2010
}

\begin{abstract}
The current financial crisis has made it abundantly clear that business cycle modeling no longer can abstract from financial factors. It is also becoming increasingly clear that the stylized modeling of labor markets without explicit unemployment that is the current standard approach has its limitations. Some questions which the dominating extant business cycle models are mute on, but that we would like to answer are: How important are financial and labor market frictions for the business cycle dynamics of a small open economy? In particular, what are the quantitative effects of financial factors on output and inflation, and how do they interact with monetary policy? What drives the variation in the intensive and extensive margin of labor supply respectively? What is the estimated Frisch elasticity in a model that allows for both an intensive and an extensive margin of labor supply? In order to address these questions we extend what is becoming the standard new Keynesian model in three important dimensions. First, we incorporate financial frictions in the accumulation and management of capital. Second, we model the labor market using a search and matching framework. Third, we extend the model into a small open economy setting. We make a theoretical contribution by incorporating endogenous job separation in this rich framework. Finally, we estimate the full model using Bayesian techniques and illustrate the importance of the various frictions.
\end{abstract}

Keywords: DSGE, financial frictions, labor market frictions, unemployment, small open economy, Bayesian estimation.

JEL codes: E0, E3, F0, F4, G0, G1, J6.

*Thanks to Malin Adolfson, Mikael Carlsson, Christopher Erceg, Simon Gilchrist, Jesper Hansson, Skander Van den Heuvel, Jesper Lindé, Henrik Lundvall, Antonella Trigari, Mattias Villani, Peter Welz and seminar participants at various presentations. The views expressed in this paper are solely the responsibility of the authors and should not be interpreted as reflecting the views of the Executive Board of Sveriges Riksbank or of the European Central Bank.

†Northwestern University, Department of Economics, 2001 Sheridan Road, Evanston, Illinois 60208, USA. Phone: +1-847-491-8231. E-mail: l-christiano@northwestern.edu.

${ }^{\ddagger}$ European Central Bank and Sveriges Riksbank. Contact Addresses: European Central Bank, Kaiserstrasse 29, 60311 Frankfurt am Main, Germany. Phone: +49 6913446321 . E-mail: mathias.trabandt@ecb.int. Sveriges Riksbank, Research Division, 10337 Stockholm, Sweden. Phone: +46-8-787 0438. E-mail: mathias.trabandt@riksbank.se

${ }^{\S}$ Sveriges Riksbank, Research Division, 10337 Stockholm, Sweden. Phone: +46-8-787 0491. E-mail: karl.walentin@riksbank.se 


\section{Contents}

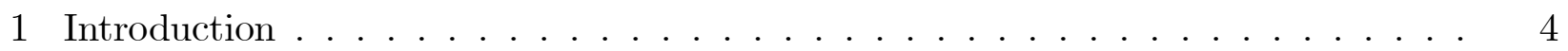

2 The Baseline Small Open Economy Model . . . . . . . . . . . . . . . . . 7

2.1 Production of the Domestic Homogeneous Good . . . . . . . . . . . . . . . 7

2.2 Production of Final Consumption and Investment Goods . . . . . . . . . . 10

2.3 Exports and Imports . . . . . . . . . . . . . . . . . . . . . . 11

2.3 .1 Exports . . . . . . . . . . . . . . . . . 13

2.3 .2 Imports . . . . . . . . . . . . . . . . . . . . . . 15

2.4 Households . . . . . . . . . . . . . . . . . . . . . . . . . . . . . . . . . . 18

2.4.1 Technology for Capital Accumulation . . . . . . . . . . . . . . . 18

2.4.2 Household Consumption and Investment Decisions _ . . . . . . . . . 18

2.4 .3 Financial Assets . . . . . . . . . . . . . . . . . . . . . . . 20

2.4.4 Wage Setting . . . . . . . . . . . . . . . . . . . 23

2.5 Fiscal and Monetary Authorities . . . . . . . . . . . . . . . . . . 24

2.6 Foreign variables . . . . . . . . . . . . . . . . . . . . . . . . . . . . . . . 26

2.7 Resource Constraints . . . . . . . . . . . . . . . . . . . . . . . . 27

2.7.1 Resource constraint for domestic homogeneous output . . . . . . . . 28

2.7 .2 Trade Balance . . . . . . . . . . . . . . . . . . . . . . . . . . . . 28

2.7 .3 Restrictions across inflation rates . . . . . . . . . . . . . . . 29

2.8 Endogenous Variables of the Baseline Model . . . . . . . . . . . . . . . . 30

3 Introducing Financial Frictions into the Model . . . . . . . . . . . . . . . . 30

3.1 Modifying the Baseline Model . . . . . . . . . . . . . . . . . . 33

3.1 .1 The Individual Entrepreneur . . . . . . . . . . . . . . . . . . . . 33

3.1.2 Aggregation Across Entrepreneurs and the Risk Premium . . . . . . . 37

3.2 Solving the Financial Frictions Model . . . . . . . . . . . . . . . . . 38

3.2.1 Equilibrium Conditions . . . . . . . . . . . . . . . . . . . . 38

4 Introducing Employment Frictions into the Model . . . . . . . . . . . . . . . . . 40

4.1 Sketch of the Model . . . . . . . . . . . . . . . . . . . . . . . . . . 41

4.2 Labor Hours . . . . . . . . . . . . . . . . . . . . . . . . . . . . 43

4.3 Vacancies and the Employment Agency Problem . . . . . . . . . . . . . . 45

4.4 Worker Value Functions . . . . . . . . . . . . . . . . . . . . 47

4.5 Separation Decision . . . . . . . . . . . . . . . . . . . . 48

4.6 Bargaining Problem . . . . . . . . . . . . . . . . . . . 50

4.7 Resource Constraint in the Employment Frictions Model . . . . . . . . . . . 51

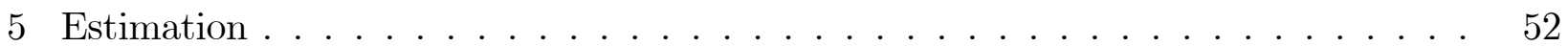

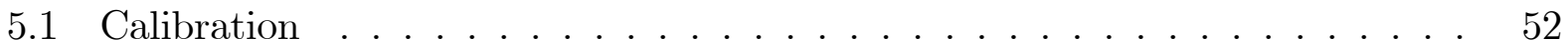

5.2 Choice of priors . . . . . . . . . . . . . . . . . . 54

5.3 Data . . . . . . . . . . . . . . . . . . . 55

5.4 Shocks . . . . . . . . . . . . . . . . . . . 56

5.5 Measurement errors . . . . . . . . . . . . . . . . . . . . . . . 57

5.6 Measurement equations . . . . . . . . . . . . . . . . . . . . 57

5.7 Estimation results . . . . . . . . . . . . . . . . . . . . . . . . . . . . . 59

5.7 .1 Posterior parameter values . . . . . . . . . . . . . . . 59

5.7.2 Model Moments and Variance Decomposition . . . . . . . . . . . 60 
5.7.3 Smoothed shock processes and impulse response functions . . . . . 61

5.8 Extension - vacancy posting costs vs. hiring costs . . . . . . . . . . . 62

6 Conclusion . . . . . . . . . . . . . . . . . . . . . . . . . . . . . . . . . . . . . . . . . 63

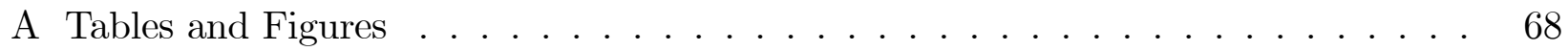

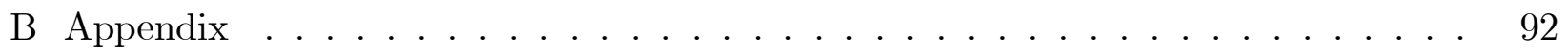

B.1 Scaling of Variables . . . . . . . . . . . . . . . . . . . . . . . . . . . . . . . . . . .

B.2 Functional forms . . . . . . . . . . . . . . . . . . . . . 93

B.3 Baseline Model . . . . . . . . . . . . . . . . . . . 94

B.3.1 First order conditions for domestic homogenous good price setting . 94

B.3.2 First order conditions for export good price setting . . . . . . . . . 96

B.3.3 Demand for domestic inputs in export production . . . . . . . . . . . 97

B.3.4 First order conditions for export good price setting . . . . . . . . . . 98

B.3.5 Wage setting conditions in baseline model . . . . . . . . . . . . 99

B.3.6 Output and aggregate factors of production . . . . . . . . . . . . . 104

B.4 Equilibrium Conditions from the Employment Frictions Model . . . . . . . 106

B.4.1 Labor Hours . . . . . . . . . . . . . . . . . . 106

B.4.2 Vacancies and the Employment Agency Problem . . . . . . . . . . . . 106

B.4.3 Agency Separation Decisions . . . . . . . . . . . . . . . . 111

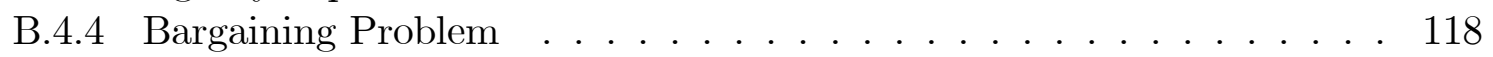

B.4.5 Final equilibrium conditions . . . . . . . . . . . . . . . . 120

B.4.6 Characterization of the Bargaining Set . . . . . . . . . . . . 121

B.5 Summary of equilibrium conditions for Employment Frictions in the Baseline

Model . . . . . . . . . . . . . . . . . . . . 122

B.6 Summary of equilibrium conditions of the Full Model . . . . . . . . . . . . . 122 


\section{Introduction}

The current financial crisis has made it abundantly clear that business cycle modeling no longer can abstract from financial factors. It is also becoming increasingly clear that the stylized modeling of labor markets without explicit unemployment that is the current standard approach has its limitations, and that there are potential benefits from integrating recent progress in labor market modeling into richer macro models. Some questions that the dominating extant business cycle models are mute on, but that we would like to answer are: How important are financial and labor market frictions for the business cycle dynamics of a small open economy? In particular, what are the quantitative effects of financial factors on output and inflation, and how do they interact with monetary policy? Furthermore, what drives the variation in the intensive and extensive margin of labor supply respectively? What is the estimated Frisch elasticity in a model that allows for both an intensive and an extensive margin of labor supply? What are the spillover effects of financial market disturbances to unemployment in a small open economy? In order to address these questions we extend what is becoming the standard new Keynesian model, see e.g. Christiano, Eichenbaum and Evans (2005) in three important dimensions.

First, we incorporate financial frictions in the accumulation and management of capital similar to Bernanke, Gertler and Gilchrist (1999) and Christiano, Motto and Rostagno (2003, 2008). The financial frictions we introduce reflect that borrowers and lenders are different people, and that they have different information. Thus, we introduce 'entrepreneurs'. These are agents who have a special skill in the operation and management of capital. Although these agents have their own financial resources, their skill in operating capital is such that it is optimal for them to operate more capital than their own resources can support, by borrowing additional funds. There is a financial friction because the management of capital is risky. Individual entrepreneurs are subject to idiosyncratic shocks which are observed only by them. The agents that they borrow from, 'banks', can only observe the idiosyncratic shocks by paying a monitoring cost. This type of asymmetric information implies that it is impractical to have an arrangement in which banks and entrepreneurs simply divide up the proceeds of entrepreneurial activity, because entrepreneurs have an incentive to understate their earnings. Entrepreneurs who suffer an especially bad idiosyncratic income shock and who therefore cannot afford to pay the required interest, are 'bankrupt'. Banks pay the cost of monitoring these entrepreneurs and take all of their net worth in partial compensation for the interest that they are owed.

In the model, the interest rate that households receive is nominally non state-contingent. This gives rise to potentially interesting wealth effects of the sort emphasized by Irving Fisher (1933). For example, when a shock occurs which drives the price level down, households 
receive a wealth transfer. Because this transfer is taken from entrepreneurs, their net worth is reduced. With the tightening in their balance sheets, their ability to invest is reduced, and this produces an economic slowdown.

Second, we include the labor market search and matching framework of Mortensen and Pissarides (1994), Hall (2005a,b,c), Shimer (2005a,b), Gertler and Trigari (2009, henceforth GT), Gertler, Sala and Trigari (2008, henceforth GST) and Christiano, Ilut, Motto, and Rostagno (2007) into the small open economy model. We integrate this into our specific framework - which includes capital and monetary factors - following the labor market version of Gertler, Sala and Trigari (2008). A key feature of the GST model is that there are wagesetting frictions, but they do not have a direct impact on on-going worker employer relations. However, wage-setting frictions have an impact on the effort of an employer in recruiting new employees. In this sense, the setup is not vulnerable to the Barro (1977) critique of sticky wages. The model is also attractive because of the richness of its labor market implications: the model differentiates between hours worked and the quantity of people employed, it has unemployment and vacancies.

The labor market in our model is a modified version of the GST model. GST assume wage-setting frictions of the Calvo type, while we instead work with Taylor-type frictions. GST shut down the intensive margin of labor supply, while we allow for variation in this margin.

An important step forward is that we allow for endogenous separation of employees from their jobs. This has been done earlier, e.g. by den Haan, Ramey and Watson (2000), but not in such a rich monetary DSGE model. ${ }^{1}$ The importance of time-varying separation rates is strongly motivated by empirical evidence on their cyclicality by Fujita and Ramey (2007). For a paper that focuses entirely on the labor market and analyzes endogenous job separation in this type of model, see Christiano, Trabandt and Walentin (2009).

In the standard new Keynesian model, the homogeneous labor services supplied to the competitive labor market by labor retailers (contractors) who combine the labor services supplied to them by households who monopolistically supply specialized labor services (see Erceg, Henderson and Levin (2000)). Our search-based model dispenses with the specialized labor services abstraction. Labor services are instead supplied to the homogeneous labor market by 'employment agencies'.

Each employment agency retains a large number of workers. At the beginning of the period a fraction of workers is randomly selected to separate from the firm and go into unemployment. Also, a number of new workers arrive from unemployment in proportion to

\footnotetext{
${ }^{1}$ Trigari (2009) also estimates a model with endogenous separation, but in a simpler macroeconomic setting.
} 
the number of vacancies posted by the agency in the previous period. After separation and new arrivals occur, the nominal wage rate is set. Then idiosyncratic shocks to workers' productivities are realized and endogenous separation decisions are made. A nice feature of this approach is the high degree of symmetry with the modeling of entrepreneurial idiosyncratic risk and bankruptcy.

The nominal wage paid to an individual worker is determined by Nash bargaining, which occurs once every $N$ periods. Each employment agency is permanently allocated to one of $N$ different cohorts. Cohorts are differentiated according to the period in which they renegotiate their wage. Since there is an equal number of agencies in each cohort, $1 / N$ of the agencies bargain in each period. The wage in agencies that do not bargain in the current period is updated from the previous period according to the same indexing rule used in the standard new Keynesian model. The intensity of labor effort is determined by equating the worker's marginal cost to the agency's marginal benefit.

Third, we extend the model into a small open economy setting by incorporating the small open economy structure of Adolfson, Laséen, Lindé and Villani (2005, 2007, 2008) (henceforth ALLV). We model the foreign economy as a VAR in foreign inflation, interest rate, output and two worldwide unit-root technology shocks, neutral and investment-specific. We follow the open economy part of ALLV closely and allow for both an exogenous shock and an endogenous risk-adjustment term that induce deviations from uncovered interest parity (UIP). The international interaction consists of trade of goods as well as in riskless bonds. The three final goods, consumption, investment and exports, are produced by combining the domestic homogenous good with specific imported inputs for each type of final good. We allow for Calvo price rigidity both of imports and exports and in that way allow for limited pass-through. Finally, it is worth noting that banking, and therefore financing of entrepreneurs, is a purely domestic activity.

We estimate the full model using Bayesian techniques on Swedish data 1995q1-2009q2, i.e. including the recent financial crisis. By doing so we can give quantitative answers to a number of questions posed above. We start by noting that simple data analysis using the method of Hansen (1985) indicates that roughly 4/5th of the variation in total hours worked comes from variation in employment and $1 / 5$ th from variation in hours per worker. In other words a model that allows for variation in both margins is needed. The first empirical result worth highlighting is that the financial shock to entrepreneurial wealth is important in explaining the dynamics of several variables. The second empirical result comes from the fact that our model allows for both an intensive and an extensive margin of labor supply. We can therefore provide a meaningful estimate of the elasticity of labor supply and find 
it to be close to micro-evidence, i.e. a Frisch elasticity of $1 / 9$. The third result is that in contrast to the existing literature of estimated DSGE models, e.g. Smets and Wouters (2003), ALLV and GST, our model does not contain any "wage-markup shocks" or similar shocks (labor preferences, wage bargaining) with low autocorrelation, and we still match both hours worked, unemployment and wage data series. Finally, an interesting question to be analyzed further is the relative importance of the investment-specific shock vs. the entrepreneurial wealth shock, as the results in the present paper contrast starkly with Justiniano, Primiceri and Tambalotti (2008).

The paper is organized as follows. In section 2 we describe the baseline small open economy model which basically is a small open economy version of Christiano, Eichenbaum and Evans (2005). Section 3 introduces financial frictions while section 4 incorporates employment frictions into the model. Section 5 contains the estimation of the full model which include both financial and labor market frictions. Finally, section 6 concludes. The bulk of the derivations are in the Appendix.

\section{The Baseline Small Open Economy Model}

This section describes our baseline model. The model is based on Christiano, Eichenbaum and Evans (2005) and ALLV from which it inherits most of its open economy structure. The structure of goods production is worth outlining at this point. The three final goods, consumption, investment and exports, are produced by combining the domestic homogenous good with specific imported inputs for each type of final good. See Figure A in the Appendix for a graphical illustration. Below we will go through the production of all these goods, and describe imports.

\subsection{Production of the Domestic Homogeneous Good}

A homogeneous domestic good, $Y_{t}$, is produced using

$$
Y_{t}=\left[\int_{0}^{1} Y_{i, t}^{\frac{1}{\lambda_{d, t}}} d i\right]^{\lambda_{d, t}}, 1 \leq \lambda_{d, t}<\infty .
$$

The domestic good is produced by a competitive, representative firm which takes the price of output, $P_{t}$, and the price of inputs, $P_{i, t}$, as given.

The $i^{t h}$ intermediate good producer has the following production function:

$$
Y_{i, t}=\left(z_{t} H_{i, t}\right)^{1-\alpha} \epsilon_{t} K_{i, t}^{\alpha}-z_{t}^{+} \phi
$$

where $K_{i, t}$ denotes the capital services rented by the $i^{t h}$ intermediate good producer. Also, $\log \left(z_{t}\right)$ is a technology shock whose first difference has a positive mean, $\log \left(\epsilon_{t}\right)$ is a stationary 
neutral technology shock and $\phi$ denotes a fixed production cost. The economy has two sources of growth: the positive drift in $\log \left(z_{t}\right)$ and a positive drift in $\log \left(\Psi_{t}\right)$, where $\Psi_{t}$ is the state of an investment-specific technology shock discussed below. The object, $z_{t}^{+}$, in (2.2) is defined as: ${ }^{2}$

$$
z_{t}^{+}=\Psi_{t}^{\frac{\alpha}{1-\alpha}} z_{t}
$$

In (2.2), $H_{i, t}$ denotes homogeneous labor services hired by the $i^{\text {th }}$ intermediate good producer. Firms must borrow a fraction of the wage bill, so that one unit of labor costs is denoted by

$$
W_{t} R_{t}^{f}
$$

with

$$
R_{t}^{f}=\nu_{t}^{f} R_{t}+1-\nu_{t}^{f}
$$

where $W_{t}$ is the aggregate wage rate, $R_{t}$ is the interest rate on working capital loans, and $\nu_{t}^{f}$ corresponds to the fraction that must be financed in advance.

The firm's marginal cost, divided by the price of the homogeneous good is denoted by $m c_{t}$ :

$$
m c_{t}=\tau_{t}^{d}\left(\frac{1}{1-\alpha}\right)^{1-\alpha}\left(\frac{1}{\alpha}\right)^{\alpha}\left(r_{t}^{k}\right)^{\alpha}\left(\bar{w}_{t} R_{t}^{f}\right)^{1-\alpha} \frac{1}{\epsilon_{t}},
$$

where $r_{t}^{k}$ is the nominal rental rate of capital scaled by $P_{t}$. Also, $\tau_{t}^{d}$ is a tax-like shock, which affects marginal cost, but does not appear in a production function. In the linearization of a version of the model in which there are no price and wage distortions in the steady state, $\tau_{t}^{d}$ is isomorphic to a disturbance in $\lambda_{d}$, i.e., a markup shock.

Productive efficiency dictates that another expression for marginal cost must also be satisfied:

$$
\begin{aligned}
m c_{t} & =\tau_{t}^{d} \frac{1}{P_{t}} \frac{W_{t} R_{t}^{f}}{M P_{l, t}} \\
& =\tau_{t}^{d} \frac{\left(\mu_{\Psi, t}\right)^{\alpha} \bar{w}_{t} R_{t}^{f}}{\epsilon_{t}(1-\alpha)\left(\frac{k_{i, t}}{\mu_{z^{+}, t}} / H_{i, t}\right)^{\alpha}}
\end{aligned}
$$

where $\bar{w}_{t}=W_{t} /\left(z_{t}^{+} P_{t}\right)$.

The $i^{\text {th }}$ firm is a monopolist in the production of the $i^{\text {th }}$ good and so it sets its price. Price setting is subject Calvo frictions. With probability $\xi_{d}$ the intermediate good firm cannot reoptimize its price, in which case,

$$
P_{i, t}=\tilde{\pi}_{d, t} P_{i, t-1}, \tilde{\pi}_{d, t} \equiv\left(\pi_{t-1}\right)^{\kappa_{d}}\left(\bar{\pi}_{t}^{c}\right)^{1-\kappa_{d}-\varkappa_{d}}(\breve{\pi})^{\varkappa_{d}}
$$

\footnotetext{
${ }^{2}$ All the details regarding the scaling of variables are collected in section B.1 in the Appendix. In general lower-case letters denote scaled variables throughout.
} 
where $\kappa_{d}, \varkappa_{d}, \kappa_{d}+\varkappa_{d} \in(0,1)$ are parameters, $\pi_{t-1}$ is the lagged inflation rate and $\bar{\pi}_{t}^{c}$ is the central bank's target inflation rate. Also, $\breve{\pi}$ is a scalar which allows us to capture, among other things, the case in which non-optimizing firms either do not change price at all (i.e., $\breve{\pi}=\varkappa_{d}=1$ ) or that they index only to the steady state inflation rate (i.e., $\breve{\pi}=\bar{\pi}, \varkappa_{d}=1$ ). Note that we get price dispersion in steady state if $\varkappa_{d}>0$ and if $\breve{\pi}$ is different from the steady state value of $\pi$. See Yun (1996) for a discussion of steady state price dispersion.

With probability $1-\xi_{d}$ the firm can change its price. The problem of the $i^{\text {th }}$ domestic intermediate good producer which has the opportunity to change price is to maximize discounted profits:

$$
E_{t} \sum_{j=0}^{\infty} \beta^{j} v_{t+j}\left\{P_{i, t+j} Y_{i, t+j}-m c_{t+j} P_{t+j} Y_{i, t+j}\right\},
$$

subject to the requirement that production equal demand. In the above expression, $v_{t}$ is the multiplier on the household's nominal budget constraint. It measures the marginal value to the household of one unit of profits, in terms of currency. In states of nature when the firm can reoptimize price, it does so to maximize its discounted profits, subject to the price setting frictions and to the requirement that it satisfy demand given by:

$$
\left(\frac{P_{t}}{P_{i, t}}\right)^{\frac{\lambda_{d}}{\lambda_{d}-1}} Y_{t}=Y_{i, t}
$$

The equilibrium conditions associated with price setting problem and their derivation are reported in section B.3.1 in the Appendix.

The domestic intermediate output good is allocated among alternative uses as follows:

$$
Y_{t}=G_{t}+C_{t}^{d}+I_{t}^{d}+\int_{0}^{1} X_{i, t}^{d}
$$

Here, $C_{t}^{d}$ denotes intermediate goods used (together with foreign consumption goods) to produce final household consumption goods. Also, $I_{t}^{d}$ is the amount of intermediate domestic goods used in combination with imported foreign investment goods to produce a homogeneous investment good. Some of this good is used to add to the physical stock of capital, $\bar{K}_{t}$. The rest of the investment good is used in maintenance expenditures, which arise from the utilization of capital, $a\left(u_{t}\right) \bar{K}_{t}$. See section B.2 in the Appendix for the functional form of $a\left(u_{t}\right) . u_{t}$ denotes the utilization rate of capital, with capital services being defined by:

$$
K_{t}=u_{t} \bar{K}_{t}
$$

Finally, the integral in (2.8) denotes domestic resources allocated to exports. The determination of consumption, investment and export demand is discussed below. 


\subsection{Production of Final Consumption and Investment Goods}

Final consumption goods are purchased by households. These goods are produced by a representative competitive firm using the following linear homogeneous technology:

$$
C_{t}=\left[\left(1-\omega_{c}\right)^{\frac{1}{\eta_{c}}}\left(C_{t}^{d}\right)^{\frac{\left(\eta_{c}-1\right)}{\eta_{c}}}+\omega_{c}^{\frac{1}{\eta_{c}}}\left(C_{t}^{m}\right)^{\frac{\left(\eta_{c}-1\right)}{\eta_{c}}}\right]^{\frac{\eta_{c}}{\eta_{c}-1}}
$$

The representative firm takes the price of final consumption goods output, $P_{t}^{c}$, as given. Final consumption goods output is produced using two inputs. The first, $C_{t}^{d}$, is a onefor-one transformation of the homogeneous domestic good and therefore has price, $P_{t}$. The second input, $C_{t}^{m}$, is the homogeneous composite of specialized consumption import goods discussed in the next subsection. The price of $C_{t}^{m}$ is $P_{t}^{m, c}$. The representative firm takes the input prices, $P_{t}$ and $P_{t}^{m, c}$ as given. Profit maximization leads to the following demand for the intermediate inputs in scaled form:

$$
\begin{aligned}
c_{t}^{d} & =\left(1-\omega_{c}\right)\left(p_{t}^{c}\right)^{\eta_{c}} c_{t} \\
c_{t}^{m} & =\omega_{c}\left(\frac{p_{t}^{c}}{p_{t}^{m, c}}\right)^{\eta c} c_{t} .
\end{aligned}
$$

where $p_{t}^{c}=P_{t}^{c} / P_{t}$ and $p_{t}^{m, c}=P_{t}^{m, c} / P_{t}$. The price of $C_{t}$ is related to the price of the inputs by:

$$
p_{t}^{c}=\left[\left(1-\omega_{c}\right)+\omega_{c}\left(p_{t}^{m, c}\right)^{1-\eta_{c}}\right]^{\frac{1}{1-\eta_{c}}}
$$

The rate of inflation of the consumption good is:

$$
\pi_{t}^{c}=\frac{P_{t}^{c}}{P_{t-1}^{c}}=\pi_{t}\left[\frac{\left(1-\omega_{c}\right)+\omega_{c}\left(p_{t}^{m, c}\right)^{1-\eta_{c}}}{\left(1-\omega_{c}\right)+\omega_{c}\left(p_{t-1}^{m, c}\right)^{1-\eta_{c}}}\right]^{\frac{1}{1-\eta_{c}}}
$$

Investment goods are produced by a representative competitive firm using the following technology:

$$
I_{t}+a\left(u_{t}\right) \bar{K}_{t}=\Psi_{t}\left[\left(1-\omega_{i}\right)^{\frac{1}{\eta_{i}}}\left(I_{t}^{d}\right)^{\frac{\eta_{i}-1}{\eta_{i}}}+\omega_{i}^{\frac{1}{\eta_{i}}}\left(I_{t}^{m}\right)^{\frac{\eta_{i}-1}{\eta_{i}}}\right]^{\frac{\eta_{i}}{\eta_{i}-1}}
$$

where we define investment to be the sum of investment goods, $I_{t}$, used in the accumulation of physical capital, plus investment goods used in capital maintenance. Capital maintenance are expenses that arise from the utilization of capital. We discuss maintenance in section 2.4 below.

To accommodate the observation that the price of investment goods relative to the price of consumption goods is declining over time, we assume that $\Psi_{t}$ is a unit root process with positive drift. The details of the law of motion of this process is discussed below. As in the consumption good sector the representative investment goods producers takes all relevant 
prices as given. Profit maximization leads to the following demand for the intermediate inputs in scaled form:

$$
\begin{aligned}
i_{t}^{d} & =\left(p_{t}^{i}\right)^{\eta_{i}}\left(i_{t}+a\left(u_{t}\right) \frac{\bar{k}_{t}}{\mu_{\psi, t} \mu_{z^{+}, t}}\right)\left(1-\omega_{i}\right) \\
i_{t}^{m} & =\omega_{i}\left(\frac{p_{t}^{i}}{p_{t}^{m, i}}\right)^{\eta_{i}}\left(i_{t}+a\left(u_{t}\right) \frac{\bar{k}_{t}}{\mu_{\psi, t} \mu_{z^{+}, t}}\right)
\end{aligned}
$$

where $p_{t}^{i}=\Psi_{t} P_{t}^{i} / P_{t}$ and $p_{t}^{m, i}=P_{t}^{m, i} / P_{t}$.

The price of $I_{t}$ is related to the price of the inputs by:

$$
p_{t}^{i}=\left[\left(1-\omega_{i}\right)+\omega_{i}\left(p_{t}^{m, i}\right)^{1-\eta_{i}}\right]^{\frac{1}{1-\eta_{i}}} .
$$

The rate of inflation of the investment good is:

$$
\pi_{t}^{i}=\frac{\pi_{t}}{\mu_{\Psi, t}}\left[\frac{\left(1-\omega_{i}\right)+\omega_{i}\left(p_{t}^{m, i}\right)^{1-\eta_{i}}}{\left(1-\omega_{i}\right)+\omega_{i}\left(p_{t-1}^{m, i}\right)^{1-\eta_{i}}}\right]^{\frac{1}{1-\eta_{i}}} .
$$

\subsection{Exports and Imports}

This section reviews the structure of imports and exports. Both activities involve Calvo price setting frictions, and so require the presence of market power. In each case, we follow the Dixit-Stiglitz strategy of introducing a range of specialized goods. This allows there to be market power without the counterfactual implication that there is a small number of firms in the export and import sector. Thus, exports involve a continuum of exporters, each of which is a monopolist which produces a specialized export good. Each monopolist produces the export good using a homogeneous domestically produced good and a homogeneous good derived from imports. The specialized export goods are sold to foreign, competitive retailers which create a homogeneous good that is sold to foreign citizens.

In the case of imports, specialized domestic importers purchase a homogeneous foreign good, which they turn into a specialized input and sell to domestic retailers. There are three types of domestic retailers. One uses the specialized import goods to create the homogeneous good used as an input into the production of specialized exports. Another uses the specialized import goods to create an input used in the production of investment goods. The third type uses specialized imports to produce a homogeneous input used in the production of consumption goods. See Figure A for a graphical illustration.

We emphasize two features of this setup. First, before being passed on to final domestic users, imported goods must be combined with domestic inputs. This is consistent with the view emphasized by Burstein, Eichenbaum and Rebelo $(2005,2007)$ that there are substantial distribution costs associated with imports. Second, there are pricing frictions in all sectors of 
the model. The pricing frictions in the homogeneous domestic good sector are standard, and

perhaps do not require additional elaboration. Instead we elaborate on the pricing frictions in the part of the model related to imports and exports.

In all cases we assume that prices are set in the currency of the buyer ("pricing to market"). Pricing frictions in the case of imports help the model account for the evidence that exchange rate shocks take time to pass into domestic prices. Pricing frictions in the case of exports help the model to produce a hump-shape in the response of output to a monetary shock. To see this, it is useful to recall how a hump-shape is produced in a closed economy version of the model. In that version, the hump shape occurs because there are costs to quickly expanding consumption and investment demand. Consumption is not expanded rapidly because of the assumption of habit persistence in preferences and investment is not expanded because of the assumption that there are adjustment costs associated with changing the flow of investment. When the closed economy is opened up, another potential source of demand in the wake of a monetary policy shock is introduced, namely, exports.

There are two additional observations worth making concerning the role of price frictions in the export sector. First, it is interesting to note that the price frictions in the import of goods used as inputs into the production of exports work against us. These price frictions increase the need for price frictions in the export sector to damp the response of $X$ to an expansionary domestic monetary shock. The reason is that in the absence of price frictions on imports, the marginal cost of exports would jump in the face of an expansionary monetary policy shock, as pass through from the exchange rate to the domestic currency price of imports of goods destined for export increases. From the perspective of achieving a humpshaped response of output to an expansionary monetary policy shock, we suspect that it would be better to treat the import of goods destined for the export sector asymmetrically by supposing there are low or no price frictions in those goods.

The second observation on the role of price frictions in the export sector is related to the first. We make assumptions in the model that have the effect of also producing a hump-shape response of the nominal (and real) exchange rate to an monetary policy shock. The model follows ALLV in capturing, in a reduced form way, the notion that holders of domestic assets require less compensation for risk in the wake of an expansionary monetary policy shock. As a result, the model does not display the classic Dornbusch 'overshooting' pattern in the exchange rate in response to a monetary policy shock. Instead, the nominal exchange rate rises slowly in response to an expansionary monetary policy shock. The slow response in the exchange rate reduces the burden on price frictions in $P^{x}$ to slow the response of $X$ to a monetary policy shock. 


\subsubsection{Exports}

There is a total demand by foreigners for domestic exports, which takes on the following form:

$$
X_{t}=\left(\frac{P_{t}^{x}}{P_{t}^{*}}\right)^{-\eta_{f}} Y_{t}^{*}
$$

In scaled form, this is

$$
x_{t}=\left(p_{t}^{x}\right)^{-\eta_{f}} y_{t}^{*}
$$

Here, $Y_{t}^{*}$ is foreign GDP and $P_{t}^{*}$ is the foreign currency price of foreign homogeneous goods. Also, $P_{t}^{x}$ is an index of export prices, whose determination is discussed below. The goods, $X_{t}$, are produced by a representative, competitive foreign retailer firm using specialized inputs as follows:

$$
X_{t}=\left[\int_{0}^{1} X_{i, t}^{\frac{1}{\lambda_{x}}} d i\right]^{\lambda_{x}} .
$$

where $X_{i, t}, i \in(0,1)$, are exports of specialized goods. The retailer that produces $X_{t}$ takes its output price, $P_{t}^{x}$, and its input prices, $P_{i, t}^{x}$, as given. Optimization leads to the following demand for specialized exports:

$$
X_{i, t}=\left(\frac{P_{i, t}^{x}}{P_{t}^{x}}\right)^{\frac{-\lambda_{x, t}}{\lambda_{x, t}-1}} X_{t}
$$

Combining (2.18) and (2.19), we obtain:

$$
P_{t}^{x}=\left[\int_{0}^{1}\left(P_{i, t}^{x}\right)^{\frac{1}{1-\lambda_{x, t}}} d i\right]^{1-\lambda_{x, t}} .
$$

The $i^{\text {th }}$ specialized export is produced by a monopolist using the following technology:

$$
X_{i, t}=\left[\omega_{x}^{\frac{1}{\eta_{x}}}\left(X_{i, t}^{m}\right)^{\frac{\eta_{x}-1}{\eta_{x}}}+\left(1-\omega_{x}\right)^{\frac{1}{\eta_{x}}}\left(X_{i, t}^{d}\right)^{\frac{\eta_{x}-1}{\eta_{x}}}\right]^{\frac{\eta_{x}}{\eta_{x}-1}}
$$

where $X_{i, t}^{m}$ and $X_{i, t}^{d}$ are the $i^{t h}$ exporter's use of the imported and domestically produced goods, respectively. We derive the marginal cost associated with the CES production function from the multiplier associated with the Lagrangian representation of the cost minimization problem:

$C=\min \tau_{t}^{x}\left[P_{t}^{m, x} R_{t}^{x} X_{i, t}^{m}+P_{t} R_{t}^{x} X_{i, t}^{d}\right]+\lambda\left\{X_{i, t}-\left[\omega_{x}^{\frac{1}{\eta_{x}}}\left(X_{i, t}^{m}\right)^{\frac{\eta_{x}-1}{\eta_{x}}}+\left(1-\omega_{x}\right)^{\frac{1}{\eta_{x}}}\left(X_{i, t}^{d}\right)^{\frac{\eta_{x}-1}{\eta_{x}}}\right]^{\frac{\eta_{x}}{\eta_{x}-1}}\right\}$,

where $P_{t}^{m, x}$ is the price of the homogeneous import good and $P_{t}$ is the price of the homogeneous domestic good. Using the first order conditions of this problem and the production function we derive the real marginal cost in terms of stationary variables, $m c_{t}^{x}$ : 


$$
m c_{t}^{x}=\frac{\lambda}{S_{t} P_{t}^{x}}=\frac{\tau_{t}^{x} R_{t}^{x}}{q_{t} p_{t}^{c} p_{t}^{x}}\left[\omega_{x}\left(p_{t}^{m, x}\right)^{1-\eta_{x}}+\left(1-\omega_{x}\right)\right]^{\frac{1}{1-\eta_{x}}}
$$

where

$$
R_{t}^{x}=\nu_{t}^{x} R_{t}+1-\nu_{t}^{x}
$$

and where we have used

$$
\frac{S_{t} P_{t}^{x}}{P_{t}}=\frac{S_{t} P_{t}^{*}}{P_{t}^{c}} \frac{P_{t}^{c}}{P_{t}} \frac{P_{t}^{x}}{P_{t}^{*}}=q_{t} p_{t}^{c} p_{t}^{x}
$$

From the solution to the same problem we also get the demand for domestic inputs for export production:

$$
X_{i, t}^{d}=\left(\frac{\lambda}{\tau_{t}^{x} R_{t}^{x} P_{t}}\right)^{\eta_{x}} X_{i, t}\left(1-\omega_{x}\right)
$$

The quantity of the domestic homogeneous good used by specialized exporters is:

$$
\int_{0}^{1} X_{i, t}^{d} d i
$$

and this needs to be expressed in terms of aggregates. Plugging eq. (2.23) into this integral we derive (see section B.3.3 in the Appendix):

$$
X_{t}^{d}=\int_{0}^{1} X_{i, t}^{d} d i=\left[\omega_{x}\left(p_{t}^{m, x}\right)^{1-\eta_{x}}+\left(1-\omega_{x}\right)\right]^{\frac{\eta_{x}}{1-\eta_{x}}}\left(1-\omega_{x}\right)\left(\stackrel{\circ}{p_{t}^{x}}\right)^{\frac{-\lambda_{x, t}}{\lambda_{x, t}-1}}\left(p_{t}^{x}\right)^{-\eta_{f}} Y_{t}^{*}
$$

where $\stackrel{\circ}{p}_{t}^{x}$ is a measure of the price dispersion and is defined in the same Appendix. Note how the impact of price dispersion operates - to produce a given total of the homogenous export good, $X_{t}$, one needs more of the homogeneous input good, $X_{t}^{d}$, to the extent that there is price dispersion. In that case $\stackrel{\circ}{p}_{t}^{x}<1$ and $\left(\stackrel{\circ}{p}_{t}^{x}\right)^{\frac{-\lambda_{x, t}}{\lambda_{x, t}-1}}>1$, and more dispersion is reflected in a lower $\stackrel{\circ}{p}_{t}^{x}$.

We also require an expression for imported inputs for export production in terms of aggregates. Using a similar derivation it can be shown to be, in scaled terms:

$$
x_{t}^{m}=\omega_{x}\left(\frac{\left[\omega_{x}\left(p_{t}^{m, x}\right)^{1-\eta_{x}}+\left(1-\omega_{x}\right)\right]^{\frac{1}{1-\eta_{x}}}}{p_{t}^{m, x}}\right)^{\eta_{x}}\left(\stackrel{\circ}{p_{t}^{x}}\right)^{\frac{-\lambda_{x, t}}{\lambda_{x, t}-1}}\left(p_{t}^{x}\right)^{-\eta_{f}} y_{t}^{*}
$$

The $i^{\text {th }}, i \in(0,1)$, export good firm takes (2.19) as its demand curve. This producer sets prices subject to a Calvo sticky-price mechanism. With probability $\xi_{x}$ the $i^{\text {th }}$ export good firm cannot reoptimize its price, in which case it update its price as follows:

$$
P_{i, t}^{x}=\tilde{\pi}_{t}^{x} P_{i, t-1}^{x}, \quad \tilde{\pi}_{t}^{x}=\left(\pi_{t-1}^{x}\right)^{\kappa_{x}}\left(\pi^{x}\right)^{1-\kappa_{x}-\varkappa_{x}}(\breve{\pi})^{\varkappa_{x}}
$$

where $\kappa_{x}, \varkappa_{x}, \kappa_{x}+\varkappa_{x} \in(0,1)$. 
The equilibrium conditions associated with price setting by exporters that do get to reoptimize their prices are analogous to the ones derived for domestic intermediate good producers and are reported in section B.3.2 in the Appendix. ${ }^{3}$

\subsubsection{Imports}

We now turn to a discussion of imports. Foreign firms sell a homogeneous good to domestic importers. The importers convert the homogeneous good into a specialized input (they "brand name it") and supply that input monopolistically to domestic retailers. Importers are subject to Calvo price setting frictions. There are three types of importing firms: (i) one produces goods used to produce an intermediate good for the production of consumption, (ii) one produces goods used to produce an intermediate good for the production of investment, and (iii) one produces goods used to produce an intermediate good for the production of exports.

Consider (i) first. The production function of the domestic retailer of imported consumption goods is:

$$
C_{t}^{m}=\left[\int_{0}^{1}\left(C_{i, t}^{m}\right)^{\frac{1}{\lambda^{m, C}}} d i\right]^{\lambda^{m, C}},
$$

where $C_{i, t}^{m}$ is the output of the $i^{t h}$ specialized producer and $C_{t}^{m}$ is an intermediate good used in the production of consumption goods. Let $P_{t}^{m, c}$ denote the price index of $C_{t}^{m}$ and let $P_{i, t}^{m, c}$ denote the price of the $i^{\text {th }}$ intermediate input. The domestic retailer is competitive and takes $P_{t}^{m, c}$ and $P_{i, t}^{m, c}$ as given. In the usual way, the demand curve for specialized inputs is given by the domestic retailer's first order necessary condition for profit maximization:

$$
C_{i, t}^{m}=C_{t}^{m}\left(\frac{P_{t}^{m, c}}{P_{i, t}^{m, c}}\right)^{\frac{\lambda^{m}, C}{\lambda^{m, C}-1}} .
$$

We now turn to the producer of $C_{i, t}^{m}$, who takes the previous equation as a demand curve. This producer buys the homogeneous foreign good and converts it one-for-one into the domestic differentiated good, $C_{i, t}^{m}$. The intermediate good producer's marginal cost is

$$
\tau_{t}^{m, c} S_{t} P_{t}^{*} R_{t}^{\nu, *}
$$

${ }^{3}$ When we linearize around steady state and $\varkappa_{m, j}=0$, equations (B.16)-(B.19) reduce to:

$$
\begin{aligned}
\hat{\pi}_{t}^{x}= & \frac{\beta}{1+\kappa_{x} \beta} E_{t} \hat{\pi}_{t+1}^{x}+\frac{\kappa_{x}}{1+\kappa_{x} \beta} \hat{\pi}_{t-1}^{x} \\
& +\frac{1}{1+\kappa_{x} \beta} \frac{\left(1-\beta \xi_{x}\right)\left(1-\xi_{x}\right)}{\xi_{x}} \widehat{m c}_{t}^{x},
\end{aligned}
$$

where a hat over a variable indicates log deviation from steady state. 
where

$$
R_{t}^{\nu, *}=\nu_{t}^{*} R_{t}^{*}+1-\nu_{t}^{*}
$$

and $R_{t}^{*}$ is the foreign nominal, intratemporal rate of interest. The notion here is that the intermediate good firm must pay the inputs with foreign currency and because they have no resources themselves at the beginning of the period, they must borrow those resources if they are to buy the foreign inputs needed to produce $C_{i, t}^{m}$. There is no risk to this firm, because all shocks are realized at the beginning of the period, and so there is no uncertainty within the duration of the working capital loan about the realization of prices and exchanges rates. $^{4}$

As in the homogenous domestic good sector, $\tau_{t}^{m, c}$ is a tax-like shock, which affects marginal cost, but does not appear in a production function. In the linearization of a version of the model in which there are no price and wage distortions in the steady state, $\tau_{t}^{m, c}$ is isomorphic to a markup shock.

It is of interest to have a measure of the total imports of the intermediate good producers:

$$
S_{t} P_{t}^{*} R_{t}^{\nu, *} \int_{0}^{1} C_{i, t}^{m} d i .
$$

In order to relate this to $C_{t}^{m}$, we substitute the demand curve into the previous expression:

$$
\begin{aligned}
& S_{t} P_{t}^{*} R_{t}^{\nu, *} \int_{0}^{1} C_{t}^{m}\left(\frac{P_{t}^{m, c}}{P_{i, t}^{m, c}}\right)^{\frac{\lambda^{m, C}}{\lambda^{m, C}-1}} d i \\
= & S_{t} P_{t}^{*} R_{t}^{\nu, *} C_{t}^{m}\left(P_{t}^{m, c}\right)^{\frac{\lambda^{m}, C}{\lambda^{m, C}-1}} \int_{0}^{1}\left(P_{i, t}^{m, c}\right)^{\frac{-\lambda^{m}, C}{\lambda^{m}, C}-1} \\
= & S_{t} P_{t}^{*} R_{t}^{\nu, *} C_{t}^{m}\left(\frac{\stackrel{P}{P}_{t}^{m, c}}{P_{t}^{m, c}}\right)^{\frac{\lambda^{m, C}}{1-\lambda^{m, C}}}
\end{aligned}
$$

where

$$
\stackrel{\circ}{P}_{t}^{m, c}=\left[\int_{0}^{1}\left(P_{i, t}^{m, c}\right)^{\frac{\lambda^{m, C}}{1-\lambda^{m, C}}}\right]^{\frac{1-\lambda^{m, C}}{\lambda^{m, C}}}
$$

We conclude that total imports accounted for by the consumption sector is:

$$
S_{t} P_{t}^{*} R_{t}^{\nu, *} C_{t}^{m}\left(\stackrel{\circ}{p}_{t}^{m, c}\right)^{\frac{\lambda^{m}, C}{1-\lambda^{m, C}}}
$$

where

$$
\stackrel{\circ}{p}_{t}^{m, c}=\frac{\stackrel{\circ}{P}_{t}^{m, c}}{P_{t}^{m, c}}
$$

\footnotetext{
${ }^{4}$ We are somewhat uncomfortable with this feature of the model. The fact that interest is due and matters indicates that some time evolves over the duration of the loan. Our assumption that no uncertainty is realized over a period of significant duration of time seems implausible. We suspect that a more realistic representation would involve some risk. Our timing assumptions in effect abstract away from this risk, and we conjecture that this does not affect the first order properties of the model.
} 
Now consider (ii). The production function for the domestic retailer of imported investment goods, $I_{t}^{m}$, is:

$$
I_{t}^{m}=\left[\int_{0}^{1}\left(I_{i, t}^{m}\right)^{\frac{1}{\lambda_{t}^{m, I}}} d i\right]^{\lambda_{t}^{m, I}} .
$$

The retailer of imported investment goods is competitive and takes output prices, $P_{t}^{m, i}$, and input prices, $P_{i, t}^{m, i}$, as given.

The producer of the $i^{\text {th }}$ intermediate input into the above production function buys the homogeneous foreign good and converts it one-for-one into the domestic differentiated good, $I_{i, t}^{m}$. The marginal cost of $I_{i, t}^{m}$ is also (2.27). Note that this implies the importing firm's cost is $P_{t}^{*}$ (before borrowing costs and exchange rate conversion), which is the same cost for the specialized inputs used to produce $C_{t}^{m}$. This may seem inconsistent with the property of the domestic economy that domestically produced consumption and investment goods have different relative prices. We assume that (2.27) applies to both types of producer in order to simplify notation. Below, we suppose that the efficiency of imported investment goods grows over time, in a way that makes our assumptions about the relative costs of consumption and investment, whether imported or domestically produced.

The total value of imports associated with the production of investment goods is analogous to what we obtained for the consumption good sector:

$$
S_{t} P_{t}^{*} R_{t}^{\nu, *} I_{t}^{m}\left(\stackrel{\circ}{p}_{t}^{m, i}\right)^{\frac{\lambda^{m, i}}{1-\lambda^{m, i}}}, \stackrel{{ }_{p}^{m}}{t}{ }^{m, i}=\frac{P_{i, t}^{m, i}}{P_{t}^{m, i}}
$$

Now consider (iii). The production function of the domestic retailer of imported goods used in the production of an input, $X_{t}^{m}$, for the production of export goods is:

$$
X_{t}^{m}=\left[\int_{0}^{1}\left(X_{i, t}^{m}\right)^{\frac{1}{\lambda_{t}^{m, X}}} d i\right]^{\lambda_{t}^{m, X}} .
$$

The imported good retailer is competitive, and takes output prices, $P_{t}^{m, x}$, and input prices, $P_{i, t}^{m, x}$, as given. The producer of the specialized input, $X_{i, t}^{m}$, has marginal cost, (2.27). The total value of imports associated with the production of $X_{t}^{m}$ is:

$$
S_{t} P_{t}^{*} R_{t}^{\nu, *} X_{t}^{m}\left(\stackrel{\circ}{p}_{t}^{m, x}\right)^{\frac{\lambda^{m, x}}{1-\lambda^{m, x}}}, \stackrel{\circ}{p_{t}^{m, x}}=\frac{P_{i, t}^{m, x}}{P_{t}^{m, x}}
$$

Each of the above three types of intermediate good firm is subject to Calvo price-setting frictions. With probability $1-\xi_{m, j}$, the $j^{\text {th }}$ type of firm can reoptimize its price and with probability $\xi_{m, j}$ it sets price according to the following relation:

$$
P_{i, t}^{m, j}=\tilde{\pi}_{t}^{m, j} P_{i, t-1}^{m, j}, \tilde{\pi}_{t}^{m, j} \equiv\left(\pi_{t-1}^{m, j}\right)^{\kappa_{m, j}}\left(\bar{\pi}_{t}^{c}\right)^{1-\kappa_{m, j}-\varkappa_{m, j}} \breve{\pi}^{\varkappa_{m, j}} .
$$


for $j=c, i, x$.

The equilibrium conditions associated with price setting by importers are analogous to the ones derived for domestic intermediate good producers and are reported in section B.3.4 in the Appendix. Real after tax marginal cost is

$$
\begin{aligned}
m c_{t}^{m, j} & =\tau_{t}^{m, j} \frac{S_{t} P_{t}^{*}}{P_{t}^{m, j}} R_{t}^{\nu, *}=\tau_{t}^{m, j} \frac{S_{t} P_{t}^{*} P_{t}^{c} P_{t}}{P_{t}^{c} P_{t}^{m, j} P_{t}} R_{t}^{\nu, *} \\
& =\tau_{t}^{m, j} \frac{q_{t} p_{t}^{c}}{p_{t}^{m, j}} R_{t}^{\nu, *}
\end{aligned}
$$

for $j=c, i, x$.

\subsection{Households}

Household preferences are given by:

$$
E_{0}^{j} \sum_{t=0}^{\infty} \beta^{t}\left[\zeta_{t}^{c} \ln \left(C_{t}-b C_{t-1}\right)-\zeta_{t}^{h} A_{L} \frac{\left(h_{j, t}\right)^{1+\sigma_{L}}}{1+\sigma_{L}}\right] .
$$

The household owns the economy's stock of physical capital. It determines the rate at which the capital stock is accumulated and the rate at which it is utilized. The household owns the stock of net foreign assets and determines its rate of accumulation.

\subsubsection{Technology for Capital Accumulation}

The law of motion of the physical stock of capital takes into account investment adjustment costs as introduced by Christiano, Eichenbaum and Evans (2005):

$$
\bar{K}_{t+1}=(1-\delta) \bar{K}_{t}+\Upsilon_{t}\left(1-\tilde{S}\left(\frac{I_{t}}{I_{t-1}}\right)\right) I_{t}
$$

In scaled terms the law of motion of capital can be written ${ }^{5}$

$$
\bar{k}_{t+1}=\frac{1-\delta}{\mu_{z^{+}, t} \mu_{\Psi, t}} \bar{k}_{t}+\Upsilon_{t}\left(1-\tilde{S}\left(\frac{\mu_{z^{+}, t} \mu_{\Psi, t} i_{t}}{i_{t-1}}\right)\right) i_{t} .
$$

\subsubsection{Household Consumption and Investment Decisions}

The first order condition for consumption is:

$$
\frac{\zeta_{t}^{c}}{c_{t}-b c_{t-1} \frac{1}{\mu_{z^{+}, t}}}-\beta b E_{t} \frac{\zeta_{t+1}^{c}}{c_{t+1} \mu_{z^{+}, t+1}-b c_{t}}-\psi_{z^{+}, t} p_{t}^{c}\left(1+\tau_{t}^{c}\right)=0 .
$$

\footnotetext{
${ }^{5}$ See subsection B.2 in the Appendix for the functional form of the investment adjustment costs, $\tilde{S}$.
} 
where

$$
\psi_{z^{+}, t}=v_{t} P_{t} z_{t}^{+}
$$

is the marginal value of one unit of the consumption good at time $t$.

To define the intertemporal Euler equation associated with the household's capital accumulation decision, we need to define the rate of return on a period $t$ investment in a unit of physical capital, $R_{t+1}^{k}$ :

$$
R_{t+1}^{k}=\frac{\left(1-\tau_{t}^{k}\right)\left[u_{t+1} \bar{r}_{t+1}^{k}-\frac{p_{t+1}^{i}}{\Psi_{t+1}} a\left(u_{t+1}\right)\right] P_{t+1}+(1-\delta) P_{t+1} P_{k^{\prime}, t+1}+\tau_{t}^{k} \delta P_{t} P_{k^{\prime}, t}}{P_{t} P_{k^{\prime}, t}}
$$

where

$$
\frac{p_{t}^{i}}{\Psi_{t}} P_{t}=P_{t}^{i}
$$

is the date $t$ price of the homogeneous investment good and $\bar{r}_{t}^{k}=\Psi_{t} r_{t}^{k}$ is the scaled real rental rate of capital. Here, $P_{k^{\prime}, t}$ denotes the price of a unit of newly installed physical capital, which operates in period $t+1$. This price is expressed in units of the homogeneous good, so that $P_{t} P_{k^{\prime}, t}$ is the domestic currency price of physical capital. The numerator in the expression for $R_{t+1}^{k}$ represents the period $t+1$ payoff from a unit of additional physical capital. The timing of the capital tax rate reflects the assumption that the relevant tax rate is known at the time the investment decision is made. The expression in square brackets in (2.37) captures the idea that maintenance expenses associated with the operation of capital are deductible from taxes. The last expression in the numerator expresses the idea that physical depreciation is deductible at historical cost. It is convenient to express $R_{t}^{k}$ in scaled terms:

$$
R_{t+1}^{k}=\frac{\pi_{t+1}}{\mu_{\Psi, t+1}} \frac{\left(1-\tau_{t}^{k}\right)\left[u_{t+1} \bar{r}_{t+1}^{k}-p_{t+1}^{i} a\left(u_{t+1}\right)\right]+(1-\delta) p_{k^{\prime}, t+1}+\tau_{t}^{k} \delta \frac{\mu_{\Psi, t+1}}{\pi_{t+1}} p_{k^{\prime}, t}}{p_{k^{\prime}, t}} .
$$

where $p_{k^{\prime}, t}=\Psi_{t} P_{k^{\prime}, t}$. Capital is a good hedge against inflation, except for the way depreciation is treated. A rise in inflation effectively raises the tax rate on capital because of the practice of valuing depreciation at historical cost. The first order condition for capital implies:

$$
\psi_{z^{+}, t}=\beta E_{t} \psi_{z^{+}, t+1} \frac{R_{t+1}^{k}}{\pi_{t+1} \mu_{z^{+}, t+1}} .
$$

By differentiating the Lagrangian representation of the household's problem with respect to $I_{t}$ one can derive the investment first order condition in scaled terms:

$$
\begin{aligned}
-\psi_{z^{+}, t} p_{t}^{i}+ & \psi_{z^{+}, t} p_{k^{\prime}, t} \Upsilon_{t}\left[1-\tilde{S}\left(\frac{\mu_{z^{+}, t} \mu_{\Psi, t} i_{t}}{i_{t-1}}\right)-\tilde{S}^{\prime}\left(\frac{\mu_{z^{+}, t} \mu_{\Psi, t} i_{t}}{i_{t-1}}\right) \frac{\mu_{z^{+}, t} \mu_{\Psi, t} i_{t}}{i_{t-1}}\right] \\
& +\beta \psi_{z^{+}, t+1} p_{k^{\prime}, t+1} \Upsilon_{t+1} \tilde{S}^{\prime}\left(\frac{\mu_{z^{+}, t+1} \mu_{\Psi, t+1} i_{t+1}}{i_{t}}\right)\left(\frac{i_{t+1}}{i_{t}}\right)^{2} \mu_{\Psi, t+1} \mu_{z^{+}, t+1}=0
\end{aligned}
$$


The first order condition associated with capital utilization is, in scaled terms:

$$
\bar{r}_{t}^{k}=p_{t}^{i} a^{\prime}\left(u_{t}\right) .
$$

The tax rate on capital income does not enter here because of the deductibility of maintenance costs.

\subsubsection{Financial Assets}

The household does the economy's saving. Period $t$ saving occurs by the acquisition of net foreign assets, $A_{t+1}^{*}$, and a domestic asset. The domestic asset is used to finance the working capital requirements of firms. This asset pays a nominally non-state contingent return from $t$ to $t+1, R_{t}$. The first order condition associated with this asset is:

$$
-\psi_{z^{+}, t}+\beta E_{t} \frac{\psi_{z^{+}, t+1}}{\mu_{z^{+}, t+1}}\left[\frac{R_{t}-\tau_{t}^{b}\left(R_{t}-\pi_{t+1}\right)}{\pi_{t+1}}\right]=0,
$$

where $\tau_{t}^{b}$ is the tax rate on the real interest rate on bond income (for additional discussion of $\tau^{b}$, see section 2.5.) A consequence of our treatment of the taxation on domestic bonds is that the steady state real after tax return on bonds is invariant to $\pi$.

In the model the tax treatment of domestic agents' earnings on foreign bonds is the same as the tax treatment of agents' earnings on foreign bonds. The scaled date $t$ first order condition associated with $A_{t+1}^{*}$ :

$$
v_{t} S_{t}=\beta E_{t} v_{t+1}\left[S_{t+1} R_{t}^{*} \Phi_{t}-\tau^{b}\left(S_{t+1} R_{t}^{*} \Phi_{t}-\frac{S_{t}}{P_{t}} P_{t+1}\right)\right] .
$$

Recall that $S_{t}$ is the domestic currency price of a unit of foreign currency. On the left side of this expression, we have the cost of acquiring a unit of foreign assets. The currency cost is $S_{t}$ and this is converted into utility terms by multiplying by the multiplier on the household's budget constraint, $v_{t}$. The term in square brackets is the after tax payoff of the foreign asset, in domestic currency units. The first term is the period $t+1$ pre-tax interest payoff on $A_{t+1}^{*}$, which is $S_{t+1} R_{t}^{*} \Phi_{t}$. Here, $R_{t}^{*}$ is the foreign nominal rate of interest, which is risk free in foreign currency units. The term, $\Phi_{t}$ represents a risk adjustment, so that a unit of the foreign asset acquired in $t$ pays off $R_{t}^{*} \Phi_{t}$ units of foreign currency in $t+1$. The determination of $\Phi_{t}$ is discussed below. The remaining term in parentheses pertains to the impact of taxation on the return on foreign assets. If we ignore the term after the minus sign in parentheses, then we see that taxation is applied to the whole nominal payoff on the bond, including principle. The term after the minus sign is designed to ensure that the principal is deducted from taxes. The principal is expressed in nominal terms and is set so that the real value at $t+1$ coincides with the real value of the currency used to purchase 
the asset in period $t$. In particular, recall that $S_{t}$ is the period $t$ domestic currency cost of a unit (in terms of foreign currency) of foreign assets. So, the period $t$ real cost of the asset is $S_{t} / P_{t}$. The domestic currency value in period $t+1$ of this real quantity is $P_{t+1} S_{t} / P_{t}$.

We scale the first order condition, eq. (2.43), by multiplying both sides by $P_{t} z_{t}^{+} / S_{t}$ :

$$
\psi_{z^{+}, t}=\beta E_{t} \frac{\psi_{z^{+}, t+1}}{\pi_{t+1} \mu_{z^{+}, t+1}}\left[s_{t+1} R_{t}^{*} \Phi_{t}-\tau_{t}^{b}\left(s_{t+1} R_{t}^{*} \Phi_{t}-\pi_{t+1}\right)\right]
$$

where

$$
s_{t}=\frac{S_{t}}{S_{t-1}}
$$

The risk adjustment term has the following form:

$$
\Phi_{t}=\Phi\left(a_{t}, E_{t} s_{t+1} s_{t}, \tilde{\phi}_{t}\right)=\exp \left(-\tilde{\phi}_{a}\left(a_{t}-\bar{a}\right)-\tilde{\phi}_{s}\left(E_{t} s_{t+1} s_{t}-s^{2}\right)+\tilde{\phi}_{t}\right)
$$

where, recall,

$$
a_{t}=\frac{S_{t} A_{t+1}}{P_{t} z_{t}^{+}}
$$

and $\tilde{\phi}_{t}$ is a mean zero shock whose law of motion is discussed below. In addition, $\tilde{\phi}_{a}, \tilde{\phi}_{s}$, $\bar{a}$ are positive parameters. In the steady state discussion in the Appendix, we derive the equilibrium outcomes that $a_{t}$ coincides with $\bar{a}$ and $\Phi_{t}=1$ in non-stochastic steady state.

The dependence of $\Phi_{t}$ on $a_{t}$ ensures, in the usual way, that there is a unique steady state value of $a_{t}$ that is independent of the initial net foreign assets and capital of the economy. The dependence of $\Phi_{t}$ on the anticipated growth rate of the exchange rate is designed to allow the model to reproduce two types of observations. The first concerns observations related uncovered interest parity. The second concerns the hump-shaped response of output to a monetary policy shock.

We first consider interest rate parity. To understand this, consider the standard text book representation of uncovered interest parity:

$$
R_{t}-R_{t}^{*}=E_{t} \log S_{t+1}-\log S_{t}+\phi_{t}
$$

where $\phi_{t}$ denotes the risk premium on domestic assets. A log linear approximation of our model implies the above expression in which $\phi_{t}$ corresponds to the log deviation of $\Phi_{t}$ about its steady state value of unity. Consider first the case in which $\phi_{t} \equiv 0$. In this case, a fall in $R_{t}$ relative to $R_{t}^{*}$ produces an anticipated appreciation of the currency. This drop in $E_{t} \log S_{t+1}-\log S_{t}$ is accomplished in part by an instantaneous depreciation in $\log S_{t}$. The idea behind this is that asset holders respond to the unfavorable domestic rate of return by attempting to sell domestic assets and acquire foreign exchange for the purpose of acquiring foreign assets. This selling pressure pushes $\log S_{t}$ up, until the anticipated appreciation precisely compensates traders in international financial assets holding domestic assets. 
There are two types of evidence that the preceding scenario does not hold in the data. Vector autoregression evidence on the response of financial variables to an expansionary domestic monetary policy shock suggests that $E_{t} \log S_{t+1}-\log S_{t}$ actually rises for a period of time (see, e.g., Eichenbaum and Evans (1995)). Also, regressions of realized future exchange rate changes on current interest rate differentials fail to produce the expected value of unity. Indeed, the typical result is a statistically significant negative coefficient.

One interpretation of these results is that when the domestic interest rate is reduced, say by a monetary policy shock, then risk in the domestic economy falls and that alone makes traders happier to hold domestic financial assets in spite of their lower nominal return and the losses they expect to make in the foreign exchange market. Our functional form for $\phi_{t}$ is designed to capture this idea. According to this functional form, when a shock occurs which causes an anticipated appreciation in the level of the exchange rate, then the assessment of risk in the domestic economy, $\Phi_{t}$, falls. Later, when we introduce financial frictions, we will have access to additional mechanism for achieving this outcome. A concern we have with the current model is its unfortunate implication that any shock that creates an expectation of a depreciation in the currency makes domestic financial assets seem less risky. As a general proposition, this seems implausible. When we consider financial frictions, we will have variables such as the bankruptcy rate, which falls in the wake of an expansionary monetary shock, and which may accomplish the same equilibrium outcome as the ALLV specification, though perhaps the mechanism is more plausible in this case.

When we turn to the regression interpretation of the uncovered interest parity result, it is useful to consider the regression coefficient:

$$
\begin{aligned}
\gamma & =\frac{\operatorname{cov}\left(\log S_{t+1}-\log S_{t}, R_{t}-R_{t}^{f}\right)}{\operatorname{var}\left(R_{t}-R_{t}^{f}\right)}=\overbrace{1}^{\text {in theory }} \text { but } \overbrace{<0}^{\text {in data }} \\
\gamma & =\frac{\operatorname{cov}\left(\log S_{t+1}-\log S_{t}, R_{t}-R_{t}^{f}\right)}{\operatorname{var}\left(R_{t}-R_{t}^{f}\right)} \\
& =\frac{\operatorname{cov}\left(R_{t}-R_{t}^{f}-\log \Phi_{t}, R_{t}-R_{t}^{f}\right)}{\operatorname{var}\left(R_{t}-R_{t}^{f}\right)} \\
& =1-\frac{\operatorname{cov}\left(R_{t}-R_{t}^{f}, \tilde{\phi}_{s}\left(R_{t}-R_{t}^{f}-\left(R-R^{f}\right)\right)\right)}{\operatorname{var}\left(R_{t}-R_{t}^{f}\right)} \\
& =1-\tilde{\phi}_{s}
\end{aligned}
$$


according to our linearized expression above. Then,

$$
\gamma=1-\frac{\operatorname{cov}\left(R_{t}-R_{t}^{f}, \phi_{t}\right)}{\operatorname{var}\left(R_{t}-R_{t}^{f}\right)}
$$

and

$$
\gamma=\frac{\operatorname{cov}\left(\log S_{t+1}-\log S_{t}, R_{t}-R_{t}^{*}\right)}{\operatorname{var}\left(R_{t}-R_{t}^{*}\right)}=\frac{\operatorname{cov}\left(R_{t}-R_{t}^{*}-\phi_{t}, R_{t}-R_{t}^{*}\right)}{\operatorname{var}\left(R_{t}-R_{t}^{*}\right)},
$$

according to our linearized expression above. Then,

$$
\gamma=1-\frac{\operatorname{cov}\left(R_{t}-R_{t}^{*}, \phi_{t}\right)}{\operatorname{var}\left(R_{t}-R_{t}^{*}\right)}
$$

Thus, any specification of $\phi_{t}$ which causes it to have a positive covariance with the interest rate differential will help in accounting for the regression coefficient specification of the uncovered interest rate puzzle. That is, such a covariance could result in $\gamma$ being negative. This motivates an alternative to the risk specification in (2.45):

$$
\Phi_{t}=\Phi\left(a_{t}, R_{t}^{*}-R_{t}, \tilde{\phi}_{t}\right)=\exp \left(-\tilde{\phi}_{a}\left(a_{t}-\bar{a}\right)-\tilde{\phi}_{s}\left(R_{t}^{*}-R_{t}-\left(R^{*}-R\right)\right)+\tilde{\phi}_{t}\right)
$$

where a variable without time subscript denotes the corresponding value in nonstochastic steady state. We use this specification in our benchmark model.

We now turn to the connection between $\Phi_{t}$ and the hump-shape response of output to an expansionary monetary policy shock. As explained in section 2.3, a key ingredient in obtaining this type of response lies in factors that slow the response of demand to an expansionary monetary policy shock. The response of foreign purchases of domestic goods in the wake of such a shock depends on how much the exchange depreciates. The mechanism we have described slows the depreciation, and this simultaneously reduces the expansion of foreign demand.

\subsubsection{Wage Setting}

Finally, we consider wage setting. We suppose that the specialized labor supplied by households is combined by labor contractors into a homogeneous labor service as follows:

$$
H_{t}=\left[\int_{0}^{1}\left(h_{j, t}\right)^{\frac{1}{\lambda_{w}}} d j\right]^{\lambda_{w}}, 1 \leq \lambda_{w}<\infty
$$

where $h_{j}$ denotes the $j^{\text {th }}$ household supply of labor services. Households are subject to Calvo wage setting frictions as in Erceg, Henderson and Levin (2000) (EHL). With probability 
$1-\xi_{w}$ the $j^{\text {th }}$ household is able to reoptimize its wage and with probability $\xi_{w}$ it sets its wage according to:

$$
\begin{aligned}
& W_{j, t+1}=\tilde{\pi}_{w, t+1} W_{j, t} \\
& \tilde{\pi}_{w, t+1}=\left(\pi_{t}^{c}\right)^{\kappa_{w}}\left(\bar{\pi}_{t+1}^{c}\right)^{\left(1-\kappa_{w}-\varkappa_{w}\right)}(\breve{\pi})^{\varkappa_{w}}\left(\mu_{z^{+}}\right)^{\vartheta_{w}},
\end{aligned}
$$

where $\kappa_{w}, \varkappa_{w}, \vartheta_{w}, \kappa_{w}+\varkappa_{w} \in(0,1)$. The wage updating factor, $\tilde{\pi}_{w, t+1}$, is sufficiently flexible that we can adopt a variety of interesting schemes.

Consider the $j^{\text {th }}$ household that has an opportunity to reoptimize its wage at time $t$. We denote this wage rate by $\tilde{W}_{t}$. This is not indexed by $j$ because the situation of each household that optimizes its wage is the same. In choosing $\tilde{W}_{t}$, the household considers the discounted utility (neglecting currently irrelevant terms in the household objective) of future histories when it cannot reoptimize:

$$
E_{t}^{j} \sum_{i=0}^{\infty}\left(\beta \xi_{w}\right)^{i}\left[-\zeta_{t+i}^{h} A_{L} \frac{\left(h_{j, t+i}\right)^{1+\sigma_{L}}}{1+\sigma_{L}}+v_{t+i} W_{j, t+i} h_{j, t+i} \frac{1-\tau_{t+i}^{y}}{1+\tau_{t+i}^{w}}\right],
$$

where $\tau_{t}^{y}$ is a tax on labor income and $\tau_{t}^{w}$ is a payroll tax. Also, recall that $v_{t}$ is the multiplier on the household's period $t$ budget constraint. The demand for the $j^{\text {th }}$ household's labor services, conditional on it having optimized in period $t$ and not again since, is:

$$
h_{j, t+i}=\left(\frac{\tilde{W}_{t} \tilde{\pi}_{w, t+i} \cdots \tilde{\pi}_{w, t+1}}{W_{t+i}}\right)^{\frac{\lambda w}{1-\lambda w}} H_{t+i} .
$$

Here, it is understood that $\tilde{\pi}_{w, t+i} \cdots \tilde{\pi}_{w, t+1} \equiv 1$ when $i=0$. The equilibrium conditions associated with this problem, i.e. wage setting of households that do get to reoptimize, are derived and reported in section B.3.5 in the Appendix.

\subsection{Fiscal and Monetary Authorities}

For purposes of estimating our models, we must make assumptions about how policy was conducted in the historical sample. In the case of Sweden there was a break in policy in 1992. In the decade before 1992, the value of the Krona in relation to a basket of currencies was held fixed. ${ }^{6}$ Starting in 1995q1 the formal inflation target regime of Sveriges Riksbank was in place. From 1995 there are three ways to represent monetary policy. One is to imagine that the Riksbank conducted policy with commitment with the object of maximizing the following criterion:

$$
\begin{aligned}
& E_{t} \sum_{j=0}^{\infty} \beta^{j}\left\{\left(100\left[\pi_{t}^{c} \pi_{t-1}^{c} \pi_{t-2}^{c} \pi_{t-3}^{c}-\left(\bar{\pi}_{t}^{c}\right)^{4}\right]\right)^{2}+\lambda_{y}\left(100 \log \left(\frac{y_{t}}{y}\right)\right)^{2}+\lambda_{\Delta R}\left(400\left[R_{t}-R_{t-1}\right]\right)^{2}\right. \\
& \left.+\lambda_{s}\left(S_{t}-\bar{S}\right)^{2}\right\}
\end{aligned}
$$

\footnotetext{
${ }^{6}$ There was some adjustment to the exchange because the basket of currencies was changed.
} 
This approach takes the parameters in the criterion, $\lambda_{y}, \lambda_{\Delta R}$ and $\lambda_{s}$ as unknown parameters to be estimated. A second approach is to suppose that policy was Ramsey-optimal, that is that it was chosen with commitment to maximize the discounted social welfare criterion. A virtue of this approach is that there are no policy parameters to be estimated. A third approach is to suppose that policy was conducted according to a Taylor rule of the following form:

$$
\begin{aligned}
\log \left(\frac{R_{t}}{R}\right)= & \rho_{R} \log \left(\frac{R_{t-1}}{R}\right)+\left(1-\rho_{R}\right)\left[\log \left(\frac{\bar{\pi}_{t}^{c}}{\bar{\pi}^{c}}\right)+r_{\pi} \log \left(\frac{\pi_{t}^{c}}{\bar{\pi}_{t}^{c}}\right)\right. \\
& \left.+r_{y} \log \left(\frac{g d p_{t}}{g d p}\right)+r_{q} \log \left(\frac{q_{t}}{q}\right)\right]+r_{\Delta \pi} \Delta \log \left(\frac{\pi_{t}^{c}}{\pi^{c}}\right)+r_{\Delta y} \Delta \log \left(\frac{g d p_{t}}{g d p}\right)+\varepsilon_{R, t} .
\end{aligned}
$$

Here too, the parameters would be taken as unknowns to be estimated. $g d p$ denotes measured GDP in the data, which might be different from $y$ in the model. In addition, $\bar{\pi}_{t}^{c}$ is an exogenous process that characterizes the central bank's consumer price index inflation target and its steady state value corresponds to the steady state of actual inflation. Regarding the timing of the Taylor rule it is important to note that a rule reacting to lagged inflation (as in e.g. ALLV) implies counterfactual dynamics if one allows for nominal debt-contracts for firms as we do in the financial frictions extension of the model (see section 3). That kind of rule leads to an initial decrease in investment following a positive stationary technology shock, for most reasonable parameters. The reason is that the real value of debt increase too strongly as inflation falls and the central bank initially does not respond to the fall in the inflation level. The entrepreneurial wealth therefore decrease so much that investment initially falls.

Among these alternatives we choose the Taylor rule approach, eq. (2.51) and we estimate the model on data from 1995q1. This starting period is chosen to coincide with start of the formal inflation target regime. The data discussed below refers to this period.

We model government consumption expenditures as

$$
G_{t}=g_{t} z_{t}^{+}
$$

where $g_{t}$ is an exogenous stochastic process, orthogonal to the other shocks in the model. We suppose that

$$
\log g_{t}=\left(1-\rho_{g}\right) \log g+\rho_{g} \log g_{t-1}+\varepsilon_{t}^{g} .
$$

where $g=\eta_{g} Y$. We set $\eta_{g}=0.297$, the sample average of government consumption as a fraction of GDP.

The tax rates in our model are:

$$
\tau_{t}^{k}, \tau_{t}^{b}, \tau_{t}^{y}, \tau_{t}^{c}, \tau_{t}^{w}
$$


We briefly discuss the treatment of these tax rates. In the versions of our model without financial frictions, capital is accumulated and capital income accrues directly to the household. However, an observationally equivalent representation of the model has these activities occurring in the firm. This latter interpretation is the convenient one, when thinking about the data and, in particular, the measurement of $\tau^{k}$. We set the tax rate on capital income, $\tau^{k}$, to 0.25 . We arrived at this number as follows. The statutory rate on household capital income is 30 percent and the statutory rate on corporate income is 28 percent. Combining these two numbers we conclude that the statutory rate on corporate and household income is 50 percent. Indirect evidence from Devereux, Griffith and Klemm (2002) suggests to us that the effective tax on capital income may be one half this amount, and this is why we set $\tau^{k}=0.25$ in the model. We reach this conclusion because of the Devereux, Griffith and Klemm observation that the effective corporate income tax is roughly $1 / 2$ of the statutory rate and we adopt the rough approximation that the same applies to the household tax rate. Our assumption that $\tau^{k}$ is constant is also motivated by Devereux, Griffith and Klemm. Their measure of the corporate component of the effective capital income tax rate exhibits very little variation over the part that overlaps with our sample, i.e. 1995-2005.

Now we turn to the tax rate on bonds, $\tau^{b}$. We set $\tau^{b}=0$ to be able to match the pre-tax real rate on bonds of $2.25 \%$ in the data. Setting $\tau^{b}=0$ is required to get the interest rate on bonds to be this low, given the high GDP growth rate, log utility of consumption and $\beta$ not too close to 1 .

For evidence on $\tau^{w}$ we use the data collected by ALLV. Based on these data, we set the payroll tax rate, $\tau^{w}$, to 0.35 . Data on the value-added tax on consumption, $\tau^{c}$, and the personal income tax rate that applies to labor, $\tau^{y}$, are available from Statistics Sweden and indicate $\tau^{c}=0.25$ and $\tau^{y}=0.3$. These are the average values of the corresponding tax rates over the period 1995-2004. We hold these tax rates constant because they exhibit very little variability over this period.

\subsection{Foreign variables}

Below, we describe the stochastic process driving the foreign variables. Our representation takes into account our assumption that foreign output, $Y_{t}^{*}$, is affected by disturbances to $z_{t}^{+}$, just as domestic variables are. In particular, our model of $Y_{t}^{*}$ is:

$$
\begin{aligned}
\log Y_{t}^{*} & =\log y_{t}^{*}+\log z_{t}^{+} \\
& =\log y_{t}^{*}+\log z_{t}+\frac{\alpha}{1-\alpha} \log \psi_{t}
\end{aligned}
$$


where $\log \left(y_{t}^{*}\right)$ is assumed to be a stationary process. We assume:

$$
\begin{aligned}
\left(\begin{array}{c}
\log \left(\frac{y_{t}^{*}}{y^{*}}\right) \\
\pi_{t}^{*}-\pi^{*} \\
R_{t}^{*}-R^{*} \\
\log \left(\frac{\mu_{z, t}}{\mu_{z}}\right) \\
\log \left(\frac{\mu_{\psi, t}}{\mu_{\psi}}\right)
\end{array}\right)= & {\left[\begin{array}{ccccc}
a_{11} & a_{12} & a_{13} & 0 & 0 \\
a_{21} & a_{22} & a_{23} & a_{24} & \frac{a_{24} \alpha}{1-\alpha} \\
a_{31} & a_{32} & a_{33} & a_{34} & \frac{a_{34} \alpha}{1-\alpha} \\
0 & 0 & 0 & \rho_{\mu_{z}} & 0 \\
0 & 0 & 0 & 0 & \rho_{\mu_{\psi}}
\end{array}\right]\left(\begin{array}{c}
\log \left(\frac{y_{t-1}^{*}}{y^{*}}\right) \\
\pi_{t-1}^{*}-\pi^{*} \\
R_{t-1}^{*}-R^{*} \\
\log \left(\frac{\mu_{z, t-1}}{\mu_{z}}\right) \\
\log \left(\frac{\mu_{\psi, t-1}}{\mu_{\psi}}\right)
\end{array}\right) } \\
+ & {\left[\begin{array}{ccccc}
\sigma_{y^{*}} & 0 & 0 & 0 & 0 \\
c_{21} & \sigma_{\pi^{*}} & 0 & c_{24} & \frac{c_{24} \alpha}{1-\alpha} \\
c_{31} & c_{32} & \sigma_{R^{*}} & c_{34} & \frac{c_{34} \alpha}{1-\alpha} \\
0 & 0 & 0 & \sigma_{\mu_{z}} & 0 \\
0 & 0 & 0 & 0 & \sigma_{\mu_{\psi}}
\end{array}\right]\left(\begin{array}{c}
\varepsilon_{y^{*}, t} \\
\varepsilon_{\pi^{*}, t} \\
\varepsilon_{R^{*}, t} \\
\varepsilon_{\mu_{z}, t} \\
\varepsilon_{\mu_{\psi}, t}
\end{array}\right), }
\end{aligned}
$$

where the $\varepsilon_{t}$ 's are mean zero, unit variance, i.i.d. processes uncorrelated with each other. In matrix form,

$$
X_{t}^{*}=A X_{t-1}^{*}+C \varepsilon_{t},
$$

in obvious notation. Note that the matrix $C$ has 10 elements, so that the order condition for identification is satisfied, since $C C^{\prime}$ represents 15 independent equations.

We now briefly discuss the intuition underlying the zero restrictions in $A$ and $C$. First, we assume that the shock, $\varepsilon_{y^{*}, t}$, affects the first three variables in $X_{t}^{*}$, while $\varepsilon_{\pi^{*}, t}$ only affects the second two and $\varepsilon_{R^{*}, t}$ only affects the third. The assumption about $\varepsilon_{R^{*}, t}$ corresponds to one strategy for identifying a monetary policy shock, in which it is assumed that inflation and output are predetermined relative to the monetary policy shock. Under this interpretation of $\varepsilon_{R^{*}, t}$, our treatment of the foreign monetary policy shock and the domestic one are inconsistent because in our model domestic prices are not predetermined in the period of a monetary policy shock. Second, note from the zeros in the last two columns of the first row in $A$ and $C$, that the technology shocks do not affect $y_{t}^{*}$. This reflects our assumption that the impact of technology shocks on $Y_{t}^{*}$ is completely taken into account by $z_{t}^{+}$, while all other shocks to $Y_{t}^{*}$ are orthogonal to $z_{t}^{+}$and they affect $Y_{t}^{*}$ via $y_{t}^{*}$. Third, the $A$ and $C$ matrices capture the notion that innovations to technology affect foreign inflation and the interest rate via their impact on $z_{t}^{+}$. Fourth, our assumptions on $A$ and $C$ imply that

$\log \left(\frac{\mu_{\psi, t}}{\mu_{\psi}}\right)$ and $\log \left(\frac{\mu_{z, t}}{\mu_{z}}\right)$ are univariate first order autoregressive processes driven by $\varepsilon_{\mu_{\psi}, t}$ and $\varepsilon_{\mu_{z}, t}$, respectively. This is a standard assumption made on technology shocks in DSGE models.

\subsection{Resource Constraints}

The fact that we potentially have steady state price dispersion both in prices and wages complicates the expression for the domestic homogeneous good, $Y_{t}$ in terms of aggregate 
factors of production. The relationship is derived in section B.3.6 in the Appendix and can be expressed as:

$$
y_{t}=\left(\stackrel{\circ}{p}_{t}\right)^{\frac{\lambda_{d}}{\lambda_{d}-1}}\left[\epsilon_{t}\left(\frac{1}{\mu_{\Psi, t}} \frac{1}{\mu_{z^{+}, t}} k_{t}\right)^{\alpha}\left({\stackrel{\circ}{w_{t}}}^{-\frac{\lambda w}{1-\lambda_{w}}} h_{t}\right)^{1-\alpha}-\phi\right]
$$

\subsubsection{Resource constraint for domestic homogeneous output}

Above we defined real, scaled GDP in terms of aggregate factors of production. It is convenient to also have an expression that exhibits the uses of domestic homogeneous output. Using (2.24),

$$
z_{t}^{+} y_{t}=G_{t}+C_{t}^{d}+I_{t}^{d}+\left[\omega_{x}\left(p_{t}^{m, x}\right)^{1-\eta_{x}}+\left(1-\omega_{x}\right)\right]^{\frac{\eta_{x}}{1-\eta_{x}}}\left(1-\omega_{x}\right)\left(\stackrel{\circ}{p}_{t}^{x}\right)^{\frac{-\lambda_{x, t}}{\lambda_{x, t}-1}}\left(p_{t}^{x}\right)^{-\eta_{f}} Y_{t}^{*},
$$

or, after scaling by $z_{t}^{+}$and using (2.10):

$$
\begin{aligned}
y_{t}= & g_{t}+\left(1-\omega_{c}\right)\left(p_{t}^{c}\right)^{\eta_{c}} c_{t}+\left(p_{t}^{i}\right)^{\eta_{i}}\left(i_{t}+a\left(u_{t}\right) \frac{\bar{k}_{t}}{\mu_{\psi, t} \mu_{z^{+}, t}}\right)\left(1-\omega_{i}\right) \\
& +\left[\omega_{x}\left(p_{t}^{m, x}\right)^{1-\eta_{x}}+\left(1-\omega_{x}\right)\right]^{\frac{\eta_{x}}{1-\eta_{x}}}\left(1-\omega_{x}\right)\left(\stackrel{\circ}{p}_{t}^{x}\right)^{\frac{-\lambda_{x, t}}{\lambda_{x, t}-1}}\left(p_{t}^{x}\right)^{-\eta_{f}} y_{t}^{*} .
\end{aligned}
$$

When we match GDP to the data we use subtract capital utilization costs from $y_{t}$. See section 5.6 for details.

$$
g d p_{t}=y_{t}-\left(p_{t}^{i}\right)^{\eta_{i}}\left(a\left(u_{t}\right) \frac{\bar{k}_{t}}{\mu_{\psi, t} \mu_{z^{+}, t}}\right)\left(1-\omega_{i}\right)
$$

\subsubsection{Trade Balance}

We begin by developing the link between net exports and the current account. Expenses on imports and new purchases of net foreign assets, $A_{t+1}$, must equal income from exports and from previously purchased net foreign assets:

$$
S_{t} A_{t+1}+\text { expenses on } \text { imports }_{t}=\text { receipts from exports } t+R_{t-1}^{*} \Phi_{t-1} S_{t} A_{t}^{*},
$$

where $\Phi_{t}$ is as defined in (2.46) in our benchmark model. Expenses on imports correspond to the purchases of specialized importers for the consumption, investment and export sectors:

$$
\text { expenses on imports } t=S_{t} P_{t}^{*} R_{t}^{\nu, *}\left(C_{t}^{m}\left(\stackrel{\circ}{p}_{t}^{m, c}\right)^{\frac{\lambda^{m, C}}{1-\lambda^{m, C}}}+I_{t}^{m}\left(\stackrel{\circ}{p_{t}^{m, i}}\right)^{\frac{\lambda^{m, i}}{1-\lambda^{m, i}}}+X_{t}^{m}\left(\stackrel{\circ}{p_{t}^{m, x}}\right)^{\frac{\lambda^{m, x}}{1-\lambda^{m, x}}}\right),
$$

using $(2.29),(2.30)$ and $(2.31)$. Note the presence of the price distortion terms here. To understand these terms, recall that, for example, $C_{t}^{m}$ is produced as a linear homogeneous function of specialized imported goods. Because the specialized importers only buy foreign 
goods, it is their total expenditures that interests us here. When the imports are distributed evenly across differentiated goods, then the total quantity of those imports is $C_{t}^{m}$, and the value of imports associated with domestic production of consumption goods is $S_{t} P_{t}^{*} R_{t}^{\nu, *} C_{t}^{m}$. When there are price distortions among imported intermediate goods, then the sum of the homogeneous import goods is higher for any given value of $C_{t}^{m}$.

We conclude that the current account can be written as follows:

$$
\begin{aligned}
& S_{t} A_{t+1}^{*}+S_{t} P_{t}^{*} R_{t}^{\nu, *}\left(C_{t}^{m}\left(\stackrel{\circ}{p}_{t}^{m, c}\right)^{\frac{\lambda^{m, C}}{1-\lambda^{m, C}}}+I_{t}^{m}\left(\stackrel{\circ}{p}_{t}^{m, i}\right)^{\frac{\lambda^{m, i}}{1-\lambda^{m, i}}}+X_{t}^{m}\left(\stackrel{\circ}{p}_{t}^{m, x}\right)^{\frac{\lambda^{m, x}}{1-\lambda^{m, x}}}\right) \\
= & S_{t} P_{t}^{x} X_{t}+R_{t-1}^{*} \Phi_{t-1} S_{t} A_{t}^{*},
\end{aligned}
$$

where $\Phi_{t}$ is defined in section 2.4.3. Writing the current account in scaled form and dividing by $P_{t} z_{t}^{+}$, we obtain using $(2.22)$

$$
\begin{array}{r}
a_{t}+q_{t} p_{t}^{c} R_{t}^{\nu, *}\left(c_{t}^{m}\left(\stackrel{\circ}{p}_{t}^{m, c}\right)^{\frac{\lambda^{m}, C}{1-\lambda^{m, C}}}+i_{t}^{m}\right. \\
\left.\left(\stackrel{\circ}{p_{t}^{m}}\right)^{\frac{\lambda^{m, i}}{1-\lambda^{m, i}}}+x_{t}^{m}\left(\stackrel{\circ}{p}_{t}^{m, x}\right)^{\frac{\lambda^{m, x}}{1-\lambda^{m, x}}}\right) \\
=q_{t} p_{t}^{c} p_{t}^{x} x_{t}+R_{t-1}^{*} \Phi_{t-1} s_{t} \frac{a_{t-1}}{\pi_{t} \mu_{z^{+}, t}},
\end{array}
$$

where $a_{t}=S_{t} A_{t+1}^{*} /\left(P_{t} z_{t}^{+}\right)$.

\subsubsection{Restrictions across inflation rates}

We now consider the restrictions across inflation rates implied by our relative price formulas. In terms of the expressions in (B.2) there are the restrictions implied by $p_{t}^{m, j} / p_{t-1}^{m, j}, j=$ $x, c, i$, and $p_{t}^{x}$. The restrictions implied by the other two relative prices in (B.2), $p_{t}^{i}$ and $p_{t}^{c}$, have already been exploited in (2.16) and (2.35), respectively. Finally, we also exploit the restriction across inflation rates implied by $q_{t} / q_{t-1}$ and (B.3). Thus,

$$
\begin{aligned}
\frac{p_{t}^{m, x}}{p_{t-1}^{m, x}} & =\frac{\pi_{t}^{m, x}}{\pi_{t}} \\
\frac{p_{t}^{m, c}}{p_{t-1}^{m, c}} & =\frac{\pi_{t}^{m, c}}{\pi_{t}} \\
\frac{p_{t}^{m, i}}{p_{t-1}^{m, i}} & =\frac{\pi_{t}^{m, i}}{\pi_{t}} \\
\frac{p_{t}^{x}}{p_{t-1}^{x}} & =\frac{\pi_{t}^{x}}{\pi_{t}^{*}} \\
\frac{q_{t}}{q_{t-1}} & =\frac{s_{t} \pi_{t}^{*}}{\pi_{t}^{c}} .
\end{aligned}
$$

This completes the description of the baseline model. 


\subsection{Endogenous Variables of the Baseline Model}

In the above sections we derived following 71 equations,

2.3, 2.4, 2.5, B.11, B.12, B.13, B.14, B.15, B.4, 2.10, 2.11, 2.12, 2.15, 2.16, 2.14,

2.17, 2.21, 2.20, 2.26, B.16, B.17, B.18, B.19, 2.25, 2.28, B.22, B.23, B.24, B.25, 2.32,

2.33, B.5, B.6, 2.35, 2.36, 2.38, 2.39, 2.40, 2.41, 2.42, 2.44, B.30, B.31, B.32, B.28,

$2.48, B .26, B .27,2.51, B .35,2.52,2.54,2.53,2.55,2.56,2.57,2.58,2.59,2.46$

which can be used to solve for the following 71 unknowns:

$$
\begin{array}{r}
\bar{r}_{t}^{k}, \bar{w}_{t}, R_{t}^{\nu, *}, R_{t}^{f}, R_{t}^{x}, R_{t}, m c_{t}, m c_{t}^{x}, m c_{t}^{m, c}, m c_{t}^{m, i}, m c_{t}^{m, x}, \pi_{t}, \pi_{t}^{x}, \pi_{t}^{c}, \pi_{t}^{i}, \pi_{t}^{m, c}, \pi_{t}^{m, i}, \pi_{t}^{m, x}, \\
p_{t}^{c}, p_{t}^{x}, p_{t}^{i}, p_{t}^{m, x}, p_{t}^{m, c}, p_{t}^{m, i}, p_{k^{\prime}, t}, k_{t+1}, \bar{k}_{t+1}, u_{t}, h_{t}, H_{t}, q_{t}, i_{t}, c_{t}, x_{t}, a_{t}, s_{t}, \psi_{z^{+}, t}, y_{t} \\
K_{t}^{d}, F_{t}^{d}, \tilde{\pi}_{d, t}, \stackrel{\circ}{p}_{t}, K_{x, t}, F_{x, t}, \tilde{\pi}_{t}^{x}, \stackrel{o}{p}_{t}^{x},\left\{K_{m, j, t}, F_{m, j, t}, \tilde{\pi}_{t}^{m, j}, \stackrel{p_{t}^{m, j}}{m} ;=c, i, x\right\}, K_{w, t}, F_{w, t}, \tilde{\pi}_{t}^{w}, R_{t}^{k} \\
\Phi_{t}, \tilde{S}_{t}, \tilde{S}_{t}^{\prime}, a\left(u_{t}\right), \stackrel{\circ}{w}_{t}, c_{t}^{m}, i_{t}^{m}, x_{t}^{m}, \pi_{w} .
\end{array}
$$

\section{Introducing Financial Frictions into the Model}

A number of the activities in the model of the previous section require financing. Producers of specialized inputs must borrow working capital within the period. The management of capital involves financing because the construction of capital requires a substantial initial outlay of resources, while the return from capital comes in over time as a flow. In the model of the previous section financing requirements affect the allocations, but not very much. This is because none of the messy realities of actual financial markets are present. There is no asymmetric information between borrower and lender, there is no risk to lenders. In the case of capital accumulation, the borrower and lender are actually the same household, who puts up the finances and later reaps the rewards. When real-world financial frictions are introduced into a model, then intermediation becomes distorted by the presence of balance sheet constraints and other factors.

Although the literature shows how to introduce financial frictions much more extensively, here we proceed by assuming that only the accumulation and management of capital involves frictions. We will continue to assume that working capital loans are frictionless. At the end of this introduction, we briefly discuss the idea of introducing financial frictions into working capital loans. Our strategy of introducing frictions in the accumulation and management of capital follows the variant of the Bernanke, Gertler and Gilchrist (1999) (henceforth BGG) 
model implemented in Christiano, Motto and Rostagno (2003). The discussion here borrows heavily from the derivation in Christiano, Motto and Rostagno (2008) (henceforth CMR).

The financial frictions we introduce reflect fundamentally that borrowers and lenders are different people, and that they have different information. Thus, we introduce 'entrepreneurs'. These are agents who have a special skill in the operation and management of capital. Although these agents have their own financial resources, their skill in operating capital is such that it is optimal for them to operate more capital than their own resources can support, by borrowing additional funds. There is a financial friction because the management of capital is risky. Individual entrepreneurs are subject to idiosyncratic shocks which are observed only by them. The agents that they borrow from, 'banks', can only observe the idiosyncratic shocks by paying a monitoring cost. This type of asymmetric information implies that it is impractical to have an arrangement in which banks and entrepreneurs simply divide up the proceeds of entrepreneurial activity, because entrepreneurs have an incentive to understate their earnings. An alternative arrangement that is more efficient is one in which banks extend entrepreneurs a 'standard debt contract', which specifies a loan amount and a given interest payment. Entrepreneurs who suffer an especially bad idiosyncratic income shock and who therefore cannot afford to pay the required interest, are 'bankrupt'. Banks pay the cost of monitoring these entrepreneurs and take all of their net worth in partial compensation for the interest that they are owed. For a graphical illustration of the financing problem in the capital market, see Figure A.

The amount that banks are willing to lend to an entrepreneur under the standard debt contract is a function of the entrepreneur's net worth. This is how balance sheet constraints enter the model. When a shock occurs that reduces the value of the entrepreneur's assets, this cuts into their ability to borrow. As a result, they acquire less capital and this translates into a reduction in investment and ultimately into a slowdown in the economy.

The ultimate source of funds for lending to entrepreneurs is the household. The standard debt contracts extended by banks to entrepreneurs are financed by issuing liabilities to households. Although individual entrepreneurs are risky, banks themselves are not. We suppose that banks lend to a sufficiently diverse group of entrepreneurs that the uncertainty that exists in individual entrepreneurial loans washes out across all loans. Extensions of the model that introduce risk into banking have been developed, but it is not clear that the added complexity is justified.

In the model, the interest rate that households receive is nominally non state-contingent. This gives rise to potentially interesting wealth effects of the sort emphasized by Irving Fisher (1933). For example, when a shock occurs which drives the price level down, households receive a wealth transfer. Because this transfer is taken from entrepreneurs, their net worth is reduced. With the tightening in their balance sheets, their ability to invest is reduced. 
At the level of abstraction of the model, the capital stock includes both housing and business capital. As a result, the entrepreneurs can also be interpreted as households in their capacity of homeowners. An expanded version of the model would pull apart the household and business sectors to study each individually. Another straightforward expansion of the model would apply the model of financial frictions to working capital loans.

With this model, it is typically the practice to compare the net worth of entrepreneurs with a stock market quantity (index), and we follow this route. Whether this is really appropriate is uncertain. A case can be made that the 'bank loans' of entrepreneurs in the model correspond well with actual bank loans plus actual equity. It is well known that dividend payments on equity are very smooth. Firms work hard to accomplish this. For example, during the US Great Depression some firms were willing to sell their own physical capital in order to avoid cutting dividends. That this is so is perhaps not surprising. The asymmetric information problems with actual equity are surely as severe as they are for the banks in our model. Under these circumstances one might expect equity holders to demand a payment that is not contingent on the realization of uncertainty within the firm (payments could be contingent upon publicly observed variables). Under this vision, the net worth in the model would correspond not to a measure of the aggregate stock market, but to the ownership stake of the managers and others who exert most direct control over the firm. The 'bank loans' in this model would, under this view of things, correspond to the actual loans of firms (i.e., bank loans and other loans such as commercial paper) plus the outstanding equity. While this is perhaps too extreme, these observations highlight that there is substantial uncertainty over exactly what variable should be compared with net worth in the model. It is important to emphasize, however, that whatever the right interpretation is of net worth, the model potentially captures balance sheet problems very nicely.

Finally, we make some remarks on the introduction of financial frictions into working capital loans. It is possible to accomplish this with relatively little modification to the model, by following the strategy described in Fisher (1998). However, with this strategy the effects of financial frictions are quite modest, because the firms in the model which use working capital do not have assets. As a result, the balance sheet channel does not operate. We conjecture that for financial frictions in working capital to be interesting, the borrowing firms would need to have assets. One way this could be accomplished would be to assume that they use and own capital that is specific to their firm. In this way, fluctuations in the value of that capital induced by changes in asset prices would change their ability to borrow, and hence to produce. This strategy is algebra-intensive because of the fact that these firms also set their prices subject to Calvo frictions. 


\subsection{Modifying the Baseline Model}

The financial frictions bring a net increase of two equations over the equations in the model of the previous section. In addition, they introduce two new endogenous variables, one related to the interest rate paid by entrepreneurs as well as their net worth. The financial frictions also allow us to introduce two new random variables. We now provide a formal discussion of the model.

As we shall see, entrepreneurs all have different histories, as they experience different idiosyncratic shocks. Thus, in general, solving for the aggregate variables would require also solving for the distribution of entrepreneurs according to their characteristics and for the law of motion for that distribution. However, as emphasized in BGG, the right functional form assumptions have been made in the model, which guarantee the result that the aggregate variables associated with entrepreneurs are not a function of distributions. The loan contract specifies that all entrepreneurs, regardless of their net worth, receive the same interest rate. Also, the loan amount received by an entrepreneur is proportional to his level of net worth. These are enough to guarantee the aggregation result.

\subsubsection{The Individual Entrepreneur}

At the end of period $t$ each entrepreneur has a level of net worth, $N_{t+1}$. The entrepreneur's net worth, $N_{t+1}$, constitutes his state at this time, and nothing else about his history is relevant. We imagine that there are many entrepreneurs for each level of net worth and that for each level of net worth, there is a competitive bank with free entry that offers a loan contract. The contract is defined by a loan amount and by an interest rate, both of which are derived as the solution to a particular optimization problem.

Consider a type of entrepreneur with a particular level of net worth, $N_{t+1}$. The entrepreneur combines this net worth with a bank loan, $B_{t+1}$, to purchase new, installed physical capital, $\bar{K}_{t+1}$, from capital producers. The loan the entrepreneur requires for this is:

$$
B_{t+1}=P_{t} P_{k^{\prime}, t} \bar{K}_{t+1}-N_{t+1}
$$

The entrepreneur is required to pay a gross interest rate, $Z_{t+1}$, on the bank loan at the end of period $t+1$, if it is feasible to do so. After purchasing capital the entrepreneur experiences an idiosyncratic productivity shock which converts the purchased capital, $\bar{K}_{t+1}$, into $\bar{K}_{t+1} \omega$. Here, $\omega$ is a unit mean, lognormally and independently distributed random variable across entrepreneurs. The variance of $\log \omega$ is $\sigma_{t}^{2}$. The $t$ subscript indicates that $\sigma_{t}$ is itself the realization of a random variable. This allows us to consider the effects of an increase in the riskiness of individual entrepreneurs. We denote the cumulative distribution function of $\omega$ by $F(\omega ; \sigma)$. and its partial derivatives as e.g. $F_{\omega}(\omega ; \sigma), F_{\sigma}(\omega ; \sigma)$ 
After observing the period $t+1$ shocks, the entrepreneur sets the utilization rate, $u_{t+1}$, of capital and rents capital out in competitive markets at nominal rental rate, $P_{t+1} r_{t+1}^{k}$. In choosing the capital utilization rate, the entrepreneur takes into account that operating one unit of physical capital at rate $u_{t+1}$ requires $a\left(u_{t+1}\right)$ of domestically produced investment goods for maintenance expenditures, where $a$ is defined in (B.4). The entrepreneur then sells the undepreciated part of physical capital to capital producers. Per unit of physical capital purchased, the entrepreneur who draws idiosyncratic shock $\omega$ earns a return (after taxes), of $R_{t+1}^{k} \omega$, where $R_{t+1}^{k}$ is defined in (2.37) and is displayed below for convenience:

$$
R_{t+1}^{k}=\frac{\left(1-\tau_{t}^{k}\right)\left[u_{t+1} \bar{r}_{t+1}^{k}-\frac{p_{t+1}^{i}}{\Psi_{t+1}} a\left(u_{t+1}\right)\right] P_{t+1}+(1-\delta) P_{t+1} P_{k^{\prime}, t+1}+\tau_{t}^{k} \delta P_{t} P_{k^{\prime}, t}}{P_{t} P_{k^{\prime}, t}}
$$

Because the mean of $\omega$ across entrepreneurs is unity, the average return across all entrepreneurs is $R_{t+1}^{k}$.

After entrepreneurs sell their capital, they settle their bank loans. At this point, the resources available to an entrepreneur who has purchased $\bar{K}_{t+1}$ units of physical capital in period $t$ and who experiences an idiosyncratic productivity shock $\omega$ are $P_{t} P_{k^{\prime}, t} R_{t+1}^{k} \omega \bar{K}_{t+1}$. There is a cutoff value of $\omega, \bar{\omega}_{t+1}$, such that the entrepreneur has just enough resources to pay interest:

$$
\bar{\omega}_{t+1} R_{t+1}^{k} P_{t} P_{k^{\prime}, t} \bar{K}_{t+1}=Z_{t+1} B_{t+1} \text {. }
$$

Entrepreneurs with $\omega<\bar{\omega}_{t+1}$ are bankrupt and turn over all their resources,

$$
R_{t+1}^{k} \omega P_{t} P_{k^{\prime}, t} \bar{K}_{t+1}
$$

which is less than $Z_{t+1} B_{t+1}$, to the bank. In this case, the bank monitors the entrepreneur, at cost

$$
\mu R_{t+1}^{k} \omega P_{t} P_{k^{\prime}, t} \bar{K}_{t+1}
$$

where $\mu \geq 0$ is a parameter.

Banks obtain the funds loaned in period $t$ to entrepreneurs by issuing deposits to households at gross nominal rate of interest, $R_{t}$. The subscript on $R_{t}$ indicates that the payoff to households in $t+1$ is not contingent on the period $t+1$ uncertainty. This feature of the relationship between households and banks is simply assumed. There is no risk in household bank deposits, and the household Euler equation associated with deposits is exactly the same as $(2.42)$.

We suppose that there is competition and free entry among banks, and that banks participate in no financial arrangements other than the liabilities issued to households and the 
loans issued to entrepreneurs. ${ }^{7}$ It follows that the bank's cash flow in each state of period $t+1$ is zero, for each loan amount. ${ }^{8}$ For loans in the amount, $B_{t+1}$, the bank receives gross interest, $Z_{t+1} B_{t+1}$, from the $1-F\left(\bar{\omega}_{t+1} ; \sigma_{t}\right)$ entrepreneurs who are not bankrupt. The bank takes all the resources possessed by bankrupt entrepreneurs, net of monitoring costs. Thus, the state-by-state zero profit condition is:

$$
\left[1-F\left(\bar{\omega}_{t+1} ; \sigma_{t}\right)\right] Z_{t+1} B_{t+1}+(1-\mu) \int_{0}^{\bar{\omega}_{t+1}} \omega d F\left(\omega ; \sigma_{t}\right) R_{t+1}^{k} P_{t} P_{k^{\prime}, t} \bar{K}_{t+1}=R_{t} B_{t+1}
$$

or, after making use of (3.2) and rearranging,

$$
\left[\Gamma\left(\bar{\omega}_{t+1} ; \sigma_{t}\right)-\mu G\left(\bar{\omega}_{t+1} ; \sigma_{t}\right)\right] \frac{R_{t+1}^{k}}{R_{t}} \varrho_{t}=\varrho_{t}-1
$$

where

$$
\begin{aligned}
G\left(\bar{\omega}_{t+1} ; \sigma_{t}\right) & =\int_{0}^{\bar{\omega}_{t+1}} \omega d F\left(\omega ; \sigma_{t}\right) . \\
\Gamma\left(\bar{\omega}_{t+1} ; \sigma_{t}\right) & =\bar{\omega}_{t+1}\left[1-F\left(\bar{\omega}_{t+1} ; \sigma_{t}\right)\right]+G\left(\bar{\omega}_{t+1} ; \sigma_{t}\right) \\
\varrho_{t} & =\frac{P_{t} P_{k^{\prime}, t} \bar{K}_{t+1}}{N_{t+1}} .
\end{aligned}
$$

The expression, $\Gamma\left(\bar{\omega}_{t+1} ; \sigma_{t}\right)-\mu G\left(\bar{\omega}_{t+1} ; \sigma_{t}\right)$ is the share of revenues earned by entrepreneurs that borrow $B_{t+1}$, which goes to banks. Note that $\Gamma_{\bar{\omega}}\left(\bar{\omega}_{t+1} ; \sigma_{t}\right)=1-F\left(\bar{\omega}_{t+1} ; \sigma_{t}\right)>0$ and $G_{\bar{\omega}}\left(\bar{\omega}_{t+1} ; \sigma_{t}\right)=\bar{\omega}_{t+1} F_{\bar{\omega}}\left(\bar{\omega}_{t+1} ; \sigma_{t}\right)>0$. It is thus not surprising that the share of entrepreneurial revenues accruing to banks is non-monotone with respect to $\bar{\omega}_{t+1}$. BGG argue that the expression on the left of (3.3) has an inverted ' $U$ ' shape, achieving a maximum value at $\bar{\omega}_{t+1}=\omega^{*}$, say. The expression is increasing for $\bar{\omega}_{t+1}<\omega^{*}$ and decreasing for $\bar{\omega}_{t+1}>\omega^{*}$. Thus, for any given value of the leverage ratio, $\varrho_{t}$, and $R_{t+1}^{k} / R_{t}$, generically there are either no values of $\bar{\omega}_{t+1}$ or two that satisfy (3.3). The value of $\bar{\omega}_{t+1}$ realized in equilibrium must be the one on the left side of the inverted ' $U$ ' shape. This is because, according to (3.2), the lower value of $\bar{\omega}_{t+1}$ corresponds to a lower interest rate for entrepreneurs which yields them higher welfare. As discussed below, the equilibrium contract is one that maximizes entrepreneurial welfare subject to the zero profit condition on banks. This reasoning leads to the conclusion that $\bar{\omega}_{t+1}$ falls with a period $t+1$ shock that drives $R_{t+1}^{k}$ up. The fraction of entrepreneurs that experience bankruptcy is $F\left(\bar{\omega}_{t+1} ; \sigma_{t}\right)$, so it follows that a shock which drives up $R_{t+1}^{k}$ has a negative contemporaneous impact on the bankruptcy rate. According to

\footnotetext{
${ }^{7}$ If banks also had access to state contingent securities, then free entry and competition would imply that banks earn zero profits in an ex ante expected sense from the point of view of period $t$.

${ }^{8}$ Absence of state contingent securities markets guarantee that cash flow is non-negative. Free entry guarantees that ex ante profits are zero. Given that each state of nature receives positive probability, the two assumptions imply the state by state zero profit condition quoted in the text.
} 
(2.37), shocks that drive $R_{t+1}^{k}$ up include anything which raises the value of physical capital and/or the rental rate of capital.

As just noted, we suppose that the equilibrium debt contract maximizes entrepreneurial welfare, subject to the zero profit condition on banks and the specified required return on household bank liabilities. The date $t$ debt contract specifies a level of debt, $B_{t+1}$ and a state $t+1$-contingent rate of interest, $Z_{t+1}$. We suppose that entrepreneurial welfare corresponds to the entrepreneur's expected wealth at the end of the contract. It is convenient to express welfare as a ratio to the amount the entrepreneur could receive by depositing his net worth in a bank:

$$
\begin{aligned}
& \frac{E_{t} \int_{\bar{\omega}_{t+1}}^{\infty}\left[R_{t+1}^{k} \omega P_{t} P_{k^{\prime}, t} \bar{K}_{t+1}-Z_{t+1} B_{t+1}\right] d F\left(\omega ; \sigma_{t}\right)}{R_{t} N_{t+1}} \\
& =\frac{E_{t} \int_{\bar{\omega}_{t+1}}^{\infty}\left[\omega-\bar{\omega}_{t+1}\right] d F\left(\omega ; \sigma_{t}\right) R_{t+1}^{k} P_{t} P_{k^{\prime}, t} \bar{K}_{t+1}}{R_{t} N_{t+1}} \\
& =E_{t}\left\{\left[1-\Gamma\left(\bar{\omega}_{t+1} ; \sigma_{t}\right)\right] \frac{R_{t+1}^{k}}{R_{t}}\right\} \varrho_{t},
\end{aligned}
$$

after making use of (3.1), (3.2) and

$$
1=\int_{0}^{\infty} \omega d F\left(\omega ; \sigma_{t}\right)=\int_{\bar{\omega}_{t+1}}^{\infty} \omega d F\left(\omega ; \sigma_{t}\right)+G\left(\bar{\omega}_{t+1} ; \sigma_{t}\right) .
$$

We can equivalently characterize the contract by a state- $t+1$ contingent set of values for $\bar{\omega}_{t+1}$ and a value of $\varrho_{t}$. The equilibrium contract is the one involving $\bar{\omega}_{t+1}$ and $\varrho_{t}$ which maximizes entrepreneurial welfare (relative to $R_{t} N_{t+1}$ ), subject to the bank zero profits condition. The Lagrangian representation of this problem is:

$$
\max _{\varrho_{t},\left\{\bar{\omega}_{t+1}\right\}} E_{t}\left\{\left[1-\Gamma\left(\bar{\omega}_{t+1} ; \sigma_{t}\right)\right] \frac{R_{t+1}^{k}}{R_{t}} \varrho_{t}+\lambda_{t+1}\left(\left[\Gamma\left(\bar{\omega}_{t+1} ; \sigma_{t}\right)-\mu G\left(\bar{\omega}_{t+1} ; \sigma_{t}\right)\right] \frac{R_{t+1}^{k}}{R_{t}} \varrho_{t}-\varrho_{t}+1\right)\right\},
$$

where $\lambda_{t+1}$ is the Lagrange multiplier which is defined for each period $t+1$ state of nature. The first order conditions for this problem are:

$$
\begin{aligned}
E_{t}\left\{\left[1-\Gamma\left(\bar{\omega}_{t+1} ; \sigma_{t}\right)\right] \frac{R_{t+1}^{k}}{R_{t}}+\lambda_{t+1}\left(\left[\Gamma\left(\bar{\omega}_{t+1} ; \sigma_{t}\right)-\mu G\left(\bar{\omega}_{t+1} ; \sigma_{t}\right)\right] \frac{R_{t+1}^{k}}{R_{t}}-1\right)\right\} & =0 \\
-\Gamma_{\bar{\omega}}\left(\bar{\omega}_{t+1} ; \sigma_{t}\right) \frac{R_{t+1}^{k}}{R_{t}}+\lambda_{t+1}\left[\Gamma_{\bar{\omega}}\left(\bar{\omega}_{t+1} ; \sigma_{t}\right)-\mu G_{\bar{\omega}}\left(\bar{\omega}_{t+1} ; \sigma_{t}\right)\right] \frac{R_{t+1}^{k}}{R_{t}} & =0 \\
{\left[\Gamma\left(\bar{\omega}_{t+1} ; \sigma_{t}\right)-\mu G\left(\bar{\omega}_{t+1} ; \sigma_{t}\right)\right] \frac{R_{t+1}^{k}}{R_{t}} \varrho_{t}-\varrho_{t}+1 } & =0
\end{aligned}
$$

where the absence of $\lambda_{t+1}$ from the complementary slackness condition reflects that we assume $\lambda_{t+1}>0$ in each period $t+1$ state of nature. Substituting out for $\lambda_{t+1}$ from the second 
equation into the first, the first order conditions reduce to:

$$
\begin{gathered}
E_{t}\left\{\begin{array}{c}
{\left[1-\Gamma\left(\bar{\omega}_{t+1} ; \sigma_{t}\right)\right] \frac{R_{t+1}^{k}}{R_{t}}+\frac{\Gamma_{\bar{\omega}}\left(\bar{\omega}_{t+1} ; \sigma_{t}\right)}{\Gamma_{\bar{\omega}}\left(\bar{\omega}_{t+1} ; \sigma_{t}\right)-\mu G_{\bar{\omega}}\left(\bar{\omega}_{t+1} ; \sigma_{t}\right)}} \\
\left(\left[\Gamma\left(\bar{\omega}_{t+1} ; \sigma_{t}\right)-\mu G\left(\bar{\omega}_{t+1} ; \sigma_{t}\right)\right] \frac{R_{t+1}^{k}}{R_{t}}-1\right)
\end{array}\right\}=0, \\
{\left[\Gamma\left(\bar{\omega}_{t+1} ; \sigma_{t}\right)-\mu G\left(\bar{\omega}_{t+1} ; \sigma_{t}\right)\right] \frac{R_{t+1}^{k}}{R_{t}} \varrho_{t}-\varrho_{t}+1=0,}
\end{gathered}
$$

for $t=0,1,2, \ldots \infty$ and for $t=-1,0,1,2, \ldots$ respectively.

Since $N_{t+1}$ does not appear in the last two equations, we conclude that $\varrho_{t}$ and $\bar{\omega}_{t+1}$ are the same for all entrepreneurs, regardless of their net worth. The results for $\varrho_{t}$ implies that

$$
\frac{B_{t+1}}{N_{t+1}}=\varrho_{t}-1,
$$

i.e. that an entrepreneur's loan amount is proportional to his net worth. Rewriting (3.1) and (3.2) we see that the rate of interest paid by the entrepreneur is

$$
Z_{t+1}=\frac{\bar{\omega}_{t+1} R_{t+1}^{k}}{1-\frac{N_{t+1}}{P_{t} P_{k^{\prime}, t} \bar{K}_{t+1}}}=\frac{\bar{\omega}_{t+1} R_{t+1}^{k}}{1-\frac{1}{\varrho_{t}}}
$$

which is the same for all entrepreneurs, regardless of their net worth.

\subsubsection{Aggregation Across Entrepreneurs and the Risk Premium}

Let $f\left(N_{t+1}\right)$ denote the density of entrepreneurs with net worth, $N_{t+1}$. Then, aggregate average net worth, $\bar{N}_{t+1}$, is

$$
\bar{N}_{t+1}=\int_{N_{t+1}} N_{t+1} f\left(N_{t+1}\right) d N_{t+1}
$$

We now derive the law of motion of $\bar{N}_{t+1}$. Consider the set of entrepreneurs who in period $t-1$ had net worth $N$. Their net worth after they have settled with the bank in period $t$ is denoted $V_{t}^{N}$, where

$$
V_{t}^{N}=R_{t}^{k} P_{t-1} P_{k^{\prime}, t-1} \bar{K}_{t}^{N}-\Gamma\left(\bar{\omega}_{t} ; \sigma_{t-1}\right) R_{t}^{k} P_{t-1} P_{k^{\prime}, t-1} \bar{K}_{t}^{N}
$$

where $\bar{K}_{t}^{N}$ is the amount of physical capital that entrepreneurs with net worth $N_{t}$ acquired in period $t-1$. Clearing in the market for capital requires:

$$
\bar{K}_{t}=\int_{N_{t}} \bar{K}_{t}^{N} f\left(N_{t}\right) d N_{t} .
$$

Multiplying (3.7) by $f\left(N_{t}\right)$ and integrating over all entrepreneurs,

$$
V_{t}=R_{t}^{k} P_{t-1} P_{k^{\prime}, t-1} \bar{K}_{t}-\Gamma\left(\bar{\omega}_{t} ; \sigma_{t-1}\right) R_{t}^{k} P_{t-1} P_{k^{\prime}, t-1} \bar{K}_{t}
$$


Writing this out more fully:

$$
\begin{aligned}
V_{t} & =R_{t}^{k} P_{t-1} P_{k^{\prime}, t-1} \bar{K}_{t}-\left\{\left[1-F\left(\bar{\omega}_{t} ; \sigma_{t-1}\right)\right] \bar{\omega}_{t}+\int_{0}^{\bar{\omega}_{t}} \omega d F\left(\omega ; \sigma_{t-1}\right)\right\} R_{t}^{k} P_{t-1} P_{k^{\prime}, t-1} \bar{K}_{t} \\
& =R_{t}^{k} P_{t-1} P_{k^{\prime}, t-1} \bar{K}_{t} \\
& -\left\{\left[1-F\left(\bar{\omega}_{t} ; \sigma_{t-1}\right)\right] \bar{\omega}_{t}+(1-\mu) \int_{0}^{\bar{\omega}_{t}} \omega d F\left(\omega ; \sigma_{t-1}\right)+\mu \int_{0}^{\bar{\omega}_{t}} \omega d F\left(\omega ; \sigma_{t-1}\right)\right\} R_{t}^{k} P_{t-1} P_{k^{\prime}, t-1} \bar{K}_{t} .
\end{aligned}
$$

Note that the first two terms in braces correspond to the net revenues of the bank, which must equal $R_{t-1}\left(P_{t-1} P_{k^{\prime}, t-1} \bar{K}_{t}-\bar{N}_{t}\right)$. Substituting:

$V_{t}=R_{t}^{k} P_{t-1} P_{k^{\prime}, t-1} \bar{K}_{t}-\left\{R_{t-1}+\frac{\mu \int_{0}^{\bar{\omega}_{t}} \omega d F\left(\omega ; \sigma_{t-1}\right) R_{t}^{k} P_{t-1} P_{k^{\prime}, t-1} \bar{K}_{t}}{P_{t-1} P_{k^{\prime}, t-1} \bar{K}_{t}-\bar{N}_{t}}\right\}\left(P_{t-1} P_{k^{\prime}, t-1} \bar{K}_{t}-\bar{N}_{t}\right)$.

After $V_{t}$ is determined, each entrepreneur faces an identical and independent probability $1-\gamma_{t}$ of being selected to exit the economy. With the complementary probability, $\gamma_{t}$, each entrepreneur remains. Because the selection is random, the net worth of the entrepreneurs who survive is simply $\gamma_{t} \bar{V}_{t}$. A fraction, $1-\gamma_{t}$, of new entrepreneurs arrive. Entrepreneurs who survive or who are new arrivals receive a transfer, $W_{t}^{e}$. This ensures that all entrepreneurs, whether new arrivals or survivors that experienced bankruptcy, have sufficient funds to obtain at least some amount of loans. The average net worth across all entrepreneurs after the $W_{t}^{e}$ transfers have been made and exits and entry have occurred, is $\bar{N}_{t+1}=\gamma_{t} \bar{V}_{t}+W_{t}^{e}$, or,

$$
\begin{aligned}
\bar{N}_{t+1}= & \gamma_{t}\left\{R_{t}^{k} P_{t-1} P_{k^{\prime}, t-1} \bar{K}_{t}-\left[R_{t-1}+\frac{\mu \int_{0}^{\bar{\omega}_{t}} \omega d F\left(\omega ; \sigma_{t-1}\right) R_{t}^{k} P_{t-1} P_{k^{\prime}, t-1} \bar{K}_{t}}{P_{t-1} P_{k^{\prime}, t-1} \bar{K}_{t}-\bar{N}_{t}}\right]\left(P_{t-1} P_{k^{\prime}, t-1} \bar{K}_{t}-\bar{N}_{t}\right)\right\} \\
& +W_{t}^{e}
\end{aligned}
$$

\subsection{Solving the Financial Frictions Model}

In this subsection we indicate how the equilibrium conditions of the baseline model must be modified to accommodate financial frictions.

\subsubsection{Equilibrium Conditions}

Consider the households. Households no longer accumulate physical capital, and the first order condition, (2.39), must be dropped. No other changes need to be made to the household first order conditions. Equation (2.42) can be interpreted as applying to the household's decision to make bank deposits. The household equations, (2.35) and (2.40), pertaining to investment can be thought of as reflecting that the household builds and sells physical capital, or it can be interpreted as the first order condition of many identical, competitive firms that build capital (note that each has a state variable in the form of lagged investment). 
We must add the three equations pertaining to the entrepreneur's loan contract: the law of motion of net worth, the bank's zero profit condition and the optimality condition. Finally, we must adjust the resource constraints to reflect the resources used in bank monitoring and in consumption by entrepreneurs.

We adopt the following scaling of variables, noting that $W_{t}^{e}$ is set so that its scaled counterpart is constant:

$$
n_{t+1}=\frac{\bar{N}_{t+1}}{P_{t} z_{t}^{+}}, w^{e}=\frac{W_{t}^{e}}{P_{t} z_{t}^{+}} .
$$

Dividing both sides of (3.8) by $P_{t} z_{t}^{+}$, we obtain the scaled law of motion for net worth:

$$
n_{t+1}=\frac{\gamma_{t}}{\pi_{t} \mu_{z^{+}, t}}\left[R_{t}^{k} p_{k^{\prime}, t-1} \bar{k}_{t}-R_{t-1}\left(p_{k^{\prime}, t-1} \bar{k}_{t}-n_{t}\right)-\mu G\left(\bar{\omega}_{t} ; \sigma_{t-1}\right) R_{t}^{k} p_{k^{\prime}, t-1} \bar{k}_{t}\right]+w^{e},
$$

for $t=0,1,2, \ldots$. Equation (3.9) has a simple intuitive interpretation. The first object in square brackets is the average gross return across all entrepreneurs in period $t$. The two negative terms correspond to what the entrepreneurs pay to the bank, including the interest paid by non-bankrupt entrepreneurs and the resources turned over to the bank by the bankrupt entrepreneurs. Since the bank makes zero profits, the payments to the bank by entrepreneurs must equal bank costs. The term involving $R_{t-1}$ represents the cost of funds loaned to entrepreneurs by the bank, and the term involving $\mu$ represents the bank's total expenditures on monitoring costs.

The zero profit condition on banks, eq. (3.5), can be expressed in terms of the scaled variables as:

$$
\Gamma\left(\bar{\omega}_{t+1} ; \sigma_{t}\right)-\mu G\left(\bar{\omega}_{t+1} ; \sigma_{t}\right)=\frac{R_{t}}{R_{t+1}^{k}}\left(1-\frac{n_{t+1}}{p_{k^{\prime}, t} \bar{k}_{t+1}}\right),
$$

for $t=-1,0,1,2, \ldots$. The optimality condition for bank loans is (3.4).

The output equation, (2.52), does not have to be modified. Instead, the resource constraint for domestic homogenous goods (2.53) needs to be adjusted for the monitoring costs:

$$
\begin{aligned}
y_{t}-d_{t}= & g_{t}+\left(1-\omega_{c}\right)\left(p_{t}^{c}\right)^{\eta_{c}} c_{t}+\left(p_{t}^{i}\right)^{\eta_{i}}\left(i_{t}+a\left(u_{t}\right) \frac{\bar{k}_{t}}{\mu_{\psi, t} \mu_{z^{+}, t}}\right)\left(1-\omega_{i}\right) \\
& +\left[\omega_{x}\left(p_{t}^{m, x}\right)^{1-\eta_{x}}+\left(1-\omega_{x}\right)\right]^{\frac{\eta_{x}}{1-\eta_{x}}}\left(1-\omega_{x}\right)\left(\dot{\circ}_{t}^{x}\right)^{\frac{-\lambda_{x, t}}{\lambda_{x, t}-1}}\left(p_{t}^{x}\right)^{-\eta_{f}} y_{t}^{*}
\end{aligned}
$$

where

$$
d_{t}=\frac{\mu G\left(\bar{\omega}_{t} ; \sigma_{t-1}\right) R_{t}^{k} p_{k^{\prime}, t-1} \bar{k}_{t}}{\pi_{t} \mu_{z^{+}, t}}
$$

When we bring the model to the data measured GDP is $y_{t}$ adjusted for both monitoring costs and, as in the baseline model, capital utilization costs:

$$
g d p_{t}=y_{t}-d_{t}-\left(p_{t}^{i}\right)^{\eta_{i}}\left(a\left(u_{t}\right) \frac{\bar{k}_{t}}{\mu_{\psi, t} \mu_{z^{+}, t}}\right)\left(1-\omega_{i}\right)
$$


Account has to be taken of the consumption by exiting entrepreneurs. The net worth of these entrepreneurs is $\left(1-\gamma_{t}\right) V_{t}$ and we assume a fraction, $1-\Theta$, is taxed and transferred in lump-sum form to households, while the complementary fraction, $\Theta$, is consumed by the exiting entrepreneurs. This consumption can be taken into account by subtracting

$$
\Theta \frac{1-\gamma_{t}}{\gamma_{t}}\left(n_{t+1}-w^{e}\right) z_{t}^{+} P_{t}
$$

from the right side of (2.9). In practice we do not make this adjustment because we assume $\Theta$ is sufficiently small that the adjustment is negligible.

We now turn to the risk premium on entrepreneurs. The cost to the entrepreneur of internal funds (i.e., his own net worth) is the interest rate, $R_{t}$, which he loses by applying it to capital rather than just depositing it in the bank. The average payment by all entrepreneurs to the bank is the entire object in square brackets in equation (3.8). So, the term involving $\mu$ represents the excess of external funds over the internal cost of funds. As a result, this is one measure of the risk premium in the model. Another is the excess of the interest rate paid by entrepreneurs who are not bankrupt, over $R_{t}$ :

$$
Z_{t+1}-R_{t}=\frac{\bar{\omega}_{t+1} R_{t+1}^{k}}{1-\frac{n_{t+1}}{p_{k^{\prime}, t} \bar{k}_{t+1}}}-R_{t}
$$

according to (3.6).

The financial frictions brings a net increase of 2 equations (we add (3.4), (3.9) and (3.10), and delete $(2.39)$ ) and two variables, $n_{t+1}$ and $\bar{\omega}_{t+1}$. This increases the size of our system to 72 equations in 72. The financial frictions also introduce the additional shocks, $\sigma_{t}$ and $\gamma_{t}$.

\section{Introducing Employment Frictions into the Model}

This section replaces the model of the labor market in our baseline model with the search and matching framework of Mortensen and Pissarides (1994) and, more recently, Hall (2005a,b,c) and Shimer $(2005 \mathrm{a}, \mathrm{b})$. We integrate the framework into our environment - which includes capital and monetary factors - following the GST strategy implemented in Christiano, Ilut, Motto, and Rostagno (2007). A key feature of the GST model is that there are wagesetting frictions, but they do not have a direct impact on on-going worker employer relations. However, wage-setting frictions have an impact on the effort of an employer in recruiting new employees. In this sense, the setup is not vulnerable to the Barro (1977) critique of sticky wages. The model is also attractive because of the richness of its labor market implications: the model differentiates between hours worked and the quantity of people employed, it has unemployment and vacancies. 
The labor market in our alternative labor market model is a modified version of the GST model. GST assume wage-setting frictions of the Calvo type, while we instead work with Taylor-type frictions. In addition, we adopt a slightly different representation of the production sector in order to maximize comparability with our baseline model. A key difference is that we allow for endogenous separation of employees from their jobs, as in e.g. den Haan, Ramey and Watson (2000). Our main motivation for doing this is the prima facie cyclicality of separation rates, confirmed by empirical evidence for the U.S. by Fujita and Ramey (2007). In what follows, we first provide an overview and after that we present the detailed decision problems of agents in the labor market.

Our motivation for replacing the Erceg, Henderson and Levin (2000) style labor market modeling of our baseline model is simple and empirical: Most of the variation in hours worked is generated by the extensive margin of labor supply. We apply the simple data analysis method of Hansen (1985) on Swedish data 1995q1-2009q2. The decomposition is

$$
\operatorname{var}\left(H_{t}\right)=\operatorname{var}\left(\varsigma_{t}\right)+\operatorname{var}\left(L_{t}\right)+2 \operatorname{covar}\left(\varsigma_{t}, L_{t}\right)
$$

where $H_{t}$ denotes total hours worked, $\varsigma_{t}$ hours per worker and $L_{t}$ number of people employed. $H_{t}$ and $L_{t}$ are in per capita terms (of the adult population) and all series are HP-filtered with $\lambda=1600$. This decomposition indicates that roughly $4 / 5$ th of the variation in total hours worked comes from variation in employment and $1 / 5$ th from variation in hours per worker. ${ }^{9}$ Accordingly, a model that allows for variation in both margins is needed. Even more strongly these numbers indicate that models that only allow for variation of the intensive margin lack micro foundation.

\subsection{Sketch of the Model}

As in the discussion of section 2.1, we adopt the Dixit-Stiglitz specification of homogeneous goods production. A representative, competitive retail firm aggregates differentiated intermediate goods into a homogeneous good. Intermediate goods are supplied by monopolists, who hire labor and capital services in competitive factor markets. The intermediate good firms are assumed to be subject to the same Calvo price setting frictions as in the baseline model.

In the baseline model, the homogeneous labor services are supplied to the competitive labor market by labor retailers (contractors) who combine the labor services supplied to them by households who monopolistically supply specialized labor services (see Erceg, Henderson and Levin (2000) and section 2.1). Here, in the modified model, we dispense with the specialized labor services abstraction. Labor services are instead supplied to the homogeneous

\footnotetext{
${ }^{9}$ The covariance term is close to 0 , which is in line with previous Swedish evidence and institutional factors that discourage over-time work.
} 
labor market by 'employment agencies'. See Figure B for a graphical illustration. The change leaves the equilibrium conditions associated with the production of the homogeneous good unaffected. Key labor market activities - vacancy postings, layoffs, labor bargaining, setting the intensity of labor effort - are all carried out inside the employment agencies. ${ }^{10}$

Each household is composed of many workers, each of which is in the labor force. A worker begins the period either unemployed or employed with a particular employment agency. Unemployed workers do undirected search. They find a job with a particular agency with a probability that is proportional to the efforts made by the agency to attract workers. Workers are separated from employment agencies either exogenously, or because they are actively cut. Workers pass back and forth between unemployment and employment with an agency. There are no agency to agency transitions.

The events during the period in an employment agency are displayed in Figure C. Each employment agency begins a period with a stock of workers. That stock is immediately reduced by exogenous separations and it is increased by new arrivals that reflect the agency's recruiting efforts in the previous period. Then, the economy's aggregate shocks are realized.

At this point, each agency's wage is set. The agencies are allocated permanently into $N$ equal-sized cohorts and each period $1 / N$ agencies establish a new wage by Nash bargaining. When a new wage is set, it evolves over the subsequent $N-1$ periods according to (2.47) and (2.48). The wage negotiated in a given period covers all workers employed at an agency for each of the subsequent $N-1$ periods, even those that will not arrive until later. The bargaining arrangement is atomistic, so that each worker bargains separately with a representative of the employment agency.

Next, each worker draws an idiosyncratic productivity shock. A cutoff level of productivity is determined, and workers with lower productivity are laid off. We consider two mechanisms by which the cutoff is determined. One is based on the total surplus of a given worker and the other is based purely on the employment agency's interest. Finally, the intensity of each worker's labor effort is determined by an efficiency criterion.

After the endogenous layoff decision, the employment agency posts vacancies and the intensity of work effort is chosen. At this point the employment agency supplies labor to the labor market.

We now describe these various labor market activities in greater detail. We begin with the decisions at the end of the period and work backwards to the bargaining problem. This is a convenient way to develop the model because the bargaining problem internalizes everything that comes after. The actual equilibrium conditions are displayed in the Appendix.

\footnotetext{
${ }^{10}$ An alternative, perhaps more natural, formulation would be for the intermediate good firms to do their own employment search. We instead separate the task of finding workers from production of intermediate goods in order to avoid adding a state variable to the intermediate good firm, which would complicate the solution of their price-setting problem.
} 


\subsection{Labor Hours}

Labor intensity is chosen to equate the value of labor services to the employment agency with the cost of providing it by the household. To explain the latter, we display the utility function of the household, which is a modified version of (2.34):

$$
E_{t} \sum_{l=0}^{\infty} \beta^{l-t}\left\{\zeta_{t+l}^{c} \log \left(C_{t+l}-b C_{t+l-1}\right)-\zeta_{t+l}^{h} A_{L}\left[\sum_{i=0}^{N-1} \frac{\left(\varsigma_{i, t+l}\right)^{1+\sigma_{L}}}{1+\sigma_{L}}\left[1-\mathcal{F}\left(\bar{a}_{t+l}^{i}\right)\right] l_{t+l}^{i}\right]\right\}
$$

Here, $i \in\{0, \ldots, N-1\}$ indexes the cohort to which the employment agency belongs. The index, $i=0$ corresponds to the cohort whose employment agency renegotiates the wage in the current period, $i=1$ corresponds to the cohort that renegotiated in the previous period, and so on. The object, $l_{t}^{i}$ denotes the number of workers in cohort $i$, after exogenous separations and new arrivals from unemployment have occurred. Let $a_{t}^{i}$ denote the idiosyncratic productivity shock drawn by a worker in cohort $i$. Then, $\bar{a}_{t}^{i}$, denotes the endogenously-determined cutoff such that all workers with $a_{t}^{i}<\bar{a}_{t}^{i}$ are laid off from the firm. Also, let

$$
\mathcal{F}\left(\bar{a}_{t}^{i}\right)=P\left[a_{t}^{i}<\bar{a}_{t}^{i}\right]
$$

denote the cumulative distribution function of the idiosyncratic productivity shock. (In practice, we assume that $\mathcal{F}$ is lognormal with $E a=1$ and standard deviation of $\log (a)$ equal to $\sigma_{a}$.) Then,

$$
\left[1-\mathcal{F}\left(\bar{a}_{t}^{i}\right)\right] l_{t}^{i}
$$

denotes the number of workers with an employment agency in the $i^{\text {th }}$ cohort who survive the endogenous layoffs.

Let $\varsigma_{i, t}$ denote the number of hours supplied by a worker in the $i^{\text {th }}$ cohort. The absence of the index, $a$, on $\varsigma_{i, t}$ reflects our assumption that each worker who survives endogenous layoffs in cohort $i$ works the same number of hours, regardless of the realization of their idiosyncratic level of productivity. The disutility experienced by a worker that works $\varsigma_{i, t}$ hours is:

$$
\zeta_{t}^{h} A_{L} \frac{\left(\varsigma_{i, t}\right)^{1+\sigma_{L}}}{1+\sigma_{L}}
$$

The utility function in (4.1) sums the disutility experienced by the workers in each cohort.

Although the individual worker's labor market experience - whether employed or unemployed - is determined by idiosyncratic shocks, each household has sufficiently many workers that the total fraction of workers employed,

$$
L_{t}=\sum_{i=0}^{N-1}\left[1-\mathcal{F}\left(\bar{a}_{t}^{i}\right)\right] l_{t}^{i}
$$


as well as the fractions allocated among the different cohorts, $\left[1-\mathcal{F}\left(\bar{a}_{t}^{i}\right)\right] l_{t}^{i}, i=0, \ldots, N-1$, are the same for each household. We suppose that all the household's workers are supplied inelastically to the labor market (i.e., labor force participation is constant).

The household's currency receipts arising from the labor market are:

$$
\left(1-\tau_{t}^{y}\right)\left(1-L_{t}\right) P_{t} b^{u} z_{t}^{+}+\sum_{i=0}^{N-1} W_{t}^{i}\left[1-\mathcal{F}\left(\bar{a}_{t}^{i}\right)\right] l_{t}^{i} \varsigma_{i, t} \frac{1-\tau_{t}^{y}}{1+\tau_{t}^{w}}
$$

where $W_{t}^{i}$ is the nominal wage rate earned by workers in cohort $i=0, \ldots, N-1$. The presence of the term involving $b^{u}$ indicates the assumption that unemployed workers, $1-L_{t}$, receive a pre-tax payment of $b^{u} z_{t}^{+}$final consumption goods. These unemployment benefits are financed by lump sum taxes. As in our baseline model, there is a labor income tax $\tau_{t}^{y}$ and a payroll $\operatorname{tax} \tau_{t}^{w}$ that affect the after-tax wage.

Let $W_{t}$ denote the price received by employment agencies for supplying one unit of labor service. It represents the marginal gain to the employment agency that occurs when an individual worker increases time spent working by one unit. Because the employment agency is competitive in the supply of labor services, it takes $W_{t}$ as given. We treat $W_{t}$ as an unobserved variable in the data. In practice, it is the shadow value of an extra worker supplied by the human resources department to a firm.

Following GST, we assume that labor hours are chosen to equate the worker's marginal cost of working with the agency's marginal benefit:

$$
W_{t} \mathcal{G}_{t}^{i}=\zeta_{t}^{h} A_{L} \varsigma_{i, t}^{\sigma_{L}} \frac{1}{v_{t} \frac{1-\tau_{t}^{y}}{1+\tau_{t}^{w}}}
$$

for $i=0, \ldots, N-1$. Here, $\mathcal{G}_{t}^{i}$ denotes expected productivity of workers who survive endogenous separation:

$$
\mathcal{G}_{t}^{i}=\frac{\mathcal{E}_{t}^{i}}{1-\mathcal{F}_{t}^{i}}
$$

where

$$
\begin{aligned}
\mathcal{E}_{t}^{i} & \equiv \mathcal{E}\left(\bar{a}_{t}^{i} ; \sigma_{a, t}\right) \equiv \int_{\bar{a}_{t}^{i}}^{\infty} a d \mathcal{F}\left(a ; \sigma_{a, t}\right) \\
\mathcal{F}_{t}^{i} & =\mathcal{F}\left(\bar{a}_{t}^{i} ; \sigma_{a, t}\right)=\int_{0}^{\bar{a}_{t}^{i}} d \mathcal{F}\left(a ; \sigma_{a, t}\right) .
\end{aligned}
$$

To understand the expression on the right of (4.4), note that the marginal cost, in utility terms, to an individual worker who increases labor intensity by one unit is $\zeta_{t}^{h} A_{L} \varsigma_{i, t}^{\sigma_{L}}$. This is converted to currency units by dividing by the multiplier, $v_{t}$, on the household's nominal budget constraint, and by the tax wedge $\left(1-\tau_{t}^{y}\right) /\left(1+\tau_{t}^{w}\right)$. The left side of (4.4) represents the increase in revenues to the employment agency from increasing hours worked by one 
unit (recall, all workers who survive endogenous layoffs work the same number of hours.) Division by $1-\mathcal{F}_{t}^{i}$ is required in (4.5) so that the expectation is relative to the distribution of $a$ conditional on $a \geq \bar{a}_{t}^{j}$.

Labor intensity is potentially different across cohorts because $\mathcal{G}_{t}^{i}$ in (4.4) is indexed by cohort. When the wage rate is determined by Nash bargaining, it is taken into account that labor intensity is determined according to (4.4) and that some workers will endogenously separate.

\subsection{Vacancies and the Employment Agency Problem}

The employment agency in the $i^{\text {th }}$ cohort determines how many employees it will have in period $t+1$ by choosing vacancies, $v_{t}^{i}$. The vacancy posting costs associated with $v_{t}^{i}$ are:

$$
\frac{\kappa z_{t}^{+}}{\varphi}\left(\frac{Q_{t}^{\iota} v_{t}^{i}}{\left[1-\mathcal{F}\left(\bar{a}_{t}^{i}\right)\right] l_{t}^{i}}\right)^{\varphi}\left[1-\mathcal{F}\left(\bar{a}_{t}^{i}\right)\right] l_{t}^{i}
$$

units of the domestic homogeneous good. The parameter $\varphi$ determines the curvature of the cost function and in practice we set $\varphi=2$. Also, $\kappa z_{t}^{+} / \varphi$ is a cost parameter which is assumed to grow at the same rate as the overall economic growth rate and, as noted above, $\left[1-\mathcal{F}\left(\bar{a}_{t}^{i}\right)\right] l_{t}^{i}$ denotes the number of employees in the $i^{t h}$ cohort after endogenous separations have occurred. Also, $Q_{t}$ is the probability that a posted vacancy is filled, a quantity that is exogenous to an individual employment agency. The functional form of our cost function reduces to the function used in GT and GST when $\iota=1$. With this parameterization, costs are a function of the number of people hired, not the number of vacancies per se. We interpret this as reflecting that the GT and GST specifications emphasize internal costs (such as training and other) of adjusting the work force, and not search costs. In models used in the search literature (see, e.g., Shimer (2005a)), vacancy posting costs are independent of $Q_{t}$, i.e., they set $\iota=0$. To understand the implications for our type of empirical analysis, consider a shock that triggers an economic expansion and also produces a fall in the probability of filling a vacancy, $Q_{t}$. We expect the expansion to be smaller in a version of the model that emphasizes search costs (i.e., $\iota=0$ ) than in a version that emphasizes internal costs (i.e., $\iota=1)$.

To further describe the vacancy decisions of the employment agencies, we require their objective function. We begin by considering $F\left(l_{t}^{0}, \omega_{t}\right)$, the value function of the representative employment agency in the cohort, $i=0$, that negotiates its wage in the current period. The arguments of $F$ are the agency's workforce after beginning-of-period exogenous separations and new arrivals, $l_{t}^{0}$, and an arbitrary value for the nominal wage rate, $\omega_{t}$. That is, we consider the value of the firm's problem after the wage rate has been set.

We suppose that the firm chooses a particular monotone transform of vacancy postings, 
which we denote by $\tilde{v}_{t}^{i}$ :

$$
\tilde{v}_{t}^{i} \equiv \frac{Q_{t}^{\iota} v_{t}^{i}}{\left(1-\mathcal{F}_{t}^{j}\right) l_{t}^{i}},
$$

where $1-\mathcal{F}_{t}^{j}$ denotes the fraction of the beginning-of-period $t$ workforce in cohort $j$ which survives endogenous separations. The agency's hiring rate, $\chi_{t}^{i}$, is related to $\tilde{v}_{t}^{i}$ by:

$$
\chi_{t}^{i}=Q_{t}^{1-\iota} \tilde{v}_{t}^{i}
$$

To construct $F\left(l_{t}^{0}, \omega_{t}\right)$, we must derive the law of motion of the firm's work force, during the period of the wage contract. If $l_{t}^{i}$ is the period $t$ work force just after exogenous separations and new arrivals, then (4.2) is the size of the workforce after endogenous separations. The time $t+1$ workforce of the representative agency in the $i^{t h}$ cohort at time $t$ is denoted $l_{t+1}^{i+1}$. That workforce reflects the endogenous separations in period $t$ as well as the exogenous separations and new arrivals at the start of period $t+1$. Let $\rho$ denote the probability that an individual worker attached to an employment agency at the start of a period survives the exogenous separation. Then, given the hiring rate, $\chi_{t}^{i}$, we have

$$
l_{t+1}^{j+1}=\left(\chi_{t}^{j}+\rho\right)\left(1-\mathcal{F}_{t}^{j}\right) l_{t}^{j},
$$

for $j=0,1, \ldots, N-1$, with the understanding here and throughout that $j=N$ is to be interpreted as $j=0$. Expression (4.9) is deterministic, reflecting the assumption that the representative employment agency in cohort $j$ employs a large number of workers.

The value function of the firm is:

$$
\begin{aligned}
F\left(l_{t}^{0}, \omega_{t}\right)= & \sum_{j=0}^{N-1} \beta^{j} E_{t} \frac{v_{t+j}}{v_{t}} \underset{\left(\tilde{v}_{t+j}^{j} \bar{a}_{t+j}^{j}\right)}{\max }\left[\int_{\bar{a}_{t+j}^{j}}^{\infty}\left(W_{t+j} a-\Gamma_{t, j} \omega_{t}\right) \varsigma_{j, t+j} d \mathcal{F}(a)\right. \\
& \left.-P_{t+j} \frac{\kappa z_{t+j}^{+}}{\varphi}\left(\tilde{v}_{t+j}^{j}\right)^{\varphi}\left(1-\mathcal{F}_{t+j}^{j}\right)\right] l_{t+j}^{j} \\
& +\beta^{N} E_{t} \frac{v_{t+N}}{v_{t}} F\left(l_{t+N}^{0}, \tilde{W}_{t+N}\right),
\end{aligned}
$$

where $l_{t}^{j}$ evolves according to (4.9), $\varsigma_{j, t}$ satisfies (4.4) and

$$
\Gamma_{t, j}=\left\{\begin{array}{cc}
\tilde{\pi}_{w, t+j} \cdots \tilde{\pi}_{w, t+1}, & j>0 \\
1 & j=0
\end{array} .\right.
$$

Here, $\tilde{\pi}_{w, t}$ is defined in (2.48). The term, $\Gamma_{t, j} \omega_{t}$, represents the wage rate in period $t+j$, given the wage rate was $\omega_{t}$ at time $t$ and there have been no wage negotiations in periods $t+1$, $t+2$, up to and including period $t+j$. In (4.10), $\tilde{W}_{t+N}$ denotes the Nash bargaining wage that is negotiated in period $t+N$, which is when the next round of bargaining occurs. At time $t$, the agency takes the state $t+N$-contingent function, $\tilde{W}_{t+N}$, as given. The vacancy decision of employment agencies solve the maximization problem in (4.10). 
It is easily verified using $(4.10)$ that $F\left(l_{t}^{0}, \omega_{t}\right)$ is linear in $l_{t}^{0}$ :

$$
F\left(l_{t}^{0}, \omega_{t}\right)=J\left(\omega_{t}\right) l_{t}^{0}
$$

where $J\left(\omega_{t}\right)$ is not a function of $l_{t}^{0}$. The function, $J\left(\omega_{t}\right)$, is the surplus that a firm bargaining in the current period enjoys from a match with an individual worker, when the current wage is $\omega_{t}$. Although later in the period workers become heterogeneous when they draw an idiosyncratic shock to productivity, the fact that that draw is i.i.d. over time means that workers are all identical at the time that (4.12) is evaluated.

\subsection{Worker Value Functions}

In order to discuss the endogenous separation decisions, as well as the bargaining problem, we must have the value functions of the individual worker. For the bargaining problem, we require the worker's value function before he knows what his idiosyncratic productivity draw is. For the endogenous separation problem, we need to know the worker's value function after he knows he has survived the endogenous separation. For both the bargaining and separation problem, we need to know the value of unemployment to the worker.

Let $V_{t}^{i}$ denote the period $t$ value of being a worker in an agency in cohort $i$, after that worker has survived that period's endogenous separation:

$$
\begin{aligned}
V_{t}^{i}= & \Gamma_{t-i, i} \tilde{W}_{t-i} \varsigma_{i, t} \frac{1-\tau_{t}^{y}}{1+\tau_{t}^{w}}-A_{L} \frac{\zeta_{t}^{h} \varsigma_{i, t}^{1+\sigma_{L}}}{\left(1+\sigma_{L}\right) v_{t}} \\
& +\beta E_{t} \frac{v_{t+1}}{v_{t}}\left[\rho\left(1-\mathcal{F}_{t+1}^{i+1}\right) V_{t+1}^{i+1}+\left(1-\rho+\rho \mathcal{F}_{t+1}^{i+1}\right) U_{t+1}\right],
\end{aligned}
$$

for $i=0,1, \ldots, N-1$. In (4.13), $\tilde{W}_{t-i}$ denotes the wage negotiated $i$ periods in the past, and $\Gamma_{t-i, i} \tilde{W}_{t-i}$ represents the wage received in period $t$ by workers in cohort $i$. The two terms after the equality in (4.13) represent a worker's period $t$ flow utility, converted into units of currency. ${ }^{11}$ The terms in square brackets in (4.13) correspond to utility in the two possible period $t+1$ states of the world. With probability $\rho\left(1-\mathcal{F}_{t+1}^{i+1}\right)$ the worker survives the exogenous and endogenous separations in period $t+1$, in which case its value function in $t+1$ is $V_{t+1}^{i+1}$. With the complementary probability, $1-\rho+\rho \mathcal{F}_{t+1}^{i+1}$, the worker separates into unemployment in period $t+1$, and enjoys utility, $U_{t+1}$.

The currency value of being unemployed in period $t$ is:

$$
U_{t}=P_{t} z_{t}^{+} b^{u}\left(1-\tau_{t}^{y}\right)+\beta E_{t} \frac{v_{t+1}}{v_{t}}\left[f_{t} V_{t+1}^{x}+\left(1-f_{t}\right) U_{t+1}\right]
$$

\footnotetext{
${ }^{11}$ Note the division of the disutility of work in (4.13) by $v_{t}$, the multiplier on the budget constraint of the household optimization problem.
} 
where $f_{t}$ is the probability that an unemployed worker will land a job in period $t+1$. Also, $V_{t+1}^{x}$ is the period $t+1$ value function of a worker who knows that he has matched with an employment agency at the start of $t+1$, but does not know which one. In particular,

$$
V_{t+1}^{x}=\sum_{i=0}^{N-1} \frac{\chi_{t}^{i}\left(1-\mathcal{F}_{t}^{i}\right) l_{t}^{i}}{m_{t}} \tilde{V}_{t+1}^{i+1} .
$$

Here, total new matches at the start of period $t+1, m_{t}$, is given by:

$$
m_{t}=\sum_{j=0}^{N-1} \chi_{t}^{j}\left(1-\mathcal{F}_{t}^{j}\right) l_{t}^{j} .
$$

In (4.15),

$$
\frac{\chi_{t}^{i}\left(1-\mathcal{F}_{t}^{i}\right) l_{t}^{i}}{m_{t}}
$$

is the probability of finding a job in $t+1$ in an agency belonging to cohort $i$ in period $t$. Note that this is a proper probability distribution because it is positive for each $i$ and it sums to unity by (4.16).

In (4.15), $\tilde{V}_{t+1}^{i+1}$ is the analog of $V_{t+1}^{i+1}$, except that the former is defined before the worker knows if he survives the endogenous productivity cut, while the latter is defined after survival. The superscript $i+1$ appears on $\tilde{V}_{t+1}^{i+1}$ because the probabilities in (4.15) refer to activities in a particular agency cohort in period $t$, while in period $t+1$ the index of that cohort is incremented by unity.

We complete the definition of $U_{t}$ in (4.14) by giving the formal definition of $\tilde{V}_{t}^{j}$ :

$$
\tilde{V}_{t}^{j}=\mathcal{F}_{t}^{j} U_{t}+\left(1-\mathcal{F}_{t}^{j}\right) V_{t}^{j}
$$

That is, at the start of the period, the worker has probability $\mathcal{F}_{t}^{j}$ of returning to unemployment, and the complementary probability of surviving in the firm to work and receive a wage in period $t$.

\subsection{Separation Decision}

This section describes the separation decision of employment agencies. We discuss the separation decision of a representative agency in the $j=0$ cohort which renegotiates the wage in the current period. The decisions of other cohorts are made in a similar way. Details appear in the Appendix.

Just prior to the realization of idiosyncratic worker uncertainty, the number of workers attached to the representative agency in the $j=0$ cohort is $l_{t}^{0}$. Each of the workers in $l_{t}^{0}$ independently draws a productivity, $a$, from the cumulative distribution function, $\mathcal{F}$. The workers who draw a value of $a$ below a productivity cutoff, $\bar{a}_{t}^{0}$, are separated from the agency 
and the rest remain. The productivity cutoff is selected by the representative agency taking as given all variables determined outside the agency. We consider alternative criteria for selecting $\bar{a}_{t}^{0}$. The different criteria correspond to different ways of weighting the surplus enjoyed by the agency and the surplus enjoyed by the workers, $l_{t}^{0}$, attached to the agency.

The aggregate surplus across all the $l_{t}^{0}$ workers in the representative agency is given by:

$$
\left(V_{t}^{0}-U_{t}\right)\left(1-\mathcal{F}_{t}^{0}\right) l_{t}^{0}
$$

To see this, note that each worker among the fraction, $1-\mathcal{F}_{t}^{0}$, workers with $a \geq \bar{a}_{t}^{0}$ who stay with the agency experiences the same surplus, $V_{t}^{0}-U_{t}$. The fraction, $\mathcal{F}_{t}^{0}$, of workers in $l_{t}^{0}$ who leave enjoys zero surplus. The object, $\mathcal{F}_{t}^{0}$, is a function of $\bar{a}_{t}^{0}$ as indicated in (4.7).

The surplus enjoyed by the representative employment agency before idiosyncratic worker uncertainty is realized and when the workforce is $l_{t}^{0}$, is given by (4.10). According to (4.12) agency surplus per worker in $l_{t}^{0}$ is given by $J\left(\omega_{t}\right)$ and this is readily confirmed to have the following structure:

$$
J\left(\omega_{t}\right)=\max _{\bar{a}_{t}^{0}} \tilde{J}\left(\omega_{t} ; \bar{a}_{t}^{0}\right)\left(1-\mathcal{F}_{t}^{0}\right)
$$

where

$$
\tilde{J}\left(\omega_{t} ; \bar{a}_{t}^{0}\right)=\max _{\tilde{v}_{t}^{0}}\left\{\left(W_{t} \mathcal{G}_{t}^{0}-\omega_{t}\right) \varsigma_{0, t}-P_{t} z_{t}^{+} \frac{\kappa}{\varphi}\left(\tilde{v}_{t}^{0}\right)^{\varphi}+\beta \frac{v_{t+1}}{v_{t}}\left(\chi_{t}^{0}+\rho\right) J_{t+1}^{1}\left(\omega_{t}\right)\right\} .
$$

Here, it is understood that $\chi_{t}^{0}, \tilde{v}_{t}^{0}$ are connected by (4.8). Thus, the surplus of the representative agency with workforce, $l_{t}^{0}$, expressed as a function of an arbitrary value of $\bar{a}_{t}^{0}$ is:

$$
\tilde{J}\left(\omega_{t} ; \bar{a}_{t}^{0}\right)\left(1-\mathcal{F}_{t}^{0}\right) l_{t}^{0}
$$

This expression displays the two ways that $\bar{a}_{t}^{0}$ impacts on firm profits: $\bar{a}_{t}^{0}$ affects the number of workers, $1-\mathcal{F}_{t}^{0}$, employed in period $t$, as well as their average productivity, $\tilde{J}$. The impact of $\bar{a}_{t}^{0}$ on the number of workers can be deduced from (4.7). Although at first glance it may appear that the cutoff affects $\tilde{J}$ in several ways, in fact it only affects $\tilde{J}$ through two channels. For example, by the envelope theorem we can ignore the impact of $\bar{a}_{t}^{0}$ on $\tilde{J}$ via its impact on the choice of $\tilde{v}_{t}^{0}$ and $\chi_{t}^{0}$. In addition, the function $J_{t+1}^{1}$ is invariant to the choice of $\bar{a}_{t}^{0}$. As a result, in differentiating $\tilde{J}\left(\omega_{t} ; \bar{a}_{t}^{0}\right)$ with respect to $\bar{a}_{t}^{0}$ we can ignore $J_{t+1}^{1}$ and any variables whose values are determined in the maximization problem implicit in $J_{t+1}^{1}$. For example, we can ignore the impact of $\bar{a}_{t}^{0}$ on the agency's future cutoff decisions, $\bar{a}_{t+i}^{i}, i>0$.

The surplus criterion governing the choice of $\bar{a}_{t}^{0}$ is specified to be a weighted sum of the worker surplus and employer surplus described above:

$$
\left[s_{w}\left(V_{t}^{0}-U_{t}\right)+s_{e} \tilde{J}\left(\omega_{t} ; \bar{a}_{t}^{0}\right)\right]\left(1-\mathcal{F}_{t}^{0}\right) l_{t}^{0}
$$


The parameters $s_{w}, s_{e} \in\{0,1\}$ allow for a variety of interesting surplus measures. If $s_{w}=$ 0 and $s_{e}=1$ we have employer surplus. If $s_{w}=1$ and $s_{e}=1$ we have total surplus. Accordingly, the employer surplus model is the one in which $\bar{a}_{t}^{0}$ is chosen to optimize (4.21) with $s_{w}=0, s_{e}=1$ and the total surplus model is the one that optimizes (4.21) with $s_{w}=s_{e}=1$. The first order necessary condition for an interior optimum is:

$$
s_{w} V_{t}^{0 \prime}+s_{e} \tilde{J}_{\bar{a}^{0}}\left(\omega_{t} ; \bar{a}_{t}^{0}\right)=\left[s_{w}\left(V_{t}^{0}-U_{t}\right)+s_{e} \tilde{J}\left(\omega_{t} ; \bar{a}_{t}^{0}\right)\right] \frac{\mathcal{F}_{t}^{0 \prime}}{1-\mathcal{F}_{t}^{0}} .
$$

According to (4.22), $\bar{a}_{t}^{0}$ is selected to balance the impact on surplus along intensive and extensive margins. The expression on the left of the equality characterizes the impact on the intensive margin: the surplus per worker that survives the cut increases with $\bar{a}_{t}^{0}$. The expression on the right side of (4.22) captures the extensive margin, the loss of surplus associated with the $\mathcal{F}_{t}^{0 \prime} /\left(1-\mathcal{F}_{t}^{0}\right)$ workers who do not survive the cut. The equations that characterize the choice of $\bar{a}_{t}^{j}, j=1, \ldots, N-1$ are essentially the same as (4.22) and so the discussion of these appears in the Appendix.

The expression, (4.22), assumes an arbitrary wage outcome, $\omega_{t}$. In the next subsection we discuss the bargaining problem that determines a value for $\omega_{t}$.

\subsection{Bargaining Problem}

We suppose that bargaining occurs among a continuum of worker-agency representative pairs. Each bargaining session takes the outcomes of all other bargaining sessions as given. Because each bargaining session is atomistic, each session ignores its impact on the wage earned by workers arriving in the future during the contract. We assume that those future workers are simply paid the average of the outcome of all bargaining sessions. Since each bargaining problem is identical, the wage that solves each problem is the same and so the average wage coincides with the wage that solves the individual bargaining problem. Because each bargaining session is atomistic, it also ignores the impact of the wage bargain on decisions like vacancies and separations, taken by the firm.

The Nash bargaining problem that determines the wage rate is a combination of the worker surplus and firm surplus

$$
\max _{\omega_{t}}\left(\tilde{V}_{t}^{0}-U_{t}\right)^{\eta} J\left(\omega_{t}\right)^{(1-\eta)} .
$$

Here, the firm surplus, $J\left(\omega_{t}\right)$, reflects that the outside option of the firm in the bargaining problem is zero. We denote the wage that solves this problem by $\tilde{W}_{t}$. The above problem 
has an interesting structure. Note first (ignoring the impact of $\omega_{t}$ on the vacancy decision):

$$
\begin{aligned}
J_{w, t}= & -\left(1-\mathcal{F}_{t}^{0}\right) \varsigma_{0, t} \\
& +\beta \frac{v_{t+1}}{v_{t}}\left[-\Gamma_{t, 1} \varsigma_{1, t+1} \rho\left(1-\mathcal{F}_{t+1}^{1}\right)\left(1-\mathcal{F}_{t}^{0}\right)\right] \\
& +\beta^{2} \frac{v_{t+2}}{v_{t}}\left[-\Gamma_{t, 2} \varsigma_{2, t+2}\right] \rho^{2}\left(1-\mathcal{F}_{t+2}^{2}\right)\left(1-\mathcal{F}_{t+1}^{1}\right)\left(1-\mathcal{F}_{t}^{0}\right) \\
& +\ldots+ \\
& +\beta^{N-1} \frac{v_{t+N-1}}{v_{t}}\left[-\Gamma_{t, N-1} \varsigma_{N-1, t+N-1}\right] \rho^{N-1}\left(1-\mathcal{F}_{t+N-1}^{N-1}\right) \cdots\left(1-\mathcal{F}_{t}^{0}\right),
\end{aligned}
$$

where $J_{w, t}$ denotes the derivative of the surplus with respect to the wage rate. A rise in the wage reduces $J_{t}$ only in future states of the world in which the worker survives both exogenous and endogenous separation. If we abstract from taxes it is easy to verify that $J_{w, t}=-\tilde{V}_{w, t}$. That is, a contemplated increase in the wage simply reallocates resources between the firm and the worker.

Until now we have implicitly assumed that the negotiated wage paid by an employment agency which has renegotiated most recently $i$ periods in the past is always inside the bargaining set, $\left[\underline{\mathrm{w}}_{t}^{i}, \bar{w}_{t}^{i}\right], i=0,1, \ldots, N-1$. In other words, the wage paid is not lower than the workers reservation wage and not higher than the wage an employment agency is willing to pay. The fact that we allow for endogenous separations when either to total or employer surplus of a match is negative does not strictly guarantee that wages are in the bargaining set, i.e. that both employer and worker have a non-negative surplus of the match. In Appendix B.4.6 we describe how we check that the wage always is within the bargaining set.

\subsection{Resource Constraint in the Employment Frictions Model}

We assume that the posting of vacancies uses the homogeneous domestic good. We leave the production technology equation, (2.52), unchanged, and we alter the resource constraint:

$$
\begin{aligned}
y_{t}-\frac{\kappa}{2} \sum_{j=0}^{N-1}\left(\tilde{v}_{t}^{j}\right)^{2}\left[1-\mathcal{F}_{t}^{j}\right] l_{t}^{j}= & g_{t}+c_{t}^{d}+i_{t}^{d} \\
& +\left(R_{t}^{x}\right)^{\eta_{x}}\left[\omega_{x}\left(p_{t}^{m, x}\right)^{1-\eta_{x}}+\left(1-\omega_{x}\right)\right]^{\frac{\eta_{x}}{1-\eta_{x}}}\left(1-\omega_{x}\right)\left(p_{t}^{x}\right)^{-\eta_{f}} y_{t}^{*} .
\end{aligned}
$$

Measured GDP is $y_{t}$ adjusted for both recruitment costs and capital utilization costs:

$$
g d p_{t}=y_{t}-\frac{\kappa}{2} \sum_{j=0}^{N-1}\left(\tilde{v}_{t}^{j}\right)^{2}\left[1-\mathcal{F}_{t}^{j}\right] l_{t}^{j}-\left(p_{t}^{i}\right)^{\eta_{i}}\left(a\left(u_{t}\right) \frac{\bar{k}_{t}}{\mu_{\psi, t} \mu_{z^{+}, t}}\right)\left(1-\omega_{i}\right)
$$

This completes the description of the employment friction representation of the labor market. This version of the model also brings three new shocks $\eta_{t}, \sigma_{m, t}$ and $\sigma_{a, t}$ into the model. 


\section{Estimation}

We estimate the full model which includes both financial and labor market frictions using Bayesian techniques The equilibrium conditions of the model are summarized in Appendix B.6. We choose the version of the labor market where endogenous breakups are determined using employer surplus, i.e. $s_{w}=0$ and $s_{e}=1 .^{12}$

\subsection{Calibration}

We calibrate and later estimate our model using Swedish data. The time unit is a quarter. Parameters that are related to "great ratios" and other observable quantities related to steady state values calibrated. These include the discount factor $\beta$ and the tax rate on bonds $\tau_{b}$ which are calibrated to yield a real interest of rate equal to the sample average of 2.25 percent annually. We calibrate the capital share $\alpha$ to 0.375 which yields a capital-output ratio slightly below 2 on an annual basis. The capital share is set higher than most of the literature to compensate for the effect of a positive external finance premium.

Four observable ratios are chosen to be exactly matched throughout the estimation, and accordingly we recalibrate four corresponding parameters for each parameter draw: We set the depreciation rate $\delta$ to match the ratio of investment over output, $p_{i} i / y$, the entrepreneurial survival rate $\gamma$ to match the net worth to assets, $n /\left(p_{k^{\prime}} k\right)$, ratio ${ }^{13}$, the steady state real exchange rate $\tilde{\varphi}$ to match the export share $P^{x} X /(P Y)$ of 0.45 in the data and finally we set the disutility of labor scaling parameter $A_{L}$ to fix the fraction of their time that individuals spend working.

\begin{tabular}{lllll}
\hline \hline & Parameter description & Posterior mean & Moment & Moment value \\
\hline \hline$\delta$ & Depreciation rate of capital & 0.020 & $p_{i} i / y$ & 0.17 \\
$\gamma$ & Entrepreneurial survival rate & 0.964 & $n /\left(p_{k^{\prime}} k\right)$ & 0.5 \\
$\tilde{\varphi}$ & Real exchange rate & 0.089 & $P^{x} X /(P Y)$ & 0.45 \\
$A_{L}$ & Scaling of disutility of work & 212330 & $L \varsigma$ & 0.25 \\
\hline \hline
\end{tabular}

Table 0. Matched moments and corresponding parameters.

Sample averages are used when available, e.g. for the various import shares $\omega_{i}, \omega_{c}, \omega_{x}$ (obtained from input-output tables), the remaining tax rates, the government consumption share of GDP, $\eta_{g}$, growth rates of technology (using investment prices to disentangle neutral from investment-specific technology) and several other parameters. To calibrate the steady value of the inflation target we simply use the inflation target stated by Sveriges Riksbank.

\footnotetext{
${ }^{12}$ For a comparison of the dynamics of the model across the various separation criteria, see Christiano, Trabandt and Walentin (2009).

${ }^{13}$ We used micro data to calculate the average equity/total assets during the sample period both for all Swedish firms and for only the stock market listed firms. In the first case book values where used, and in the second case market value of equity was used. Both ratios where close to 0.5.
} 
We let the markup of export good producers $\lambda_{x}$ be low so as to avoid double marking up of these goods. All other price markups are set to 1.2, following a wide literature. We require full working capital financing in all appropriate sectors. We set $\vartheta_{w}$ so that there is full indexation of wages to the steady state real growth. The indexation parameters $\varkappa^{j}$, $j=d, x, m c, m i, m x, w$ are set so that there is no indexation to the inflation target, but instead to $\breve{\pi}$ which is set equal to the steady state inflation. This implies that we do not allow for partial indexation in this estimation, which would result in steady state price and wage dispersion.

For the financial block of the model we set $F(\bar{\omega})$ equal to the sample average bankruptcy rate according to microdata from the leading Swedish credit registry, called "UC AB". $W_{e} / y$ has no other noticeable effect than jointly with $\gamma$ determining the $n /\left(p_{k^{\prime}} k\right)$ and is set arbitrarily.

For the labor block, $1-L$ is set to the sample average unemployment rate, the length of a wage contract $N$ to annual negotiation frequency, $\varphi=2$ to yield quadratic recruitment costs, $\rho$ and the prior mean of $\mathcal{F}$ is set jointly so that it takes an unemployed person on average 3 quarters to find a job (i.e. $f=1 / 3$ ), in line with the evidence presented in Forslund and Johansson (2007) for completed unemployment spells. Holmlund (2006) present evidence of unemployment duration for all unemployment spells being slightly higher, around 4 quarters. The matching function parameter $\sigma$ is set so that number of unemployed and vacancies have equal factor shares in the production of matches. $\sigma_{m}$ is calibrated to match the probability $Q=0.9$ of filling a vacancy within a quarter, although this is merely a normalization. We assume hiring costs, and not search costs by setting $\iota=1$ and thereby follow GST. In an extension below we instead estimate this parameter. We are reinforced in this calibration by the limited importance of search costs that has been documented using Swedish microdata by Carlsson, Eriksson and Gottfries (2006). The calibrated values are displayed in Table 1. 


\begin{tabular}{|c|c|c|}
\hline Parameter & Value & Description \\
\hline$\alpha$ & 0.375 & Capital share in production \\
\hline$\beta$ & 0.9986 & Discount factor \\
\hline$\omega_{i}$ & 0.43 & Import share in investment goods \\
\hline$\omega_{c}$ & 0.25 & Import share in consumption goods \\
\hline$\omega_{x}$ & 0.35 & Import share in export goods \\
\hline$\eta_{g}$ & 0.3 & Government consumption share on GDP \\
\hline$\tau_{k}$ & 0.25 & Capital tax rate \\
\hline$\tau_{w}$ & 0.35 & Payroll tax rate \\
\hline$\tau_{c}$ & 0.25 & Consumption tax rate \\
\hline$\tau_{y}$ & 0.30 & Labor income tax rate \\
\hline$\tau_{b}$ & 0 & Bond tax rate \\
\hline$\mu_{z}$ & 1.0039 & Steady state growth rate of neutral technology \\
\hline$\mu_{\psi}$ & 1.0005 & Steady state growth rate of investment technology \\
\hline $\bar{\pi}$ & 1.005 & Steady state gross inflation target \\
\hline$\lambda_{x}$ & 1.05 & Export price markup \\
\hline$\lambda_{j}$ & 1.2 & Price markups, $j=d, m c, m i, m x$ \\
\hline$\nu_{t}^{*}, \nu_{t}^{x}, \nu_{t}^{f}$ & 1 & Working capital shares \\
\hline$\vartheta_{w}, \kappa_{w}$ & 0 & Wage indexation to real growth trend and lagged inflation \\
\hline$\varkappa^{j}$ & $1-\kappa^{j}$ & Indexation to inflation target for $j=d, x, m c, m i, m x, w$ \\
\hline$\breve{\pi}$ & 1.005 & Third indexing base \\
\hline$F(\bar{\omega})$ & 0.01 & Steady state bankruptcy rate \\
\hline$W_{e} / y$ & 0.001 & Transfers to entrepreneurs \\
\hline$L$ & $1-0.08$ & Steady state fraction of employment \\
\hline$N$ & 4 & Number of agency cohorts/length of wage contracts \\
\hline$\varphi$ & 2 & Curvature of recruitment costs \\
\hline$\rho$ & 0.9735 & Exogenous survival rate of a match \\
\hline$\sigma$ & 0.5 & Unemployment share in matching technology \\
\hline$\sigma_{m}$ & 0.5475 & Level parameter in matching function \\
\hline$\iota$ & 1 & Employment adj. costs dependence on tightness \\
\hline
\end{tabular}

Table 1. Calibrated parameters.

\subsection{Choice of priors}

We estimate 27 structural parameters, 16 VAR parameters for the foreign economy, 8 AR1 coefficients and 17 shock standard deviations. The priors are displayed in tables A1 and A2. The general approach has been to choose diffuse priors, with the exceptions to this rule detailed below.

For the exogenous technology processes where we use tight priors (a standard deviation of 0.075 ) on the persistence parameters and a mode at 0.85. For the Calvo price stickiness parameters we use a mode of 0.75 corresponding to annual price setting based on micro evidence in Apel, Friberg and Hallsten (2005) and tight priors. An exception is made for $\xi_{m x}$ were we use a diffuse prior, to allow for low pass-through to marginal cost for export 
production, as discussed in section 2.3. For habit formation we follow a wide literature by setting the prior mode at 0.65 . For the Taylor rule we only allow for reaction to contemporaneous inflation and GDP. For these parameters we similar priors as Smets and Wouters (2003) and ALLV. Regarding the parameters for indexation to past inflation we are agnostic and use a diffuse beta prior centered at 0.5. We follow Smets and Wouters (2003) in setting a prior for $\sigma_{a}$ around 0.2. For the elasticities of substitution between foreign and domestic goods we choose prior means of 1.5 based on values used in the macro literature and the estimate in Whalley (1995). We set the prior mean of the UIP risk adjustment parameter $\tilde{\phi}_{s}$ equal to 1.5 to get a slight hump-shape in the real exchange rate response to a monetary policy shock.

The persistence of the entrepreneurial parameters $\gamma_{t}$ and $\sigma_{t}$ have the same priors as the technology processes. The prior mode for $\mu$ is set to yield a $1.6 \%$ annual external finance premium, as this is the sample average. We choose a diffuse prior so as to let data determine the elasticity of the finance premium in terms of basis points, as this is what affects the dynamics of the economy. ${ }^{14}$

For the labor block we use a diffuse prior for $\sigma_{L}$ centered around 7.5, implying a Frisch elasticity of $1 / 7.5=0.133$. Because we have both an extensive and an intensive margin of labor supply in the model we choose this prior to be closer to micro evidence than normally used in macro models. MacCurdy (1986) found a Frisch elasticity of 0.15 for U.S. men and similar values have been found by later studies. For the fraction of GDP spent on vacancy costs we use a prior with a mode of $0.1 \%$ corresponding to $\kappa=2.3 .{ }^{15}$ We set the mode for the replacement rate for unemployed workers, bshare, slightly above the average statutory replacement ratio after tax for this time period which is 0.71 . The reason to put the prior above the statutory rate is that the latter ignores the utility value of leisure and any private unemployment insurance, which is reasonably common. Finally we set the prior mean of the endogenous employer-employee match breakup rate, $\mathcal{F}$, to $0.25 \%$, i.e. roughly $1 / 10$ th of the total breakup rate.

\subsection{Data}

We estimate the model using Swedish data. Our sample period is 1995Q1-2009Q2. All real quantities are in per capita terms. We use the same 15 macro variables as in ALLV. Further, we use 4 additional data series. First, we add the time series for government consumption.

\footnotetext{
${ }^{14}$ In this way we are not constrained by the assumption for the functional form of the idiosyncratic risk.

${ }^{15}$ Formally the steady state recruitment share is defined as

$$
\text { recruitshare }=\frac{\frac{\kappa}{2} N \tilde{v}^{2} l}{y}
$$
}


Second, we add a time series for stock prices (the 'OMX Stockholm PI' index, formerly 'SAX All Shares') scaled by the domestic price level as a measure of real net worth. Third, we match a proxy for the spread between the risk-free rate and the loan rate entrepreneurs face. In particular, we compute the spread between the interest rate on all outstanding loans to non-financial corporations and the interest rate on government bonds with a maturity of 6 months. ${ }^{16}$ The choice of bond duration is made to match the duration of the corporate debt. Fourth, we include the official time series for the unemployment rate.

We match the levels of the following 6 (nominal) time series:

$$
R_{t}^{\text {data }}, \pi_{t}^{\text {data }}, \pi_{t}^{c, \text { data }}, \pi_{t}^{i, d a t a}, \pi_{t}^{*, \text { data }}, R_{t}^{*, \text { data }}
$$

For the remaining 13 time series we take logs and first differences.

$$
\begin{aligned}
& \Delta \ln \left(W_{t} / P_{t}\right)^{\text {data }}, \Delta \ln C_{t}^{\text {data }}, \Delta \ln I_{t}^{\text {data }}, \Delta \ln q_{t}^{\text {data }}, \Delta \ln H_{t}^{\text {data }}, \Delta \ln Y_{t}^{\text {data }}, \Delta \ln X_{t}^{\text {data }} \\
& \Delta \ln M_{t}^{\text {data }}, \Delta \ln Y_{t}^{* \text { data }}, \Delta \ln G_{t}^{\text {data }}, \Delta \ln N_{t}^{\text {data }}, \Delta \text { Spread }_{t}^{\text {data }}, \Delta \ln \text { Unemprate }_{t}^{\text {data }} .
\end{aligned}
$$

In addition we demean each first-differenced time series because in our sample variables such as output, consumption, real wages, investment, exports, imports, stock prices grow on average at substantially different rates. The model, however, allows for two different real long-run growth rates only. In order to match these different trends in the data the estimation would be likely to result in a series of negative or positive shocks for some exogenous process. We want to avoid this and therefore demean the data. After the estimation we compare the growth rates of the data with those implied by the model.

See Figure D in the Appendix for plots of the above data used in the estimation.

\subsection{Shocks}

In total, there are 23 exogenous stochastic variables in the model. 12 of these evolve according to $\mathrm{AR}(1)$ processes:

$$
\epsilon, \Upsilon, \bar{\pi}^{c}, \zeta^{c}, \zeta^{h}, \tilde{\phi}, \sigma, \gamma, g, \eta, \sigma_{m}, \sigma_{a}
$$

Further, we have 6 shock processes that are i.i.d.:

$$
\tau^{d}, \tau^{x}, \tau^{m i}, \tau^{m c}, \tau^{m x}, \varepsilon_{R}
$$

Finally, the last 5 shock processes are assumed to follow a VAR(1):

$$
y^{*}, \pi^{*}, R^{*}, \mu_{z}, \mu_{\Psi} .
$$

\footnotetext{
${ }^{16}$ Ideally one would like to match interest data on newly issued loans for the same maturity as in the model. Unfortunately, such data is not available for Sweden.
} 
In the estimation we only allow for 17 shocks. Accordingly we do not allow six shocks present in the theoretical model: the inflation target shock $\bar{\pi}^{c}$, the shock to bargaining power $\eta$, the shock to matching technology $\sigma_{m}$, the shock to the standard deviation of idiosyncratic productivity of workers $\sigma_{a}$, the unit root shock to investment-specific technology $\mu_{\Psi}$ and the idiosyncratic entrepreneur risk shock $\sigma$. Indeed for our sample, 1995-2009, the de jure inflation target has been in place the entire period and has been constant. $\eta$ also seems superfluous as we already have the standard labor supply shock - the labor preference shock $\zeta^{h}$. We excluded $\mu_{\Psi}$ as it did not contribute substantially to explaining any variable in preliminary estimations. For $\sigma$ the reason for exclusion was the high correlation with the other financial shock, $\gamma$.

\subsection{Measurement errors}

Similarly to Adolfson, Laséen, Lindé and Villani $(2007,2008)$ we allow for measurement errors, except for the domestic nominal interest rate and the and foreign variables, since Swedish macro data is measured with substantial noise. We calibrate the variance of the measurement errors so that they correspond to $10 \%$ of the variance of each data series. For the two financial dataseries $\left(\Delta \ln N_{t}^{\text {data }}, \Delta\right.$ Spread $_{t}^{\text {data }}$ ) we estimate the measurement errors using a prior mean equal to $10 \%$ of the variance of the corresponding data series. As can be seen in Figure D in the Appendix the size of the measurement errors are small: data and the smoothed series of the model without measurement errors are almost indistinguishable, with the key exception of net worth which has a large estimated measurement error.

\subsection{Measurement equations}

Below we report the measurement equations we use to link the model to the data. First differences are written in percentages so model variables are multiplied by 100 accordingly. Furthermore our data series for inflation and interest rates are annualized, so we make the same transformation for the model variables i.e. multiplying by $400:^{17}$

\footnotetext{
${ }^{17}$ Note that in the data we measure $\pi_{t}^{\text {data }}=400\left(\log P_{t}^{\text {data }}-\log P_{t-1}^{\text {data }}\right)$. In the model, we have defined $\pi_{t}=\frac{P_{t}}{P_{t-1}}$. Matching data with the model results in the above measurement equations for inflation.
} 


$$
\begin{aligned}
R_{t}^{\text {data }} & =400\left(R_{t}-1\right)-\vartheta_{1} 400(R-1) \\
R_{t}^{*, \text { data }} & =400\left(R_{t}^{*}-1\right)-\vartheta_{1} 400\left(R^{*}-1\right) \\
\pi_{t}^{\text {data }} & =400 \log \pi_{t}-\vartheta_{1} 400 \log \pi+\varepsilon_{\pi, t}^{m e} \\
\pi_{t}^{c, \text { data }} & =400 \log \pi_{t}^{c}-\vartheta_{1} 400 \log \pi^{c}+\varepsilon_{\pi^{c}, t}^{m e} \\
\pi_{t}^{i, \text { data }} & =400 \log \pi_{t}^{i}-\vartheta_{1} 400 \log \pi^{i}+\varepsilon_{\pi^{i}, t}^{m e} \\
\pi_{t}^{*, \text { data }} & =400 \log \pi_{t}^{*}-\vartheta_{1} 400 \log \pi^{*}+\varepsilon_{\pi^{*}, t}^{m e},
\end{aligned}
$$

where $\varepsilon_{i, t}^{m e}$ denote the measurement errors for the respective variables. In addition, we introduce the parameters $\vartheta_{1} \in\{0,1\}$ and $\vartheta_{2} \in\{0,1\}$ which allows us to handle demeaned and non-demeaned data. In particular, our data for inflation and interest rates is not demeaned, and we therefore set $\vartheta_{1}=0$. An alternative specification would be that we use demeaned inflation and interest rates which would require to set $\vartheta_{1}=1$ in order to correctly match the data with the model.

We use demeaned first-differenced data for the remaining variables. This implies setting the second indicator variable $\vartheta_{2}=1$.

$$
\begin{aligned}
& \Delta \ln Y_{t}^{\text {data }}=100\left(\ln \mu_{z^{+}, t}+\Delta \ln \left(y_{t}-p_{t}^{i} a\left(u_{t}\right) \frac{\bar{k}_{t}}{\mu_{\psi, t} \mu_{z^{+}, t}}-d_{t}-\frac{\kappa}{2} \sum_{j=0}^{N-1}\left(\tilde{v}_{t}^{j}\right)^{2}\left[1-\mathcal{F}_{t}^{j}\right] l_{t}^{j}\right)\right)- \\
& \vartheta_{2} 100\left(\ln \mu_{z^{+}}\right)+\varepsilon_{y, t}^{m e} \\
& \Delta \ln Y_{t}^{*, \text { data }}=100\left(\ln \mu_{z^{+}, t}+\Delta \ln y_{t}^{*}\right)-\vartheta_{2} 100\left(\ln \mu_{z^{+}}\right)+\varepsilon_{y^{*}, t}^{m e} \\
& \Delta \ln C_{t}^{\text {data }}=100\left(\ln \mu_{z^{+}, t}+\Delta \ln c_{t}\right)-\vartheta_{2} 100\left(\ln \mu_{z^{+}}\right)+\varepsilon_{c, t}^{m e} \\
& \Delta \ln X_{t}^{\text {data }}=100\left(\ln \mu_{z^{+}, t}+\Delta \ln x_{t}\right)-\vartheta_{2} 100\left(\ln \mu_{z^{+}}\right)+\varepsilon_{x, t}^{m e} \\
& \Delta \ln q_{t}^{\text {data }}=100 \Delta \ln q_{t}+\varepsilon_{q, t}^{m e} \\
& \Delta \ln H_{t}^{\text {data }}=100 \Delta \ln H_{t}^{\text {meas }}+\varepsilon_{H, t}^{m e} \\
& \Delta \ln M_{t}^{\text {data }}=100\left(\ln \mu_{z^{+}, t}+\Delta \ln \operatorname{Imports}_{t}\right)-\vartheta_{2} 100\left(\ln \mu_{z^{+}}\right)+\varepsilon_{M, t}^{m e} \\
& =100\left[\ln \mu_{z^{+}, t}+\Delta \ln \left(\begin{array}{c}
c_{t}^{m}\left(\stackrel{\circ}{p}_{t}^{m, c}\right)^{\frac{\lambda^{m, C}}{1-\lambda^{m, C}}} \\
+i_{t}^{m}\left(\stackrel{\circ}{p}_{t}^{m, i}\right)^{\frac{\lambda^{m, i}}{1-\lambda^{m, i}}} \\
+x_{t}^{m}\left(\stackrel{\circ}{p}_{t}^{m, x}\right)^{\frac{\lambda^{m, x}}{1-\lambda^{m, x}}}
\end{array}\right)\right]-\vartheta_{2} 100\left(\ln \mu_{z^{+}}\right)+\varepsilon_{M, t}^{m e} \\
& \Delta \ln I_{t}^{\text {data }}=100\left[\ln \mu_{z^{+}, t}+\ln \mu_{\psi, t}+\Delta \ln i_{t}\right]-\vartheta_{2} 100\left(\ln \mu_{z^{+}}+\ln \mu_{\psi}\right)+\varepsilon_{I, t}^{m e} \\
& \Delta \ln G_{t}^{\text {data }}=100\left(\ln \mu_{z^{+}, t}+\Delta \ln g_{t}\right)-\vartheta_{2} 100\left(\ln \mu_{z^{+}}\right)+\varepsilon_{g, t}^{m e}
\end{aligned}
$$

Note that neither measured GDP nor measured investment include investment goods used for capital maintenance. The reason is that the documentation for calculation of the Swedish 
National Accounts (SOU (2002)) indicate that these are not included in the investment definition (and the national accounts are primarily based on the expenditure side). To calculate measured GDP we also exclude monitoring costs and recruitment costs. Note that it is measured GDP that enters the Taylor rule.

The real wage is measured by the employment-weighted average Nash bargaining wage in the model:

$$
w_{t}^{a v g}=\frac{1}{L} \sum_{j=0}^{N-1} l_{t}^{j} G_{t-j, j} w_{t-j} \bar{w}_{t-j}
$$

Given this definition the measurement equation for demeaned wages is:

$$
\Delta \ln \left(W_{t} / P_{t}\right)^{\text {data }}=100 \Delta \ln \frac{\tilde{W}_{t}}{z_{t}^{+} P_{t}}=100\left(\ln \mu_{z^{+}, t}+\Delta \ln w_{t}^{a v g}\right)-\vartheta_{2} 100\left(\ln \mu_{z^{+}}\right)+\varepsilon_{W / P, t}^{m e}
$$

Finally, we measure demeaned net worth, interest rate spread and unemployment as follows:

$$
\begin{aligned}
\Delta \ln N_{t}^{\text {data }} & =100\left(\ln \mu_{z^{+}, t}+\Delta \ln n_{t}\right)-\vartheta_{2} 100\left(\ln \mu_{z^{+}}\right)+\varepsilon_{N, t}^{m e} \\
\Delta \ln \text { Spread }_{t}^{\text {data }} & =100 \Delta \ln \left(Z_{t+1}-R_{t}\right)=100 \Delta \ln \left(\frac{\bar{\omega}_{t+1} R_{t+1}^{k}}{1-\frac{n_{t+1}}{p_{k^{\prime}, \bar{t}_{t+1}}}}-R_{t}\right)+\varepsilon_{\text {Spread }, t}^{m e} \\
\Delta \ln \text { Unemp }_{t}^{\text {data }} & =100 \Delta \ln \left(1-L_{t}\right)+\varepsilon_{\text {Unemp }, t}^{\text {me }} .
\end{aligned}
$$

\subsection{Estimation results}

We obtain the estimation results using a random walk Metropolis-Hasting chain with 175 000 draws after a burn-in of 100000 draws and with an acceptance rate of 0.22 .

\subsubsection{Posterior parameter values}

We start by commenting briefly on the parameter estimates. See the prior-posterior tables, Table A1 and A2, in the Appendix. We focus our discussion on the posterior mean which is used for all computations below.

All Calvo price rigidity parameters except imported inputs for export production have a posterior mean of roughly 0.8. Imported inputs for export production are instead substantially more flexible, and are re-set optimally almost twice per year $\left(\xi_{m x}=0.45\right)$. The price rigidities on both import and export prices are substantially below earlier work on Swedish data by ALLV (2008). Both the later sample and the additional internal propagation in our richer model might contribute to this difference. We find only a moderate degree of indexation to lagged inflation, slightly above $1 / 3$, with the exception of $\kappa_{x}=0.61$.

Both the habit parameter $b$ and the investment adjustment costs parameter $S^{\prime \prime}$ are estimated to be low compared to the literature. In the case of $S^{\prime \prime}$ it is clear that the financial 
frictions induce the gradual response that the investment adjustment mechanism where introduced to generate. The posterior mean of the curvature of capacity utilization $\sigma_{a}=0.15$ is very close to what Smets and Wouters (2003) find for Euro area data, and allows for substantial variation in utilization. The estimated Taylor rule parameters are roughly in line with the existing literature.

The posterior median of $\mu$ of 0.37 is slightly above the prior mean of 0.33 , indicating that the elasticity of the interest rate spread, in terms of basis points, is higher than implied by the sample average and the functional form assumption we have made.

Moving on to the labor block we find a replacement ratio of 0.86 , i.e. substantially higher than the statutory replacement rate of the public Swedish unemployment insurance. The recruitment costs as a fraction of GDP is estimated to be 0.03 percent, corresponding to $\kappa=0.98$. The endogenous breakup rate $\mathcal{F}$ is estimated to be $0.11 \%$. The bargaining power of workers, $\eta$, is solved for to yield a steady state unemployment rate matching the sample average. The value of $\eta$ at the posterior mean is 0.92 which is slightly above the value of $\eta=0.85$ implied by the prior mean parameter vector.

We are able to estimate the curvature of the increasing disutility of labor supply as our model, and fact that we match data series for both total hours and employment, allow for identification of the intensive margin of labor supply. The posterior mean of $\sigma_{L}$ is 9.0 (implying a Frisch elasticity of $1 / 9=0.11$ ),.i.e. slightly above the prior based on micro evidence and substantially higher than most macro models.

As we will see in the IRFs below the posterior mean of $\tilde{\phi}_{s}=1.16$, does not generates a hump-shaped response of the exchange rate to monetary policy shocks. This is in contrast to the response to the exchange rate at the prior mean. The deviation from UIP is still large though.

We note from the posterior standard deviations in Table A1 that data is informative about all the estimated parameters.

\subsubsection{Model Moments and Variance Decomposition}

In Table A3 we present a comparison of data and model means and standard deviations for the observed time series. We note a substantial variation of real growth rates in the data, which is the reason why we demeaned the growth rates in the first place, before matching the model to the data. There is a noticeable tendency for the standard deviations implied by the model to be higher than in the data for the nominal variables, while the model does well on real quantities.

We compute the variance decomposition and present it in Table A4 (1, 8 and 20 quarters ahead). We focus the analysis below on the 8 quarters ahead case, noting that the decomposition is very similar for both 4 (not presented) and 20 quarters. First, note the 
importance of the entrepreneurial wealth shock. It explains more than half of the variation in investment, 5 percent of GDP and is also the most important shock for both the financial variables. It seems to "crowd out" the stationary investment-specific technology shock, which has limited importance and affect almost all variables less than the financial shock. Second, note the high importance of the stationary neutral technology shock for key macro variables, in particular output, all inflation rates, the nominal interest rate, hours worked and unemployment. Third, also the unit-root neutral technology shock is important, especially for output and the foreign variables. Finally, note how the variation in employment and hours is quite evenly spread out over many different shocks, with similar effects on both variables and stationary neutral technology and export markup being the most important shocks for both variables.

\subsubsection{Smoothed shock processes and impulse response functions}

Figure E presents the smoothed values for the shock processes. None of them contain any obvious trend, but the current financial crisis shows up as an extreme value in many shocks. Finally, we plot impulse response functions at the posterior mean for all shocks. For comparison purposes and to quantify the importance of the different frictions we plot the IRFs, for the same fixed parameter vector, for smaller versions of the model as well. ${ }^{18}$ The units on the $y$-axis are either in terms of percentage deviation (\% dev.) from steady state, annualized basis points (ABP), or level deviation (Lev. dev.).

The IRFs for the monetary policy shock is reasonably standard: A 50 basis point temporary increase in the nominal interest rate is amplified by the financial frictions. Entrepreneurial net worth is reduced both because of the falling price of capital and because of the surprise disinflation that increases the real value of the nominal debt. Accordingly the interest rate risk spread increase by 14 basis points. Comparing across model we see how the increased spread cause amplification in the response of investment. We note that our assumption regarding the country risk premium implies that the real exchange rate moves substantially less than one-for-one with the nominal interest rate, although not in a humpshaped manner. The exchange rate appreciates more in the models with financial frictions because of the larger decrease in imported investment (recall that $\omega_{i}>\omega_{c}$ ) and exports therefore decrease more in those models. Surprisingly, total output decrease less in the models with financial frictions as resources used up in monitoring increase following the shock. The monetary policy shock implies an increase in unemployment from the steady state value

\footnotetext{
${ }^{18}$ Only one parameter is recalibrated between models: $\alpha$ has to be re-set to keep the capital-output ratio unchanged in the baseline and unemployment model specifications. The absence of financial frictions in these two versions of the model imply that the required rate of return on capital is substantially lower. We therefore set $\alpha=0.1957$ to keep the capital-output ratio constant.
} 
of $8 \%$ to a maximum of $8.22 \%$ after 3 quarters. In the full model total hours respond less and real wages more than in the smaller models, and this is a general tendency for most shocks. Note that the decrease in hours is entirely on the extensive margin - hours per employee actually increase slightly because of the increase in marginal value of wealth.

The response to a stationary technology shock in our estimated model is reasonably standard. Both margins of labor supply fall substantially initially. Comparing across models we note that financial frictions dampens the response of investment as net worth of entrepreneurs initially falls. This is a standard result for supply shocks in the presence of the Fisher debt deflation mechanism, which in turn is generated by nominal debt contracts.

Finally, we analyze the entrepreneurial wealth shock. The interesting part is that it moves consumption and investment in opposite directions for the first year or two, which is a similarity with the stationary investment-specific shock (see Justiniano, Primiceri and Tambalotti (2008), and many earlier papers e.g. Greenwood, Hercowitz and Krusell (2000)). The key difference versus the investment-specific shock is that the wealth shock implies an increase in net worth (the stock market). This characteristic makes the entrepreneurial wealth shock a more plausible candidate for explaining the main part of the increase in investment both in the late 1990's and in the last boom-bust cycle when financial data is included in the analysis (also see the smoothed shock values in Figure E). In the financial frictions model the entrepreneurial wealth shock has some of the characteristics of a classic demand shock: It drives up both CPI inflation and output, but in the full model inflation instead falls slightly and gradually.

\subsection{Extension - vacancy posting costs vs. hiring costs}

Recall that the costs associated with posting vacancies $v_{t}^{i}$ are:

$$
\frac{\kappa z_{t}^{+}}{2}\left(\frac{Q_{t}^{\iota} v_{t}^{i}}{\left[1-\mathcal{F}\left(\bar{a}_{t}^{i}\right)\right] l_{t}^{i}}\right)^{\varphi}\left[1-\mathcal{F}\left(\bar{a}_{t}^{i}\right)\right] l_{t}^{i},
$$

units of the domestic homogeneous good. The denominator in this expression is simply the labor stock at the time of the vacancy decision. In our main specification we calibrate $\iota=1$ implying that the costs of adjusting employment is related to the hiring rate (as $Q_{t}^{1} v_{t}^{i}$ is the number of new hires), but unaffected by the tightness of the labor market measured by vacancies over unemployment, $V / U$. In this extension we instead estimate this parameter. To be agnostic in this exercise we use a beta prior centered at 0.5 and with a standard deviation of 0.25 . The posterior mode of $\iota$ is 0.90 with a standard deviation of 0.11 . This means that the data series that we match indicate that tightness of the labor market is unimportant for the costs of hiring. This is in line with we micro evidence in Carlsson, Eriksson and Gottfries (2006). But, our result is weakened by the fact that we do not match 
any data series for vacancies, as there is no reliable such series for Sweden. For U.S. data, a recent paper by Cheremukhin and Restrepo Echavarria (2009) documents a similar tendency. In that paper the low matching rates in slack labor markets is interpreted as a procyclical variation in the matching productivity. We instead interpret this result as reflecting that employment adjustment costs are a function mainly of hiring rates.

\section{Conclusion}

This paper incorporates two important extensions of the emerging standard monetary DSGE model in a small open economy setting. We add financial frictions in the accumulation of capital in a well established way, based on Bernanke, Gertler and Gilchrist (1999) and Christiano, Motto and Rostagno (2008). We then add labor market frictions building on a large literature where we are closest to Gertler, Sala and Trigari (2008) and Christiano, Ilut, Motto and Rostagno (2007). We make an important contribution to the literature by endogenizing the job separation decision in this rich setting.

We estimate the full model, which contains the financial frictions as well as the employment frictions, with Bayesian techniques. The first empirical result worth highlighting is that the financial shock to entrepreneurial wealth is important in explaining the dynamics

of several variables. The second empirical result comes from the fact that our model allows for both an intensive and an extensive margin of labor supply. We can therefore provide a meaningful estimate of the elasticity of labor supply and find it to be close to micro-evidence, i.e. a Frisch elasticity of $1 / 9$. The third result is that in contrast to the existing literature of estimated DSGE models, e.g. Smets and Wouters (2003), ALLV and GST, our model does not contain any "wage-markup shocks" or similar shocks with low autocorrelation, and we still match both hours worked, unemployment and wage data series. Finally, an interesting question to be analyzed further is the relative importance of the investment-specific shock vs. the entrepreneurial wealth shock as the results in the present paper contrast starkly with Justiniano, Primiceri and Tambalotti (2008). 


\section{References}

[1] Adolfson, Malin, Stefan Laséen, Jesper Linde and Mattias Villani (2005), "The Role of Sticky Prices in An Estimated Open Economy DSGE Model: A Bayesian Investigation", Journal of the European Economic Association Papers and Proceedings, Vol 3(2-3), 444457.

[2] Adolfson, Malin, Stefan Laseén, Jesper Lindé and Mattias Villani (2007), "Bayesian Estimation of an Open Economy DSGE Model with Incomplete Pass-Through", Journal of International Economics, Vol 72, 481-511.

[3] Adolfson, Malin, Stefan Laséen, Jesper Lindé and Mattias Villani (2008), "Evaluating An Estimated New Keynesian Small Open Economy Model", Journal of Economic Dynamics and Control, Vol 32(8), 2690-2721.

[4] Altig, David, Christiano, Lawrence J, Martin Eichenbaum and Jesper Linde (2004), "Firm-Specific Capital, Nominal Rigidities and the Business Cycle", manuscript, Northwestern University.

[5] Apel, Mikael, Richard Friberg and Kerstin Hallsten (2005), "Microfoundations of Macroeconomic Price Adjustment: Survey Evidence from Swedish Firms," Journal of Money, Credit and Banking, Vol 37(2), 313-338.

[6] Barro, Robert (1977), "Long-Term Contracting, Sticky Prices and Monetary Policy," Journal of Monetary Economics, Vol 3(3), 305-316.

[7] Bernanke, Ben, Mark Gertler and Simon Gilchrist. (1999), "The Financial Accelerator in a Quantitative Business Cycle Framework," Handbook of Macroeconomics, edited by John B. Taylor and Michael Woodford, 1341-1393. Amsterdam, New York and Oxford: Elsevier Science, North-Holland.

[8] Burstein, Ariel, Martin Eichenbaum and Sergio Rebelo (2005), "Large Devaluations and the Real Exchange Rate", Journal of Political Economy, Vol 113, 742-784 .

[9] Burstein, Ariel, Martin Eichenbaum and Sergio Rebelo (2007), "Modeling Exchange Rate Passthrough After Large Devaluations", Journal of Monetary Economics, Vol 54(2), 346-368.

[10] Carlsson, Mikael, Stefan Eriksson and Nils Gottfries (2006), "Testing Theories of Job Creation: Does Supply Create its Own Demand", Sveriges Riksbank Working Paper 194. 
[11] Cheremukhin, Anton and Paulina Restrepo Echavarria, (2009), "The Labor Wedge as a Matching Friction", mimeo, UCLA.

[12] Christiano, Lawrence, Martin Eichenbaum and Charles Evans (2005), "Nominal Rigidities and the Dynamic Effects of a Shock to Monetary Policy", Journal of Political Economy, Vol. 113(1), 1-45.

[13] Christiano, Lawrence, Roberto Motto, and Massimo Rostagno (2003). "The Great Depression and the Friedman-Schwartz Hypothesis," Journal of Money, Credit, and Banking, Vol 35, 1119-1198.

[14] Christiano, Lawrence, Roberto Motto and Massimo Rostagno (2008), "Shocks, structures or monetary policies? The Euro Area and US after 2001," Journal of Economic Dynamics and Control, Vol 32(8), 2476-2506.

[15] Christiano, Lawrence, Cosmin Ilut, Roberto Motto and Massimo Rostagno (2007), "Monetary Policy and Stock Market Boom-Bust Cycles", manuscript, Northwestern University.

[16] Christiano, Lawrence, Mathias Trabandt and Karl Walentin (2009), "DSGE Models for Monetary Policy", prepared for the Handbook of Monetary Economics, editors Friedman and Woodford.

[17] den Haan, Wouter, Garey Ramey and Joel Watson (2000), "Job Destruction and Propagation of Shocks", American Economic Review, Vol 90(3), 482-498.

[18] Devereux, Michael P., Rachel Griffith and Alexander Klemm (2002), "Corporate income tax reforms and international tax competition," Economic Policy, Vol. 17, 449-495, October.

[19] Eichenbaum, Martin and Charles Evans (1995), "Some Empirical Evidence on the Effects of Shocks to Monetary Policy on Exchange Rates," The Quarterly Journal of Economics, Vol. 110(4), 975-1009.

[20] Erceg, Christopher, Henderson, Dale and Andrew Levin (2000), "Optimal Monetary Policy with Staggered Wage and Price Contracts," Journal of Monetary Economics, Vol 46, 281-313.

[21] Fisher, Irving (1933), "The Debt-Deflation Theory of Great Depressions," Econometrica, Vol 1, 337-357. 
[22] Fisher, Jonas (1998), "Credit market imperfections and the heterogeneous response of firms to monetary shocks", Federal Reserve Bank of Chicago, Working Paper Series, 96-23.

[23] Forslund, A. and K. Johansson (2007), "Random and stock-flow models of labour market matching - Swedish evidence", Working paper 2007:11, IFAU

[24] Fujita, Shigeru and Garey Ramey (2007), "The Cyclicality of Separation and Job Finding Rates", Working Paper 07-19, Federal Reserve Bank of Philadelphia.

[25] Gertler, Mark, Luca Sala and Antonella Trigari (2008), "An Estimated Monetary DSGE Model with Unemployment and Staggered Nominal Wage Bargaining," Journal of Money, Credit and Banking, Vol 40(8), 1713-1764.

[26] Gertler, Mark and Antonella Trigari (2009), "Unemployment Fluctuations with Staggered Nash Bargaining," Journal of Political Economy, Vol 117(1), 38-86.

[27] Greenwood, Jeremy, Zvi Hercowitz and Per Krusell (2000), "The Role of InvestmentSpecific Technological Change in the Business Cycle", European Economic Review, Vol 44(1), 91-115.

[28] Hall, Robert (2005a), "Employment Fluctuations with Equilibrium Wage Stickiness," American Economic Review, Vol 95(1), 50-65.

[29] Hall, Robert (2005b), "Employment Efficiency and Sticky Wages: Evidence from Flows in the Labor Market," Review of Economics and Statistics, Vol 87(3), 397-407.

[30] Hall, Robert (2005c), "Job Loss, Job Finding, and Unemployment in the U.S. Economy over the Past Fifty Years," NBER Macroeconomics Annual, Gertler, M., Rogoff, K., eds, MIT Press, 101-137.

[31] Hansen, Gary D., "Indivisible labor and the business cycle", Journal of Monetary Economics, $\operatorname{Vol}(3), 309-327$.

[32] Holmlund, Bertil (2006), "The Rise and Fall of Swedish Unemployment," In M. Werding (ed.), Structural Unemployment in Western Europe: Reasons and Remedies, MIT Press.

[33] Justiniano, Alejandro, Giorgio Primiceri and Andrea Tambalotti (2008), "Investment Shocks and Business Cycles", Staff Report no 322, Federal Reserve Bank of New York.

[34] Levin, Andrew and David Lopez-Salido (2004), "Optimal Monetary Policy with Endogenous Capital Accumulation", manuscript, Federal Reserve Board. 
[35] Levin, Andrew, Alexei Onatski, John Williams and Noah Williams (2005), "Monetary Policy under Uncertainty in Microfounded Macroeconometric Models," NBER Macroeconomics Annual, Gertler, M., Rogoff, K., eds, MIT Press.

[36] Merz, Monika (1995), "Search in the Labor Market and the Real Business Cycle", Journal Monetary Economics, Vol 36, 269-300.

[37] Mortensen, Dale and Christopher Pissarides (1994), "Job Creation and Job Destruction in the Theory of Unemployment," Review of Economic Studies, Vol 61, 397-415.

[38] Shimer, Robert (2005a), "The Cyclical Behavior of Equilibrium Unemployment Vacancies, and Wages: Evidence and Theory," American Economic Review, Vol 95(1), 25-49.

[39] Shimer, Robert (2005b), "Reassessing the Ins and Outs of Unemployment," manuscript, University of Chicago.

[40] Smets, Frank and Raf Wouters, 2003, "An Estimated Dynamic Stochastic General Equilibrium Model of the Euro Area," Journal of the European Economic Association, Vol $1(5), 1123-1175$.

[41] SOU, (2002), "Beräkningsrutiner för nationalräkenskaperna", SOU 2002:118, Appendix 3 , in "Utveckling och förbättring av den ekonomiska statistiken", Fritzes.

[42] Trigari, Antonella (2009), "Equilibrium Unemployment, Job flows and Inflation Dynamics", Journal of Money, Credit and Banking, Vol 41(1), 1-33.

[43] Whalley, John, (1985), Trade Liberalization among Major World Trading Areas, MIT Press, Cambridge, MA.

[44] Yun, Tack (1996), "Nominal Price Rigidity, Money Supply Endogeneity, and Business Cycles," Journal of Monetary Economics, Vol 37(2), 345-370. 


\section{A. Tables and Figures}

\begin{tabular}{|c|c|c|c|c|c|c|c|}
\hline & \multirow[b]{2}{*}{ Distr. } & \multicolumn{2}{|l|}{ Prior } & \multicolumn{2}{|c|}{ Posterior } & \multirow[b]{2}{*}{$5 \%$} & \multirow[b]{2}{*}{$95 \%$} \\
\hline & & Mean & S.d. & Mean & S.d. & & \\
\hline$\xi_{d}$ & $\beta$ & 0.750 & 0.075 & 0.828 & 0.0202 & 0.7925 & 0.8581 \\
\hline$\xi_{x}$ & $\beta$ & 0.750 & 0.075 & 0.774 & 0.0214 & 0.7386 & 0.8069 \\
\hline$\xi_{m c}$ & $\beta$ & 0.750 & 0.075 & 0.831 & 0.0235 & 0.7964 & 0.8711 \\
\hline$\xi_{m i}$ & $\beta$ & 0.750 & 0.075 & 0.815 & 0.0291 & 0.7714 & 0.8651 \\
\hline$\xi_{m x}$ & $\beta$ & 0.750 & 0.150 & 0.449 & 0.0346 & 0.3970 & 0.5075 \\
\hline$\kappa_{d}$ & $\beta$ & 0.500 & 0.150 & 0.395 & 0.0451 & 0.3210 & 0.4646 \\
\hline$\kappa_{x}$ & $\beta$ & 0.500 & 0.150 & 0.611 & 0.0578 & 0.5070 & 0.6898 \\
\hline$\kappa_{m c}$ & $\beta$ & 0.500 & 0.150 & 0.361 & 0.0396 & 0.2985 & 0.4272 \\
\hline$\kappa_{m i}$ & $\beta$ & 0.500 & 0.150 & 0.410 & 0.1094 & 0.2531 & 0.5856 \\
\hline$\kappa_{m x}$ & $\beta$ & 0.500 & 0.150 & 0.379 & 0.0406 & 0.3138 & 0.4400 \\
\hline$\kappa_{w}$ & $\beta$ & 0.500 & 0.150 & 0.355 & 0.0433 & 0.2960 & 0.4251 \\
\hline$\sigma_{L}$ & $\Gamma$ & 7.500 & 2.000 & 9.047 & 0.8465 & 7.7603 & 10.4682 \\
\hline$b$ & $\beta$ & 0.650 & 0.150 & 0.477 & 0.0344 & 0.4256 & 0.5376 \\
\hline$S^{\prime \prime}$ & $\Gamma$ & 5.000 & 1.500 & 2.720 & 0.6070 & 1.8210 & 3.6960 \\
\hline$\sigma_{a}$ & $\Gamma$ & 0.200 & 0.075 & 0.148 & 0.0286 & 0.1076 & 0.1924 \\
\hline$\rho_{R}$ & $\beta$ & 0.800 & 0.100 & 0.869 & 0.0188 & 0.8377 & 0.8987 \\
\hline$r_{\pi}$ & $N$ & 1.700 & 0.150 & 1.821 & 0.0726 & 1.7331 & 1.9443 \\
\hline$r_{y}$ & $N$ & 0.125 & 0.150 & 0.074 & 0.0392 & 0.0133 & 0.1345 \\
\hline$\eta_{x}$ & $\Gamma$ & 1.500 & 0.250 & 1.197 & 0.0892 & 1.0401 & 1.3269 \\
\hline$\eta_{c}$ & $\Gamma$ & 1.500 & 0.250 & 1.231 & 0.0855 & 1.1179 & 1.3705 \\
\hline & $\Gamma$ & 1.500 & 0.250 & 1.511 & 0.1260 & 1.3140 & 1.7057 \\
\hline$\eta_{f}$ & $\Gamma$ & 1.500 & 0.250 & 1.552 & 0.1062 & 1.3557 & 1.6983 \\
\hline$\tilde{\phi}_{s}$ & $\Gamma$ & 1.500 & 0.250 & 1.156 & 0.0527 & 1.0694 & 1.2513 \\
\hline & $\beta$ & 0.330 & 0.100 & 0.367 & 0.0584 & 0.2955 & 0.4819 \\
\hline recshare, $\%$ & $\Gamma$ & 0.100 & 0.075 & 0.027 & 0.0057 & 0.0180 & 0.0358 \\
\hline bshare & $\beta$ & 0.750 & 0.075 & 0.858 & 0.0265 & 0.8171 & 0.8987 \\
\hline$F, \%$ & $\beta$ & 0.250 & 0.050 & 0.113 & 0.0206 & 0.0787 & 0.1447 \\
\hline$\overline{\rho_{\mu_{z}}}$ & $\beta$ & 0.500 & 0.100 & 0.646 & 0.0470 & 0.5785 & 0.7337 \\
\hline$\rho_{\varepsilon}$ & $\beta$ & 0.850 & 0.075 & 0.880 & 0.0174 & 0.8531 & 0.9058 \\
\hline$\rho_{\Upsilon}$ & $\beta$ & 0.850 & 0.075 & 0.694 & 0.0184 & 0.6659 & 0.7251 \\
\hline$\rho_{\zeta^{c}}$ & $\beta$ & 0.850 & 0.075 & 0.878 & 0.0232 & 0.8391 & 0.9141 \\
\hline$\rho_{\zeta^{h}}$ & $\beta$ & 0.850 & 0.075 & 0.893 & 0.0222 & 0.8567 & 0.9259 \\
\hline$\rho_{\tilde{\phi}}$ & $\beta$ & 0.850 & 0.075 & 0.758 & 0.0161 & 0.7334 & 0.7867 \\
\hline$\rho_{g}$ & $\beta$ & 0.850 & 0.075 & 0.851 & 0.0418 & 0.7806 & 0.9196 \\
\hline$\rho_{\gamma}$ & $\beta$ & 0.850 & 0.075 & 0.857 & 0.0276 & 0.8069 & 0.8920 \\
\hline$a 11$ & $N$ & 0.500 & 0.500 & 0.919 & 0.0223 & 0.8834 & 0.9540 \\
\hline$a 22$ & $N$ & 0.000 & 0.500 & 0.022 & 0.0899 & -0.1176 & 0.1722 \\
\hline$a 3$ & N & 0.500 & & 1.004 & 0.0347 & 0.9460 & 1.0604 \\
\hline & $N$ & 0.000 & 0.500 & -0.208 & 0.1231 & -0.3964 & 0.0097 \\
\hline$a 13$ & $N$ & 0.000 & 0.500 & -0.273 & 0.1090 & -0.4518 & -0.1072 \\
\hline$a 21$ & $N$ & 0.000 & 0.5 & 0.045 & 0.0223 & 0.0094 & 0.0813 \\
\hline$a 23$ & $N$ & 0.000 & 0.5 & 0.368 & 0.0893 & 0.2209 & 0.5135 \\
\hline$a 24$ & $N$ & 0.000 & 0.5 & 0.117 & 0.0720 & 0.0018 & 0.2331 \\
\hline a31 & $N$ & 0.000 & 0.500 & 0.026 & 0.0112 & 0.0093 & 0.0427 \\
\hline$a 32$ & $N$ & 0.000 & 0.5 & -0.005 & 0.0365 & -0.0687 & 0.0520 \\
\hline a34 & $N$ & 0.000 & 0.5 & 0.166 & 0.0275 & 0.1221 & 0.2086 \\
\hline$c 21$ & $N$ & 0.000 & 0.500 & 0.308 & 0.1308 & 0.07 & 0.4894 \\
\hline$c 31$ & $N$ & 0.000 & 0.500 & -0.027 & 0.0486 & -0.1006 & 0.0476 \\
\hline$c 32$ & $N$ & 0.000 & 0.500 & 0.127 & 0.0555 & 0.0383 & 0.2194 \\
\hline$c 24$ & $N$ & 0.000 & 0.500 & -0.209 & 0.1008 & -0.3788 & -0.0553 \\
\hline$c 34$ & $N$ & 0.000 & 0.500 & 0.143 & 0.0305 & 0.0953 & 0.1908 \\
\hline
\end{tabular}

Table A1. Estimation results. Parameters. 


\begin{tabular}{|c|c|c|c|c|c|c|c|}
\hline & \multicolumn{3}{|c|}{ Prior } & \multicolumn{2}{|c|}{ Posterior } & \multirow[b]{2}{*}{$5 \%$} & \multirow[b]{2}{*}{$95 \%$} \\
\hline & Distr. & Mean & S.d. & Mean & S.d. & & \\
\hline$\mu_{z}$ & Inv- $\Gamma$ & 0.15 & $\operatorname{Inf}$ & 0.324 & 0.0474 & 0.2445 & 0.3990 \\
\hline$\varepsilon$ & $\operatorname{Inv}-\Gamma$ & 0.50 & $\operatorname{Inf}$ & 0.535 & 0.0634 & 0.4390 & 0.6428 \\
\hline$\Upsilon$ & Inv- $\Gamma$ & 0.50 & $\operatorname{Inf}$ & 0.311 & 0.0510 & 0.2314 & 0.3970 \\
\hline$\zeta^{c}$ & Inv- $\Gamma$ & 0.15 & $\operatorname{Inf}$ & 0.191 & 0.0274 & 0.1470 & 0.2345 \\
\hline$\zeta^{h}$ & $\operatorname{Inv}-\Gamma$ & 0.15 & $\operatorname{Inf}$ & 0.458 & 0.0651 & 0.3541 & 0.5610 \\
\hline$\tilde{\phi}$ & Inv- $\Gamma$ & 0.15 & $\operatorname{Inf}$ & 0.587 & 0.0837 & 0.4458 & 0.7210 \\
\hline$\varepsilon_{R}$ & $\operatorname{Inv}-\Gamma$ & 0.15 & $\operatorname{Inf}$ & 0.134 & 0.0140 & 0.1112 & 0.1558 \\
\hline$g$ & Inv- $\Gamma$ & 0.50 & $\operatorname{Inf}$ & 0.921 & 0.0955 & 0.7594 & 1.0709 \\
\hline$\tau^{d}$ & Inv $-\Gamma$ & 0.15 & $\operatorname{Inf}$ & 0.155 & 0.0363 & 0.0951 & 0.2086 \\
\hline$\tau^{x}$ & Inv- $\Gamma$ & 0.15 & Inf & 0.255 & 0.0475 & 0.1831 & 0.3291 \\
\hline$\tau^{m c}$ & Inv $-\Gamma$ & 0.15 & Inf & 0.389 & 0.1292 & 0.2083 & 0.5616 \\
\hline$\tau^{m i}$ & Inv $-\Gamma$ & 0.15 & Inf & 0.184 & 0.0652 & 0.0901 & 0.2850 \\
\hline$\tau^{m x}$ & Inv- $\Gamma$ & 0.15 & $\operatorname{Inf}$ & 0.137 & 0.0325 & 0.0829 & 0.1878 \\
\hline$\gamma$ & Inv- $\Gamma$ & 0.50 & $\operatorname{Inf}$ & 0.450 & 0.0543 & 0.3619 & 0.5387 \\
\hline$y^{*}$ & Inv- $\Gamma$ & 0.50 & Inf & 0.298 & 0.0632 & 0.1970 & 0.4031 \\
\hline$\pi^{*}$ & Inv $-\Gamma$ & 0.50 & $\operatorname{Inf}$ & 0.199 & 0.0263 & 0.1564 & 0.2434 \\
\hline$R^{*}$ & $\operatorname{Inv}-\Gamma$ & 0.50 & $\operatorname{Inf}$ & 0.243 & 0.0669 & 0.1340 & 0.3467 \\
\hline ME (spread) & $\Gamma$ & 4.00 & 0.25 & 4.049 & 0.1807 & 3.7750 & 4.3393 \\
\hline $\operatorname{ME}(\mathrm{N})$ & $\Gamma$ & 3.40 & 0.25 & 5.184 & 0.0379 & 5.1306 & 5.2395 \\
\hline
\end{tabular}

Table A2. Estimation results. Standard deviation of shocks.

\begin{tabular}{|l|cc|cc|}
\hline \multicolumn{2}{c}{} & \multicolumn{2}{c}{ Means } & \multicolumn{2}{c|}{ Standard Deviations } \\
\cline { 2 - 5 } & Data & Model & Data & Model \\
\hline Domestic. Inflation & 1.69 & 2.00 & 1.84 & 3.61 \\
CPI inflation & 1.50 & 2.00 & 1.38 & 3.72 \\
Invest. price inflation & 1.52 & 1.80 & 2.14 & 3.79 \\
Nom. interest rate & 3.74 & 4.25 & 1.73 & 3.42 \\
& & & & \\
GDP growth & 0.42 & 0.42 & 0.96 & 0.86 \\
Real wage growth & 0.64 & 0.42 & 0.72 & 0.67 \\
Consumption growth & 0.41 & 0.42 & 0.78 & 0.99 \\
Investment growth & 0.65 & 0.47 & 2.97 & 4.10 \\
Real exch. rate growth & 0.25 & 0.00 & 2.77 & 2.80 \\
Total hours growth & -0.02 & 0.00 & 0.56 & 0.82 \\
Gov. cons. growth & 0.08 & 0.42 & 0.95 & 1.09 \\
Exports growth & 1.05 & 0.42 & & \\
Import growth & 0.89 & 0.42 & 2.44 & 2.44 \\
& & & 2.63 & 2.05 \\
Stock market growth & 1.13 & 0.42 & & \\
Interest spread growth & 0.24 & 0.00 & 10.74 & 9.94 \\
Unemployment growth & -0.43 & 0.00 & 4.47 & 25.00 \\
Foreign GDP growth & & & & 8.05 \\
Foreign inflation & 0.31 & 0.42 & 0.64 & 0.53 \\
Foreign nom. int. rate & 1.81 & 2.00 & 1.01 & 1.30 \\
& 3.79 & 4.25 & 1.11 & 2.71 \\
\hline
\end{tabular}

Table A3. Data and model moments (in percent). 


\begin{tabular}{|c|c|c|c|c|c|c|c|c|c|c|c|c|c|c|c|c|c|c|c|}
\hline Shocks/Variables & Pid & Pic & Pii & $\mathbf{R}$ & dy & $\mathrm{dw}$ & dc & di & $\mathrm{dq}$ & $\mathrm{dH}$ & dG & $\operatorname{dexp}$ & $\operatorname{dimp}$ & dn & dspread & dunemp & $\mathbf{y}^{\star}$ & $\mathbf{p i}^{\mathbf{*}}$ & $\mathbf{R}^{\boldsymbol{*}}$ \\
\hline Stat. neutr. tech. & 5.2 & 3.8 & 3.6 & 1.6 & 16.7 & 0.2 & 5.7 & $\begin{array}{c}0.1 \\
\end{array}$ & 4.3 & 27.4 & 0.0 & 0.0 & 3.2 & 1.0 & 1.4 & 23.0 & & & \\
\hline Stat. invest. tech. & 0.0 & 0.0 & 0.0 & 0.0 & 0.0 & 0.3 & 0.2 & 22.4 & 0.1 & 2.6 & 0.0 & 0.0 & 7.8 & 18.0 & 19.3 & 3.0 & & & \\
\hline Consumption pref. & 1.0 & 1.5 & 2.9 & 1.0 & 9.3 & 0.0 & 52.8 & 0.4 & 6.7 & 10.7 & 0.0 & 0.1 & 3.9 & 0.9 & 1.1 & 5.4 & & & \\
\hline Labor pref. & 0.9 & 0.7 & 0.8 & 0.3 & 2.8 & 0.7 & 1.5 & 0.0 & 1.1 & 9.5 & 0.0 & 0.0 & 0.4 & 0.3 & 0.4 & 18.0 & & & \\
\hline Monetary policy & 0.2 & 0.3 & 0.6 & 50.0 & 5.4 & 0.4 & 10.5 & 10.8 & 1.1 & 0.7 & 0.0 & 0.1 & 4.6 & 19.4 & 16.9 & 4.2 & & & \\
\hline Gov. consumption & 0.1 & 0.1 & 0.1 & 0.1 & 4.1 & 0.1 & 0.6 & 0.0 & 0.1 & 5.2 & 81.3 & 0.0 & 0.8 & 0.0 & 0.0 & 4.3 & & & \\
\hline Domestic markup & 83.4 & 32.5 & 9.9 & 16.6 & 3.4 & 79.5 & 5.5 & 0.7 & 0.0 & 4.0 & 0.0 & 0.0 & 0.3 & 1.7 & 0.1 & 5.1 & & & \\
\hline Export markup & 0.3 & 0.2 & 0.2 & 0.2 & 10.5 & 0.7 & 1.5 & 0.1 & 0.2 & 14.4 & 0.0 & 78.9 & 27.2 & 0.0 & 0.0 & 13.0 & & & \\
\hline Cons. import mkup & 0.2 & 54.7 & 0.0 & 28.9 & 0.0 & 0.1 & 6.6 & 1.5 & 2.5 & 0.8 & 0.0 & 0.0 & 5.6 & 4.5 & 3.8 & 0.5 & & & \\
\hline Invest. import mkup & 0.1 & 0.0 & 64.5 & 0.0 & 0.8 & 0.0 & 0.0 & 0.3 & 0.1 & 0.6 & 0.0 & 0.0 & 1.1 & 2.2 & 2.3 & 0.7 & & & \\
\hline Export import mkup & 0.0 & 0.0 & 0.0 & 0.0 & 10.7 & 0.3 & 0.1 & 0.0 & 0.3 & 13.8 & 0.0 & 1.3 & 11.4 & 0.1 & 0.1 & 13.4 & & & \\
\hline Entrepreneur survival & 0.0 & 0.0 & 0.1 & 0.0 & 3.1 & 0.0 & 0.8 & 49.0 & 0.6 & 0.1 & 0.0 & 0.0 & 3.8 & 45.1 & 49.2 & 0.3 & & & \\
\hline Risk premium & 0.4 & 1.8 & 5.9 & 1.1 & 2.0 & 0.0 & 1.2 & 0.7 & 69.5 & 2.5 & 0.0 & 1.0 & 1.4 & 0.2 & 0.2 & 2.3 & & & \\
\hline Unit-root neutr. tech. & 0.0 & 0.1 & 0.6 & 0.1 & 12.6 & 1.0 & 4.4 & 3.3 & 0.0 & 0.0 & 10.1 & 0.9 & 2.1 & 6.4 & 5.3 & 0.6 & 54.3 & 8.8 & 62.5 \\
\hline Foreign output & 0.0 & 0.2 & 0.5 & 0.1 & 0.2 & 0.1 & 0.1 & 0.1 & 2.0 & 0.3 & 0.0 & 2.9 & 2.7 & 0.2 & 0.2 & 0.4 & 45.8 & 16.0 & 1.9 \\
\hline Foreign inflation & 0.0 & 0.0 & 0.0 & 0.0 & 0.2 & 0.0 & 0.1 & 0.0 & 0.0 & 0.2 & 0.0 & 1.4 & 0.4 & 0.0 & 0.0 & 0.1 & 0.0 & 75.2 & 18.4 \\
\hline Foreign nom.int. rate & 0.0 & 0.0 & 0.0 & 0.0 & 0.0 & 0.0 & 0.0 & 0.0 & 0.1 & 0.0 & 0.0 & 0.0 & 0.0 & 0.0 & 0.0 & 0.0 & 0.0 & 0.0 & 17.2 \\
\hline
\end{tabular}

Variance decomposition. 1 quarter ahead (in percent).

\begin{tabular}{|c|c|c|c|c|c|c|c|c|c|c|c|c|c|c|c|c|c|c|c|}
\hline Shocks/Variables & Pid & Pic & Pit & $\mathbf{R}$ & dy & $d w$ & dc & di & dq & $\mathrm{dH}$ & $\mathrm{dG}$ & $\operatorname{dexp}$ & $\operatorname{dimp}$ & dn & dspread & dunemp & $\mathbf{y}^{*}$ & $p^{i}{ }^{*}$ & $\mathbf{R}^{*}$ \\
\hline Stat. neutr. tech. & 15.7 & $\overline{11.6}$ & 10.0 & 16.9 & 12.5 & 2.2 & 7.3 & 0.6 & 4.3 & 21.8 & 0.0 & 0.1 & 5.3 & 1.2 & 1.4 & 17.5 & & & \\
\hline Stat. invest. tech. & 0.3 & 0.3 & 0.4 & 0.2 & 1.1 & 0.7 & 0.3 & 17.5 & 0.0 & 2.4 & 0.0 & 0.0 & 6.9 & 18.5 & 19.0 & 2.7 & & & \\
\hline Consumption pref. & 5.4 & 6.4 & 8.7 & 16.6 & 9.5 & 1.1 & 49.9 & 1.8 & 6.2 & 11.3 & 0.0 & 0.3 & 4.4 & 1.0 & 1.0 & 8.6 & & & \\
\hline Labor pref. & 3.3 & 2.6 & 2.3 & 4.0 & 2.5 & 2.3 & 1.8 & 0.2 & 1.0 & 7.7 & 0.0 & 0.0 & 1.2 & 0.3 & 0.4 & 13.5 & & & \\
\hline Monetary policy & 0.9 & 1.1 & 1.7 & 20.6 & 5.0 & 1.4 & 10.0 & 9.5 & 1.0 & 3.1 & 0.0 & 0.2 & 4.7 & 20.2 & 17.9 & 5.7 & & & \\
\hline Gov. consumption & 0.2 & 0.2 & 0.2 & 0.6 & 3.3 & 0.4 & 0.7 & 0.1 & 0.1 & 3.9 & 77.1 & 0.0 & 1.0 & 0.0 & 0.0 & 3.0 & & & \\
\hline Domestic markup & 63.2 & 24.3 & 6.8 & 11.5 & 3.9 & 63.0 & 6.1 & 0.7 & 0.2 & 5.5 & 0.0 & 0.1 & 0.4 & 1.9 & 0.1 & 7.6 & & & \\
\hline Export markup & 0.6 & 0.5 & 0.4 & 1.9 & 12.1 & 2.4 & 1.6 & 0.2 & 0.2 & 16.6 & 0.0 & 78.3 & 25.5 & 0.0 & 0.0 & 17.0 & & & \\
\hline Cons. import mkup & 0.5 & 41.8 & 0.0 & 16.2 & 0.2 & 3.6 & 8.2 & 1.4 & 2.4 & 0.9 & 0.0 & 0.1 & 5.9 & 4.8 & 3.9 & 0.6 & & & \\
\hline Invest. import mkup & 0.3 & 0.1 & 45.2 & 0.1 & 0.8 & 0.1 & 0.0 & 0.5 & 0.1 & 0.8 & 0.0 & 0.0 & 1.2 & 2.3 & 2.2 & 0.9 & & & \\
\hline Export import mkup & 0.1 & 0.1 & 0.2 & 0.2 & 11.9 & 0.7 & 0.2 & 0.0 & 0.3 & 14.8 & 0.0 & 2.2 & 10.9 & 0.1 & 0.1 & 12.7 & & & \\
\hline Entrepreneur survival & 0.3 & 0.3 & 0.3 & 0.2 & 5.0 & 0.5 & 0.9 & 56.5 & 0.5 & 0.6 & 0.0 & 0.1 & 7.8 & 43.1 & 48.1 & 0.7 & & & \\
\hline Risk premium & 1.3 & 3.2 & 8.5 & 5.4 & 3.0 & 0.6 & 1.9 & 1.3 & 71.8 & 4.0 & 0.0 & 1.9 & 1.8 & 0.2 & 0.2 & 4.3 & & & \\
\hline Unit-root neutr. tech. & 1.9 & 4.1 & 7.9 & 4.5 & 15.9 & 9.2 & 4.1 & 3.4 & 0.1 & 1.4 & 15.3 & 2.4 & 2.9 & 6.3 & 5.6 & 1.9 & 62.8 & 38.6 & 94.4 \\
\hline Foreign output & 0.4 & 0.6 & 1.2 & 1.1 & 0.2 & 0.1 & 0.2 & 0.2 & 1.8 & 0.4 & 0.0 & 2.7 & 2.1 & 0.2 & 0.2 & 0.3 & 36.2 & 12.0 & 1.4 \\
\hline Foreign inflation & 0.0 & 0.1 & 0.1 & 0.1 & 0.2 & 0.0 & 0.1 & 0.0 & 0.0 & 0.2 & 0.0 & 1.4 & 0.6 & 0.0 & 0.0 & 0.1 & 0.9 & 48.9 & 1.9 \\
\hline Foreign nom.int. rate & 0.0 & 0.0 & 0.0 & 0.0 & 0.0 & 0.0 & 0.0 & 0.0 & 0.1 & 0.0 & 0.0 & 0.0 & 0.0 & 0.0 & 0.0 & 0.0 & 0.1 & 0.5 & 2.3 \\
\hline
\end{tabular}

Variance decomposition. 8 quarters ahead (in percent).

\begin{tabular}{|c|c|c|c|c|c|c|c|c|c|c|c|c|c|c|c|c|c|c|c|}
\hline Shocks/Variables & Pid & Pic & Pii & $\mathbf{R}$ & dy & $d w$ & dc & di & $d q$ & $\mathrm{dH}$ & $\mathrm{dG}$ & $\operatorname{dexp}$ & $\operatorname{dimp}$ & $\mathrm{dn}$ & dspread & dunemp & $\mathrm{y}^{*}$ & $\mathbf{p i}^{\mathbf{p}^{*}}$ & $\mathbf{R}^{\star}$ \\
\hline Stat. neutr. tech. & 13.3 & 10.1 & 8.7 & 14.7 & 12.5 & 2.5 & 7.9 & 0.8 & 4.3 & 21.5 & 0.0 & 0.2 & 5.2 & 1.2 & 1.4 & 17.3 & & & \\
\hline Stat. invest. tech. & 1.0 & 0.9 & 0.8 & 1.0 & 1.1 & 0.7 & 0.3 & 16.2 & 0.0 & 2.4 & 0.0 & 0.0 & 6.8 & 18.7 & 19.0 & 2.7 & & & \\
\hline Consumption pref. & 5.3 & 5.9 & 7.6 & 19.0 & 10.0 & 1.2 & 48.6 & 2.0 & 6.2 & 11.4 & 0.0 & 0.3 & 4.3 & 1.0 & 1.0 & 8.7 & & & \\
\hline Labor pref. & 3.0 & 2.4 & 2.1 & 4.1 & 2.5 & 2.3 & 2.0 & 0.2 & 1.0 & 7.7 & 0.0 & 0.1 & 1.2 & 0.3 & 0.4 & 13.4 & & & \\
\hline Monetary policy & 0.9 & 1.1 & 1.7 & 12.5 & 5.0 & 1.4 & 9.7 & 9.4 & 1.0 & 3.4 & 0.0 & 0.2 & 4.9 & 20.1 & 17.7 & 5.9 & & & \\
\hline Gov. consumption & 0.2 & 0.2 & 0.2 & 0.6 & 3.2 & 0.4 & 0.7 & 0.1 & 0.1 & 3.9 & 77.2 & 0.0 & 1.0 & 0.0 & 0.0 & 3.0 & & & \\
\hline Domestic markup & 52.9 & 20.7 & 5.8 & 6.9 & 4.0 & 62.5 & 5.9 & 0.7 & 0.2 & 5.6 & 0.0 & 0.2 & 0.5 & 1.8 & 0.1 & 7.7 & & & \\
\hline Export markup & 0.5 & 0.4 & 0.4 & 1.4 & 12.0 & 2.4 & 1.6 & 0.2 & 0.2 & 16.4 & 0.0 & 78.1 & 24.5 & 0.0 & 0.0 & 16.8 & & & \\
\hline Cons. import mkup & 0.4 & 35.8 & 0.1 & 10.3 & 0.2 & 3.5 & 8.0 & 1.4 & 2.5 & 0.9 & 0.0 & 0.1 & 5.8 & 4.7 & 3.9 & 0.7 & & & \\
\hline Invest. import mkup & 0.3 & 0.1 & 38.8 & 0.1 & 0.8 & 0.1 & 0.0 & 0.5 & 0.1 & 0.8 & 0.0 & 0.0 & 1.2 & 2.3 & 2.2 & 0.9 & & & \\
\hline Export import mkup & 0.1 & 0.1 & 0.2 & 0.2 & 11.8 & 0.7 & 0.2 & 0.0 & 0.3 & 14.6 & 0.0 & 2.3 & 10.4 & 0.1 & 0.1 & 12.5 & & & \\
\hline Entrepreneur survival & 5.2 & 5.0 & 5.3 & 1.6 & 5.2 & 0.5 & 2.1 & 56.4 & 0.5 & 0.8 & 0.0 & 0.1 & 9.4 & 43.0 & 48.4 & 0.8 & & & \\
\hline Risk premium & 1.2 & 3.0 & 8.1 & 3.5 & 3.0 & 0.7 & 2.2 & 1.8 & 71.7 & 4.0 & 0.0 & 2.1 & 2.1 & 0.2 & 0.3 & 4.2 & & & \\
\hline Unit-root neutr. tech. & 10.8 & 11.3 & 13.8 & 22.8 & 15.8 & 9.3 & 4.2 & 4.5 & 0.1 & 1.5 & 15.2 & 2.4 & 3.2 & 6.3 & 5.5 & 2.0 & 62.5 & 46.6 & 92.1 \\
\hline Foreign output & 0.3 & 0.6 & 1.2 & 0.9 & 0.2 & 0.1 & 0.3 & 0.4 & 1.9 & 0.4 & 0.0 & 2.7 & 2.3 & 0.2 & 0.2 & 0.3 & 36.5 & 12.8 & 5.3 \\
\hline Foreign inflation & 0.1 & 0.1 & 0.1 & 0.2 & 0.2 & 0.0 & 0.1 & 0.0 & 0.0 & 0.2 & 0.0 & 1.4 & 0.6 & 0.0 & 0.0 & 0.1 & 0.9 & 40.0 & 1.0 \\
\hline Foreign nom.int. rate & 0.0 & 0.0 & 0.1 & 0.1 & 0.0 & 0.0 & 0.0 & 0.0 & 0.1 & 0.0 & 0.0 & 0.0 & 0.0 & 0.0 & 0.0 & 0.0 & 0.1 & 0.6 & 1.6 \\
\hline
\end{tabular}

Variance decomposition. 20 quarters ahead (in percent). 


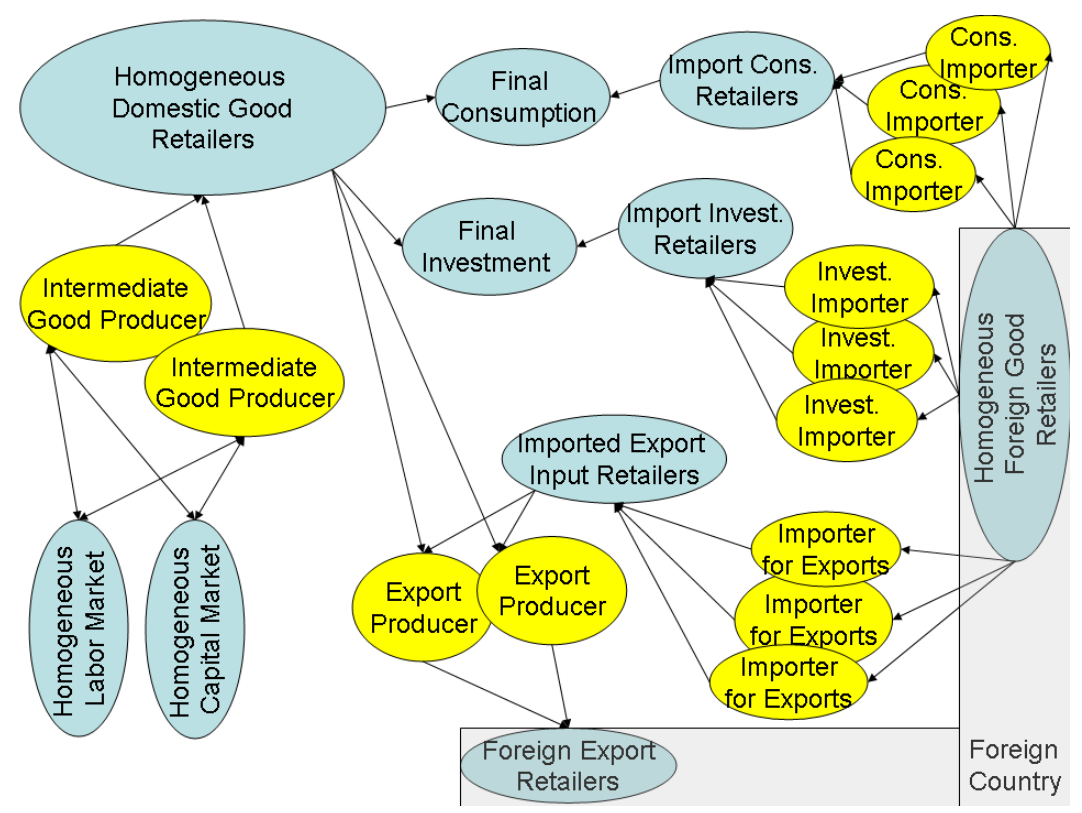

Figure A. Graphical illustration of the goods production part of the model.

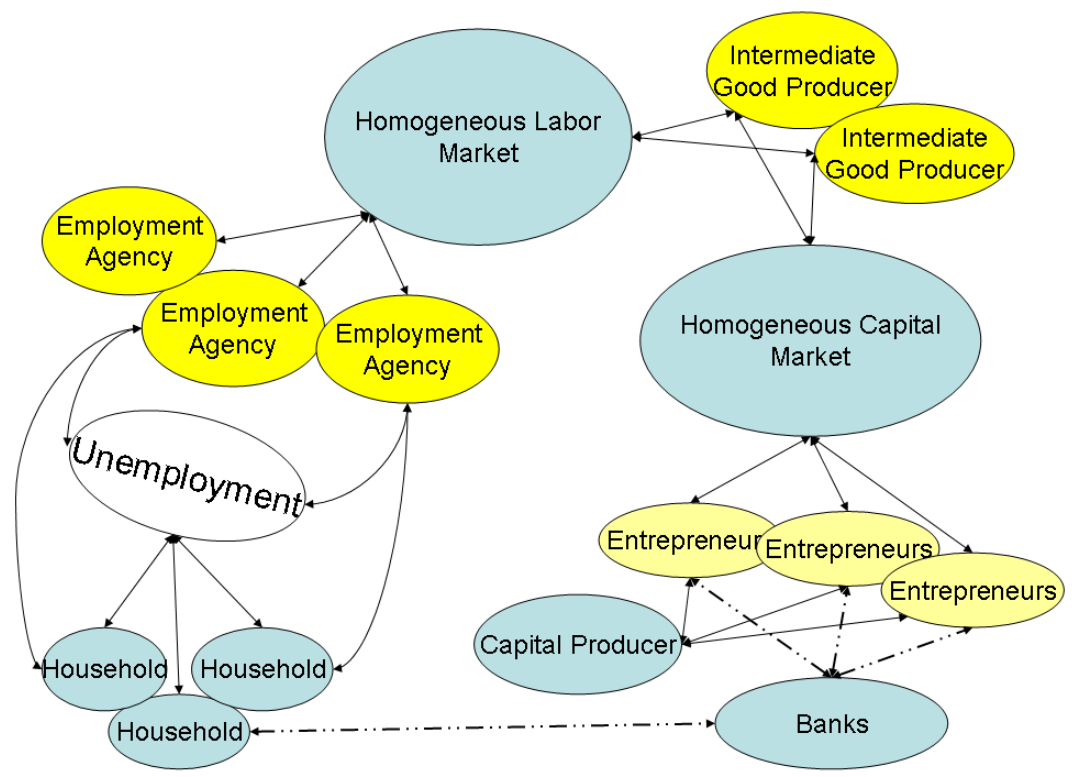

Figure B. Graphical illustration of the labor and capital markets of the model. 


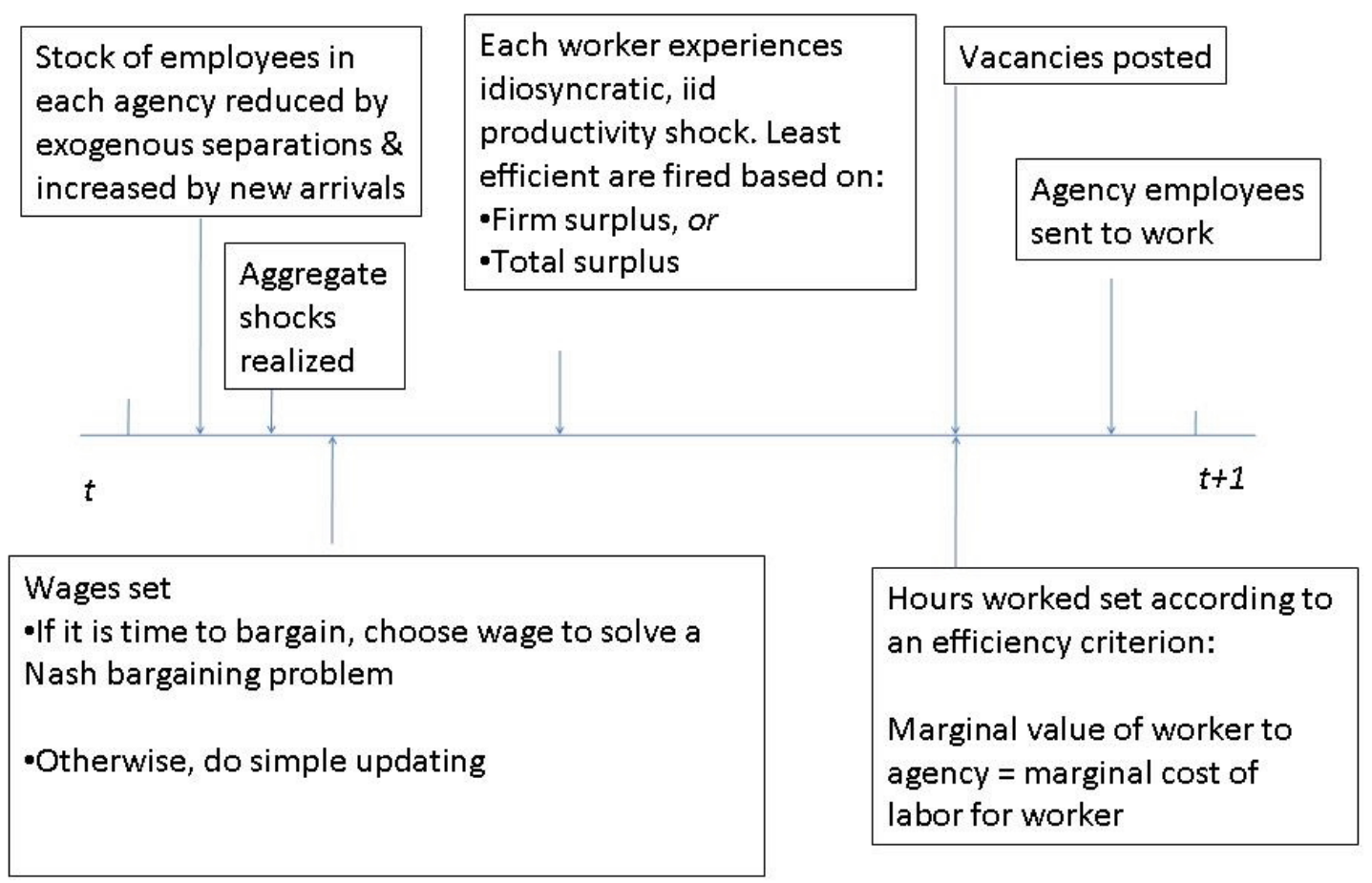

Figure C. Timeline for labor market in employment friction model. 

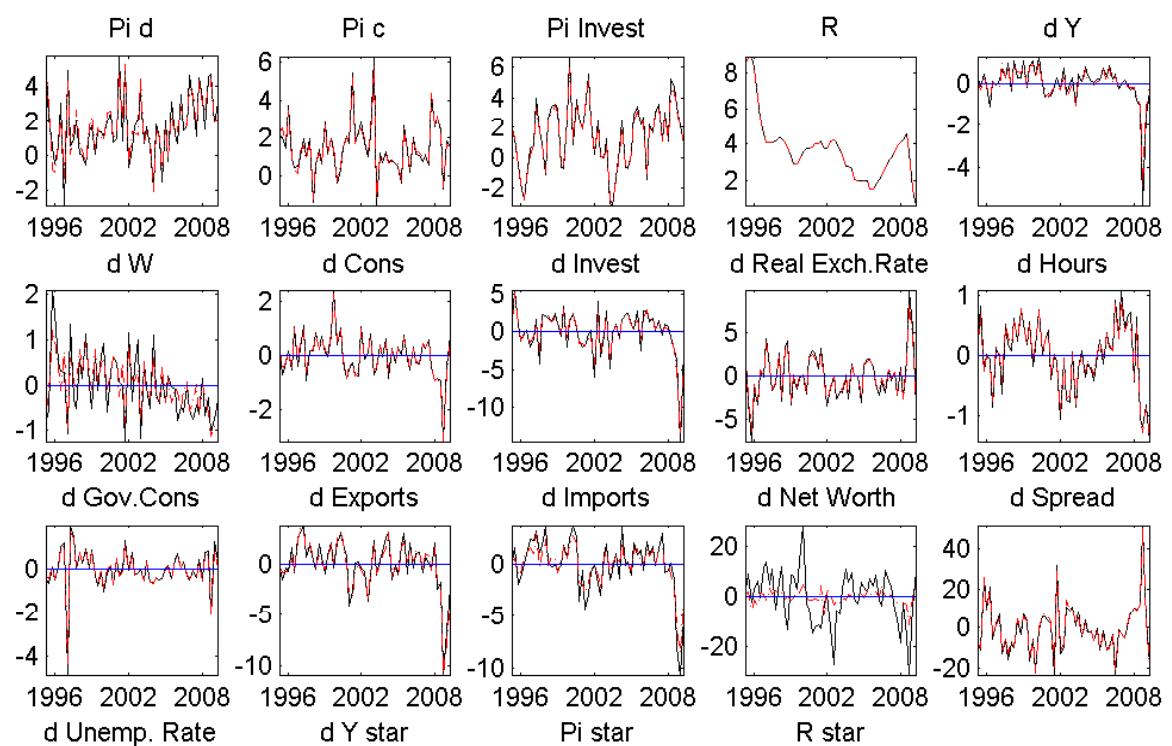

$$
\text { d Y star }
$$
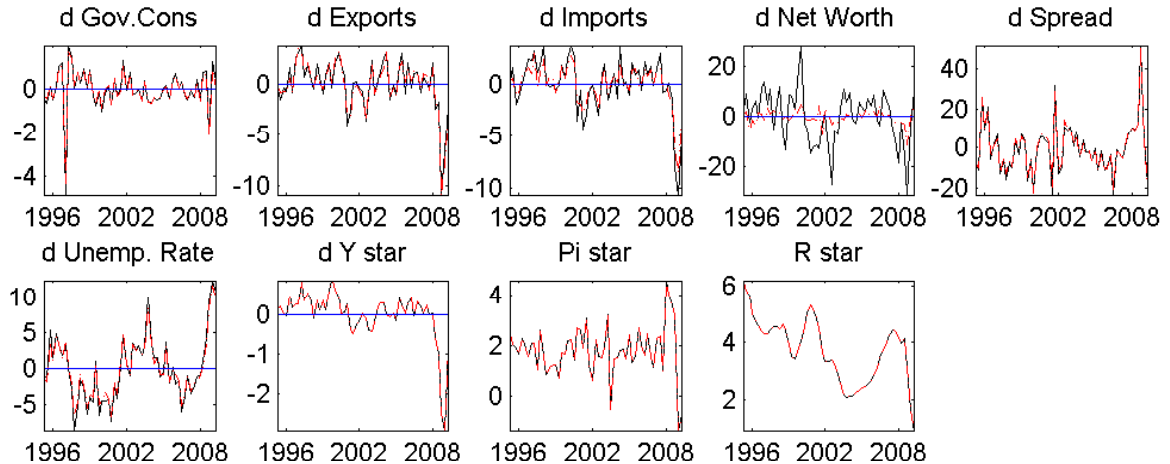

199620022008

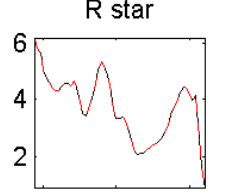

Figure D. Data series used in estimation (solid black) and smoothed variables without measurement error (in dashed red). 

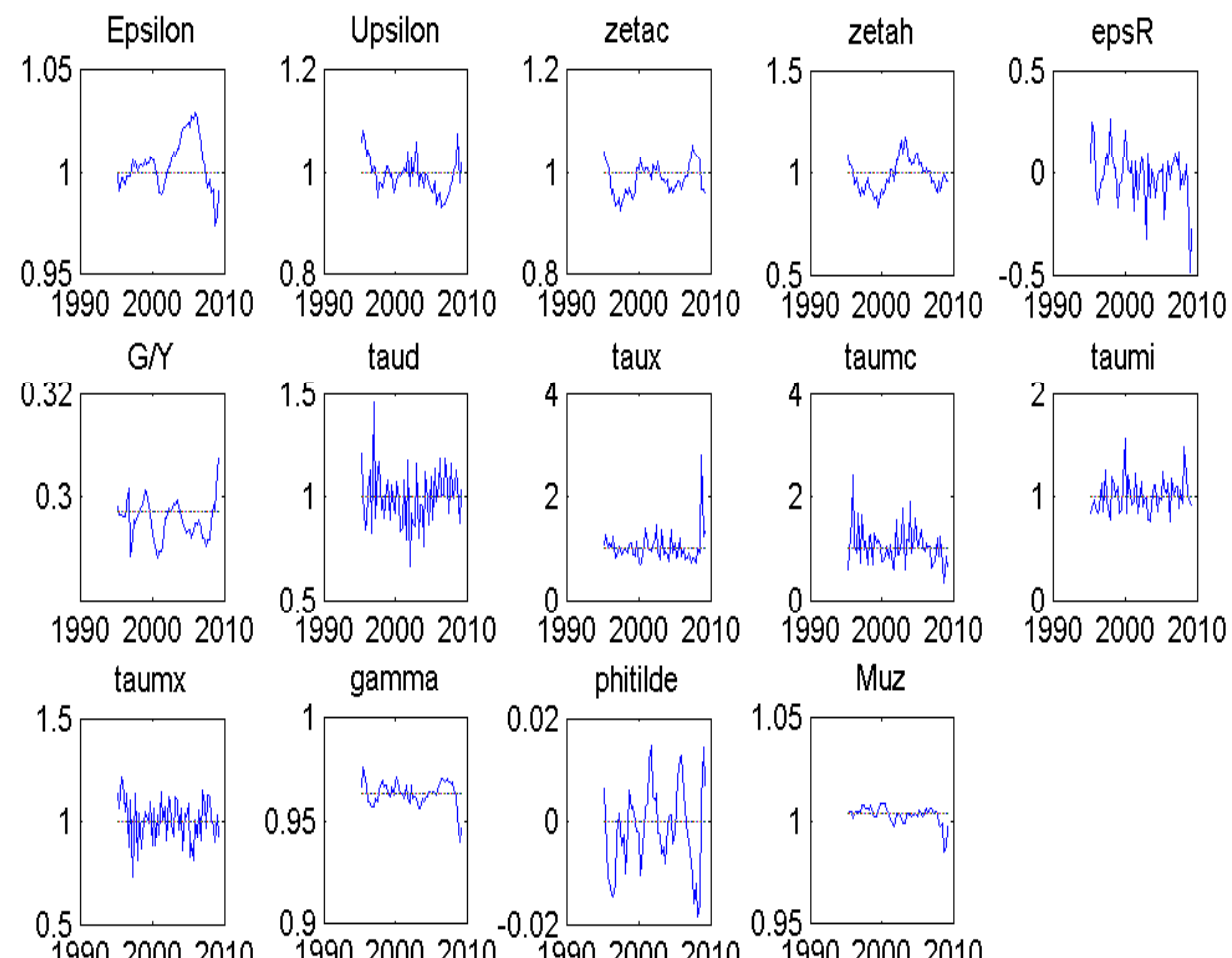

199020002010

199020002010199020002010199020002010199020002010

Figure E. Smoothed shock processes, except epsR which is the innovation to the monetary policy rule. 


\section{Monetary Policy Shock}
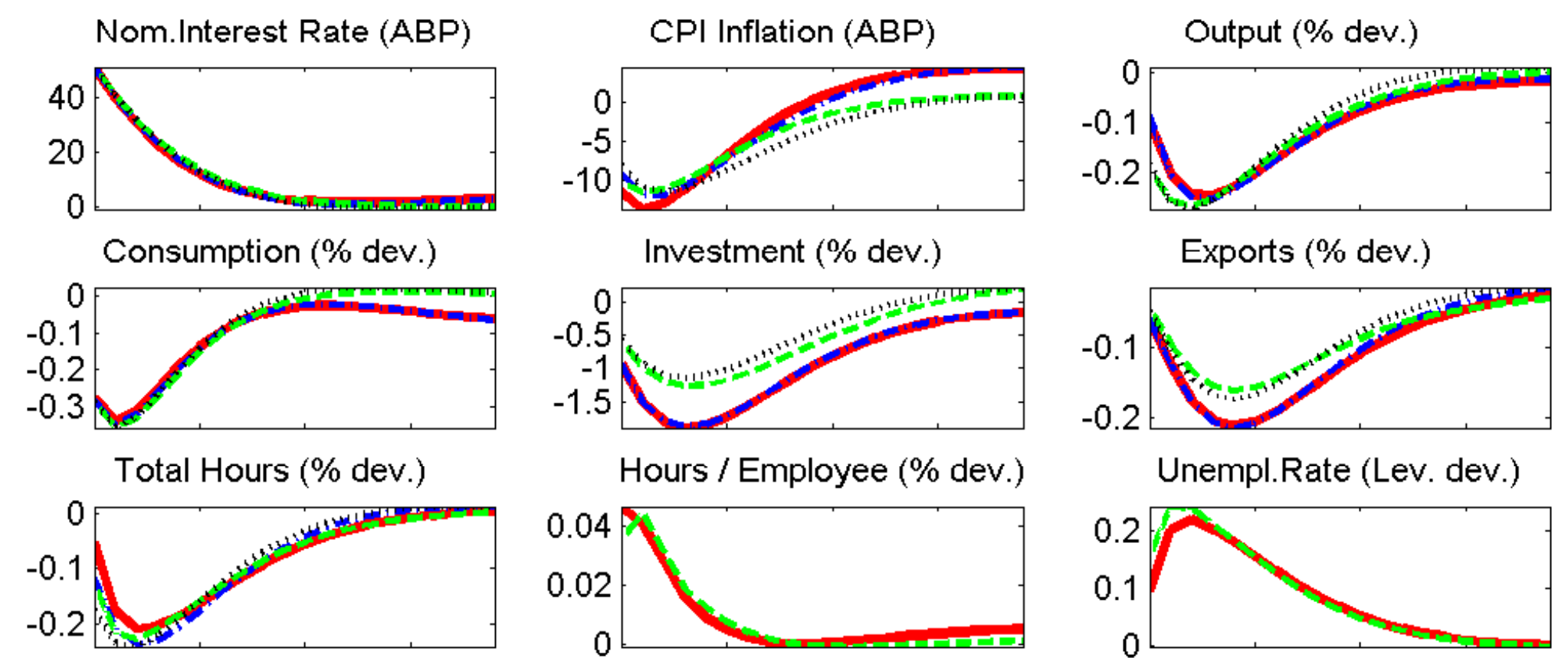

Hours / Employee (\% dev.)

Real (Nash) wage (\% dev.)
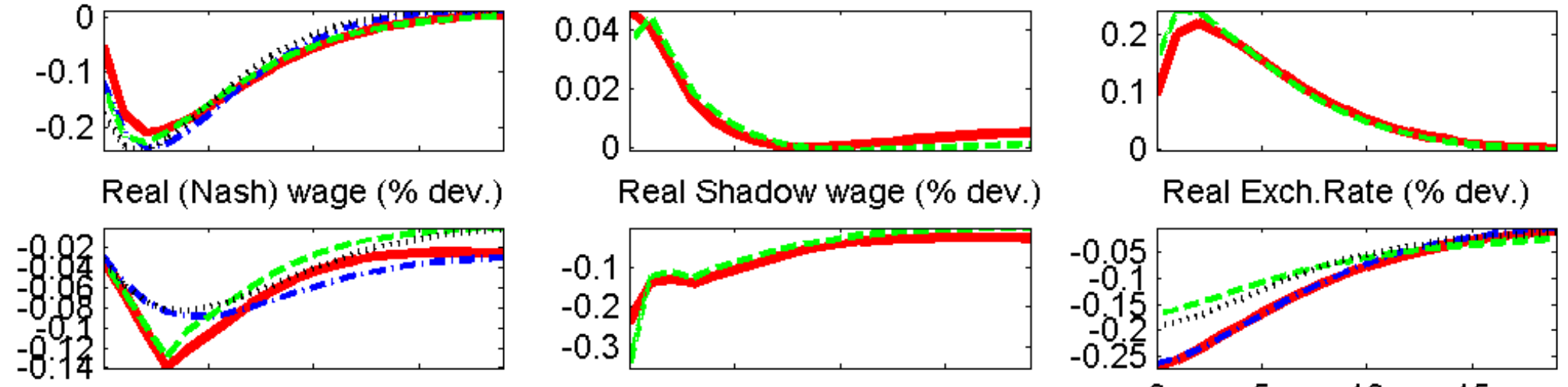

Net Worth (\% dev.)
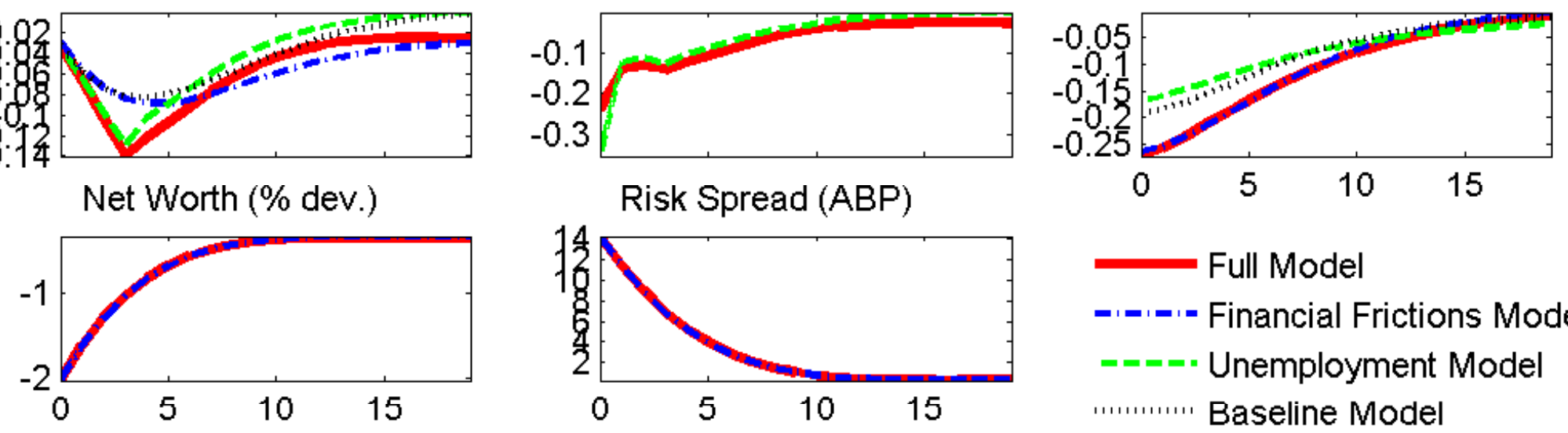

The units on the $\mathrm{y}$-axis are either in terms of percentage deviation (\% dev.) from steady state, annualized basis points (ABP), or level deviation (Lev. dev.). 


\section{Stationary Neutral Technology Shock}

Nom.Interest Rate (ABP)

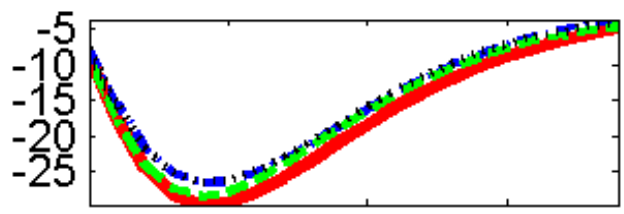

Consumption (\% dev.)

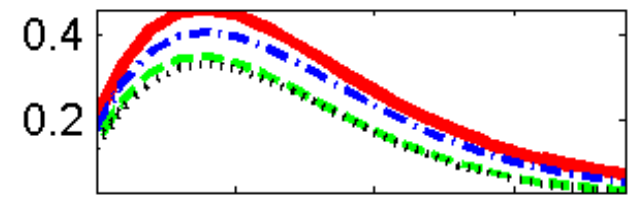

Total Hours ( $\%$ dev.)

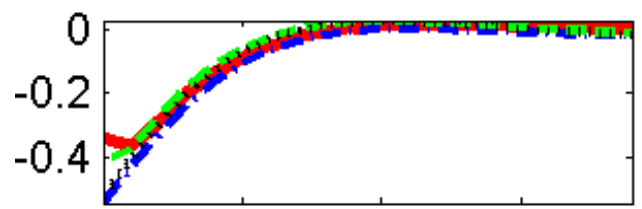

Real (Nash) wage (\% dev.)

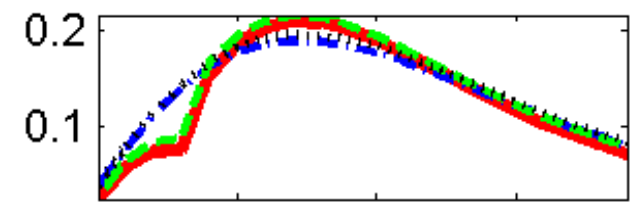

Net Worth (\% dev.)

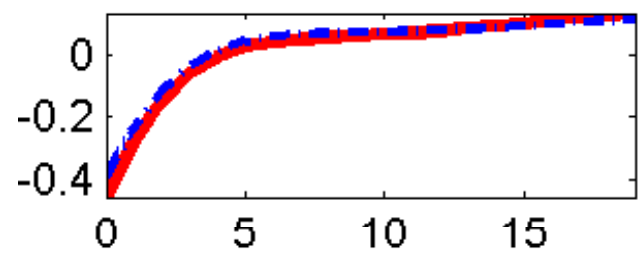

CPI Inflation (ABP)

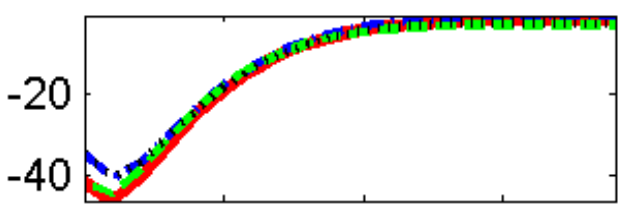

Investment (\% dev.)

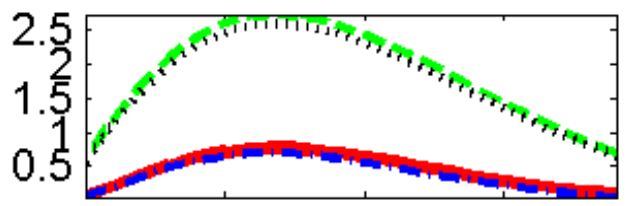

Hours / Employee (\% dev.)

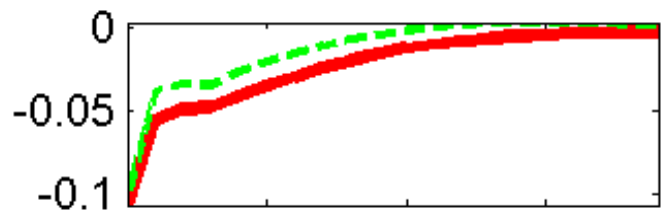

Real Shadow wage (\% dev.)

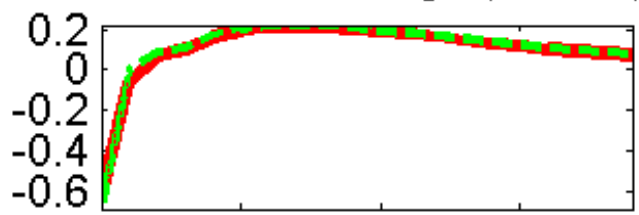

Risk Spread (ABP)

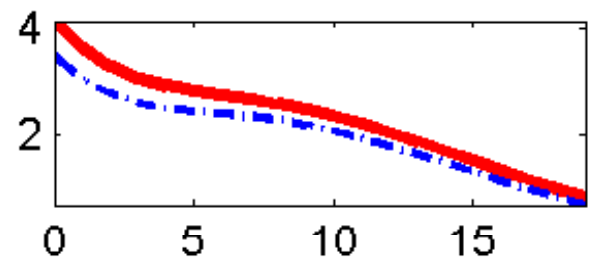

Output (\% dev.)

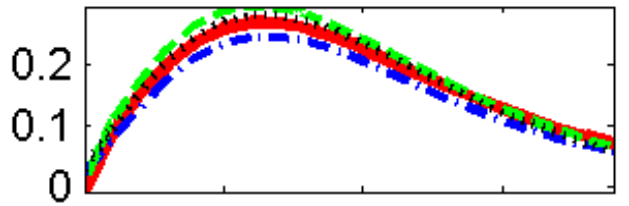

Exports (\% dev.)

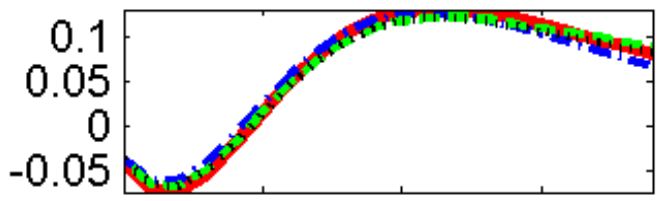

Unempl.Rate (Lev. dev.)

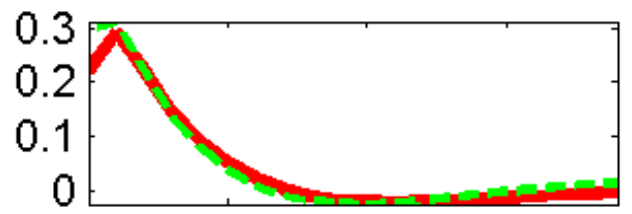

Real Exch.Rate (\% dev.)

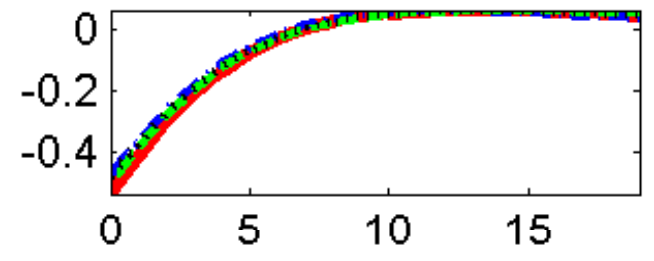

Full Model

- - - Financial Frictions Model

- ----: Unemployment Model Baseline Model 


\section{Stationary Investment Technology Shock}

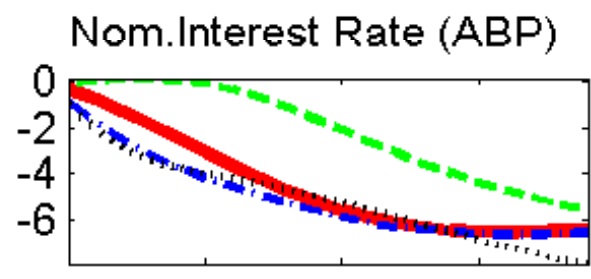

Consumption (\% dev.)

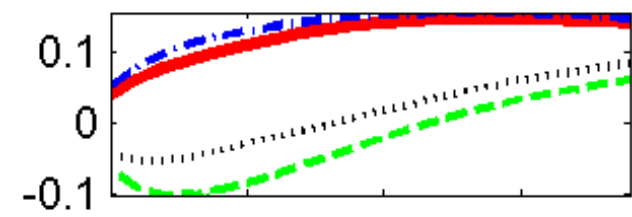

Total Hours (\% dev.)

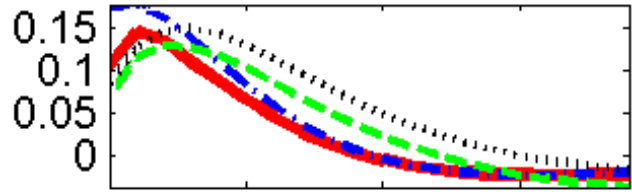

Real (Nash) wage (\% dev.)

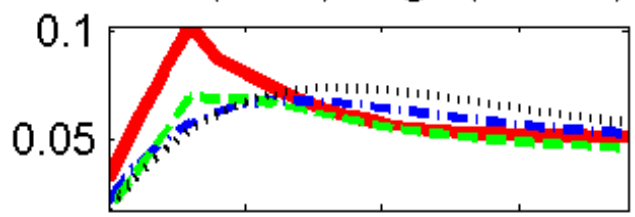

Net Worth (\% dev.)

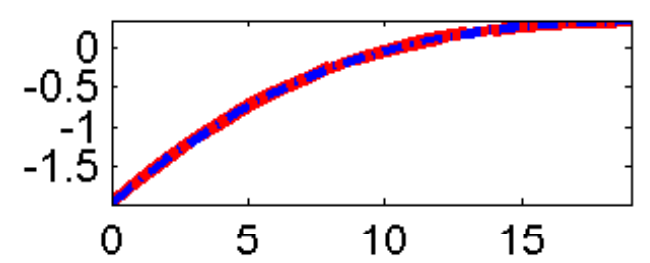

CPI Inflation (ABP)

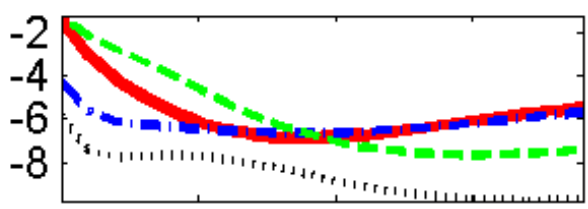

Investment (\% dev.)

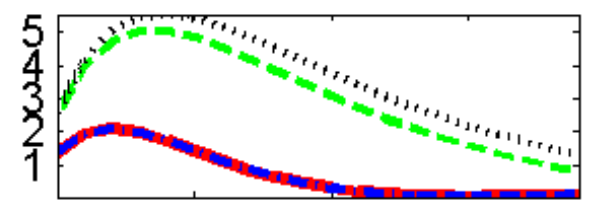

Hequ's / Employee (\% dev.)

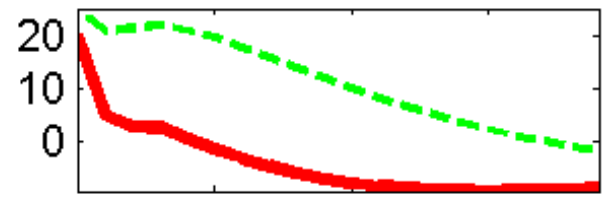

Real Shadow wage (\% dev.)

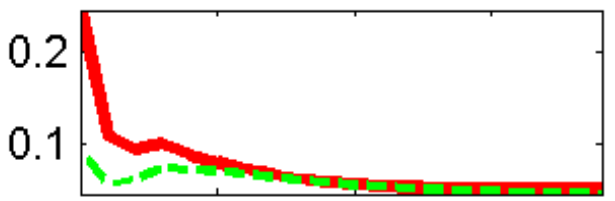

Risk Spread (ABP)

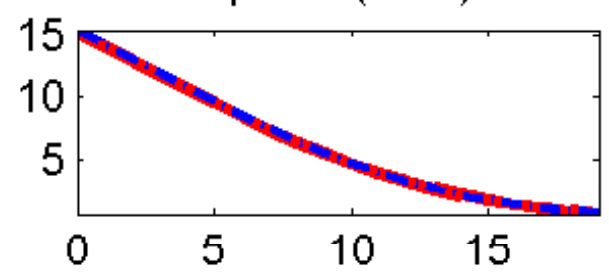

Output (\% dev.)

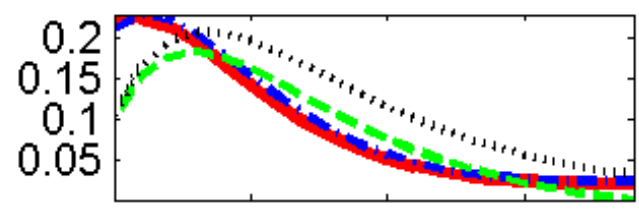

Exports (\% dev.)

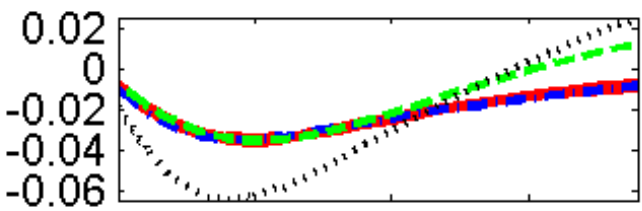

Unempl.Rate (Lev. dev.)

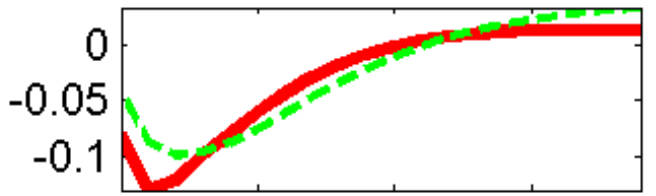

Real Exch.Rate (\% dev.)

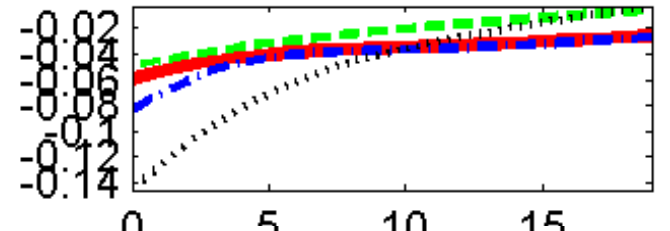

$\begin{array}{lll}5 & 10 & 15\end{array}$

Full Model

- - Financial Frictions Model

---- - Unemployment Model Baseline Model 


\section{Consumption Preference Shock}

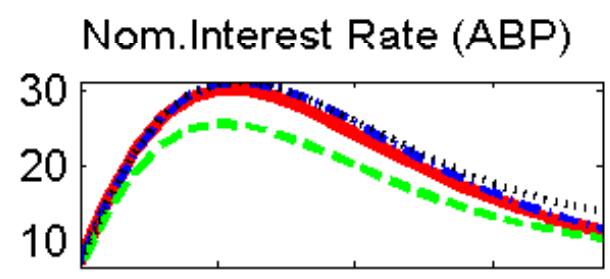

Consumption ( $\%$ dev.)

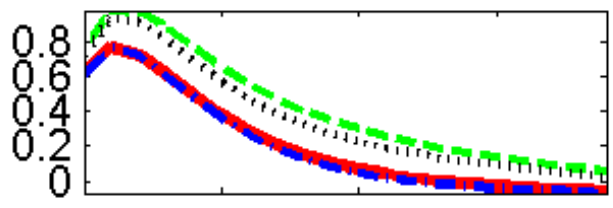

Total Hours (\% dev.)

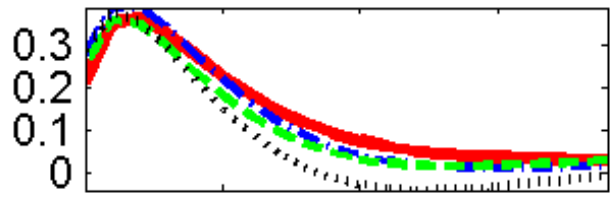

Real (Nash) wage (\% dev.)

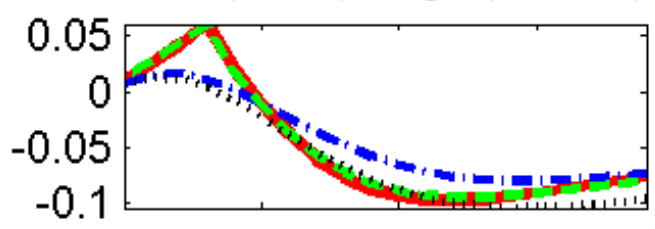

Net Worth (\% dev.)

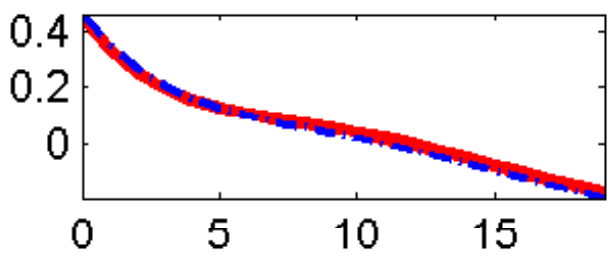

CPI Inflation (ABP)

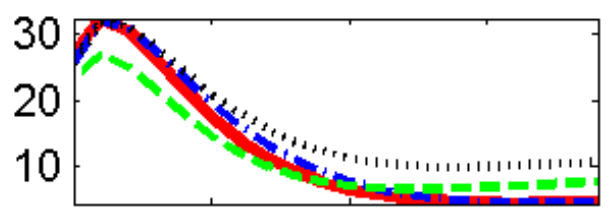

Investment (\% dev.)

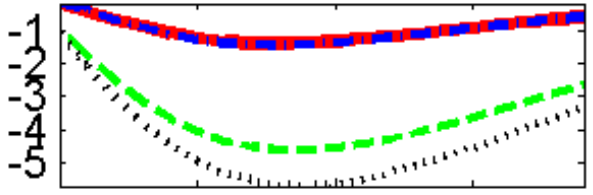

Hours / Employee (\% dev.)

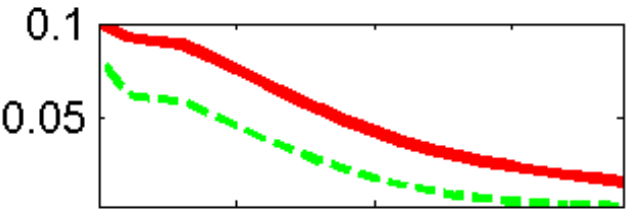

Real Shadow wage (\% dev.)

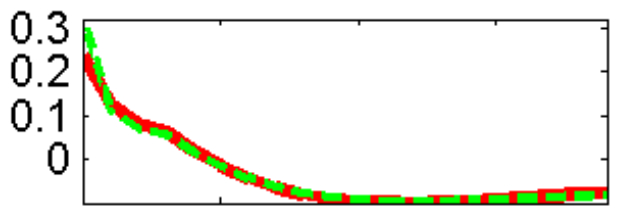

Risk Spread (ABP)

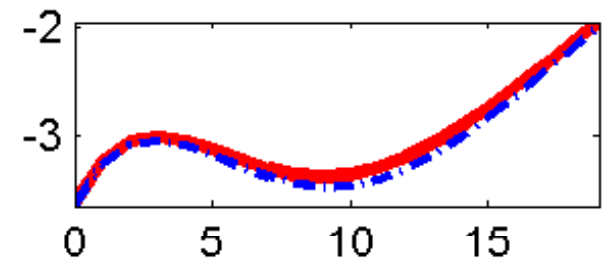

Output (\% dev.)

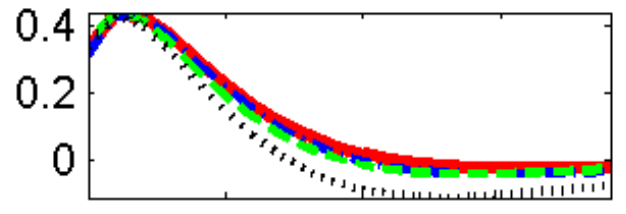

Exports (\% dev.)

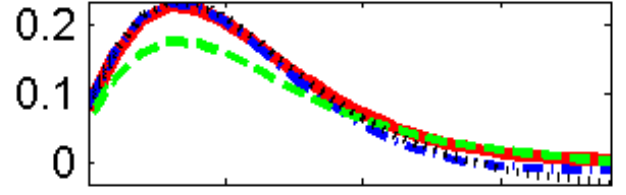

Unempl.Rate (Lev. dev.)

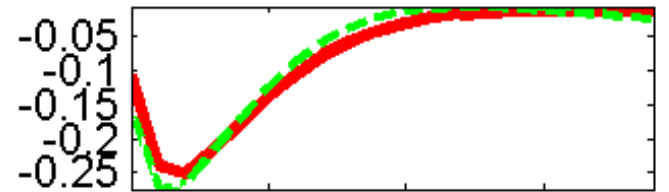

Real Exch.Rate (\% dev.)

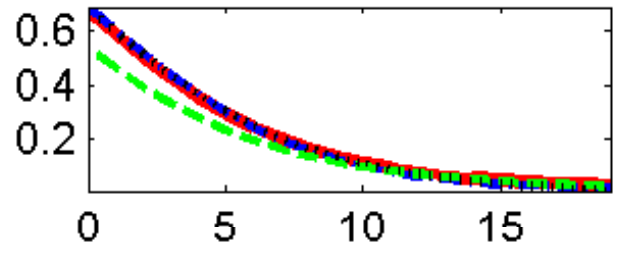

Full Model

- - - Financial Frictions Model

---=- Unemployment Model Baseline Model 


\section{Labor Preference Shock}

Nom.Interest Rate (ABP)

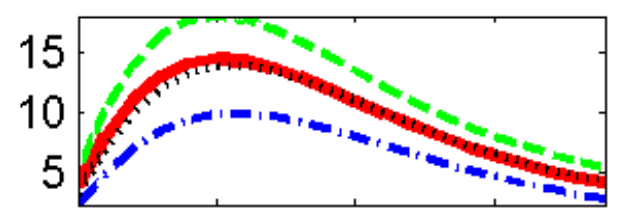

Consumption (\% dev.)

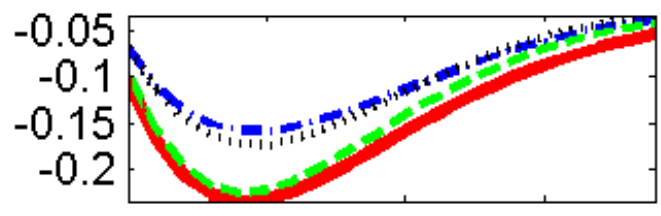

Total Hours (\% dev.)

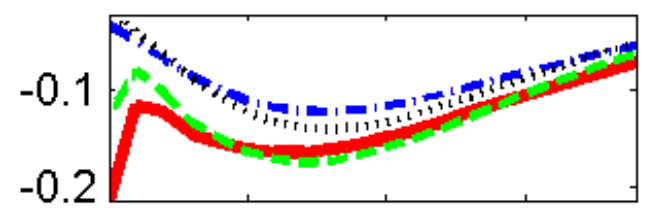

Real (Nash) wage (\% dev.)

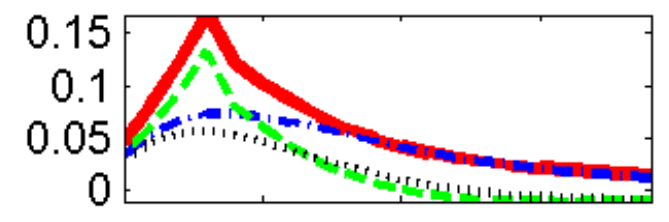

Net Worth (\% dev.)

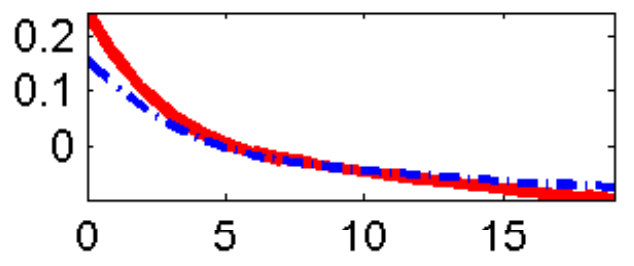

CPI Inflation (ABP)

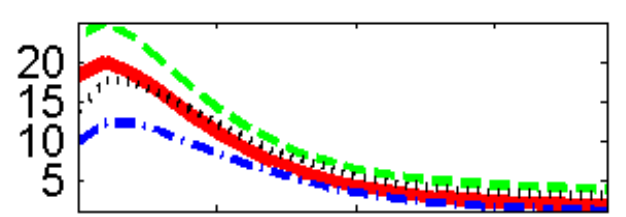

Investment (\% dev.)

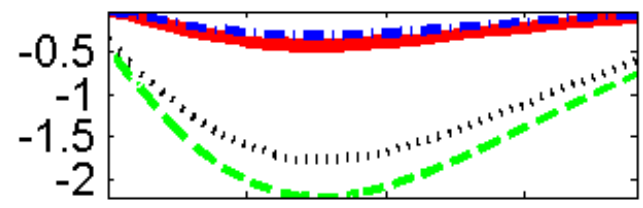

Hours / Employee (\% dev.)

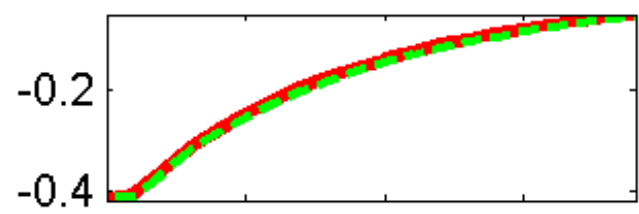

Real Shadow wage (\% dev.)
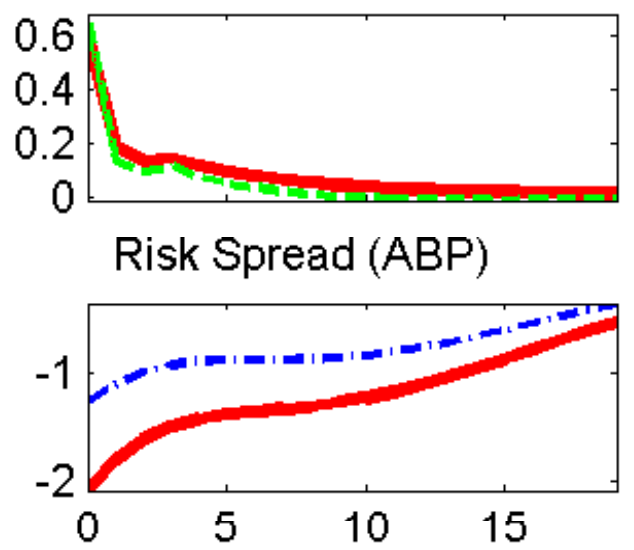

Output (\% dev.)

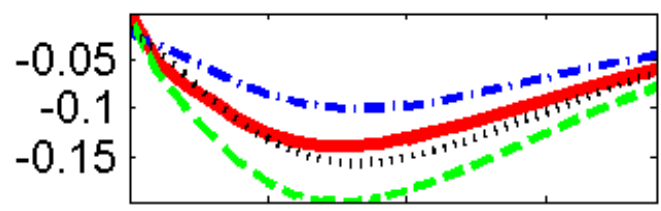

Exports (\% dev.)

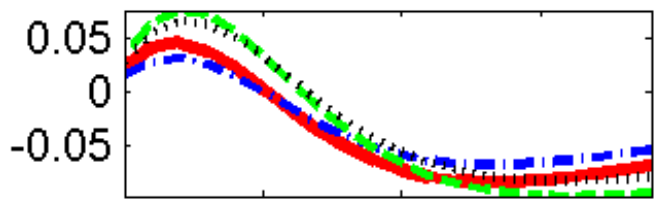

Unempl.Rate (Lev. dev.)

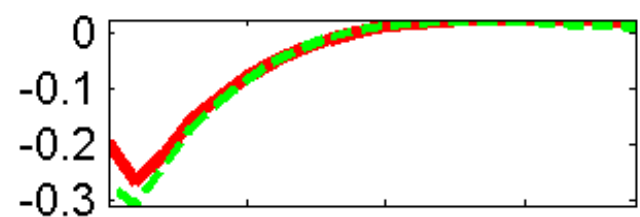

Real Exch.Rate (\% dev.)

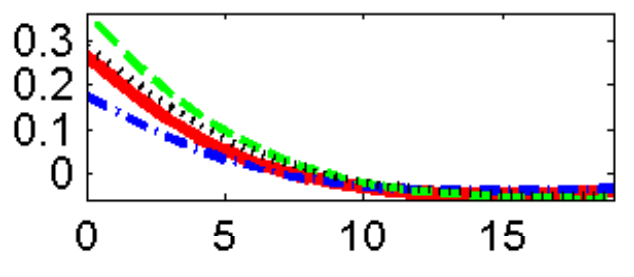

Full Model

---- Financial Frictions Mode

-- - - - Unemployment Model Baseline Model 


\section{Government Consumption Shock}

Nom.Interest Rate (ABP)

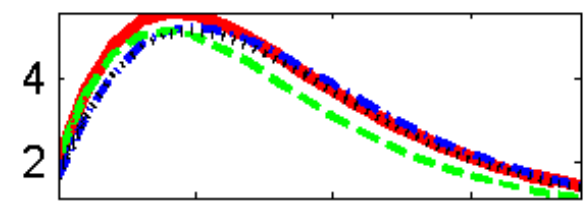

Consumption (\% dev.)

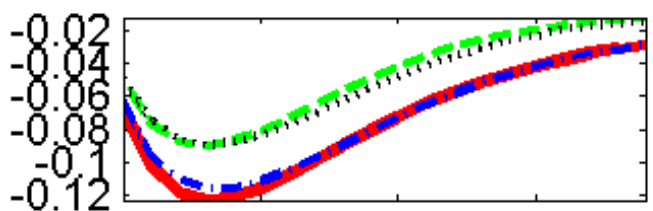

Total Hours (\% dev.)

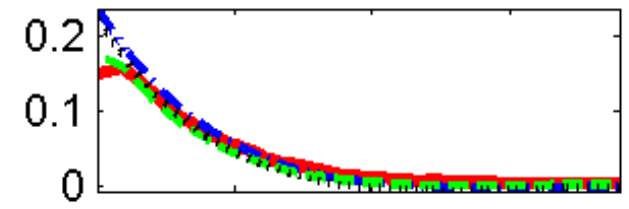

Real (Nash) wage (\% dev.)

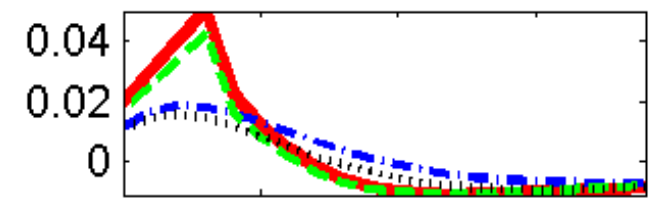

Net Worth (\% dev.)

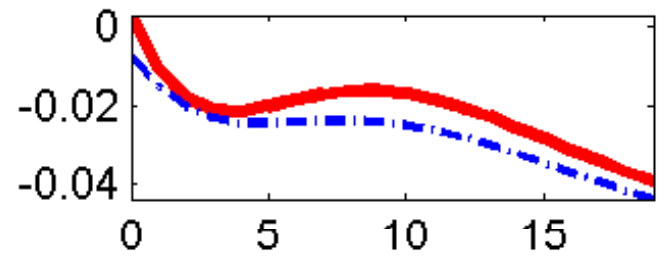

CPI Inflation (ABP)

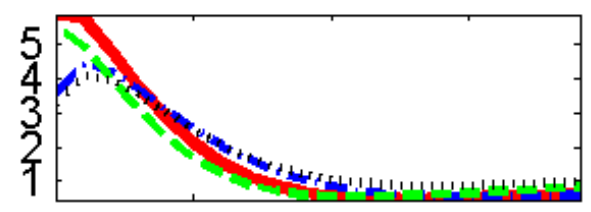

Investment (\% dev.)

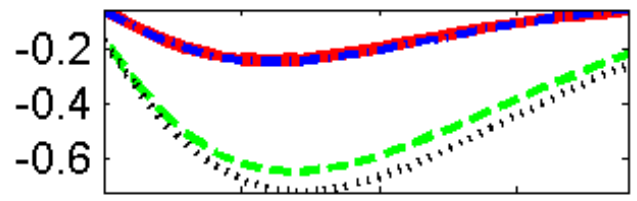

Hours / Employee (\% dev.)

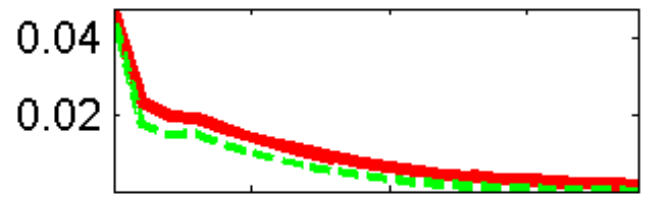

Real Shadow wage (\% dev.)

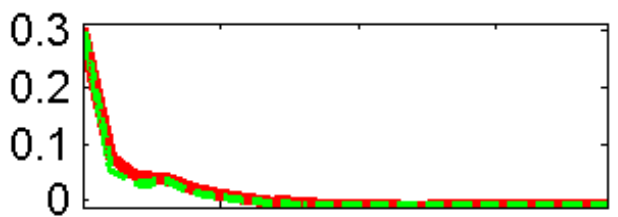

Risk Spread (ABP)

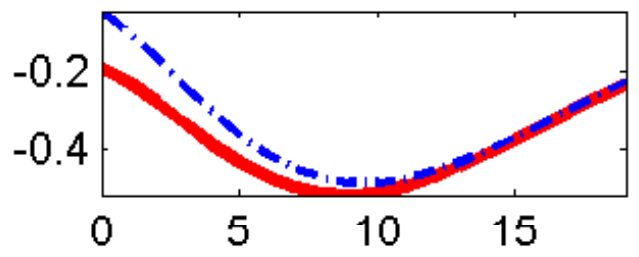

Output (\% dev.)

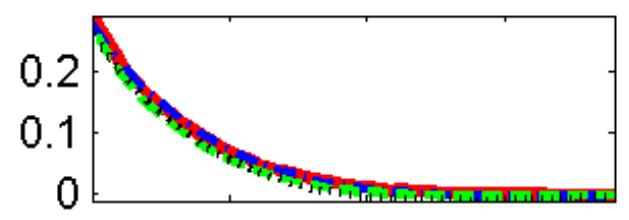

Exports (\% dev.)

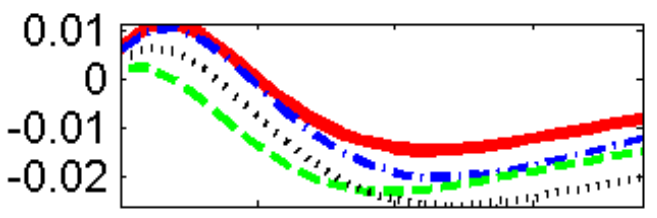

Unempl.Rate (Lev. dev.)

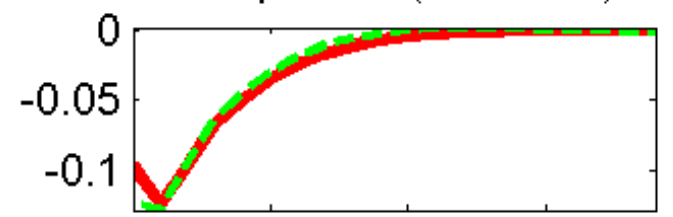

Real Exch.Rate (\% dev.)

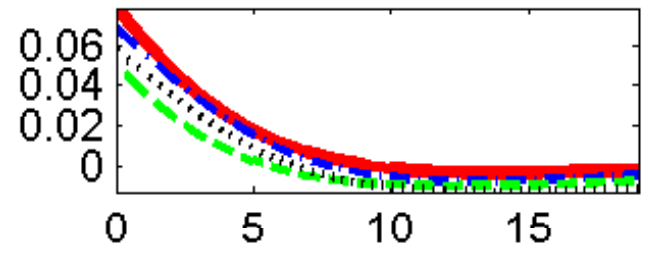

Full Model

--2-- Financial Frictions Model

--n-= Unemployment Model Baseline Model 


\section{Entrepreneur Wealth Shock}

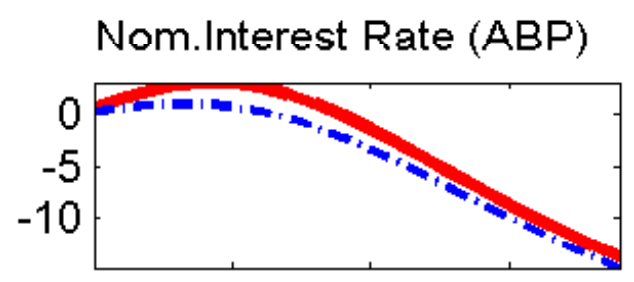

Consumption ( $\% \mathrm{dev}$.)

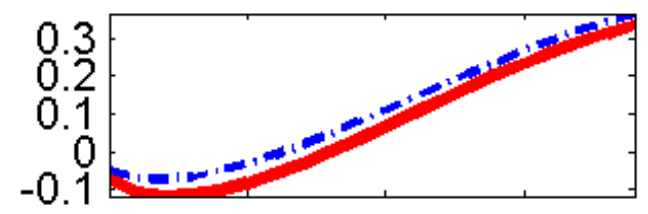

Total Hours (\% dev.)

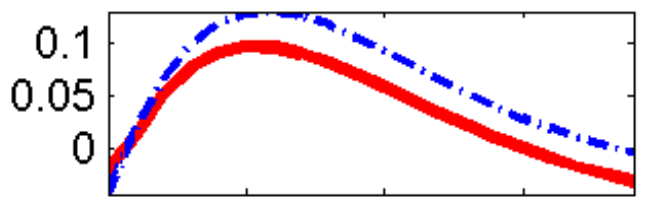

Real (Nash) wage (\% dev.)

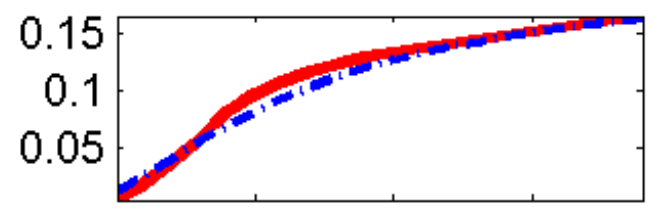

Net Worth (\% dev.)

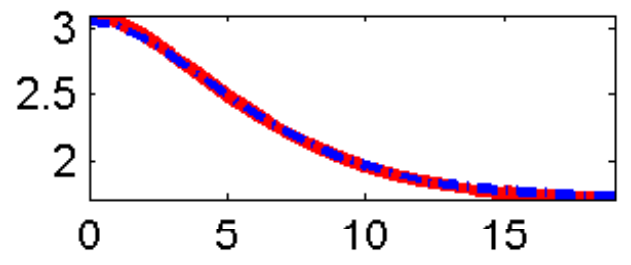

CPI Inflation (ABP)

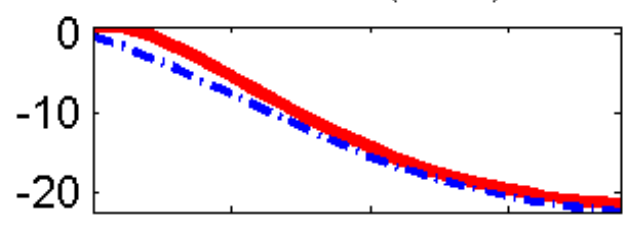

Investment (\% dev.)

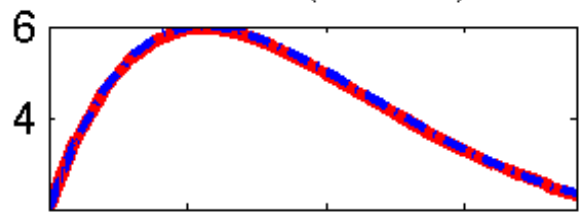

Hours / Employee (\% dev.)

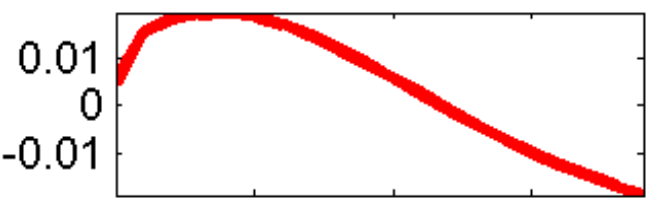

Real Shadow wage (\% dev.)

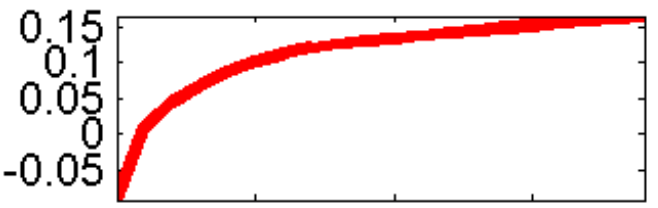

Risk Spread (ABP)

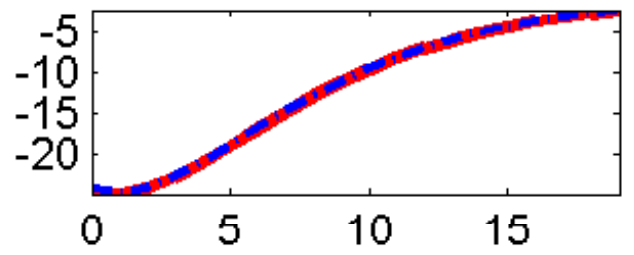

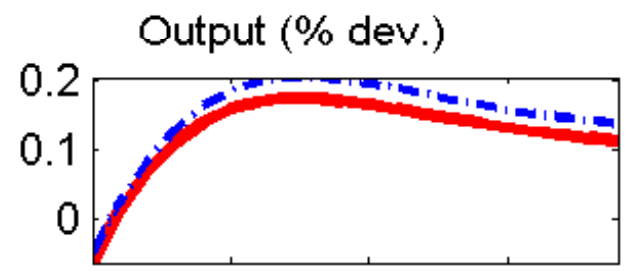

Exports (\% dev.)

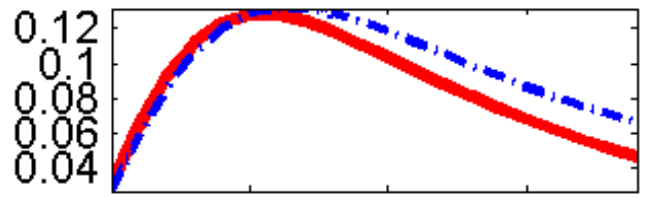

Unempl.Rate (Lev. dev.)

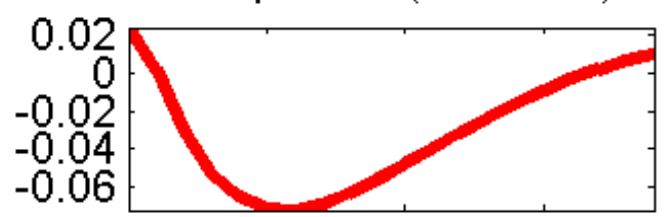

Real Exch.Rate (\% dev.)

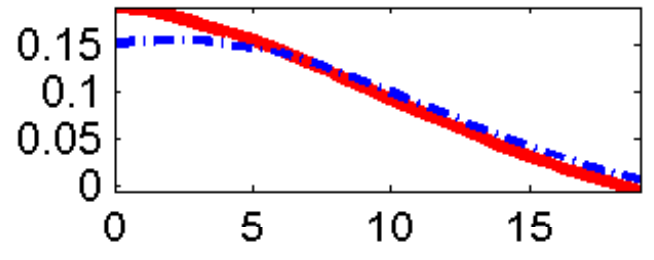

Full Model

- - - - Financial Frictions Model

----- Unemployment Model Baseline Model 


\section{Domestic Markup Shock}

Nom.Interest Rate (ABP)

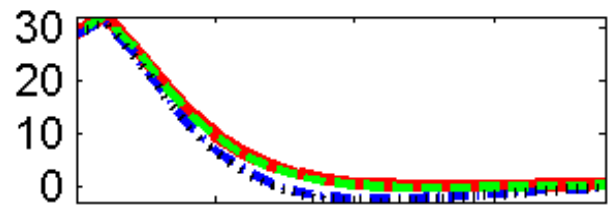

Consumption ( $\%$ dev.)

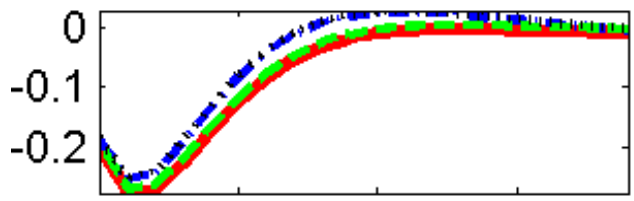

Total Hours (\% dev.)

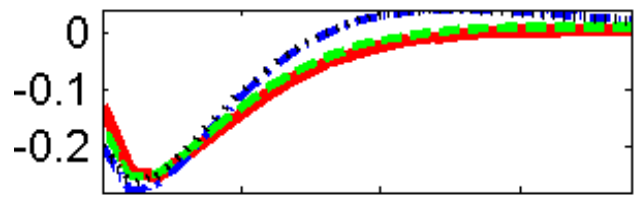

Real (Nash) wage (\% dev.)

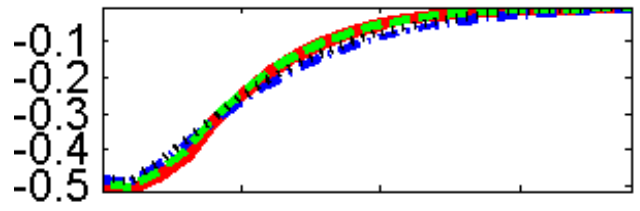

Net Worth (\% dev.)

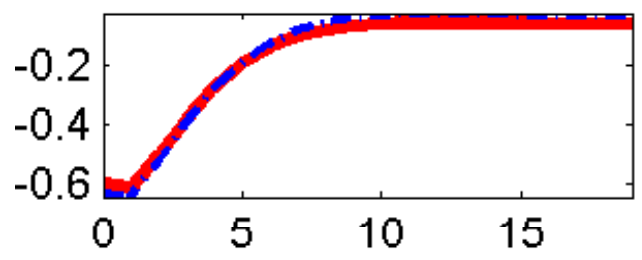

CPI Inflation (ABP)
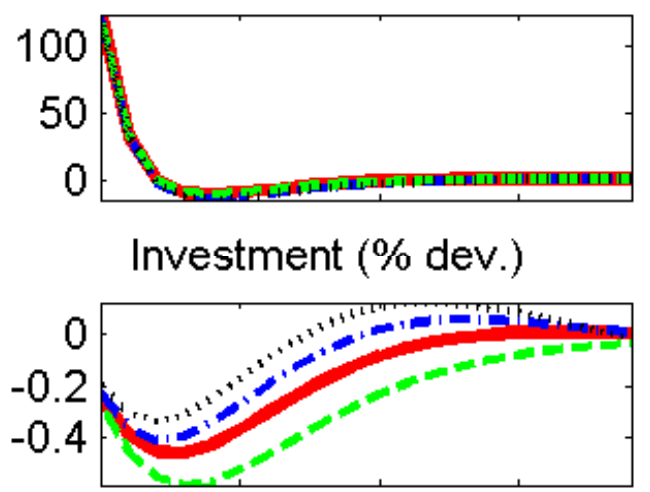

Hours / Employee (\% dev.)

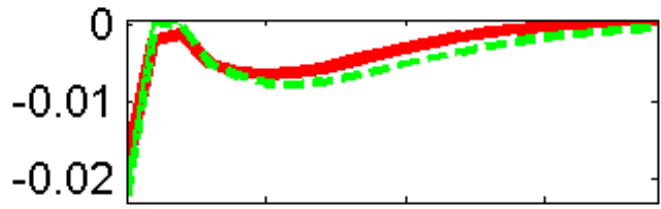

Real Shadow wage (\% dev.)

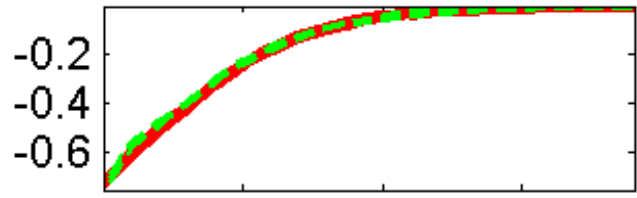

Risk Spread (ABP)

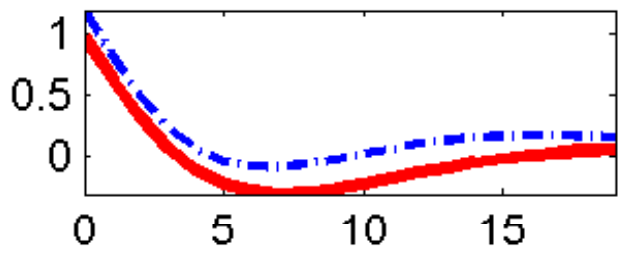

Output (\% dev.)

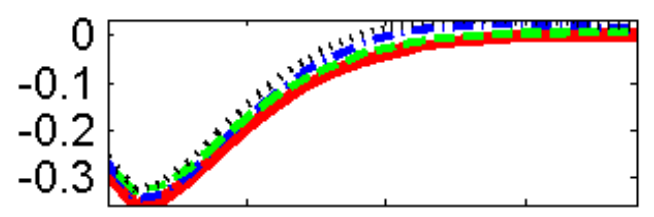

Exports (\% dev.)

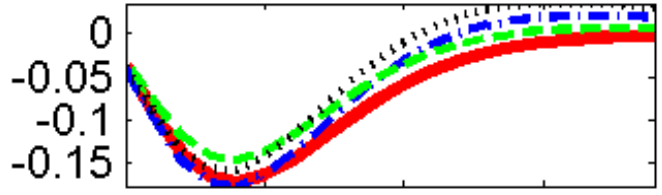

Unempl.Rate (Lev. dev.)

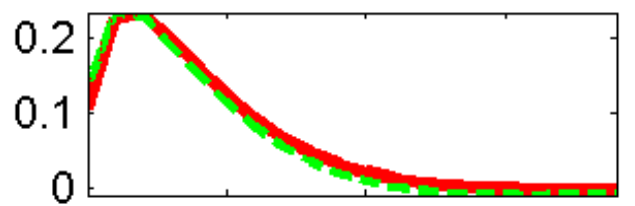

Real Exch.Rate (\% dev.)

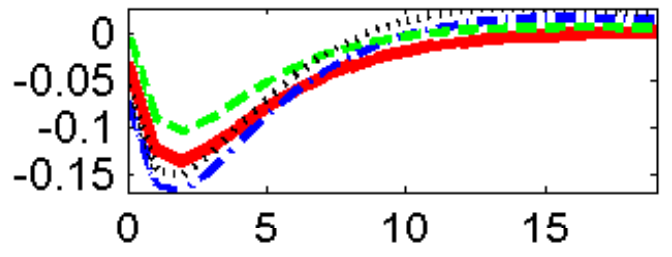

Full Model

- - - Financial Frictions Model

--n-- Unemployment Model Baseline Model 


\section{Import Consumption Markup Shock}
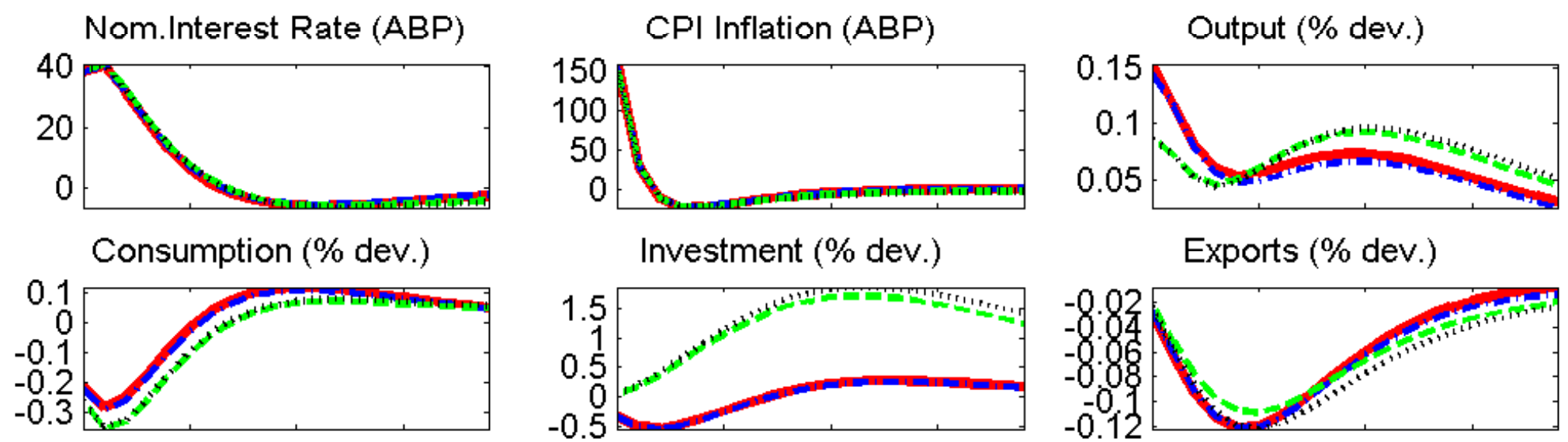

Total Hours (\% dev.)

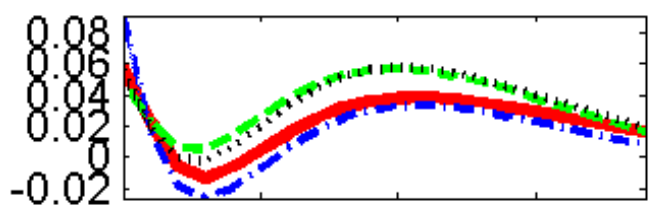

Hours / Employee (\% dev.)

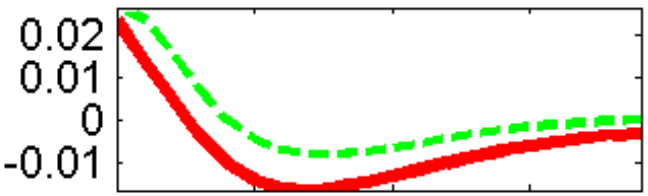

Real (Nash) wage (\% dev.)

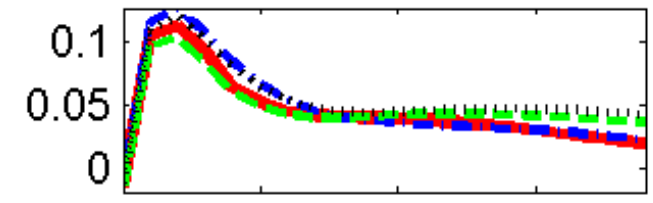

Net Worth (\% dev.)

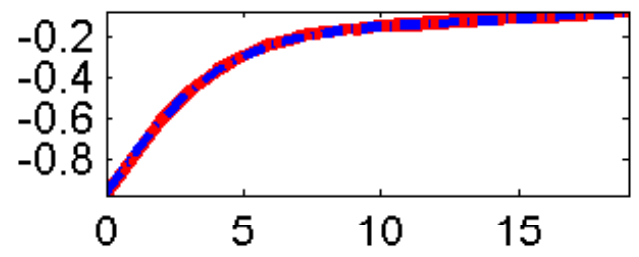

Real Shadow wage (\% dev.)

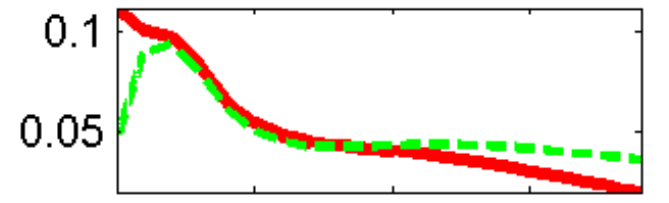

Risk Spread (ABP)

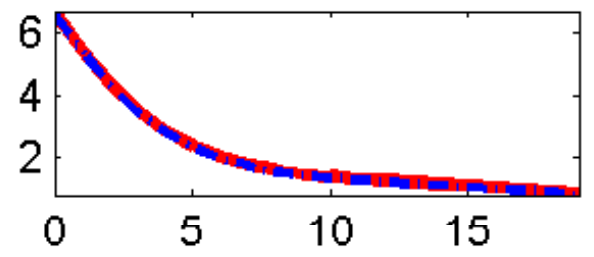

Unempl.Rate (Lev. dev.)

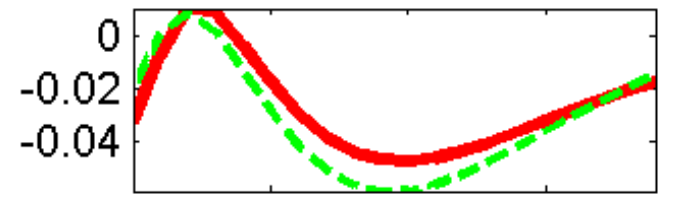

Real Exch.Rate (\% dev.)

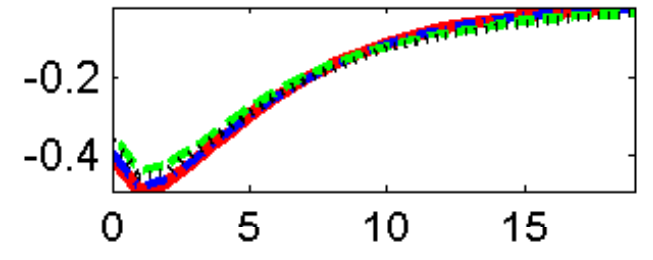

Full Model

---- Financial Frictions Model

--n- = Unemployment Model Baseline Model 


\section{Import Investment Markup Shock}

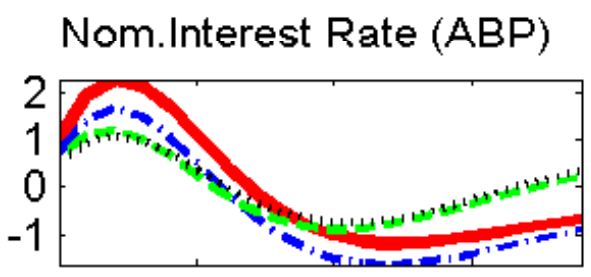

Consumption (\% dev.)

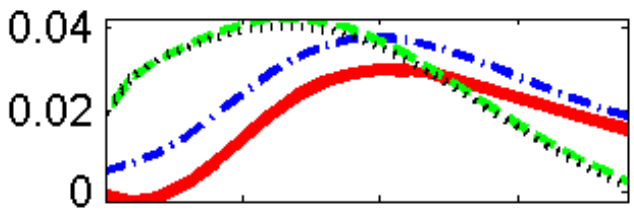

Total Hours ( $\%$ dev.)

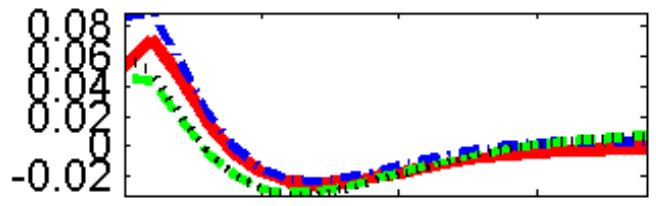

Real (Nash) wage (\% dev.)

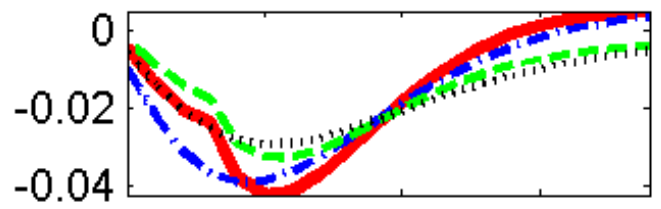

Net Worth (\% dev.)

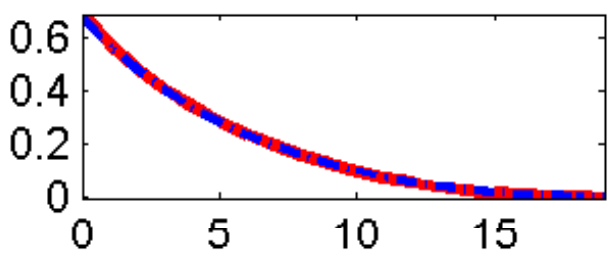

CPI Inflation (ABP)

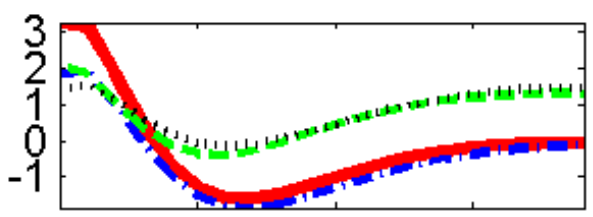

Investment (\% dev.)

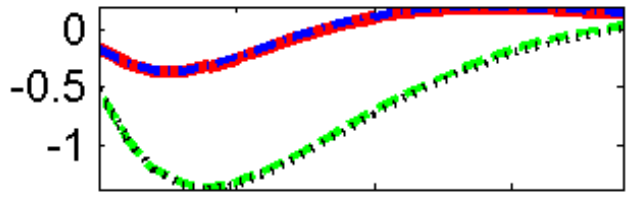

Hegrs / Employee (\% dev.)

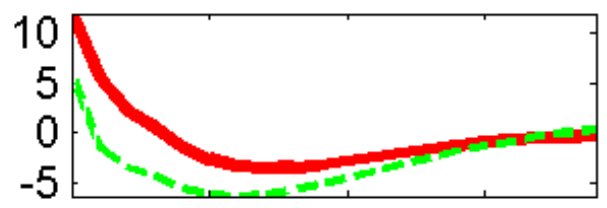

Real Shadow wage (\% dev.)

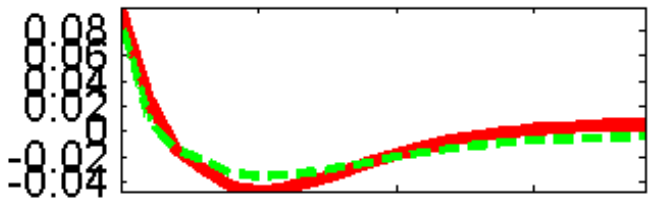

Risk Spread (ABP)

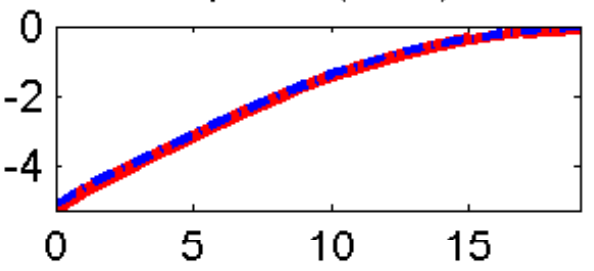

Output (\% dev.)

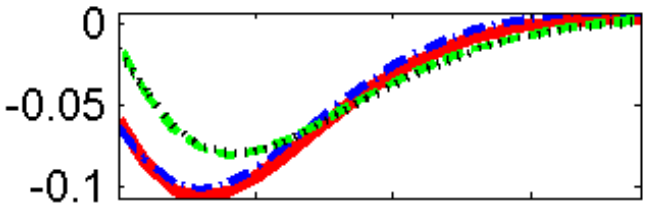

Exports (\% dev.)

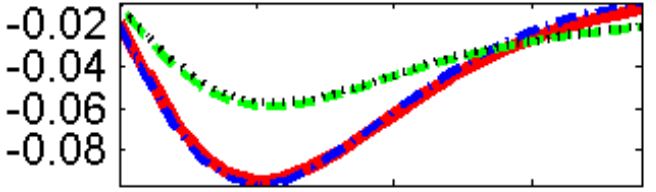

Unempl.Rate (Lev. dev.)

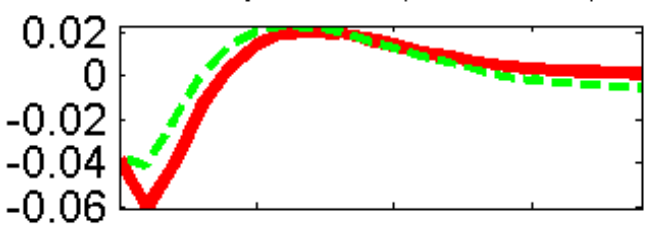

Real Exch.Rate (\% dev.)

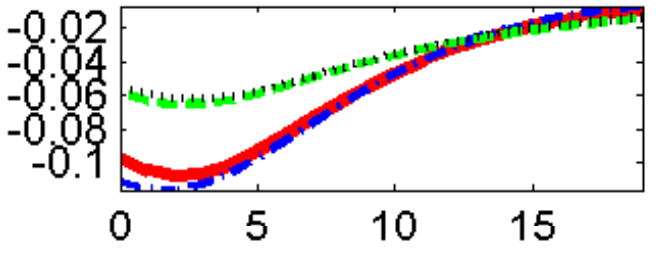

Full Model

- - - Financial Frictions Model

---=- Unemployment Model Baseline Model 


\section{Import Export Markup Shock}

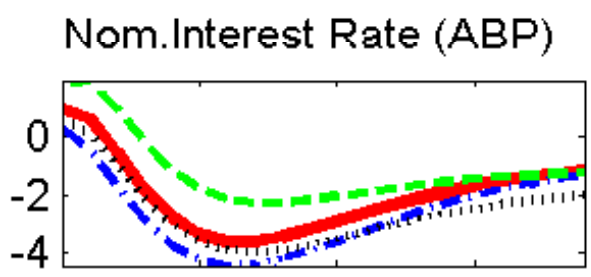

Consumption (\% dev.)

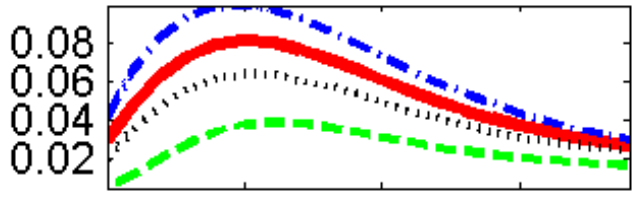

Total Hours ( $\%$ dev.)

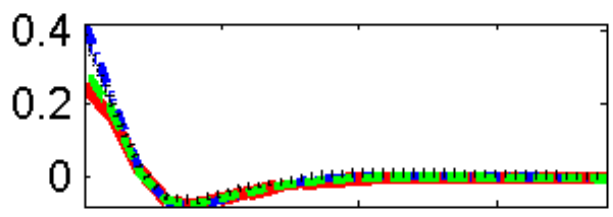

Real (Nash) wage (\% dev.)

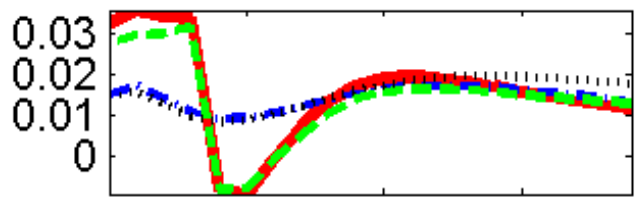

Net Worth (\% dev.)

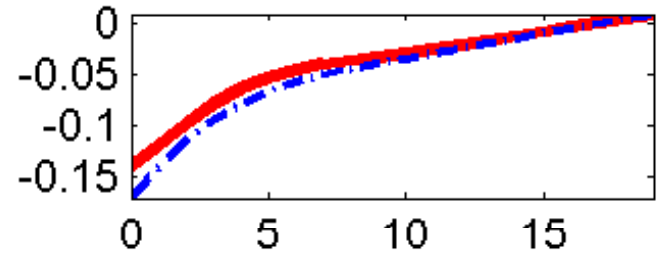

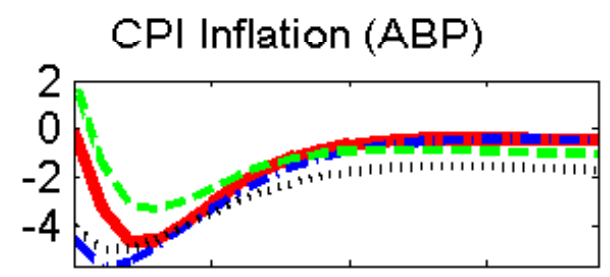

Investment (\% dev.)

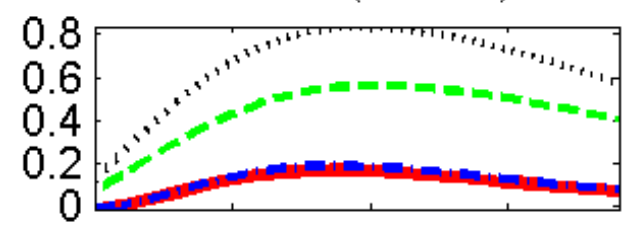

Hours / Employee (\% dev.)

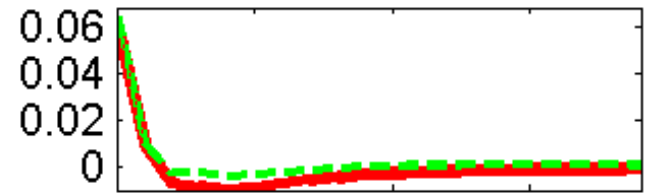

Real Shadow wage (\% dev.)

0.6
0.4
0.2
0

Risk Spread (ABP)

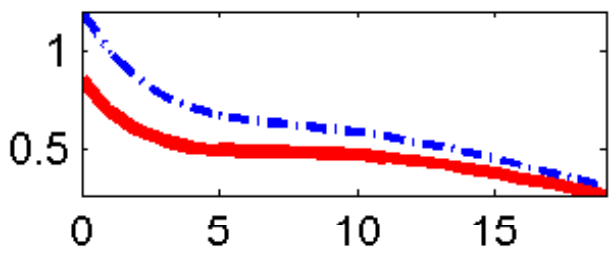

Output (\% dev.)

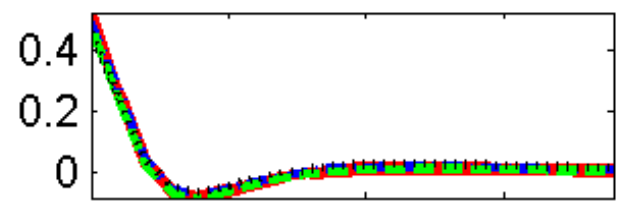

Exports (\% dev.)

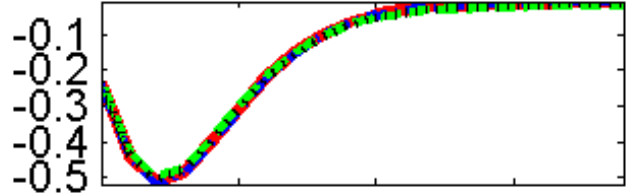

Unempl.Rate (Lev. dev.)

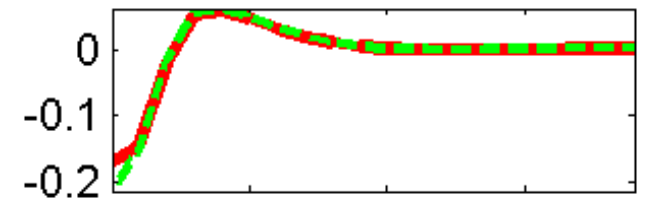

Real Exch.Rate (\% dev.)

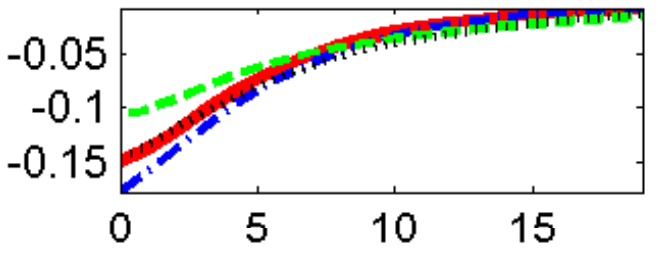

Full Model

- - - Financial Frictions Model

---=- Unemployment Model Baseline Model 


\section{Export Markup Shock}
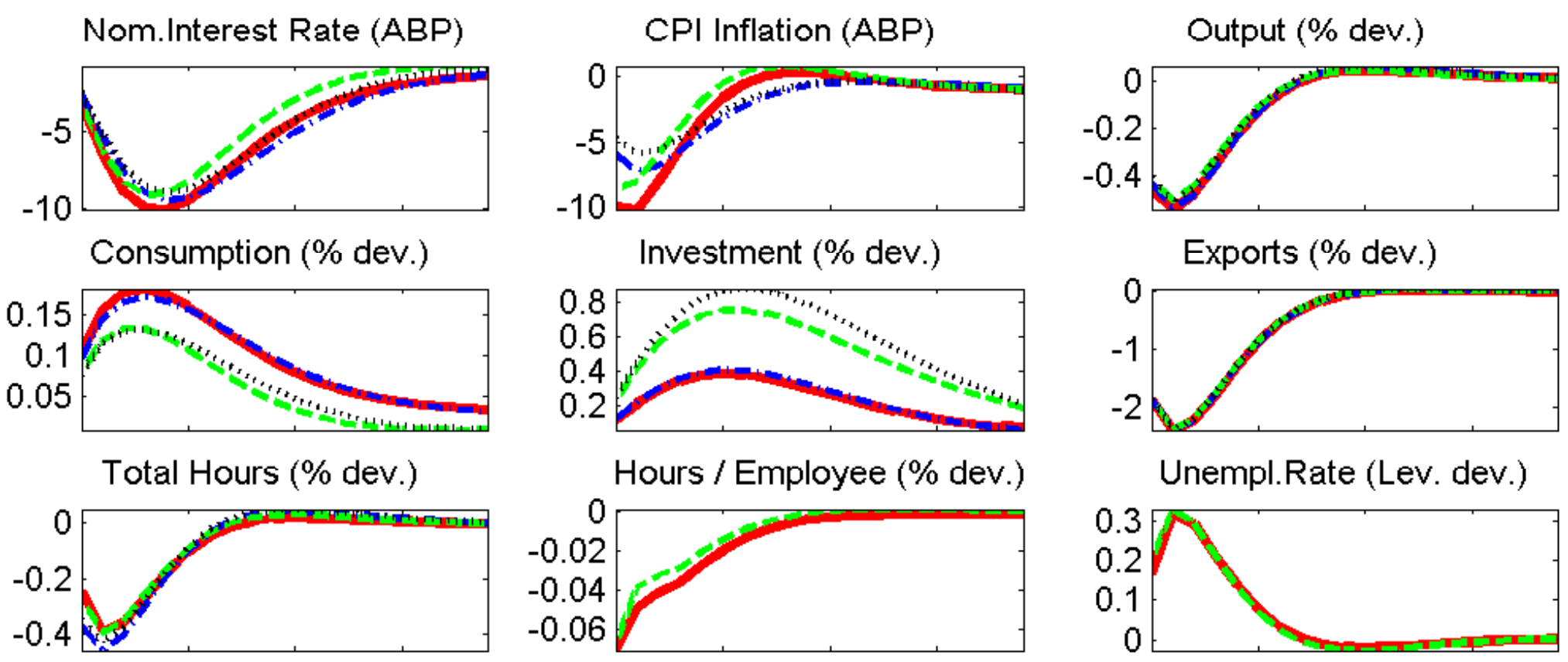

Hours / Employee (\% dev.)

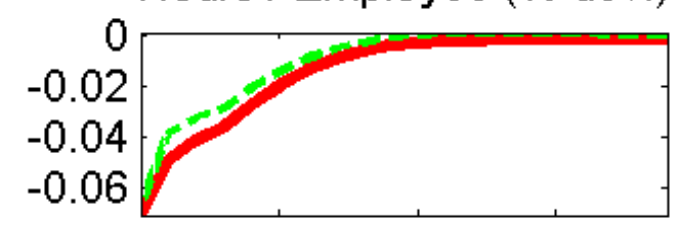

Real (Nash) wage (\% dev.)

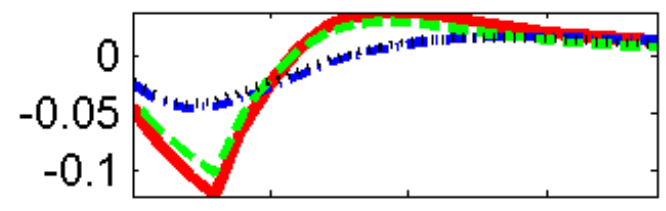

Real Shadow wage (\% dev.)

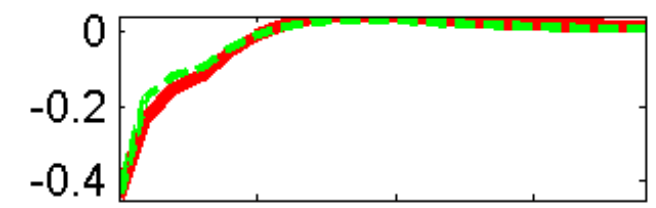

Net Worth (\% dev.)

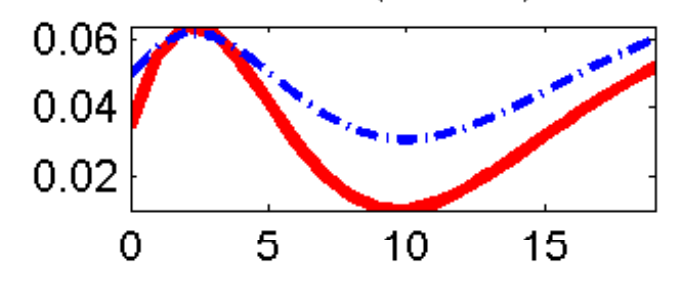

\section{Risk Spread (ABP)}

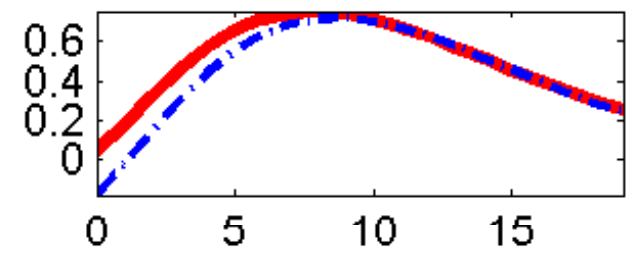

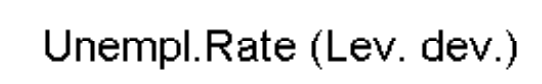

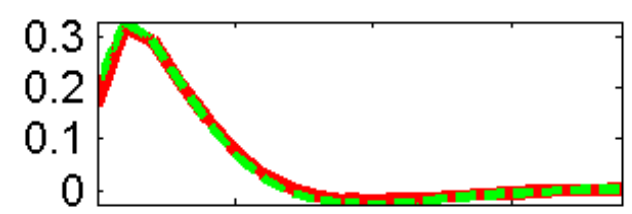

Real Exch.Rate (\% dev.)

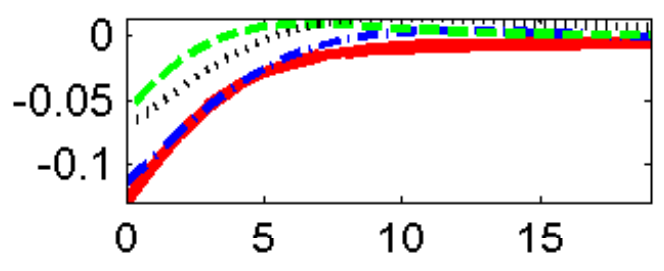

Full Model

- - - Financial Frictions Model

--n-" Unemployment Model Baseline Model 


\section{UIP Risk Premium Shock}

Nom.Interest Rate (ABP)

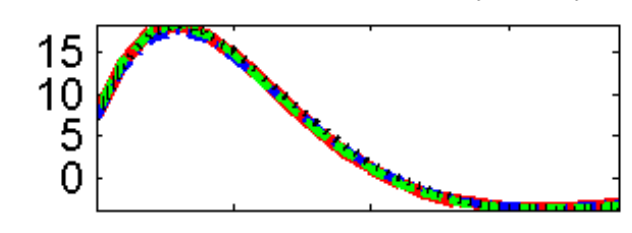

Consumption (\% dev.)

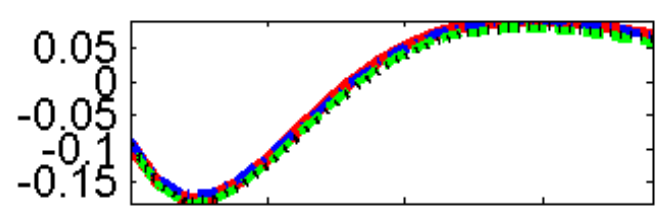

Total Hours (\% dev.)

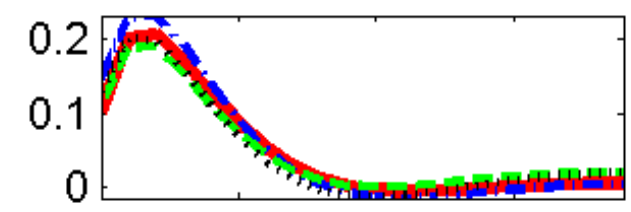

Real (Nash) wage (\% dev.)

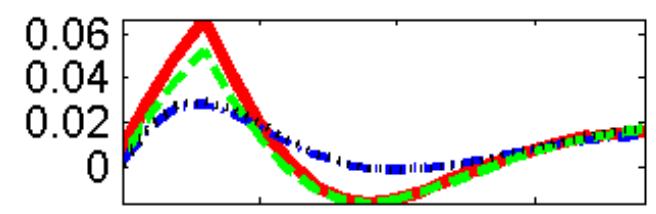

Net Worth (\% dev.)

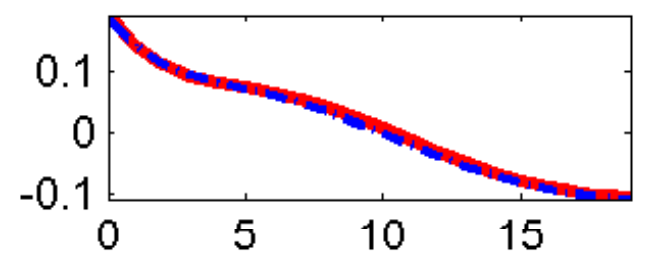

CPI Inflation (ABP)

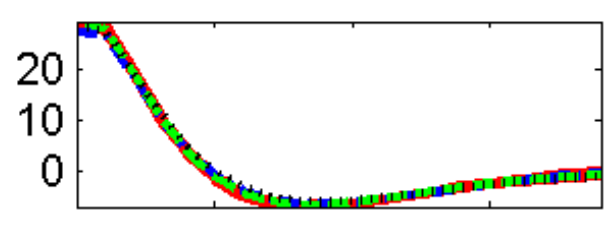

Investment (\% dev.)

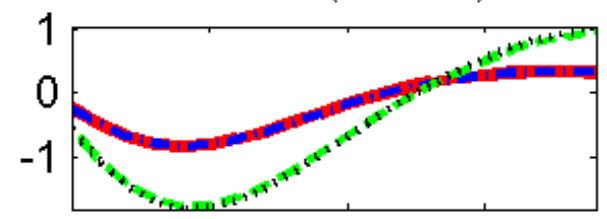

ل्रlagr's / Employee (\% dev.)

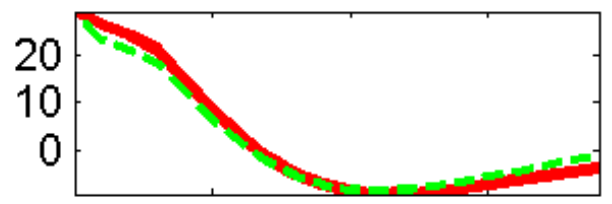

Real Shadow wage (\% dev.)

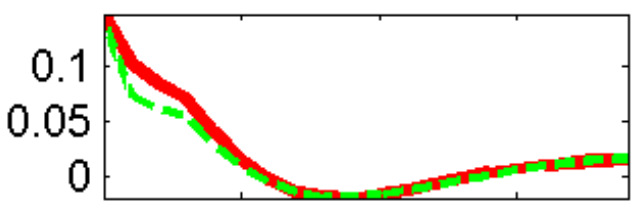

Risk Spread (ABP)

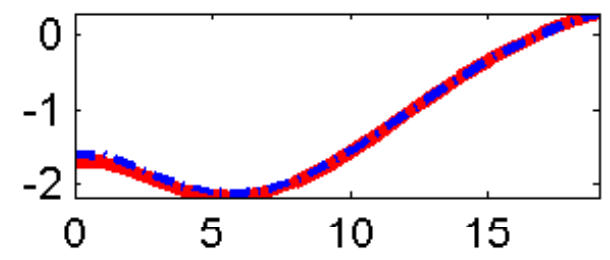

Output (\% dev.)

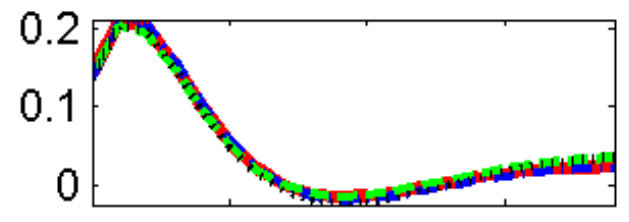

Exports (\% dev.)

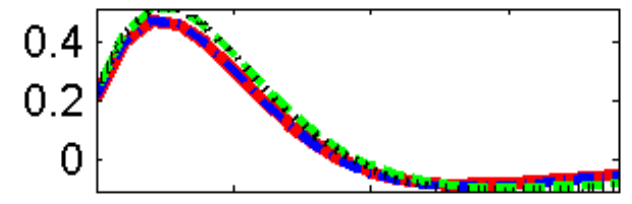

Unempl.Rate (Lev. dev.)

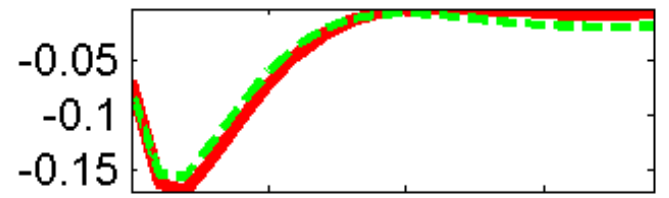

Real Exch.Rate (\% dev.)

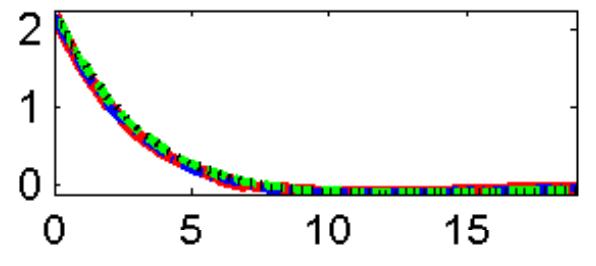

Full Model

--2-- Financial Frictions Model

--n-= Unemployment Model Baseline Model 


\section{Unit-root Neutral Technology Shock}

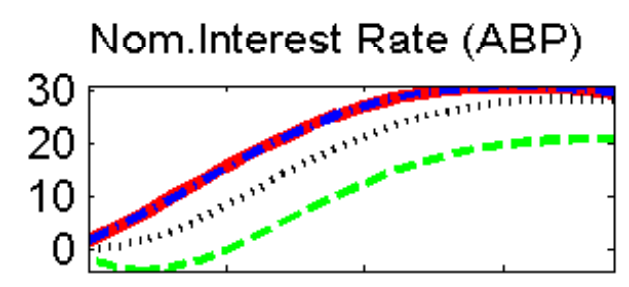

Consumption (\% dev.)

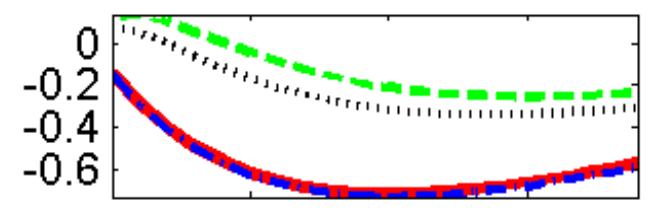

Total Hours (\% dev.)

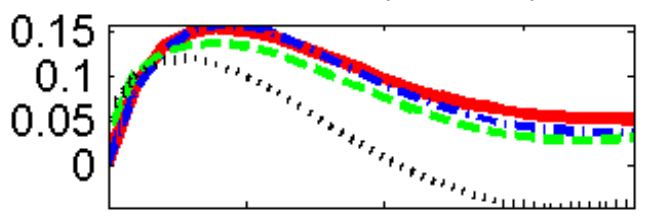

Real (Nash) wage (\% dev.)

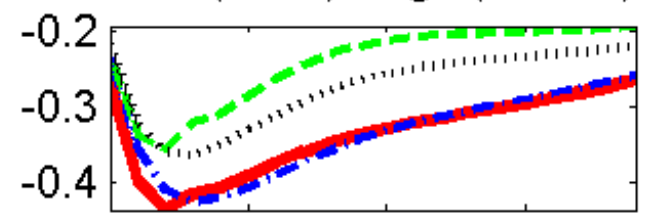

Net Worth (\% dev.)

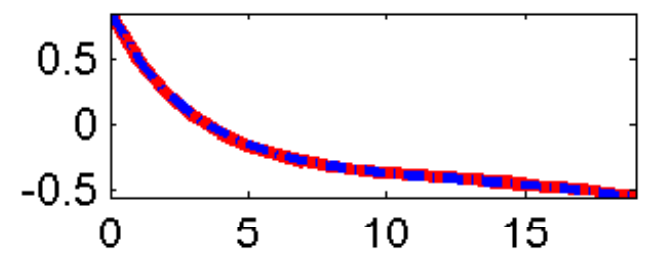

CPI Inflation (ABP)

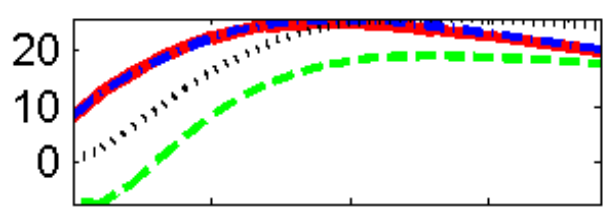

Investment (\% dev.)

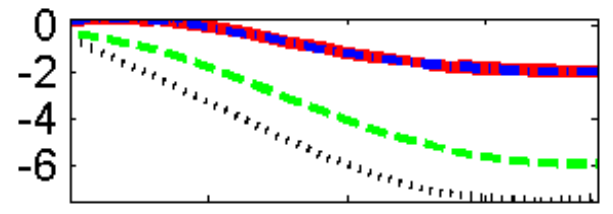

Hours / Employee (\% dev.)

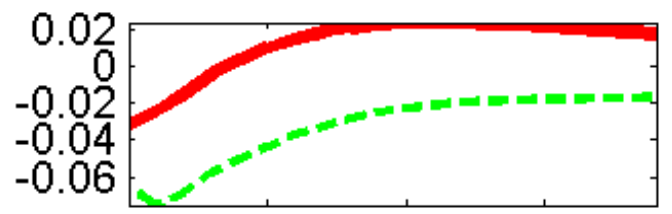

Real Shadow wage (\% dev.)

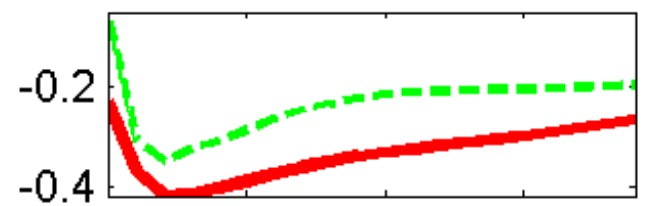

Risk Spread (ABP)

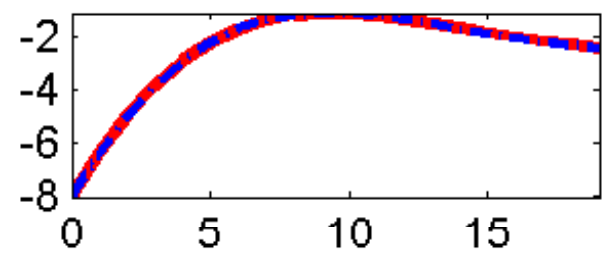

Output (\% dev.)

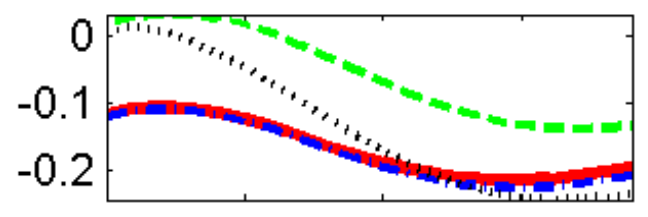

Exports (\% dev.)
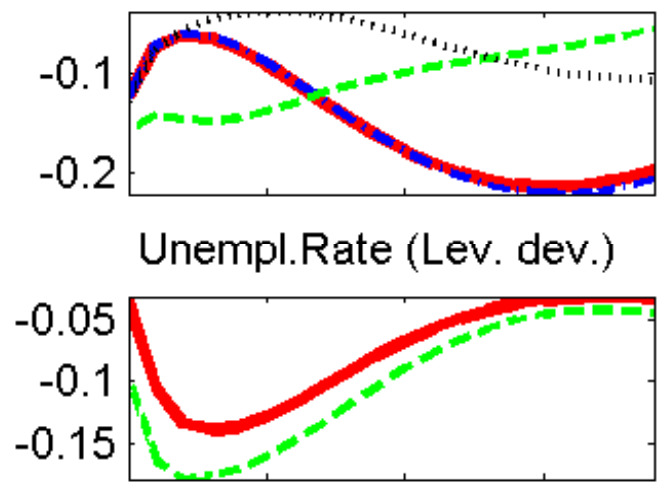

Real Exch.Rate (\% dev.)

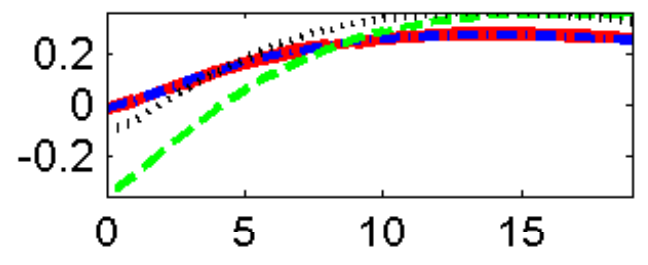

Full Model

- - - - Financial Frictions Model

----= Unemployment Model Baseline Model 


\section{Foreign Output Shock}

Nom. Interest Rate (ABP)

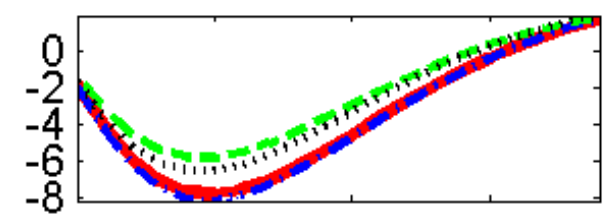

Consumption (\% dev.)

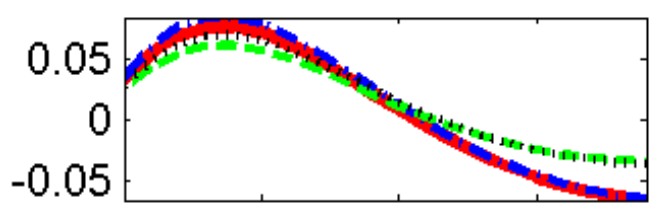

Total Hours (\% dev.)

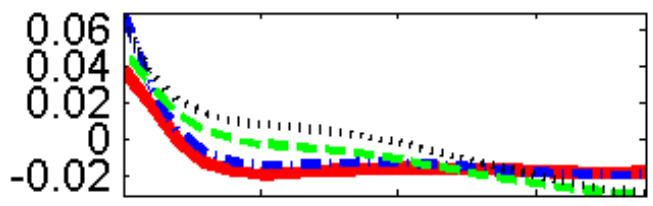

Real (Nash) wage (\% dev.)
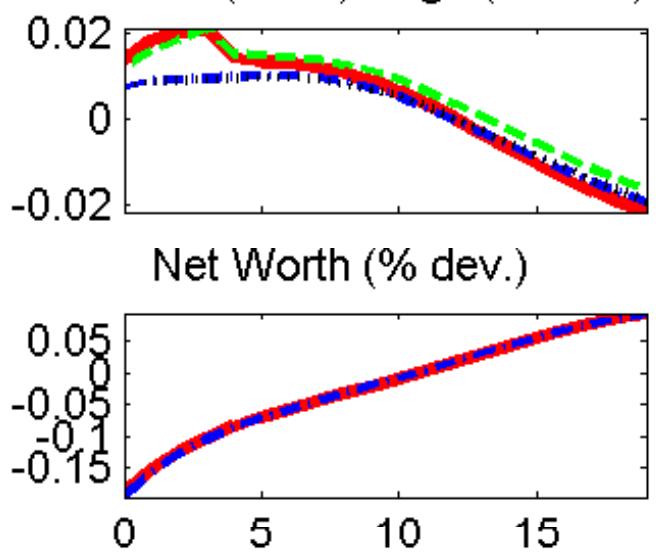

CPI Inflation (ABP)

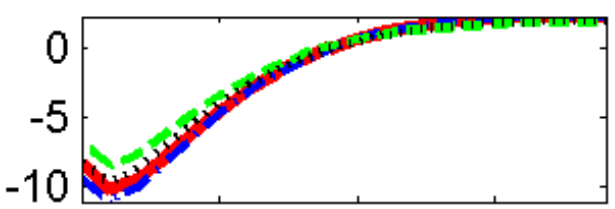

Investment (\% dev.)

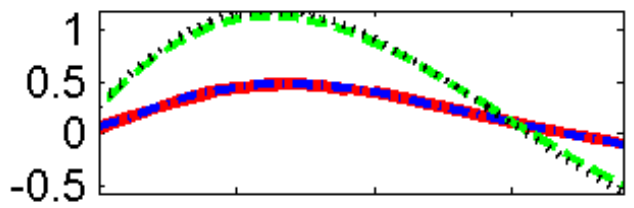

ل्रlagr's / Employee (\% dev.)

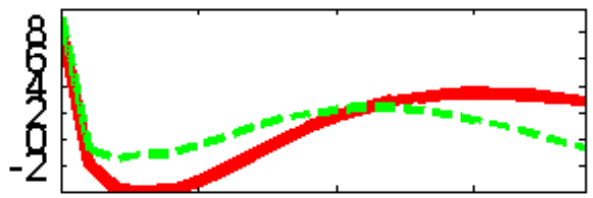

Real Shadow wage (\% dev.)

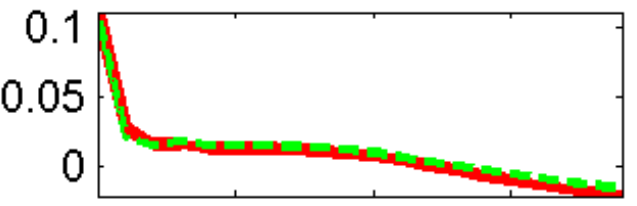

Risk Spread (ABP)

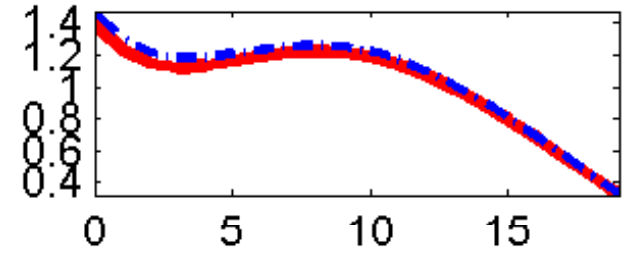

Output (\% dev.)

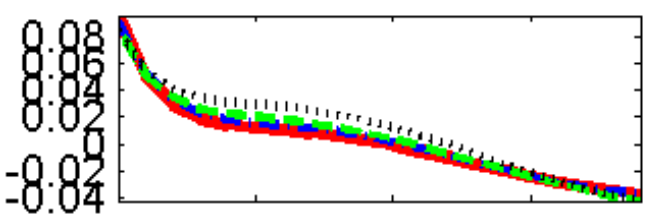

Exports (\% dev.)

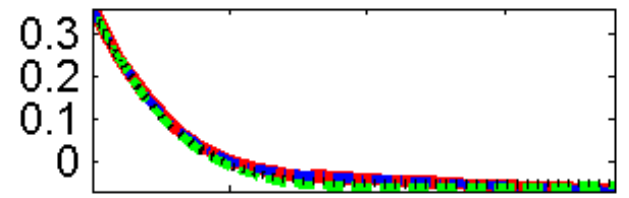

Unempl.Rate (Lev. dev.)

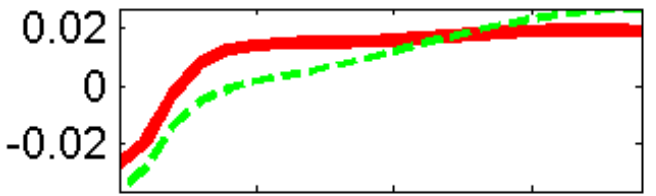

Real Exch.Rate (\% dev.)

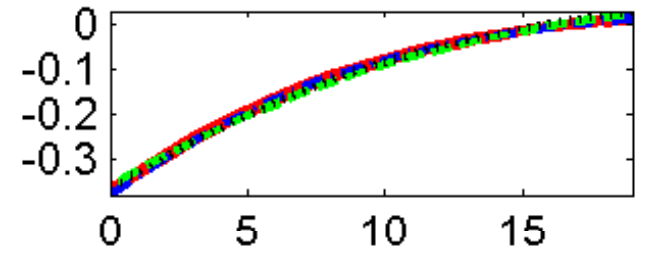

Full Model

-- Financial Frictions Model

--n-" Unemployment Model Baseline Model 


\section{Foreign Inflation Shock}

Nom.Interest Rate (ABP)

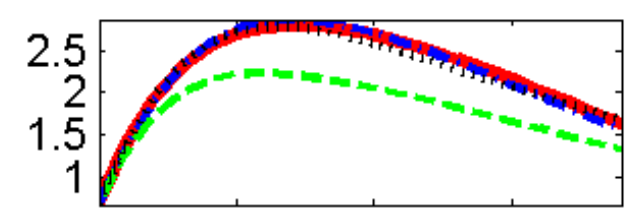

Consumption (\% dev.)

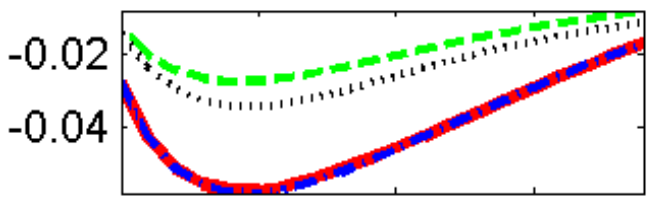

Total Hours (\% dev.)

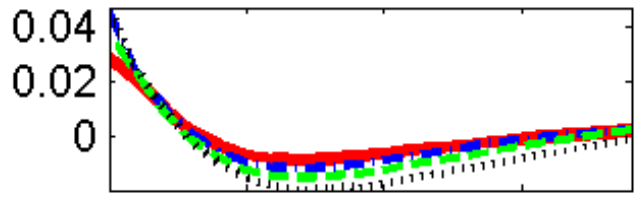

Reg (Nash) wage (\% dev.)

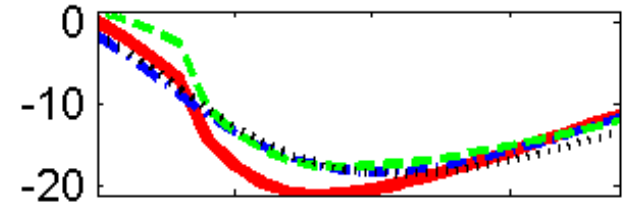

Net Worth (\% dev.)

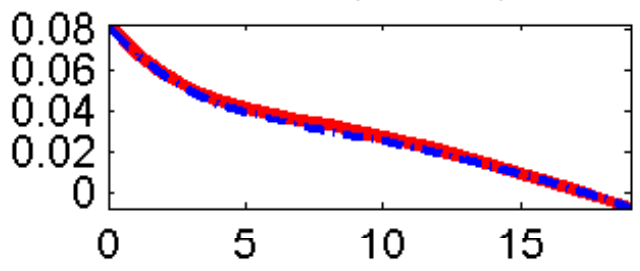

CPI Inflation (ABP)

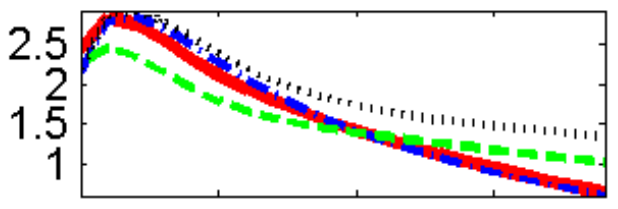

Investment (\% dev.)

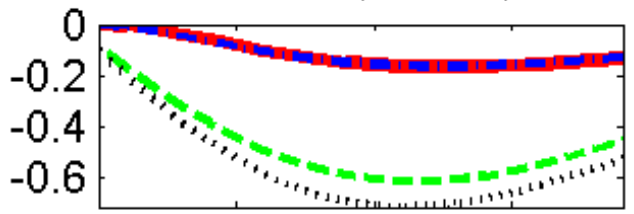

Hagrs / Employee (\% dev.)

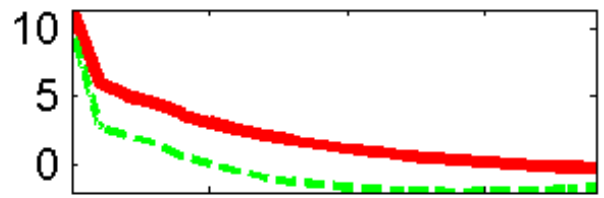

Real Shadow wage (\% dev.)
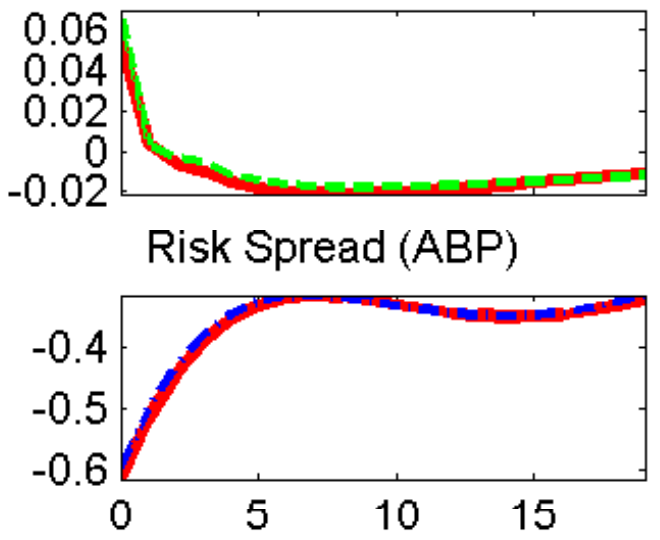

Output (\% dev.)

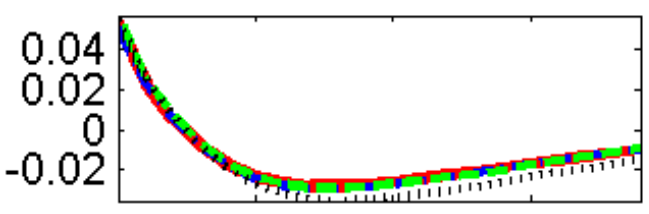

Exports (\% dev.)

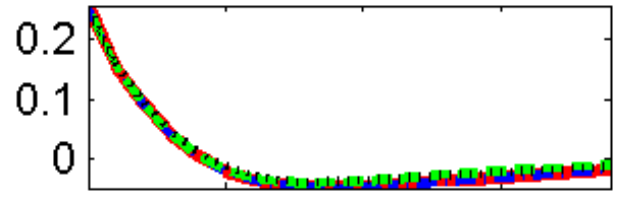

Unempl.Rate (Lev. dev.)

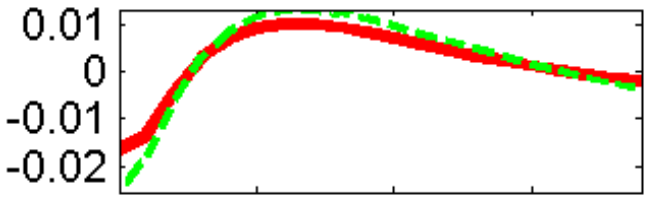

Real Exch.Rate (\% dev.)

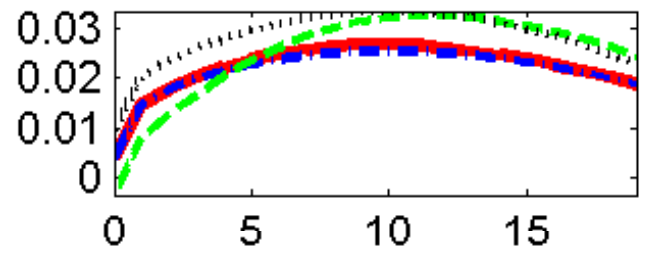

Full Model

- - - Financial Frictions Model

----- Unemployment Model Baseline Model 


\section{Foreign Nominal Interest Rate Shock}

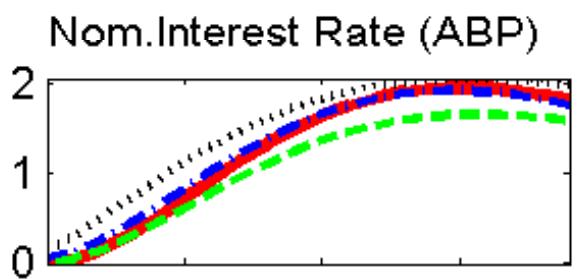

Consumption (\% dev.)

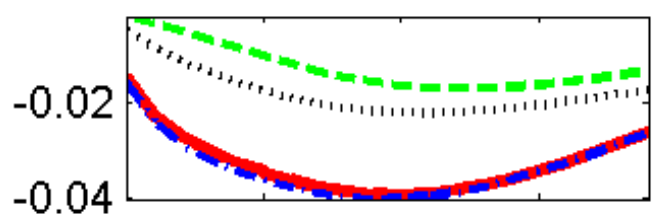

x Tigtâl Hours (\% dev.)

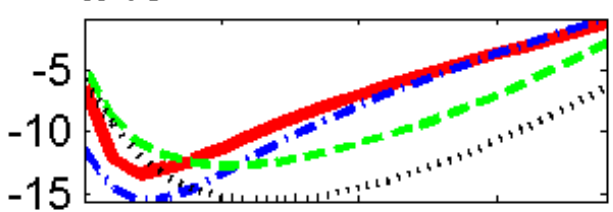

Reg (Nash) wage (\% dev.)

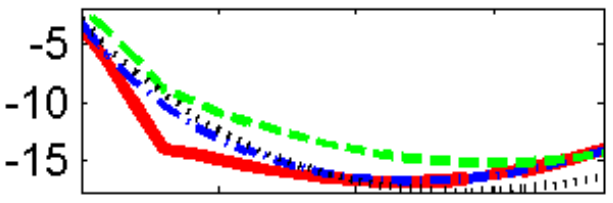

Net Worth (\% dev.)

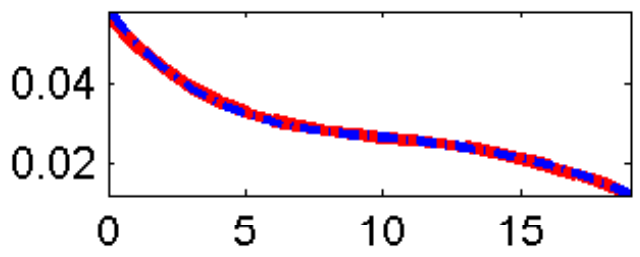

CPI Inflation (ABP)

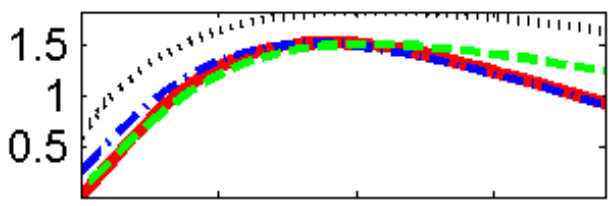

Investment (\% dev.)

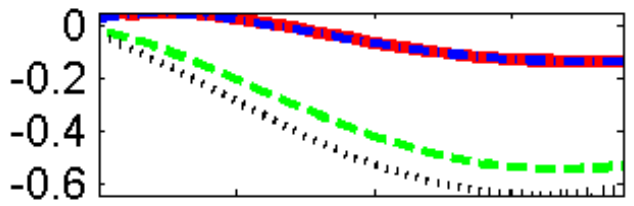

Hạrs / Employee (\% dev.)

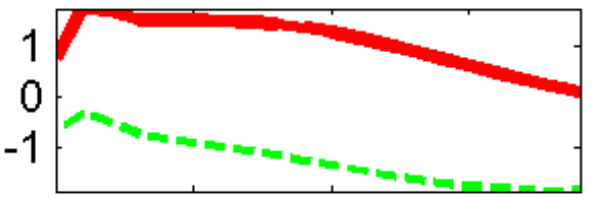

Real Shadow wage (\% dev.)

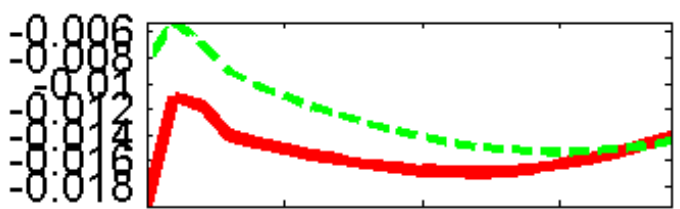

Risk Spread (ABP)

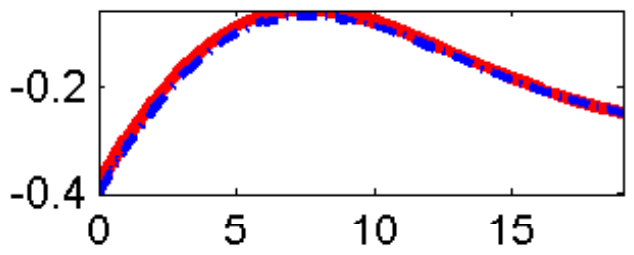

Output (\% dev.)

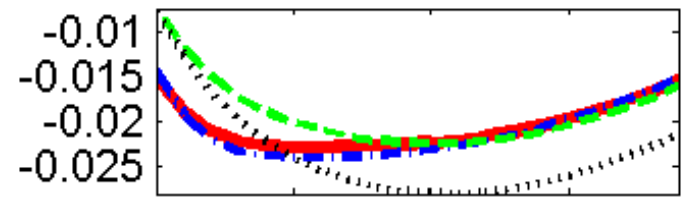

Exports (\% dev.)

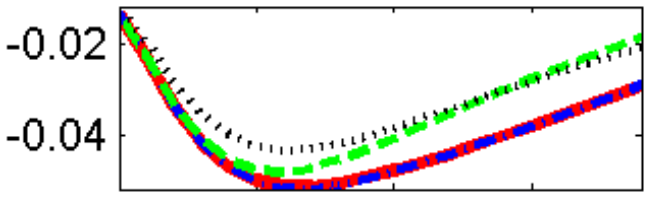

ג)ernpl.Rate (Lev. dev.)

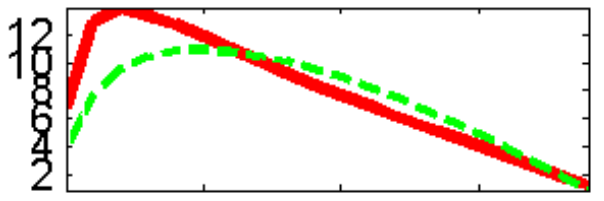

Real Exch.Rate (\% dev.)

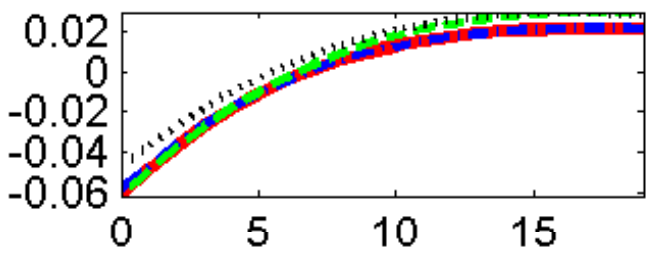

Full Model

- - - Financial Frictions Model

- - - - : Unemployment Model Baseline Model 


\section{B. Appendix}

\section{B.1. Scaling of Variables}

We adopt the following scaling of variables. The nominal exchange rate is denoted by $S_{t}$ and its growth rate is $s_{t}$ :

$$
s_{t}=\frac{S_{t}}{S_{t-1}}
$$

The neutral shock to technology is $z_{t}$ and its growth rate is $\mu_{z, t}$ :

$$
\frac{z_{t}}{z_{t-1}}=\mu_{z, t}
$$

The variable, $\Psi_{t}$, is an embodied shock to technology and it is convenient to define the following combination of embodied and neutral technology:

$$
\begin{aligned}
z_{t}^{+} & =\Psi_{t}^{\frac{\alpha}{1-\alpha}} z_{t}, \\
\mu_{z^{+}, t} & =\mu_{\Psi, t}^{\frac{\alpha}{1-\alpha}} \mu_{z, t} .
\end{aligned}
$$

Capital, $\bar{K}_{t}$, and investment, $I_{t}$, are scaled by $z_{t}^{+} \Psi_{t}$. Foreign and domestic inputs into the production of $I_{t}$ (we denote these by $I_{t}^{d}$ and $I_{t}^{m}$, respectively) are scaled by $z_{t}^{+}$. Consumption goods $\left(C_{t}^{m}\right.$ are imported intermediate consumption goods, $C_{t}^{d}$ are domestically produced intermediate consumption goods and $C_{t}$ are final consumption goods) are scaled by $z_{t}^{+}$. Government consumption, the real wage and real foreign assets are scaled by $z_{t}^{+}$. Exports ( $X_{t}^{m}$ are imported intermediate goods for use in producing exports and $X_{t}$ are final export goods) are scaled $z_{t}^{+}$. Also, $v_{t}$ is the shadow value in utility terms to the household of domestic currency and $v_{t} P_{t}$ is the shadow value of one consumption good (i.e., the marginal utility of consumption). The latter must be multiplied by $z_{t}^{+}$to induce stationarity. $\tilde{P}_{t}$ is the within-sector relative price of a good. $w_{t}$ denotes the ratio between the (Nash) wage paid to workers $\tilde{W}_{t}$ and the "rental rate of homogenous labor" $W_{t}$ in the labor market model. Finally, the expected discounted future surplus of a match to an employment agency, $D_{t}^{j}$ is scaled like most other nominal variables. Thus,

$$
\begin{aligned}
k_{t+1} & =\frac{K_{t+1}}{z_{t}^{+} \Psi_{t}}, \bar{k}_{t+1}=\frac{\bar{K}_{t+1}}{z_{t}^{+} \Psi_{t}}, i_{t}^{d}=\frac{I_{t}^{d}}{z_{t}^{+}}, i_{t}=\frac{I_{t}}{z_{t}^{+} \Psi_{t}}, i_{t}^{m}=\frac{I_{t}^{m}}{z_{t}^{+}} \\
c_{t}^{m} & =\frac{C_{t}^{m}}{z_{t}^{+}}, c_{t}^{d}=\frac{C_{t}^{d}}{z_{t}^{+}}, c_{t}=\frac{C_{t}}{z_{t}^{+}}, g_{t}=\frac{G_{t}}{z_{t}^{+}}, \bar{w}_{t}=\frac{W_{t}}{z_{t}^{+} P_{t}}, a_{t} \equiv \frac{S_{t} A_{t+1}^{*}}{P_{t} z_{t}^{+}}, \\
x_{t}^{m} & =\frac{X_{t}^{m}}{z_{t}^{+}}, x_{t}=\frac{X_{t}}{z_{t}^{+}}, \psi_{z^{+}, t}=v_{t} P_{t} z_{t}^{+},\left(y_{t}=\right) \tilde{y}_{t}=\frac{Y_{t}}{z_{t}^{+}}, \tilde{p}_{t}=\frac{\tilde{P}_{t}}{P_{t}}, w_{t}=\frac{\tilde{W}_{t}}{W_{t}}, D_{z^{+}, t}^{j} \equiv \frac{D_{t}^{j}}{P_{t} z_{t}^{+}} .
\end{aligned}
$$

We define the scaled date $t$ price of new installed physical capital for the start of period $t+1$ as $p_{k^{\prime}, t}$ and we define the scaled real rental rate of capital as $\bar{r}_{t}^{k}$ :

$$
p_{k^{\prime}, t}=\Psi_{t} P_{k^{\prime}, t}, \bar{r}_{t}^{k}=\Psi_{t} r_{t}^{k}
$$


where $P_{k^{\prime}, t}$ is in units of the domestic homogeneous good. We define the following inflation rates:

$$
\begin{aligned}
& \pi_{t}=\frac{P_{t}}{P_{t-1}}, \pi_{t}^{c}=\frac{P_{t}^{c}}{P_{t-1}^{c}}, \pi_{t}^{*}=\frac{P_{t}^{*}}{P_{t-1}^{*}}, \\
& \pi_{t}^{i}=\frac{P_{t}^{i}}{P_{t-1}^{i}}, \pi_{t}^{x}=\frac{P_{t}^{x}}{P_{t-1}^{x}}, \pi_{t}^{m, j}=\frac{P_{t}^{m, j}}{P_{t-1}^{m, j}},
\end{aligned}
$$

for $j=c, x, i$. Here, $P_{t}$ is the price of a domestic homogeneous output good, $P_{t}^{c}$ is the price of the domestic final consumption goods (i.e., the 'CPI'), $P_{t}^{*}$ is the price of a foreign homogeneous good, $P_{t}^{i}$ is the price of the domestic final investment good and $P_{t}^{x}$ is the price (in foreign currency units) of a final export good.

With one exception, we define a lower case price as the corresponding uppercase price divided by the price of the homogeneous good. When the price is denominated in domestic currency units, we divide by the price of the domestic homogeneous good, $P_{t}$. When the price is denominated in foreign currency units, we divide by $P_{t}^{*}$, the price of the foreign homogeneous good. The exceptional case has to do with handling of the price of investment goods, $P_{t}^{i}$. This grows at a rate slower than $P_{t}$, and we therefore scale it by $P_{t} / \Psi_{t}$. Thus,

$$
\begin{aligned}
p_{t}^{m, x} & =\frac{P_{t}^{m, x}}{P_{t}}, p_{t}^{m, c}=\frac{P_{t}^{m, c}}{P_{t}}, p_{t}^{m, i}=\frac{P_{t}^{m, i}}{P_{t}} \\
p_{t}^{x} & =\frac{P_{t}^{x}}{P_{t}^{*}}, p_{t}^{c}=\frac{P_{t}^{c}}{P_{t}}, p_{t}^{i}=\frac{\Psi_{t} P_{t}^{i}}{P_{t}} .
\end{aligned}
$$

Here, $m, j$ means the price of an imported good which is subsequently used in the production of exports in the case $j=x$, in the production of the final consumption good in the case of $j=c$, and in the production of final investment goods in the case of $j=i$. When there is just a single superscript the underlying good is a final good, with $j=x, c, i$ corresponding to exports, consumption and investment, respectively.

We denote the real exchange rate by $q_{t}$ :

$$
q_{t}=\frac{S_{t} P_{t}^{*}}{P_{t}^{c}} .
$$

\section{B.2. Functional forms}

We adopt the following functional form for $a$ :

$$
a(u)=0.5 \sigma_{b} \sigma_{a} u^{2}+\sigma_{b}\left(1-\sigma_{a}\right) u+\sigma_{b}\left(\left(\sigma_{a} / 2\right)-1\right)
$$

where $\sigma_{a}$ and $\sigma_{b}$ are the parameters of this function. 
The functional form for investment adjustment costs, as well as its derivatives are:

$$
\begin{aligned}
\tilde{S}(x) & =\frac{1}{2}\left\{\exp \left[\sqrt{\tilde{S}^{\prime \prime}}\left(x-\mu_{z^{+}} \mu_{\Psi}\right)\right]+\exp \left[-\sqrt{\tilde{S}^{\prime \prime}}\left(x-\mu_{z^{+}} \mu_{\Psi}\right)\right]-2\right\} \\
& =0, x=\mu_{z^{+}} \mu_{\Psi} . \\
\tilde{S}^{\prime}(x) & =\frac{1}{2} \sqrt{\tilde{S}^{\prime \prime}}\left\{\exp \left[\sqrt{\tilde{S}^{\prime \prime}}\left(x-\mu_{z^{+}} \mu_{\Psi}\right)\right]-\exp \left[-\sqrt{\tilde{S}^{\prime \prime}}\left(x-\mu_{z^{+}} \mu_{\Psi}\right)\right]\right\} \\
& =0, x=\mu_{z^{+}} \mu_{\Psi} \cdot \\
\tilde{S}^{\prime \prime}(x) & =\frac{1}{2} \tilde{S}^{\prime \prime}\left\{\exp \left[\sqrt{\tilde{S}^{\prime \prime}}\left(x-\mu_{z^{+}} \mu_{\Psi}\right)\right]+\exp \left[-\sqrt{\tilde{S}^{\prime \prime}}\left(x-\mu_{z^{+}} \mu_{\Psi}\right)\right]\right\} \\
& =\tilde{S}^{\prime \prime}, x=\mu_{z^{+}} \mu_{\Psi} .
\end{aligned}
$$

In the employment friction model we assume a log-normal distribution for idiosyncratic productivities of workers. This implies the following:

$$
\mathcal{E}\left(\bar{a}_{t}^{j} ; \sigma_{a, t}\right)=\int_{\bar{a}_{t}^{j}}^{\infty} a d \mathcal{F}\left(a ; \sigma_{a, t}\right)=1-\operatorname{prob}\left[v<\frac{\log \left(\bar{a}_{t}^{j}\right)+\frac{1}{2} \sigma_{a, t}^{2}}{\sigma_{a, t}}-\sigma_{a, t}\right],
$$

where prob refers to the standard normal distribution and eq. (B.7) simply is eq.

spelled out under this distributional assumption. We similarly spell out eq. (4.7):

$$
\begin{aligned}
\mathcal{F}\left(\bar{a}^{j} ; \sigma_{a}\right) & =\int_{0}^{\bar{a}^{j}} d \mathcal{F}\left(a ; \sigma_{a}\right)=\frac{1}{\sqrt{2 \pi}} \int_{-\infty}^{\frac{\log \left(\bar{a}^{j}\right)+\frac{1}{2} \sigma_{a}^{2}}{\sigma}} \exp ^{\frac{-v^{2}}{2}} d v \\
& =\operatorname{prob}\left[v<\frac{\log \left(\bar{a}^{j}\right)+\frac{1}{2} \sigma_{a}^{2}}{\sigma_{a}}\right] .
\end{aligned}
$$

\section{B.3. Baseline Model}

\section{B.3.1. First order conditions for domestic homogenous good price setting}

Substituting eq. (2.7) into eq. (2.6) to obtain, after rearranging,

$$
E_{t} \sum_{j=0}^{\infty} \beta^{j} v_{t+j} P_{t+j} Y_{t+j}\left\{\left(\frac{P_{i, t+j}}{P_{t+j}}\right)^{1-\frac{\lambda_{d}}{\lambda_{d}-1}}-m c_{t+j}\left(\frac{P_{i, t+j}}{P_{t+j}}\right)^{\frac{-\lambda_{d}}{\lambda_{d}-1}}\right\},
$$

or,

$$
E_{t} \sum_{j=0}^{\infty} \beta^{j} v_{t+j} P_{t+j} Y_{t+j}\left\{\left(X_{t, j} \tilde{p}_{t}\right)^{1-\frac{\lambda_{d}}{\lambda_{d}-1}}-m c_{t+j}\left(X_{t, j} \tilde{p}_{t}\right)^{\frac{-\lambda_{d}}{\lambda_{d}-1}}\right\}
$$


where

$$
\frac{P_{i, t+j}}{P_{t+j}}=X_{t, j} \tilde{p}_{t}, \quad X_{t, j} \equiv\left\{\begin{array}{c}
\frac{\tilde{\pi}_{d, t+j} \cdots \tilde{\pi}_{d, t+1}}{\pi_{t+j} \cdots \pi_{t+1}}, j>0 \\
1, j=0 .
\end{array} .\right.
$$

The $i^{t h}$ firm maximizes profits by choice of the within-sector relative price $\tilde{p}_{t}$. The fact that this variable does not have an index, $i$, reflects that all firms that have the opportunity to reoptimize in period $t$ solve the same problem, and hence have the same solution. Differ-

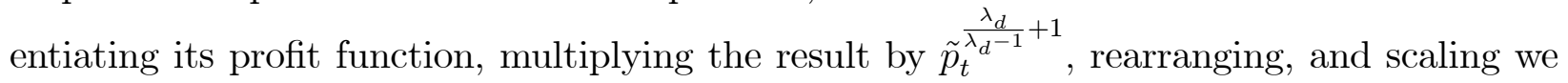
obtain:

$$
E_{t} \sum_{j=0}^{\infty}\left(\beta \xi_{d}\right)^{j} A_{t+j}\left[\tilde{p}_{t} X_{t, j}-\lambda_{d} m c_{t+j}\right]=0,
$$

where $A_{t+j}$ is exogenous from the point of view of the firm:

$$
A_{t+j}=\psi_{z^{+}, t+j} \tilde{y}_{t+j} X_{t, j}
$$

After rearranging the optimizing intermediate good firm's first order condition for prices, we obtain,

$$
\tilde{p}_{t}^{d}=\frac{E_{t} \sum_{j=0}^{\infty}\left(\beta \xi_{d}\right)^{j} A_{t+j} \lambda_{d} m c_{t+j}}{E_{t} \sum_{j=0}^{\infty}\left(\beta \xi_{d}\right)^{j} A_{t+j} X_{t, j}}=\frac{K_{t}^{d}}{F_{t}^{d}}
$$

say, where

$$
\begin{aligned}
& K_{t}^{d} \equiv E_{t} \sum_{j=0}^{\infty}\left(\beta \xi_{d}\right)^{j} A_{t+j} \lambda_{d} m c_{t+j} \\
& F_{t}^{d}=E_{t} \sum_{j=0}^{\infty}\left(\beta \xi_{d}\right)^{j} A_{t+j} X_{t, j} .
\end{aligned}
$$

These objects have the following convenient recursive representations:

$$
\begin{aligned}
E_{t}\left[\psi_{z^{+}, t} \tilde{y}_{t}+\left(\frac{\tilde{\pi}_{d, t+1}}{\pi_{t+1}}\right)^{\frac{1}{1-\lambda_{d}}} \beta \xi_{d} F_{t+1}^{d}-F_{t}^{d}\right] & =0 \\
E_{t}\left[\lambda_{d} \psi_{z^{+}, t} \tilde{y}_{t} m c_{t}+\beta \xi_{d}\left(\frac{\tilde{\pi}_{d, t+1}}{\pi_{t+1}}\right)^{\frac{\lambda_{d}}{1-\lambda_{d}}} K_{t+1}^{d}-K_{t}^{d}\right] & =0 .
\end{aligned}
$$

Turning to the aggregate price index:

$$
\begin{aligned}
P_{t} & =\left[\int_{0}^{1} P_{i t}^{\frac{1}{1-\lambda_{d}}} d i\right]^{\left(1-\lambda_{d}\right)} \\
& =\left[\left(1-\xi_{p}\right) \tilde{P}_{t}^{\frac{1}{1-\lambda_{d}}}+\xi_{p}\left(\tilde{\pi}_{d, t} P_{t-1}\right)^{\frac{1}{1-\lambda_{d}}}\right]^{\left(1-\lambda_{d}\right)}
\end{aligned}
$$


After dividing by $P_{t}$ and rearranging:

$$
\frac{1-\xi_{d}\left(\frac{\tilde{\pi}_{d, t}}{\pi_{t}}\right)^{\frac{1}{1-\lambda_{d}}}}{1-\xi_{d}}=\left(\tilde{p}_{t}^{d}\right)^{\frac{1}{1-\lambda_{d}}} .
$$

In sum, the equilibrium conditions associated with price setting for producers of the domestic homogenous good are: ${ }^{19}$

$$
\begin{aligned}
& E_{t}\left[\psi_{z^{+}, t} y_{t}+\left(\frac{\tilde{\pi}_{d, t+1}}{\pi_{t+1}}\right)^{\frac{1}{1-\lambda_{d}}} \beta \xi_{d} F_{t+1}^{d}-F_{t}^{d}\right]=0 \\
& E_{t}\left[\lambda_{d} \psi_{z^{+}, t} y_{t} m c_{t}+\beta \xi_{d}\left(\frac{\tilde{\pi}_{d, t+1}}{\pi_{t+1}}\right)^{\frac{\lambda_{d}}{1-\lambda_{d}}} K_{t+1}^{d}-K_{t}^{d}\right]=0 \\
& \stackrel{\circ}{p}_{t}=\left[\left(1-\xi_{d}\right)\left(\frac{1-\xi_{d}\left(\frac{\tilde{\pi}_{d, t}}{\pi_{t}}\right)^{\frac{1}{1-\lambda_{d}}}}{1-\xi_{d}}\right)^{\lambda_{d}}+\xi_{d}\left(\frac{\tilde{\pi}_{d, t}}{\pi_{t}} \stackrel{\circ}{t-1}^{\frac{\lambda_{d}}{1-\lambda_{d}}}\right]^{\frac{1-\lambda_{d}}{\lambda_{d}}}\right. \\
& {\left[\frac{1-\xi_{d}\left(\frac{\tilde{\pi}_{d, t}}{\pi_{t}}\right)^{\frac{1}{1-\lambda_{d}}}}{1-\xi_{d}}\right]^{\left(1-\lambda_{d}\right)}=\frac{K_{t}^{d}}{F_{t}^{d}}} \\
& \tilde{\pi}_{d, t} \equiv\left(\pi_{t-1}\right)^{\kappa_{d}}\left(\bar{\pi}_{t}^{c}\right)^{1-\kappa_{d}-\varkappa_{d}}(\breve{\pi})^{\varkappa_{d}}
\end{aligned}
$$

\section{B.3.2. First order conditions for export good price setting}

$$
\begin{aligned}
E_{t}\left[\psi_{z^{+}, t} q_{t} p_{t}^{c} p_{t}^{x} x_{t}+\left(\frac{\tilde{\pi}_{t+1}^{x}}{\pi_{t+1}^{x}}\right)^{\frac{1}{1-\lambda x}} \beta \xi_{x} F_{x, t+1}-F_{x, t}\right] & =0 \\
E_{t}\left[\lambda_{x} \psi_{z^{+}, t} q_{t} p_{t}^{c} p_{t}^{x} x_{t} m c_{t}^{x}+\beta \xi_{x}\left(\frac{\tilde{\pi}_{t+1}^{x}}{\pi_{t+1}^{x}}\right)^{\frac{\lambda_{x}}{1-\lambda_{x}}} K_{x, t+1}-K_{x, t}\right] & =0,
\end{aligned}
$$

${ }^{19}$ When we linearize about steady state and set $\varkappa_{d}=0$, we obtain,

$$
\begin{aligned}
\hat{\pi}_{t}-\widehat{\bar{\pi}}_{t}^{c}= & \frac{\beta}{1+\kappa_{d} \beta} E_{t}\left(\hat{\pi}_{t+1}-\widehat{\bar{\pi}}_{t+1}^{c}\right)+\frac{\kappa_{d}}{1+\kappa_{d} \beta}\left(\hat{\pi}_{t-1}-\widehat{\bar{\pi}}_{t}^{c}\right) \\
& -\frac{\kappa_{d} \beta\left(1-\rho_{\pi}\right)}{1+\kappa_{d} \beta} \widehat{\bar{\pi}}_{t}^{c} \\
& +\frac{1}{1+\kappa_{d} \beta} \frac{\left(1-\beta \xi_{d}\right)\left(1-\xi_{d}\right)}{\xi_{d}} \widehat{m c}_{t}
\end{aligned}
$$

where a hat indicates log-deviation from steady state. 


$$
\begin{aligned}
& \stackrel{\circ}{p}_{t}^{x}=\left[\left(1-\xi_{x}\right)\left(\frac{1-\xi_{x}\left(\frac{\tilde{\pi}_{t}^{x}}{\pi_{t}^{x}}\right)^{\frac{1}{1-\lambda_{x}}}}{1-\xi_{x}}\right)^{\lambda_{x}}+\xi_{x}\left(\frac{\tilde{\pi}_{t}^{x}}{\pi_{t}^{x}} \stackrel{p}{t-1}_{t}^{x}\right)^{\frac{\lambda x}{1-\lambda_{x}}}\right]^{\frac{1-\lambda_{x}}{\lambda_{x}}} \\
& {\left[\frac{1-\xi_{x}\left(\frac{\tilde{\pi}_{t}^{x}}{\pi_{t}^{x}}\right)^{\frac{1}{1-\lambda x}}}{1-\xi_{x}}\right]^{\left(1-\lambda_{x}\right)}=\frac{K_{x, t}}{F_{x, t}}}
\end{aligned}
$$

\section{B.3.3. Demand for domestic inputs in export production}

Integrating eq. (2.23):

$$
\begin{aligned}
\int_{0}^{1} X_{i, t}^{d} d i & =\left(\frac{\lambda}{\tau_{t}^{x} R_{t}^{x} P_{t}}\right)^{\eta_{x}}\left(1-\omega_{x}\right) \int_{0}^{1} X_{i, t} d i \\
& =\left(\frac{\lambda}{\tau_{t}^{x} R_{t}^{x} P_{t}}\right)^{\eta_{x}}\left(1-\omega_{x}\right) X_{t} \frac{\int_{0}^{1}\left(P_{i, t}^{x}\right)^{\frac{-\lambda_{x, t}}{\lambda_{x, t}-1}} d i}{\left(P_{t}^{x}\right)^{\frac{-\lambda_{x, t}}{\lambda_{x, t}-1}}}
\end{aligned}
$$

Define $\stackrel{\circ}{P}_{t}^{x}$, a linear homogeneous function of $P_{i, t}^{x}$ :

$$
\stackrel{\circ}{P}_{t}^{x}=\left[\int_{0}^{1}\left(P_{i, t}^{x}\right)^{\frac{-\lambda_{x, t}}{\lambda_{x, t}-1}} d i\right]^{\frac{\lambda_{x, t}-1}{-\lambda_{x, t}}} .
$$

Then,

$$
\left(\stackrel{\circ}{P}_{t}^{x}\right)^{\frac{-\lambda_{x, t}}{\lambda_{x, t}-1}}=\int_{0}^{1}\left(P_{i, t}^{x}\right)^{\frac{-\lambda_{x, t}}{\lambda_{x, t}-1}} d i
$$

and

$$
\int_{0}^{1} X_{i, t}^{d} d i=\left(\frac{\lambda}{\tau_{t}^{x} R_{t}^{x} P_{t}}\right)^{\eta_{x}}\left(1-\omega_{x}\right) X_{t}\left(\stackrel{\circ}{p}_{t}^{x}\right)^{\frac{-\lambda_{x, t}}{\lambda_{x, t}-1}}
$$

where

$$
\stackrel{\circ}{p}_{t}^{x} \equiv \frac{\stackrel{\circ}{P_{t}^{x}}}{P_{t}^{x}}
$$

and the law of motion of $\stackrel{p}{t}_{t}^{x}$ is given in (B.18).

We now simplify (B.21). Rewriting the second equality in (2.20), we obtain:

$$
\frac{\lambda}{P_{t} \tau_{t}^{x} R_{t}^{x}}=\frac{S_{t} P_{t}^{x}}{P_{t} q_{t} p_{t}^{c} p_{t}^{x}}\left[\omega_{x}\left(p_{t}^{m, x}\right)^{1-\eta_{x}}+\left(1-\omega_{x}\right)\right]^{\frac{1}{1-\eta_{x}}}
$$

or,

or,

$$
\frac{\lambda}{P_{t} \tau_{t}^{x} R_{t}^{x}}=\frac{S_{t} P_{t}^{x}}{P_{t} \frac{S_{t} P_{t}^{*}}{P_{t}^{c}} \frac{P_{t}^{c}}{P_{t}} \frac{P_{t}^{x}}{P_{t}^{*}}}\left[\omega_{x}\left(p_{t}^{m, x}\right)^{1-\eta_{x}}+\left(1-\omega_{x}\right)\right]^{\frac{1}{1-\eta_{x}}}
$$

$$
\frac{\lambda}{P_{t} \tau_{t}^{x} R_{t}^{x}}=\left[\omega_{x}\left(p_{t}^{m, x}\right)^{1-\eta_{x}}+\left(1-\omega_{x}\right)\right]^{\frac{1}{1-\eta_{x}}} .
$$


Substituting into (B.21), we obtain:

$$
X_{t}^{d}=\int_{0}^{1} X_{i, t}^{d} d i=\left[\omega_{x}\left(p_{t}^{m, x}\right)^{1-\eta_{x}}+\left(1-\omega_{x}\right)\right]^{\frac{\eta_{x}}{1-\eta_{x}}}\left(1-\omega_{x}\right)\left(\stackrel{\circ}{p}_{t}^{x}\right)^{\frac{-\lambda_{x, t}}{\lambda_{x, t}-1}}\left(p_{t}^{x}\right)^{-\eta_{f}} Y_{t}^{*}
$$

\section{B.3.4. First order conditions for export good price setting}

$$
\begin{gathered}
E_{t}\left[\psi_{z^{+}, t} p_{t}^{m, j} \Xi_{t}^{j}+\left(\frac{\tilde{\pi}_{t+1}^{m, j}}{\pi_{t+1}^{m, j}}\right)^{\frac{1}{1-\lambda_{m, j}}} \beta \xi_{m, j} F_{m, j, t+1}-F_{m, j, t}\right]=0 \\
E_{t}\left[\lambda_{m, j} \psi_{z^{+}, t} p_{t}^{m, j} m c_{t}^{m, j} \Xi_{t}^{j}+\beta \xi_{m, j}\left(\frac{\tilde{\pi}_{t+1}^{m, j}}{\pi_{t+1}^{m, j}}\right)^{\frac{\lambda_{m, j}}{1-\lambda_{m, j}}} K_{m, j, t+1}-K_{m, j, t}\right]=0, \\
\dot{p}_{t}^{m, j}=\left[\left(1-\xi_{m, j}\right)\left[\frac{1-\xi_{m, j}\left(\frac{\tilde{\pi}_{t}^{m, j}}{\pi_{t}^{m, j}}\right)^{\frac{1}{1-\lambda_{m, j}}}}{1-\xi_{m, j}}\right)^{\lambda_{m, j}}+\xi_{m, j}\left(\frac{\tilde{\pi}_{t}^{m, j}}{\pi_{t}^{m, j} p_{t-1}^{m, j}}\right)^{\frac{\lambda_{m, j}}{1-\lambda_{m, j}}}\right]^{\frac{1-\lambda_{m, j}}{\lambda_{m, j}}} \\
{\left[\frac{1-\xi_{m, j}\left(\frac{\tilde{\pi}_{t}^{m, j}}{\pi_{t}^{m, j}}\right)^{\frac{1}{1-\lambda_{m, j}}}}{1-\xi_{m, j}}\right]^{\left(1-\lambda_{m, j}\right)}} \\
{\left[\frac{K_{m, j, t}}{F_{m, j, t}},\right.}
\end{gathered}
$$

for $j=c, i, x .^{20}$ Here,

$$
\Xi_{t}^{j}=\left\{\begin{array}{cc}
c_{t}^{m} & j=c \\
x_{t}^{m} & j=x \\
i_{t}^{m} & j=i
\end{array} .\right.
$$

${ }^{20}$ When we linearize around steady state and $\varkappa_{m, j}=0$,

$$
\begin{aligned}
\hat{\pi}_{t}^{m, j}-\widehat{\bar{\pi}}_{t}^{c}= & \frac{\beta}{1+\kappa_{m, j} \beta} E_{t}\left(\hat{\pi}_{t+1}^{m, j}-\widehat{\bar{\pi}}_{t+1}^{c}\right)+\frac{\kappa_{m, j}}{1+\kappa_{m, j} \beta}\left(\hat{\pi}_{t-1}^{m, j}-\widehat{\bar{\pi}}_{t}^{c}\right) \\
& -\frac{\kappa_{m, j} \beta\left(1-\rho_{\pi}\right)}{1+\kappa_{m, j} \beta} \widehat{\bar{\pi}}_{t}^{c} \\
& +\frac{1}{1+\kappa_{m, j} \beta} \frac{\left(1-\beta \xi_{m, j}\right)\left(1-\xi_{m, j}\right)}{\xi_{m, j}} \widehat{m c}_{t}^{m, j},
\end{aligned}
$$




\section{B.3.5. Wage setting conditions in baseline model}

Substituting eq. (2.50) into the objective function eq. (2.49),

$$
\begin{aligned}
& E_{t}^{j} \sum_{i=0}^{\infty}\left(\beta \xi_{w}\right)^{i}\left[-\zeta_{t+i}^{h} A_{L} \frac{\left(\left(\frac{\tilde{W}_{t} \tilde{\pi}_{w, t+i} \cdots \tilde{\pi}_{w, t+1}}{W_{t+i}}\right)^{\frac{\lambda_{w}}{1-\lambda_{w}}} H_{t+i}\right)^{1+\sigma_{L}}}{1+\sigma_{L}}\right. \\
& \left.+v_{t+i} \tilde{W}_{t} \tilde{\pi}_{w, t+i} \cdots \tilde{\pi}_{w, t+1}\left(\frac{\tilde{W}_{t} \tilde{\pi}_{w, t+i} \cdots \tilde{\pi}_{w, t+1}}{W_{t+i}}\right)^{\frac{\lambda_{w}}{1-\lambda w}} H_{t+i} \frac{1-\tau_{t+i}^{y}}{1+\tau_{t+i}^{w}}\right],
\end{aligned}
$$

It is convenient to recall the scaling of variables:

$$
\psi_{z^{+}, t}=v_{t} P_{t} z_{t}^{+}, \bar{w}_{t}=\frac{W_{t}}{z_{t}^{+} P_{t}}, \tilde{y}_{t}=\frac{Y_{t}}{z_{t}^{+}}, w_{t}=\tilde{W}_{t} / W_{t}, z_{t}^{+}=\Psi_{t}^{\frac{\alpha}{1-\alpha}} z_{t} .
$$

Then,

$$
\begin{aligned}
\frac{\tilde{W}_{t} \tilde{\pi}_{w, t+i} \cdots \tilde{\pi}_{w, t+1}}{W_{t+i}} & =\frac{\tilde{W}_{t} \tilde{\pi}_{w, t+i} \cdots \tilde{\pi}_{w, t+1}}{\bar{w}_{t+i} z_{t+i}^{+} P_{t+i}}=\frac{\tilde{W}_{t}}{\bar{w}_{t+i} z_{t}^{+} P_{t}} X_{t, i} \\
& =\frac{W_{t}\left(\tilde{W}_{t} / W_{t}\right)}{\bar{w}_{t+i} z_{t}^{+} P_{t}} X_{t, i}=\frac{\bar{w}_{t}\left(\tilde{W}_{t} / W_{t}\right)}{\bar{w}_{t+i}} X_{t, i}=\frac{w_{t} \bar{w}_{t}}{\bar{w}_{t+i}} X_{t, i}
\end{aligned}
$$

where

$$
\begin{aligned}
X_{t, i} & =\frac{\tilde{\pi}_{w, t+i} \cdots \tilde{\pi}_{w, t+1}}{\pi_{t+i} \pi_{t+i-1} \cdots \pi_{t+1} \mu_{z^{+}, t+i} \cdots \mu_{z^{+}, t+1}}, i>0 \\
& =1, i=0 .
\end{aligned}
$$

It is interesting to investigate the value of $X_{t, i}$ in steady state, as $i \rightarrow \infty$. Thus,

$$
X_{t, i}=\frac{\left(\pi_{t}^{c} \cdots \pi_{t+i-1}^{c}\right)^{\kappa_{w}}\left(\bar{\pi}_{t+1}^{c} \cdots \bar{\pi}_{t+i}^{c}\right)^{\left(1-\kappa_{w}-\varkappa_{w}\right)}\left(\breve{\pi}^{i}\right)^{\varkappa_{w}}\left(\mu_{z^{+}}^{i}\right)^{\vartheta_{w}}}{\pi_{t+i} \pi_{t+i-1} \cdots \pi_{t+1} \mu_{z^{+}, t+i} \cdots \mu_{z^{+}, t+1}}
$$

In steady state,

$$
\begin{aligned}
X_{t, i} & =\frac{\left(\bar{\pi}^{i}\right)^{\kappa_{w}}\left(\bar{\pi}^{i}\right)^{\left(1-\kappa_{w}-\varkappa_{w}\right)}\left(\breve{\pi}^{i}\right)^{\varkappa_{w}}\left(\mu_{z^{+}}^{i}\right)^{\vartheta_{w}}}{\bar{\pi}^{i} \mu_{z^{+}}^{i}} \\
& =\left(\frac{\breve{\pi}^{i}}{\bar{\pi}^{i}}\right)^{\varkappa_{w}}\left(\mu_{z^{+}}^{i}\right)^{\vartheta_{w}-1} \\
& \rightarrow 0
\end{aligned}
$$

in the no-indexing case, when $\breve{\pi}=1, \varkappa_{w}=1$ and $\vartheta_{w}=0$. 
Simplifying using the scaling notation,

or,

$$
\begin{aligned}
& E_{t}^{j} \sum_{i=0}^{\infty}\left(\beta \xi_{w}\right)^{i}\left[-\zeta_{t+i}^{h} A_{L} \frac{\left(\left(\frac{w_{t} \bar{w}_{t}}{\bar{w}_{t+i}} X_{t, i}\right)^{\frac{\lambda w}{1-\lambda_{w}}} H_{t+i}\right)^{1+\sigma_{L}}}{1+\sigma_{L}}\right. \\
& \left.+v_{t+i} W_{t+i} \frac{w_{t} \bar{w}_{t}}{\bar{w}_{t+i}} X_{t, i}\left(\frac{w_{t} \bar{w}_{t}}{\bar{w}_{t+i}} X_{t, i}\right)^{\frac{\lambda w}{1-\lambda_{w}}} H_{t+i} \frac{1-\tau_{t+i}^{y}}{1+\tau_{t+i}^{w}}\right]
\end{aligned}
$$

or,

$$
\begin{aligned}
& E_{t}^{j} \sum_{i=0}^{\infty}\left(\beta \xi_{w}\right)^{i}\left[-\zeta_{t+i}^{h} A_{L} \frac{\left(\left(\frac{w_{t} \bar{w}_{t}}{\bar{w}_{t+i}} X_{t, i}\right)^{\frac{\lambda_{w}}{1-\lambda_{w}}} H_{t+i}\right)^{1+\sigma_{L}}}{1+\sigma_{L}}\right. \\
& \left.+\psi_{z^{+}, t+i} w_{t} \bar{w}_{t} X_{t, i}\left(\frac{w_{t} \bar{w}_{t}}{\bar{w}_{t+i}} X_{t, i}\right)^{\frac{\lambda_{w}}{1-\lambda_{w}}} H_{t+i} \frac{1-\tau_{t+i}^{y}}{1+\tau_{t+i}^{w}}\right]
\end{aligned}
$$

$$
\begin{aligned}
& E_{t}^{j} \sum_{i=0}^{\infty}\left(\beta \xi_{w}\right)^{i}\left[-\zeta_{t+i}^{h} A_{L} \frac{\left(\left(\frac{\bar{w}_{t}}{\bar{w}_{t+i}} X_{t, i}\right)^{\frac{\lambda_{w}}{1-\lambda_{w}}} H_{t+i}\right)^{1+\sigma_{L}}}{1+\sigma_{L}} w_{t}^{\frac{\lambda_{w}}{1-\lambda_{w}}\left(1+\sigma_{L}\right)}\right. \\
& \left.+\psi_{z^{+}, t+i} w_{t}^{1+\frac{\lambda w}{1-\lambda_{w}}} \bar{w}_{t} X_{t, i}\left(\frac{\bar{w}_{t}}{\bar{w}_{t+i}} X_{t, i}\right)^{\frac{\lambda w}{1-\lambda_{w}}} H_{t+i} \frac{1-\tau_{t+i}^{y}}{1+\tau_{t+i}^{w}}\right]
\end{aligned}
$$

Differentiating with respect to $w_{t}$,

$$
\begin{aligned}
& E_{t}^{j} \sum_{i=0}^{\infty}\left(\beta \xi_{w}\right)^{i}\left[-\zeta_{t+i}^{h} A_{L} \frac{\left(\left(\frac{\bar{w}_{t}}{\bar{w}_{t+i}} X_{t, i}\right)^{\frac{\lambda w}{1-\lambda w}} H_{t+i}\right)^{1+\sigma_{L}}}{1+\sigma_{L}} \lambda_{w}\left(1+\sigma_{L}\right) w_{t}^{\frac{\lambda w}{1-\lambda w}}\left(1+\sigma_{L}\right)-1\right. \\
& \left.+\psi_{z^{+}, t+i} w_{t}^{\frac{\lambda w}{1-\lambda_{w}}} \bar{w}_{t} X_{t, i}\left(\frac{\bar{w}_{t}}{\bar{w}_{t+i}} X_{t, i}\right)^{\frac{\lambda w}{1-\lambda w}} H_{t+i} \frac{1-\tau_{t+i}^{y}}{1+\tau_{t+i}^{w}}\right]=0
\end{aligned}
$$

Dividing and rearranging,

Solving for the wage rate:

$$
\begin{aligned}
& E_{t}^{j} \sum_{i=0}^{\infty}\left(\beta \xi_{w}\right)^{i}\left[-\zeta_{t+i}^{h} A_{L}\left(\left(\frac{\bar{w}_{t}}{\bar{w}_{t+i}} X_{t, i}\right)^{\frac{\lambda_{w}}{1-\lambda_{w}}} H_{t+i}\right)^{1+\sigma_{L}}\right. \\
& \left.+\frac{\psi_{z^{+}, t+i}}{\lambda_{w}} w_{t}^{\frac{1-\lambda_{w}\left(1+\sigma_{L}\right)}{1-\lambda_{w}}} \bar{w}_{t} X_{t, i}\left(\frac{\bar{w}_{t}}{\bar{w}_{t+i}} X_{t, i}\right)^{\frac{\lambda_{w}}{1-\lambda_{w}}} H_{t+i} \frac{1-\tau_{t+i}^{y}}{1+\tau_{t+i}^{w}}\right]=0
\end{aligned}
$$

$$
\begin{aligned}
w_{t}^{\frac{1-\lambda_{w}\left(1+\sigma_{L}\right)}{1-\lambda_{w}}} & =\frac{E_{t}^{j} \sum_{i=0}^{\infty}\left(\beta \xi_{w}\right)^{i} \zeta_{t+i}^{h} A_{L}\left(\left(\frac{\bar{w}_{t}}{\bar{w}_{t+i}} X_{t, i}\right)^{\frac{\lambda_{w}}{1-\lambda_{w}}} H_{t+i}\right)^{1+\sigma_{L}}}{E_{t}^{j} \sum_{i=0}^{\infty}\left(\beta \xi_{w}\right)^{i} \frac{\psi_{z+, t+i}}{\lambda_{w}} \bar{w}_{t} X_{t, i}\left(\frac{\bar{w}_{t}}{\bar{w}_{t+i}} X_{t, i}\right)^{\frac{\lambda w}{1-\lambda_{w}}} H_{t+i} \frac{1-\tau_{t+i}^{y}}{1+\tau_{t+i}^{w}}} \\
& =\frac{A_{L} K_{w, t}}{\bar{w}_{t} F_{w, t}}
\end{aligned}
$$


where

$$
\begin{aligned}
K_{w, t} & =E_{t}^{j} \sum_{i=0}^{\infty}\left(\beta \xi_{w}\right)^{i} \zeta_{t+i}^{h}\left(\left(\frac{\bar{w}_{t}}{\bar{w}_{t+i}} X_{t, i}\right)^{\frac{\lambda_{w}}{1-\lambda_{w}}} H_{t+i}\right)^{1+\sigma_{L}} \\
F_{w, t} & =E_{t}^{j} \sum_{i=0}^{\infty}\left(\beta \xi_{w}\right)^{i} \frac{\psi_{z^{+}, t+i}}{\lambda_{w}} X_{t, i}\left(\frac{\bar{w}_{t}}{\bar{w}_{t+i}} X_{t, i}\right)^{\frac{\lambda_{w}}{1-\lambda_{w}}} H_{t+i} \frac{1-\tau_{t+i}^{y}}{1+\tau_{t+i}^{w}} .
\end{aligned}
$$

Thus, the wage set by reoptimizing households is:

$$
w_{t}=\left[\frac{A_{L} K_{w, t}}{\bar{w}_{t} F_{w, t}}\right]^{\frac{1-\lambda_{w}}{1-\lambda_{w}\left(1+\sigma_{L}\right)}} .
$$

We now express $K_{w, t}$ and $F_{w, t}$ in recursive form:

$$
\begin{aligned}
K_{w, t}= & E_{t}^{j} \sum_{i=0}^{\infty}\left(\beta \xi_{w}\right)^{i} \zeta_{t+i}^{h}\left(\left(\frac{\bar{w}_{t}}{\bar{w}_{t+i}} X_{t, i}\right)^{\frac{\lambda w}{1-\lambda_{w}}} H_{t+i}\right)^{1+\sigma_{L}} \\
= & \zeta_{t}^{h} H_{t}^{1+\sigma_{L}}+\beta \xi_{w} \zeta_{t+1}^{h}\left(\left(\frac{\bar{w}_{t}}{\bar{w}_{t+1}} \frac{\left(\pi_{t}^{c}\right)^{\kappa_{w}}\left(\bar{\pi}_{t+1}^{c}\right)^{\left(1-\kappa_{w}-\varkappa_{w}\right)}(\breve{\pi})^{\varkappa_{w}}\left(\mu_{z^{+}}\right)^{\vartheta_{w}}}{\pi_{t+1} \mu_{z^{+}, t+1}}\right)^{\frac{\lambda w}{1-\lambda_{w}}} H_{t+1}\right)^{1+\sigma_{L}} \\
& +\left(\beta \xi_{w}\right)^{2} \zeta_{t+2}^{h}\left(\left(\frac{\bar{w}_{t}}{\bar{w}_{t+2}} \frac{\left(\pi_{t}^{c} \pi_{t+1}^{c}\right)^{\kappa_{w}}\left(\bar{\pi}_{t+1}^{c} \bar{\pi}_{t+2}^{c}\right)^{\left(1-\kappa_{w}-\varkappa_{w}\right)}\left(\breve{\pi}^{2}\right)^{\varkappa_{w}}\left(\mu_{z^{+}}^{2}\right)^{\vartheta_{w}}}{\pi_{t+2} \pi_{t+1} \mu_{z^{+}, t+2} \mu_{z^{+}, t+1}}\right)^{\frac{\lambda_{w}}{1-\lambda_{w}}} H_{t+2}\right)^{1+\sigma_{L}} \\
& +\ldots
\end{aligned}
$$

or,

$$
\begin{aligned}
K_{w, t}= & \zeta_{t}^{h} H_{t}^{1+\sigma_{L}}+E_{t} \beta \xi_{w}\left(\frac{\bar{w}_{t}}{\bar{w}_{t+1}} \frac{\left(\pi_{t}^{c}\right)^{\kappa_{w}}\left(\bar{\pi}_{t+1}^{c}\right)^{\left(1-\kappa_{w}-\varkappa_{w}\right)}(\breve{\pi})^{\varkappa_{w}}\left(\mu_{z^{+}}\right)^{\vartheta_{w}}}{\pi_{t+1} \mu_{z^{+}, t+1}}\right)^{\frac{\lambda_{w}}{1-\lambda_{w}}\left(1+\sigma_{L}\right)}\left\{\zeta_{t+1}^{h} H_{t+1}^{1+\sigma_{L}}\right. \\
& \left.+\beta \xi_{w}\left(\left(\frac{\bar{w}_{t+1}}{\bar{w}_{t+2}} \frac{\left(\pi_{t+1}^{c}\right)^{\kappa_{w}}\left(\bar{\pi}_{t+2}^{c}\right)^{\left(1-\kappa_{w}-\varkappa_{w}\right)}(\breve{\pi})^{\varkappa_{w}}\left(\mu_{z^{+}}\right)^{\vartheta_{w}}}{\pi_{t+2} \mu_{z^{+}, t+2}}\right)^{\frac{\lambda_{w}}{1-\lambda_{w}}} H_{t+2}\right)^{1+\sigma_{L}} \zeta_{t+2}^{h}+\ldots\right\} \\
= & \zeta_{t}^{h} H_{t}^{1+\sigma_{L}}+\beta \xi_{w} E_{t}\left(\frac{\bar{w}_{t}}{\bar{w}_{t+1}} \frac{\left(\pi_{t}^{c}\right)^{\kappa_{w}}\left(\bar{\pi}_{t+1}^{c}\right)^{\left(1-\kappa_{w}-\varkappa_{w}\right)}(\breve{\pi})^{\varkappa_{w}}\left(\mu_{z^{+}}\right)^{\vartheta_{w}}}{\pi_{t+1} \mu_{z^{+}, t+1}}\right)^{\frac{\lambda_{w}}{1-\lambda_{w}}\left(1+\sigma_{L}\right)} K_{w, t+1} \\
= & \zeta_{t}^{h} H_{t}^{1+\sigma_{L}}+\beta \xi_{w} E_{t}\left(\frac{\tilde{\pi}_{w, t+1}}{\pi_{w, t+1}}\right)^{\frac{\lambda_{w}}{1-\lambda_{w}}\left(1+\sigma_{L}\right)} K_{w, t+1},
\end{aligned}
$$

using,

$$
\pi_{w, t+1}=\frac{W_{t+1}}{W_{t}}=\frac{\bar{w}_{t+1} z_{t+1}^{+} P_{t+1}}{\bar{w}_{t} z_{t}^{+} P_{t}}=\frac{\bar{w}_{t+1} \mu_{z^{+}, t+1} \pi_{t+1}}{\bar{w}_{t}}
$$


Also,

$$
\begin{aligned}
F_{w, t}= & E_{t}^{j} \sum_{i=0}^{\infty}\left(\beta \xi_{w}\right)^{i} \frac{\psi_{z^{+}, t+i}}{\lambda_{w}} X_{t, i}\left(\frac{\bar{w}_{t}}{\bar{w}_{t+i}} X_{t, i}\right)^{\frac{\lambda_{w}}{1-\lambda_{w}}} H_{t+i} \frac{1-\tau_{t+i}^{y}}{1+\tau_{t+i}^{w}} \\
= & \frac{\psi_{z^{+}, t}}{\lambda_{w}} H_{t} \frac{1-\tau_{t}^{y}}{1+\tau_{t}^{w}} \\
& +\beta \xi_{w} \frac{\psi_{z^{+}, t+1}}{\lambda_{w}}\left(\frac{\bar{w}_{t}}{\bar{w}_{t+1}}\right)^{\frac{\lambda_{w}}{1-\lambda_{w}}}\left(\frac{\left(\pi_{t}^{c}\right)^{\kappa_{w}}\left(\bar{\pi}_{t+1}^{c}\right)^{\left(1-\kappa_{w}-\varkappa_{w}\right)}(\breve{\pi})^{\varkappa_{w}}\left(\mu_{z^{+}}\right)^{\vartheta_{w}}}{\pi_{t+1} \mu_{z^{+}, t+1}}\right)^{1+\frac{\lambda_{w}}{1-\lambda w}} H_{t+1} \frac{1-\tau_{t+1}^{y}}{1+\tau_{t+1}^{w}} \\
& +\left(\beta \xi_{w}\right)^{2} \frac{\psi_{z^{+}, t+2}}{\lambda_{w}}\left(\frac{\bar{w}_{t}}{\bar{w}_{t+2}}\right)^{\frac{\lambda w}{1-\lambda_{w}}} \\
& \times\left(\frac{\left(\pi_{t}^{c} \pi_{t+1}^{c}\right)^{\kappa_{w}}\left(\bar{\pi}_{t+1}^{c} \bar{\pi}_{t+2}^{c}\right)^{\left(1-\kappa_{w}-\varkappa_{w}\right)}\left(\breve{\pi}^{2}\right)^{\varkappa_{w}}\left(\mu_{z^{+}}^{2}\right)^{\vartheta_{w}}}{\pi_{t+2} \pi_{t+1} \mu_{z^{+}, t+2} \mu_{z^{+}, t+1}}\right)^{1+\frac{\lambda_{w}}{1-\lambda_{w}}} H_{t+2} \frac{1-\tau_{t+2}^{y}}{1+\tau_{t+2}^{w}} \\
& +\ldots
\end{aligned}
$$

or,

$$
\begin{aligned}
F_{w, t}= & \frac{\psi_{z^{+}, t}}{\lambda_{w}} H_{t} \frac{1-\tau_{t}^{y}}{1+\tau_{t}^{w}} \\
& +\beta \xi_{w}\left(\frac{\bar{w}_{t}}{\bar{w}_{t+1}}\right)^{\frac{\lambda_{w}}{1-\lambda_{w}}}\left(\frac{\left(\pi_{t}^{c}\right)^{\kappa_{w}}\left(\bar{\pi}_{t+1}^{c}\right)^{\left(1-\kappa_{w}-\varkappa_{w}\right)}(\breve{\pi})^{\varkappa_{w}}\left(\mu_{z^{+}}\right)^{\vartheta}}{\pi_{t+1} \mu_{z^{+}, t+1}}\right)^{1+\frac{\lambda_{w}}{1-\lambda_{w}}}\left\{\frac{\psi_{z^{+}, t+1}}{\lambda_{w}} H_{t+1} \frac{1-\tau_{t+1}^{y}}{1+\tau_{t+1}^{w}}\right. \\
& +\beta \xi_{w}\left(\frac{\bar{w}_{t+1}}{\bar{w}_{t+2}}\right)^{\frac{\lambda_{w}}{1-\lambda w}}\left(\frac{\left(\pi_{t+1}^{c}\right)^{\kappa_{w}}\left(\bar{\pi}_{t+2}^{c}\right)^{\left(1-\kappa_{w}-\varkappa_{w}\right)}(\breve{\pi})^{\varkappa_{w}}\left(\mu_{z^{+}}\right)^{\vartheta}}{\pi_{t+2} \mu_{z^{+}, t+2}}\right)^{1+\frac{\lambda_{w}}{1-\lambda_{w}}} \frac{\psi_{z^{+}, t+2}}{\lambda_{w}} H_{t+2} \frac{1-\tau_{t+2}^{y}}{1+\tau_{t+2}^{w}} \\
& +\ldots\} \\
= & \frac{\psi_{z^{+}, t}}{\lambda_{w}} H_{t} \frac{1-\tau_{t}^{y}}{1+\tau_{t}^{w}}+\beta \xi_{w}\left(\frac{\bar{w}_{t+1}}{\bar{w}_{t}}\right)\left(\frac{\tilde{\pi}_{w, t+1}}{\pi_{w, t+1}}\right)^{1+\frac{\lambda w}{1-\lambda_{w}}} F_{w, t+1},
\end{aligned}
$$

so that

$$
F_{w, t}=\frac{\psi_{z^{+}, t}}{\lambda_{w}} H_{t} \frac{1-\tau_{t}^{y}}{1+\tau_{t}^{w}}+\beta \xi_{w} E_{t}\left(\frac{\bar{w}_{t+1}}{\bar{w}_{t}}\right)\left(\frac{\tilde{\pi}_{w, t+1}}{\pi_{w, t+1}}\right)^{1+\frac{\lambda_{w}}{1-\lambda_{w}}} F_{w, t+1},
$$

We obtain a second restriction on $w_{t}$ using the relation between the aggregate wage rate and the wage rates of individual households:

$$
W_{t}=\left[\left(1-\xi_{w}\right)\left(\tilde{W}_{t}\right)^{\frac{1}{1-\lambda w}}+\xi_{w}\left(\tilde{\pi}_{w, t} W_{t-1}\right)^{\frac{1}{1-\lambda_{w}}}\right]^{1-\lambda_{w}} .
$$

Dividing both sides by $W_{t}$ and rearranging,

$$
w_{t}=\left[\frac{1-\xi_{w}\left(\frac{\tilde{\pi}_{w, t}}{\pi_{w, t}}\right)^{\frac{1}{1-\lambda_{w}}}}{1-\xi_{w}}\right]^{1-\lambda_{w}}
$$


Substituting, out for $w_{t}$ from the household's first order condition for wage optimization:

$$
\frac{1}{A_{L}}\left[\frac{1-\xi_{w}\left(\frac{\tilde{\pi}_{w, t}}{\pi_{w, t}}\right)^{\frac{1}{1-\lambda_{w}}}}{1-\xi_{w}}\right]^{1-\lambda_{w}\left(1+\sigma_{L}\right)} \quad \bar{w}_{t} F_{w, t}=K_{w, t}
$$

We now derive the relationship between aggregate homogeneous hours worked, $H_{t}$, and aggregate household hours,

$$
h_{t} \equiv \int_{0}^{1} h_{j, t} d j .
$$

Substituting the demand for $h_{j, t}$ into the latter expression, we obtain,

$$
\begin{aligned}
h_{t} & =\int_{0}^{1}\left(\frac{W_{j, t}}{W_{t}}\right)^{\frac{\lambda w}{1-\lambda w}} H_{t} d j \\
& =\frac{H_{t}}{\left(W_{t}\right)^{\frac{\lambda w}{1-\lambda w}}} \int_{0}^{1}\left(W_{j, t}\right)^{\frac{\lambda w}{1-\lambda w}} d j \\
& =\stackrel{\circ}{t}^{\frac{\lambda w}{1-\lambda w}} H_{t},
\end{aligned}
$$

where

$$
\stackrel{\circ}{w}_{t} \equiv \frac{\stackrel{\circ}{W}_{t}}{W_{t}}, \stackrel{\circ}{W}_{t}=\left[\int_{0}^{1}\left(W_{j, t}\right)^{\frac{\lambda_{w}}{1-\lambda_{w}}} d j\right]^{\frac{1-\lambda_{w}}{\lambda_{w}}} .
$$

Also,

$$
\stackrel{\circ}{W}_{t}=\left[\left(1-\xi_{w}\right)\left(\tilde{W}_{t}\right)^{\frac{\lambda_{w}}{1-\lambda w}}+\xi_{w}\left(\tilde{\pi}_{w, t} \stackrel{\circ}{t}_{t-1}\right)^{\frac{\lambda_{w}}{1-\lambda_{w}}}\right]^{\frac{1-\lambda_{w}}{\lambda_{w}}}
$$

so that,

$$
\begin{aligned}
\stackrel{\circ}{w}_{t} & =\left[\left(1-\xi_{w}\right)\left(w_{t}\right)^{\frac{\lambda w}{1-\lambda_{w}}}+\xi_{w}\left(\frac{\tilde{\pi}_{w, t}}{\pi_{w, t}} \stackrel{\circ}{t-1}_{t-1}\right)^{\frac{\lambda_{w}}{1-\lambda_{w}}}\right]^{\frac{1-\lambda_{w}}{\lambda_{w}}} \\
& =\left[\left(1-\xi_{w}\right)\left(\frac{1-\xi_{w}\left(\frac{\tilde{\pi}_{w, t}}{\pi_{w, t}}\right)^{\frac{1}{1-\lambda_{w}}}}{1-\xi_{w}}\right)^{\lambda_{w}}+\xi_{w}\left(\frac{\tilde{\pi}_{w, t}}{\pi_{w, t}} \stackrel{\circ}{t-1}^{\frac{\lambda_{w}}{1-\lambda_{w}}}\right]^{\frac{1-\lambda_{w}}{\lambda_{w}}}\right.
\end{aligned}
$$


In addition to (B.28), we have following equilibrium conditions associated with sticky wages ${ }^{21}$ :

$$
\begin{gathered}
F_{w, t}=\frac{\psi_{z^{+}, t}}{\lambda_{w}} \stackrel{\circ}{t}^{-\frac{\lambda_{w}}{1-\lambda_{w}}} h_{t} \frac{1-\tau_{t}^{y}}{1+\tau_{t}^{w}}+\beta \xi_{w} E_{t}\left(\frac{\bar{w}_{t+1}}{\bar{w}_{t}}\right)\left(\frac{\tilde{\pi}_{w, t+1}}{\pi_{w, t+1}}\right)^{1+\frac{\lambda_{w}}{1-\lambda_{w}}} F_{w, t+1} \\
K_{w, t}=\zeta_{t}^{h}\left({\stackrel{\circ}{\omega_{t}}}^{-\frac{\lambda_{w}}{1-\lambda_{w}}} h_{t}\right)^{1+\sigma_{L}}+\beta \xi_{w} E_{t}\left(\frac{\tilde{\pi}_{w, t+1}}{\pi_{w, t+1}}\right)^{\frac{\lambda w}{1-\lambda_{w}}\left(1+\sigma_{L}\right)} K_{w, t+1} \\
\frac{1}{A_{L}}\left[\frac{1-\xi_{w}\left(\frac{\tilde{\pi}_{w, t}}{\pi_{w, t}}\right)^{\frac{1}{1-\lambda_{w}}}}{1-\xi_{w}}\right]^{1-\lambda_{w}\left(1+\sigma_{L}\right)} \bar{w}_{t} F_{w, t}=K_{w, t} .
\end{gathered}
$$

\section{B.3.6. Output and aggregate factors of production}

Below we derive a relationship between total output of the domestic homogeneous good, $Y_{t}$, and aggregate factors of production.

\footnotetext{
${ }^{21} \log$ linearizing these equations about the nonstochastic steady state and under the assumption of $\varkappa_{w}=0$, we obtain

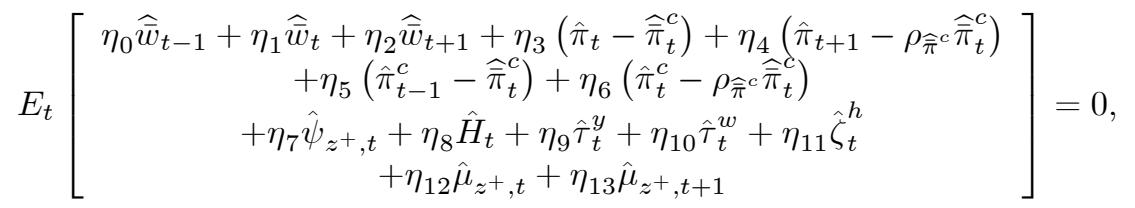

where

$$
b_{w}=\frac{\left[\lambda_{w} \sigma_{L}-\left(1-\lambda_{w}\right)\right]}{\left[\left(1-\beta \xi_{w}\right)\left(1-\xi_{w}\right)\right]}
$$

and

$$
\left(\begin{array}{c}
\eta_{0} \\
\eta_{1} \\
\eta_{2} \\
\eta_{3} \\
\eta_{4} \\
\eta_{5} \\
\eta_{6} \\
\eta_{7} \\
\eta_{8} \\
\eta_{9} \\
\eta_{10} \\
\eta_{11} \\
\eta_{12} \\
\eta_{13}
\end{array}\right)=\left(\begin{array}{c}
b_{w} \xi_{w} \\
\left(\sigma_{L} \lambda_{w}-b_{w}\left(1+\beta \xi_{w}^{2}\right)\right) \\
b_{w} \beta \xi_{w} \\
-b_{w} \xi_{w} \\
b_{w} \beta \xi_{w} \\
b_{w} \xi_{w} \kappa_{w} \\
-b_{w} \beta \xi_{w} \kappa_{w} \\
\left(1-\lambda_{w}\right) \\
-\left(1-\lambda_{w}\right) \sigma_{L} \\
-\left(1-\lambda_{w}\right) \frac{\tau^{y}}{\left(1-\tau^{y}\right)} \\
-\left(1-\lambda_{w}\right) \frac{\left.\tau^{w}\right)}{\left(1+\tau^{w}\right)} \\
-\left(1-\lambda_{w}\right) \\
-b_{w} \xi_{w} \\
b_{w} \beta \xi_{w}
\end{array}\right) .
$$


Consider the unweighted average of the intermediate goods:

$$
\begin{aligned}
Y_{t}^{\text {sum }} & =\int_{0}^{1} Y_{i, t} d i \\
& =\int_{0}^{1}\left[\left(z_{t} H_{i, t}\right)^{1-\alpha} \epsilon_{t} K_{i, t}^{\alpha}-z_{t}^{+} \phi\right] d i \\
& =\int_{0}^{1}\left[z_{t}^{1-\alpha} \epsilon_{t}\left(\frac{K_{i, t}}{H_{i t}}\right)^{\alpha} H_{i t}-z_{t}^{+} \phi\right] d i \\
& =z_{t}^{1-\alpha} \epsilon_{t}\left(\frac{K_{t}}{H_{t}}\right)^{\alpha} \int_{0}^{1} H_{i t} d i-z_{t}^{+} \phi
\end{aligned}
$$

where $K_{t}$ is the economy-wide average stock of capital services and $H_{t}$ is the economy-wide average of homogeneous labor. The last expression exploits the fact that all intermediate good firms confront the same factor prices, and so they adopt the same capital services to homogeneous labor ratio. This follows from cost minimization, and holds for all firms, regardless whether or not they have an opportunity to reoptimize. Then,

$$
Y_{t}^{\text {sum }}=z_{t}^{1-\alpha} \epsilon_{t} K_{t}^{\alpha} H_{t}^{1-\alpha}-z_{t}^{+} \phi .
$$

Recall that the demand for $Y_{j, t}$ is

$$
\left(\frac{P_{t}}{P_{i, t}}\right)^{\frac{\lambda_{d}}{\lambda_{d}-1}}=\frac{Y_{i, t}}{Y_{t}}
$$

so that

$$
\stackrel{\circ}{Y}_{t} \equiv \int_{0}^{1} Y_{i, t} d i=\int_{0}^{1} Y_{t}\left(\frac{P_{t}}{P_{i, t}}\right)^{\frac{\lambda_{d}}{\lambda_{d}-1}} d i=Y_{t} P_{t}^{\frac{\lambda_{d}}{\lambda_{d}-1}}\left(\stackrel{\circ}{P}_{t}\right)^{\frac{\lambda_{d}}{1-\lambda_{d}}}
$$

say, where

$$
\stackrel{\circ}{P}_{t}=\left[\int_{0}^{1} P_{i, t}^{\frac{\lambda_{d}}{1-\lambda_{d}}} d i\right]^{\frac{1-\lambda_{d}}{\lambda_{d}}}
$$

Dividing by $P_{t}$,

$$
\stackrel{\circ}{p}_{t}=\left[\int_{0}^{1}\left(\frac{P_{i t}}{P_{t}}\right)^{\frac{\lambda_{d}}{1-\lambda_{d}}} d i\right]^{\frac{1-\lambda_{d}}{\lambda_{d}}},
$$

or,

$$
\stackrel{\circ}{p}_{t}=\left[\left(1-\xi_{p}\right)\left(\frac{1-\xi_{p}\left(\frac{\tilde{\pi}_{d, t}}{\pi_{t}}\right)^{\frac{1}{1-\lambda_{d}}}}{1-\xi_{p}}\right)^{\lambda_{d}}+\xi_{p}\left(\frac{\tilde{\pi}_{d, t}}{\pi_{t}} \stackrel{\circ}{t-1}^{\frac{\lambda_{d}}{1-\lambda_{d}}}\right]^{\frac{1-\lambda_{d}}{\lambda_{d}}} .\right.
$$

The preceding discussion implies:

$$
Y_{t}=\left(\stackrel{\circ}{p}_{t}\right)^{\frac{\lambda_{d}}{\lambda_{d}-1}} \stackrel{\circ}{Y}_{t}=\left(\stackrel{\circ}{p}_{t}\right)^{\frac{\lambda_{d}}{\lambda_{d}-1}}\left[z_{t}^{1-\alpha} \epsilon_{t} K_{t}^{\alpha} H_{t}^{1-\alpha}-z_{t}^{+} \phi\right],
$$


or, after scaling by $z_{t}^{+}$,

$$
y_{t}=\left(\stackrel{\circ}{p}_{t}\right)^{\frac{\lambda_{d}}{\lambda_{d}-1}}\left[\epsilon_{t}\left(\frac{1}{\mu_{\Psi, t}} \frac{1}{\mu_{z^{+}, t}} k_{t}\right)^{\alpha} H_{t}^{1-\alpha}-\phi\right],
$$

where

$$
k_{t}=\bar{k}_{t} u_{t} .
$$

We need to replace aggregate homogeneous labor, $H_{t}$, with aggregate household labor, $h_{t}$. From eq. (B.27) we have $H_{t}=\stackrel{\circ}{w}_{t}^{-\frac{\lambda w}{1-\lambda w}} h_{t}$. Plugging this is we obtain:

$$
y_{t}=\left(\stackrel{\circ}{p}_{t}\right)^{\frac{\lambda_{d}}{\lambda_{d}-1}}\left[\epsilon_{t}\left(\frac{1}{\mu_{\Psi, t}} \frac{1}{\mu_{z^{+}, t}} k_{t}\right)^{\alpha}\left({\stackrel{\circ}{w_{t}}}^{-\frac{\lambda_{w}}{1-\lambda_{w}}} h_{t}\right)^{1-\alpha}-\phi\right] .
$$

which completes the derivation.

\section{B.4. Equilibrium Conditions from the Employment Frictions Model B.4.1. Labor Hours}

Scaling (4.4) by $P_{t} z_{t}^{+}$yields:

$$
\bar{w}_{t} \mathcal{G}_{t}^{i}=\zeta_{t}^{h} A_{L} \varsigma_{i, t}^{\sigma_{L}} \frac{1}{\psi_{z^{+}, t} \frac{1-\tau_{t}^{y}}{1+\tau_{t}^{w}}}
$$

Note, that the ratio

$$
\frac{\mathcal{G}_{t}^{i}}{\varsigma_{i, t}^{\sigma_{L}}}
$$

will be the same for all cohorts since no other variables in (B.36) are indexed by cohort.

\section{B.4.2. Vacancies and the Employment Agency Problem}

An employment agency in the $i^{\text {th }}$ cohort which does not renegotiate its wage in period $t$ sets the period $t$ wage, $W_{i, t}$, as in (2.47):

$$
W_{i, t}=\tilde{\pi}_{w, t} W_{i-1, t-1}, \tilde{\pi}_{w, t} \equiv\left(\pi_{t-1}\right)^{\kappa_{w}}\left(\bar{\pi}_{t}\right)^{\left(1-\kappa_{w}-\varkappa_{w}\right)}(\breve{\pi})^{\varkappa_{w}}\left(\mu_{z^{+}}\right)^{\vartheta_{w}},
$$

for $i=1, \ldots, N-1$ (note that an agency that was in the $i^{t h}$ cohort in period $t$ was in cohort $i-1$ in period $t-1)$ where $\kappa_{w}, \varkappa_{w}, \vartheta_{w}, \kappa_{w}+\varkappa_{w} \in(0,1)$.

After wages are set, employment agencies in cohort $i$ decide on endogenous separation, post vacancies to attract new workers in the next period and supply labor services, $l_{t}^{i} \varsigma_{i, t}$, 
into competitive labor markets. Simplifying,

$$
\begin{aligned}
F\left(l_{t}^{0}, \omega_{t}\right)= & \sum_{j=0}^{N-1} \beta^{j} E_{t} \frac{v_{t+j}}{v_{t}} \max _{\tilde{v}_{t+j}^{j}}\left[\left(W_{t+j} \mathcal{E}_{t+j}^{j}-\Gamma_{t, j} \omega_{t}\left[1-\mathcal{F}_{t+j}^{j}\right]\right) \varsigma_{j, t+j}\right. \\
& \left.-P_{t+j} \frac{\kappa z_{t+j}^{+}}{\varphi}\left(\tilde{v}_{t}^{j}\right)^{\varphi}\left(1-\mathcal{F}_{t+j}^{j}\right)\right] l_{t+j}^{j} \\
& +\beta^{N} E_{t} \frac{v_{t+N}}{v_{t}} F\left(l_{t+N}^{0}, \tilde{W}_{t+N}\right),
\end{aligned}
$$

For convenience, we omit the expectation operator $E_{t}$ below. Let

Writing out (B.38):

$$
\begin{aligned}
F\left(l_{t}^{0}, \omega_{t}\right)= & \max _{\left\{v_{t+j}^{j}\right\}_{j=0}^{N-1}}\left\{\left[\left(W_{t} \mathcal{E}_{t}^{0}-\omega_{t}\left(1-\mathcal{F}_{t}^{0}\right)\right) \varsigma_{t}-P_{t} \frac{\kappa z_{t}^{+}}{\varphi}\left(\tilde{v}_{t}^{0}\right)^{\varphi}\left(1-\mathcal{F}_{t}^{0}\right)\right] l_{t}^{0}\right. \\
& +\beta E_{t} \frac{v_{t+1}}{v_{t}}\left[\left(W_{t+1} \mathcal{E}_{t+1}^{1}-\Gamma_{t, 1} \omega_{t}\left(1-\mathcal{F}_{t+1}^{1}\right)\right) \varsigma_{t+1}-P_{t+1} \frac{\kappa z_{t+1}^{+}}{\varphi}\left(\tilde{v}_{t+1}^{1}\right)^{\varphi}\left(1-\mathcal{F}_{t+1}^{1}\right)\right] \\
& \times\left(\chi_{t}^{0}+\rho\right)\left[1-\mathcal{F}_{t}^{0}\right] l_{t}^{0} \\
& +\beta^{2} E_{t} \frac{v_{t+2}}{v_{t}}\left[\left(W_{t+2} \mathcal{E}_{t+2}^{2}-\Gamma_{t, 2} \omega_{t}\left(1-\mathcal{F}_{t+2}^{2}\right)\right) \varsigma_{t+2}-P_{t+2} \frac{\kappa z_{t+2}^{+}}{\varphi}\left(\tilde{v}_{t+2}^{2}\right)^{\varphi}\left(1-\mathcal{F}_{t+2}^{2}\right)\right] \\
& \times\left(\chi_{t+1}^{1}+\rho\right)\left(\chi_{t}^{0}+\rho\right)\left(1-\mathcal{F}_{t+1}^{1}\right)\left(1-\mathcal{F}_{t}^{0}\right) l_{t}^{0} \\
& +\ldots+ \\
& \left.+\beta^{N} E_{t} \frac{v_{t+N}}{v_{t}} F\left(l_{t+N}^{0}, \tilde{W}_{t+N}\right)\right\} .
\end{aligned}
$$

$$
\begin{aligned}
J\left(\omega_{t}\right)= & \max _{\left\{v_{t+j}^{j}\right\}_{j=0}^{N-1}}\left\{\left(W_{t} \mathcal{E}_{t}^{0}-\omega_{t}\left(1-\mathcal{F}_{t}^{0}\right)\right) \varsigma_{0, t}-P_{t} z_{t}^{+} \frac{\kappa}{\varphi}\left(\tilde{v}_{t}^{0}\right)^{\varphi}\left[1-\mathcal{F}_{t}^{0}\right]\right. \\
& +\beta \frac{v_{t+1}}{v_{t}}\left[\left(W_{t+1} \mathcal{E}_{t+1}^{1}-\Gamma_{t, 1} \omega_{t}\left(1-\mathcal{F}_{t+1}^{1}\right)\right) \varsigma_{1, t+1}-P_{t+1} z_{t+1}^{+} \frac{\kappa}{\varphi}\left(\tilde{v}_{t+1}^{1}\right)^{\varphi}\left(1-\mathcal{F}_{t+1}^{1}\right)\right] \times \\
& \left(\tilde{v}_{t}^{0} Q_{t}^{1-\iota}+\rho\right)\left(1-\mathcal{F}_{t}^{0}\right) \\
& +\beta^{2} \frac{v_{t+2}}{v_{t}}\left[\left(W_{t+2} \mathcal{E}_{t+2}^{2}-\Gamma_{t, 2} \omega_{t}\left(1-\mathcal{F}_{t+2}^{2}\right)\right) \varsigma_{2, t+2}-P_{t+2} z_{t+2}^{+} \frac{\kappa}{\varphi}\left(\tilde{v}_{t+2}^{2}\right)^{\varphi}\left(1-\mathcal{F}_{t+2}^{2}\right)\right] \times \\
& \left(\tilde{v}_{t}^{0} Q_{t}^{1-\iota}+\rho\right)\left(\tilde{v}_{t+1}^{1} Q_{t+1}^{1-\iota}+\rho\right)\left(1-\mathcal{F}_{t+1}^{1}\right)\left[1-\mathcal{F}_{t}^{0}\right] \\
& +\ldots+ \\
& +\beta^{N} \frac{v_{t+N}}{v_{t}} J\left(\tilde{W}_{t+N}\right)\left(\tilde{v}_{t}^{0} Q_{t}^{1-\iota}+\rho\right)\left(\tilde{v}_{t+1}^{1} Q_{t}^{1-\iota}+\rho\right) \cdots\left(\tilde{v}_{t+N-1}^{N-1} Q_{t+N-1}^{1-\iota}+\rho\right) \times \\
& \left.\left(1-\mathcal{F}_{t+N-1}^{N-1}\right) \cdots\left(1-\mathcal{F}_{t}^{0}\right)\right\} .
\end{aligned}
$$

We derive optimal vacancy posting decisions of employment agencies by differentiating 
(B.39) with respect to $\tilde{v}_{t}^{0}$ and multiply the result by $\left(\tilde{v}_{t}^{0} Q_{t}^{1-\iota}+\rho\right) / Q_{t}^{1-\iota}$, to obtain:

$$
\begin{aligned}
0= & -P_{t} z_{t}^{+} \kappa\left(\tilde{v}_{t}^{0}\right)^{\varphi-1}\left[1-\mathcal{F}_{t}^{0}\right]\left(\tilde{v}_{t}^{0} Q_{t}^{1-\iota}+\rho\right) / Q_{t}^{1-\iota} \\
& +\beta \frac{v_{t+1}}{v_{t}}\left[\left(W_{t+1} \mathcal{E}_{t+1}^{1}-\Gamma_{t, 1} \omega_{t}\left[1-\mathcal{F}_{t+1}^{1}\right]\right) \varsigma_{1, t+1}-P_{t+1} z_{t+1}^{+} \frac{\kappa}{\varphi}\left(\tilde{v}_{t+1}^{1}\right)^{\varphi}\left(1-\mathcal{F}_{t+1}^{1}\right)\right] \times \\
& \left(\tilde{v}_{t}^{0} Q_{t}^{1-\iota}+\rho\right)\left[1-\mathcal{F}_{t}^{0}\right] \\
& +\beta^{2} \frac{v_{t+2}}{v_{t}}\left[\left(W_{t+2} \mathcal{E}_{t+2}^{2}-\Gamma_{t, 2} \omega_{t}\left[1-\mathcal{F}_{t+2}^{2}\right]\right) \varsigma_{2, t+2}-P_{t+2} z_{t+2}^{+} \frac{\kappa}{\varphi}\left(\tilde{v}_{t+2}^{2}\right)^{\varphi}\left(1-\mathcal{F}_{t+2}^{2}\right)\right] \times \\
& \left(\tilde{v}_{t}^{0} Q_{t}^{1-\iota}+\rho\right)\left(\tilde{v}_{t+1}^{1} Q_{t+1}^{1-\iota}+\rho\right)\left[1-\mathcal{F}_{t+1}^{1}\right]\left[1-\mathcal{F}_{t}^{0}\right] \\
& +\ldots+ \\
& +\beta^{N} \frac{v_{t+N}}{v_{t}} J\left(\tilde{W}_{t+N}\right)\left(\tilde{v}_{t}^{0} Q_{t}^{1-\iota}+\rho\right)\left(\tilde{v}_{t+1}^{1} Q_{t}^{1-\iota}+\rho\right) \cdots\left(\tilde{v}_{t+N-1}^{N-1} Q_{t+N-1}^{1-\iota}+\rho\right) \times \\
& {\left.\left[1-\mathcal{F}_{t+N-1}^{N-1}\right] \cdots\left[1-\mathcal{F}_{t}^{0}\right]\right\} } \\
= & J\left(\omega_{t}\right)-\left(W_{t} \mathcal{E}_{t}^{0}-\omega_{t}\left(1-\mathcal{F}_{t}^{0}\right)\right) \varsigma_{0, t}+P_{t} z_{t}^{+} \frac{\kappa}{\varphi}\left(\tilde{v}_{t}^{0}\right)^{\varphi}\left[1-\mathcal{F}_{t}^{0}\right] \\
& -P_{t} z_{t}^{+} \kappa\left(\tilde{v}_{t}^{0}\right)^{\varphi-1}\left[1-\mathcal{F}_{t}^{0}\right]\left(\tilde{v}_{t}^{0} Q_{t}^{1-\iota}+\rho\right) / Q_{t}^{1-\iota}
\end{aligned}
$$

Since the latter expression must be zero, we conclude:

$$
\begin{aligned}
J\left(\omega_{t}\right)= & \left(W_{t} \mathcal{E}_{t}^{0}-\omega_{t}\left(1-\mathcal{F}_{t}^{0}\right)\right) \varsigma_{0, t}-P_{t} z_{t}^{+} \frac{\kappa}{\varphi}\left(\tilde{v}_{t}^{0}\right)^{\varphi}\left[1-\mathcal{F}_{t}^{0}\right] \\
& +P_{t} z_{t}^{+} \kappa\left(\tilde{v}_{t}^{0}\right)^{\varphi-1}\left[1-\mathcal{F}_{t}^{0}\right]\left(\tilde{v}_{t}^{0} Q_{t}^{1-\iota}+\rho\right) / Q_{t}^{1-\iota} \\
= & \left(W_{t} \mathcal{E}_{t}^{0}-\omega_{t}\left(1-\mathcal{F}_{t}^{0}\right)\right) \varsigma_{0, t}+P_{t} z_{t}^{+} \kappa\left[\left(1-\frac{1}{\varphi}\right)\left(\tilde{v}_{t}^{0}\right)^{\varphi}+\left(\tilde{v}_{t}^{0}\right)^{\varphi-1} \frac{\rho}{\left.Q_{t}^{1-\iota}\right]\left[1-\mathcal{F}_{t}^{0}\right] .}\right.
\end{aligned}
$$

Next, we obtain simple expressions for the vacancy decisions from their first order necessary conditions for optimality. Multiplying the first order condition for $\tilde{v}_{t+1}^{1}$ by

$$
\left(\tilde{v}_{t+1}^{1} Q_{t+1}^{1-\iota}+\rho\right) \frac{1}{Q_{t+1}^{1-\iota}}
$$

we obtain:

$$
\begin{aligned}
0= & -\beta \frac{v_{t+1}}{v_{t}} P_{t+1} z_{t+1}^{+} \kappa\left(\tilde{v}_{t+1}^{1}\right)^{\varphi-1}\left[1-\mathcal{F}_{t+1}^{1}\right]\left(\tilde{v}_{t}^{0} Q_{t}^{1-\iota}+\rho\right)\left(\tilde{v}_{t+1}^{1} Q_{t+1}^{1-\iota}+\rho\right) \frac{1}{Q_{t+1}^{1-\iota}}\left[1-\mathcal{F}_{t}^{0}\right] \\
& +\beta^{2} \frac{v_{t+2}}{v_{t}}\left[\left(W_{t+2} \mathcal{E}_{t+2}^{2}-\Gamma_{t, 2} \omega_{t}\left(1-\mathcal{F}_{t+2}^{2}\right)\right) \varsigma_{2, t+2}-P_{t+2} z_{t+2}^{+} \frac{\kappa}{\varphi}\left(\tilde{v}_{t+2}^{2}\right)^{\varphi}\left[1-\mathcal{F}_{t+2}^{2}\right]\right] \times \\
& \left(\tilde{v}_{t}^{0} Q_{t}^{1-\iota}+\rho\right)\left(\tilde{v}_{t+1}^{1} Q_{t+1}^{1-\iota}+\rho\right)\left[1-\mathcal{F}_{t+1}^{1}\right]\left[1-\mathcal{F}_{t}^{0}\right] \\
& +\ldots+ \\
& +\beta^{N} \frac{v_{t+N}}{v_{t}} J\left(\tilde{W}_{t+N}\right)\left(\tilde{v}_{t}^{0} Q_{t}^{1-\iota}+\rho\right)\left(\tilde{v}_{t+1}^{1} Q_{t}^{1-\iota}+\rho\right) \cdots\left(\tilde{v}_{t+N-1}^{N-1} Q_{t+N-1}^{1-\iota}+\rho\right) \times \\
& {\left[1-\mathcal{F}_{t+N-1}^{N-1}\right] \cdots\left[1-\mathcal{F}_{t}^{0}\right] . }
\end{aligned}
$$


Substitute out the period $t+2$ and higher terms in this expression using the first order condition for $\tilde{v}_{t}^{0}$. After rearranging, we obtain,

$$
\frac{P_{t} z_{t}^{+} \kappa\left(\tilde{v}_{t}^{0}\right)^{\varphi-1}}{Q_{t}^{1-\iota}}=\beta \frac{v_{t+1}}{v_{t}}\left[\begin{array}{c}
\left(W_{t+1} \mathcal{E}_{t+1}^{1}-\Gamma_{t, 1} \omega_{t}\left[1-\mathcal{F}_{t+1}^{1}\right]\right) \varsigma_{1, t+1} \\
+P_{t+1} z_{t+1}^{+} \kappa\left(1-\mathcal{F}_{t+1}^{1}\right)\left[\left(1-\frac{1}{\varphi}\right)\left(\tilde{v}_{t+1}^{1}\right)^{\varphi}+\left(\tilde{v}_{t+1}^{1}\right)^{\varphi-1} \frac{\rho}{Q_{t+1}^{1-\iota}}\right]
\end{array}\right]
$$

Following the pattern set with $\tilde{v}_{t+1}^{1}$, multiply the first order condition for $\tilde{v}_{t+2}^{2}$ by

$$
\left(\tilde{v}_{t+2}^{2} Q_{t+2}^{1-\iota}+\rho\right) \frac{1}{Q_{t+2}^{1-\iota}}
$$

Substitute the period $t+3$ and higher terms in the first order condition for $\tilde{v}_{t+2}^{2}$ using the first order condition for $\tilde{v}_{t+1}^{1}$ to obtain, after rearranging,

$$
\frac{P_{t+1} z_{t+1}^{+} \kappa\left(\tilde{v}_{t+1}^{1}\right)^{\varphi-1}}{Q_{t+1}^{1-\iota}}=\beta \frac{v_{t+2}}{v_{t+1}}\left[\begin{array}{c}
\left(W_{t+2} \mathcal{E}_{t+2}^{2}-\Gamma_{t, 2} \omega_{t}\left[1-\mathcal{F}_{t+2}^{2}\right]\right) \varsigma_{2, t+2} \\
+P_{t+2} z_{t+2}^{+} \kappa\left(1-\mathcal{F}_{t+2}^{2}\right)\left[\left(1-\frac{1}{\varphi}\right)\left(\tilde{v}_{t+2}^{2}\right)^{\varphi}+\left(\tilde{v}_{t+1}^{2}\right)^{\varphi-1} \frac{\rho}{Q_{t+2}^{1-\imath}}\right]
\end{array}\right]
$$

Continuing in this way, we obtain,

$$
\frac{P_{t+j} z_{t+j}^{+} \kappa\left(\tilde{v}_{t+j}^{j}\right)^{\varphi-1}}{Q_{t+j}^{1-\iota}}=\beta \frac{v_{t+j+1}}{v_{t+j}}\left[\begin{array}{c}
\left(W_{t+j+1} \mathcal{E}_{t+j+1}^{j+1}-\Gamma_{t, j+1} \omega_{t}\left[\begin{array}{c}
\left.\left.1-\mathcal{F}_{t+j+1}^{j+1}\right]\right) \varsigma_{j+1, t+j+1} \\
\left(1-\frac{1}{\varphi}\right)\left(\tilde{v}_{t+j+1}^{j+1}\right)^{\varphi} \\
+P_{t+j+1} z_{t+j+1}^{+} \kappa\left(1-\mathcal{F}_{t+j+1}^{j+1}\right) \\
+\left(\tilde{v}_{t+j+1}^{j+1}\right)^{\varphi-1} \frac{\rho}{Q_{t+j+1}^{1-\iota}}
\end{array}\right]\right.
\end{array}\right]
$$

for $j=0,1, \ldots, N-2$. Now consider the first order necessary condition for the optimality of $\tilde{v}_{t+N-1}^{N-1}$. After multiplying this first order condition by

$$
\left(\tilde{v}_{t+N-1}^{N-1} Q_{t+N-1}^{1-\iota}+\rho\right) \frac{1}{Q_{t+N-1}^{1-\iota}}
$$

we obtain,

$$
\begin{aligned}
0= & -\beta^{N-1} \frac{v_{t+N-1}}{v_{t}} P_{t+N-1} z_{t+N-1}^{+} \kappa\left(\tilde{v}_{t+N-1}^{N-1}\right)^{\varphi-1}\left[1-\mathcal{F}_{t+N-1}^{N-1}\right]\left(\tilde{v}_{t}^{0} Q_{t}^{1-\iota}+\rho\right)\left(\tilde{v}_{t+1}^{1} Q_{t+1}^{1-\iota}+\rho\right) \cdots \\
& \cdots\left(\tilde{v}_{t+N-2}^{N-2} Q_{t+N-2}^{1-\iota}+\rho\right)\left(\tilde{v}_{t+N-1}^{N-1} Q_{t+N-1}^{1-\iota}+\rho\right) \frac{1}{Q_{t+N-1}^{1-\iota}}\left[1-\mathcal{F}_{t+N-2}^{N-2}\right] \cdots\left[1-\mathcal{F}_{t}^{0}\right] \\
& +\beta^{N} \frac{v_{t+N}}{v_{t}} J\left(\tilde{W}_{t+N}\right)\left(\tilde{v}_{t}^{0} Q_{t}^{1-\iota}+\rho\right)\left(\tilde{v}_{t+1}^{1} Q_{t}^{1-\iota}+\rho\right) \cdots\left(\tilde{v}_{t+N-1}^{N-1} Q_{t+N-1}^{1-\iota}+\rho\right) \times \\
& {\left.\left[1-\mathcal{F}_{t+N-1}^{N-1}\right] \cdots\left[1-\mathcal{F}_{t}^{0}\right]\right\} }
\end{aligned}
$$

or,

$$
P_{t+N-1} z_{t+N-1}^{+} \kappa\left(\tilde{v}_{t+N-1}^{N-1}\right)^{\varphi-1} \frac{1}{Q_{t+N-1}^{1-\iota}}=\beta \frac{v_{t+N}}{v_{t+N-1}} J\left(\tilde{W}_{t+N}\right)
$$


Making use of our expression for $J$, we obtain:

$$
P_{t+N-1} z_{t+N-1}^{+} \kappa\left(\tilde{v}_{t+N-1}^{N-1}\right)^{\varphi-1} \frac{1}{Q_{t+N-1}^{1-\iota}}=\beta \frac{v_{t+N}}{v_{t+N-1}}\left[\begin{array}{c}
\left(W_{t+N} \mathcal{E}_{t+N}^{0}-\tilde{W}_{t+N}\left(1-\mathcal{F}_{t+N}^{0}\right)\right) \varsigma_{0, t+N} \\
+P_{t+N} z_{t+N}^{+} \kappa\left[\begin{array}{c}
\left(1-\frac{1}{\varphi}\right)\left(\tilde{v}_{t+N}^{0}\right)^{\varphi} \\
+\left(\tilde{v}_{t+N}^{0}\right)^{\varphi-1} \frac{\rho}{Q_{t+N}^{1-\iota}}
\end{array}\right]\left[\begin{array}{c}
1-\mathcal{F}_{t+N}^{0}
\end{array}\right]
\end{array}\right] .
$$

The above first order conditions apply over time to a group of agencies that bargain at date $t$. We now express the first order conditions for a fixed date and different cohorts:

$$
\begin{aligned}
P_{t} z_{t}^{+} \kappa\left(\tilde{v}_{t}^{j}\right)^{\varphi-1} \frac{1}{Q_{t}^{1-\iota}}= & \beta \frac{v_{t+1}}{v_{t}}\left[\left(W_{t+1} \mathcal{E}_{t+1}^{j+1}-\Gamma_{t-j, j+1} \tilde{W}_{t-j}\left(1-\mathcal{F}_{t+1}^{j+1}\right)\right) \varsigma_{j+1, t+1}\right. \\
& \left.+P_{t+1} z_{t+1}^{+} \kappa\left(1-\mathcal{F}_{t+1}^{j+1}\right)\left(\left(1-\frac{1}{\varphi}\right)\left(\tilde{v}_{t+1}^{j+1}\right)^{\varphi}+\left(\tilde{v}_{t+1}^{j+1}\right)^{\varphi-1} \frac{\rho}{Q_{t+1}^{1-\iota}}\right)\right], \\
& \text { for } j=0, \ldots, N-2 .
\end{aligned}
$$

Scaling by $P_{t} z_{t}^{+}$yields the following scaled first order optimality conditions:

$$
\begin{aligned}
\kappa\left(\tilde{v}_{t}^{j}\right)^{\varphi-1} \frac{1}{Q_{t}^{1-\iota}}= & \beta \frac{\psi_{z^{+}, t+1}}{\psi_{z^{+}, t}}\left[\left(\bar{w}_{t+1} \mathcal{E}_{t+1}^{j+1}-G_{t-j, j+1} w_{t-j} \bar{w}_{t-j}\left(1-\mathcal{F}_{t+1}^{j+1}\right)\right) \varsigma_{j+1, t+1}(\mathrm{~B})\right. \\
& \left.+\kappa\left(1-\mathcal{F}_{t+1}^{j+1}\right)\left(\left(1-\frac{1}{\varphi}\right)\left(\tilde{v}_{t+1}^{j+1}\right)^{\varphi}+\left(\tilde{v}_{t+1}^{j+1}\right)^{\varphi-1} \frac{\rho}{Q_{t+1}^{1-\iota}}\right)\right], \\
& \text { for } j=0, \ldots, N-2,
\end{aligned}
$$

where

$$
\begin{aligned}
G_{t-i, i+1} & =\frac{\tilde{\pi}_{w, t+1} \cdots \tilde{\pi}_{w, t-i+1}}{\pi_{t+1} \cdots \pi_{t-i+1}}\left(\frac{1}{\mu_{z^{+}, t-i+1}}\right) \cdots\left(\frac{1}{\mu_{z^{+}, t+1}}\right), i \geq 0 \\
w_{t} & =\frac{\tilde{W}_{t}}{W_{t}}, \bar{w}_{t}=\frac{W_{t}}{z_{t}^{+} P_{t}} .
\end{aligned}
$$

Also,

$$
G_{t, j}=\left\{\begin{array}{cc}
\frac{\tilde{\pi}_{w, t+j} \cdots \tilde{\pi}_{w, t+1}}{\pi_{t+j} \cdots \pi_{t+1}}\left(\frac{1}{\mu_{z^{+}, t+1}}\right) \cdots\left(\frac{1}{\mu_{z^{+}, t+j}}\right) & j>0 \\
1 & j=0
\end{array} .\right.
$$

The scaled vacancy first order condition of agencies that are in the last period of their contract is:

$$
\begin{aligned}
\kappa\left(\tilde{v}_{t}^{N-1}\right)^{\varphi-1} \frac{1}{Q_{t}^{1-\iota}}= & \beta \frac{\psi_{z^{+}, t+1}}{\psi_{z^{+}, t}}\left[\left(\bar{w}_{t+1} \mathcal{E}_{t+1}^{0}-w_{t+1} \bar{w}_{t+1}\left(1-\mathcal{F}_{t+1}^{0}\right)\right) \varsigma_{0, t+1}\right. \\
& \left.+\kappa\left(1-\mathcal{F}_{t+1}^{0}\right)\left(\left(1-\frac{1}{\varphi}\right)\left(\tilde{v}_{t+1}^{0}\right)^{\varphi}+\left(\tilde{v}_{t+1}^{0}\right)^{\varphi-1} \frac{\rho}{Q_{t+1}^{1-\iota}}\right)\right] .
\end{aligned}
$$




\section{B.4.3. Agency Separation Decisions}

This section presents details of the employment agency separation decision. We start by considering the separation decision of a representative agency in the $j=0$ cohort which renegotiates the wage in the current period. After that, we consider $j>0$.

\section{The Separation Decision of Agencies that Renegotiate the Wage in the Current}

Period We start by considering the impact of $\bar{a}_{t}^{0}$ on agency and worker surplus, respectively. The aggregate surplus across all the $l_{t}^{0}$ workers in the representative agency is given by (4.18). The object, $\mathcal{F}_{t}^{0}$, is a function of $\bar{a}_{t}^{0}$ as indicated in (4.7). We denote its derivative by

$$
\mathcal{F}_{t}^{j \prime} \equiv \frac{d \mathcal{F}_{t}^{j}}{d \bar{a}_{t}^{j}}
$$

for $j=0 \ldots N-1$. Where convenient, in this subsection we include expressions that apply to the representative agency in cohort $j>0$ as well as to those in cohort, $j=0$. According to (4.4), $\bar{a}_{t}^{0}$ affects $V_{t}^{0}$ via its impact on hours worked, $\varsigma_{0, t}$. Hours worked is a function of $\bar{a}_{t}^{0}$ because $\mathcal{G}_{t}^{0}$ is (see $(4.5),(4.4)$ and $\left.(4.13)\right)$. These observations about $V_{t}^{0}$ also apply to $V_{t}^{j}$, for $j>0$. Thus, differentiating (4.13), we obtain:

$$
V_{t}^{j \prime} \equiv \frac{d}{d \bar{a}_{t}^{j}} V_{t}^{j}=\left[\Gamma_{t-j, j} \tilde{W}_{t-j} \frac{1-\tau_{t}^{y}}{1+\tau_{t}^{w}}-A_{L} \frac{\zeta_{t} \varsigma_{j, t}^{\sigma_{L}}}{v_{t}}\right] \varsigma_{j, t}^{\prime},
$$

where

$$
\varsigma_{j, t}^{\prime} \equiv \frac{d \varsigma_{j, t}}{d \bar{a}_{t}^{j}}=\frac{1}{\sigma_{L}}\left(\varsigma_{j, t}\right)^{1-\sigma_{L}} \frac{W_{t} v_{t}}{\zeta_{t} A_{L}} \frac{1-\tau_{t}^{y}}{1+\tau_{t}^{w}} \mathcal{G}_{t}^{j \prime}
$$

and

$$
\mathcal{G}_{t}^{j \prime} \equiv \frac{d \mathcal{G}_{t}^{j}}{d \bar{a}_{t}^{j}}
$$

The counterpart to (B.46) in terms of scaled variables is:

$$
\varsigma_{j, t}^{\prime} \equiv \frac{1}{\sigma_{L}}\left(\varsigma_{j, t}\right)^{1-\sigma_{L}} \frac{\bar{w}_{t} w_{t} \psi_{z^{+}, t}}{\zeta_{t} A_{L}} \frac{1-\tau_{t}^{y}}{1+\tau_{t}^{w}} \mathcal{G}_{t}^{j \prime}
$$

The value of being unemployed, $U_{t}$, is not a function of the $\bar{a}_{t}^{0}$ chosen by the representative agency because $U_{t}$ is determined by economy-wide aggregate variables such as the job finding rate (see $(4.14))$.

According to (4.12) agency surplus per worker in $l_{t}^{0}$ is given by $J\left(\omega_{t}\right)$ and this has the following representation:

$$
J\left(\omega_{t}\right)=\max _{\bar{a}_{t}^{0}} \tilde{J}\left(\omega_{t} ; \bar{a}_{t}^{0}\right)\left(1-\mathcal{F}_{t}^{0}\right)
$$


Here, $\tilde{J}\left(\omega_{t} ; \bar{a}_{t}^{0}\right)$ is given by $(4.19)$ and

$$
\begin{aligned}
& J_{t+1}^{j+1}\left(\omega_{t}\right)=\max _{\left\{\bar{a}_{t+i}^{i}, \tilde{v}_{t+i}^{i}\right\}_{i=j}^{N-1}}\left\{\left[\left(W_{t+1} \mathcal{G}_{t+1}^{j+1}-\Gamma_{t-j, j+1} \omega_{t-j}\right) \varsigma_{j+1, t+1}-P_{t+1} z_{t+1}^{+} \frac{\kappa}{\varphi}\left(\tilde{v}_{t+1}^{j+1}\right)^{\varphi}(\beta .49)\right.\right. \\
& \times\left(1-\mathcal{F}_{t+1}^{j+1}\right) \\
& +\beta \frac{v_{t+2}}{v_{t+1}}\left[\left(W_{t+2} \mathcal{G}_{t+2}^{j+2}-\Gamma_{t-j, j+2} \omega_{t-j}\right) \varsigma_{j+2, t+2}-P_{t+2} z_{t+2}^{+} \frac{\kappa}{\varphi}\left(\tilde{v}_{t+2}^{j+2}\right)^{\varphi}\right] \\
& \times\left(1-\mathcal{F}_{t+2}^{j+2}\right)\left(\chi_{t+1}^{j+1}+\rho\right)\left(1-\mathcal{F}_{t+1}^{j+1}\right) \\
& +\ldots+ \\
& \left.+\beta^{N-j} \frac{v_{t+N-j}}{v_{t+1}} J\left(\tilde{W}_{t+N-j}\right)\left(\chi_{t+N-j-1}^{N-1}+\rho\right)\left(1-\mathcal{F}_{t+N-j-1}^{N-1}\right) \cdots\left(\chi_{t+1}^{j+1}+\rho\right)\left(1-\mathcal{F}_{t+1}^{j+1}\right)\right\},
\end{aligned}
$$

for $j=0$.

In (4.19) and (B.49), it is understood that $\chi_{t+j}^{j}, \tilde{v}_{t+j}^{j}$ are connected by (4.8). Thus, the surplus of the representative agency with workforce, $l_{t}^{0}$, expressed as a function of an arbitrary value of $\bar{a}_{t}^{0}$ is given by (4.20). Differentiation of $\tilde{J}$ with respect to $\bar{a}_{t}^{j}$ need only be concerned with the impact of $\bar{a}_{t}^{j}$ on $\mathcal{G}_{t}^{j}$ and $\varsigma_{j, t}$. Generalizing (4.19) to cohort $j$ :

$$
\tilde{J}\left(\omega_{t-j} ; \bar{a}_{t}^{j}\right)=\max _{\tilde{v}_{t}^{j}}\left\{\left(W_{t} \mathcal{G}_{t}^{j}-\Gamma_{t-j, j} \omega_{t}\right) \varsigma_{j, t}-P_{t} z_{t}^{+} \frac{\kappa}{\varphi}\left(\tilde{v}_{t}^{j}\right)^{\varphi}+\beta \frac{v_{t+1}}{v_{t}}\left(\chi_{t}^{j}+\rho\right) J_{t+1}^{j+1}\left(\omega_{t}\right)\right\} .
$$

Then,

$$
\tilde{J}_{\bar{a}^{j}}\left(\omega_{t-j} ; \bar{a}_{t}^{j}\right) \equiv \frac{d \tilde{J}\left(\omega_{t-j} ; \bar{a}_{t}^{j}\right)}{d \bar{a}_{t}^{j}}=\left(W_{t} \mathcal{G}_{t}^{j}-\Gamma_{t-j, j} \omega_{t-j}\right) \varsigma_{j, t}^{\prime}+W_{t} \mathcal{G}_{t}^{j \prime} \varsigma_{j, t},
$$

where $\varsigma_{j, t}^{\prime}$ and $\mathcal{G}_{t}^{j \prime}$ are defined in (B.46) and (B.47), respectively.

We now evaluate $\mathcal{F}_{t}^{j \prime}, \mathcal{G}_{t}^{j \prime}$ and $\varsigma_{j, t}^{\prime}$, for $j \geq 0$. We assume that productivity, $a$, is drawn from a $\log$-normal distribution having the properties, $E a=1$ and $\operatorname{Var}(\log a)=\sigma_{a}^{2}$. This assumption simplifies the analysis because analytic expressions are available for objects such as $\mathcal{F}_{t}^{j \prime}, \mathcal{G}_{t}^{j \prime}$. Although these expressions are readily available in the literature (see, for example, $\mathrm{BGG}$ ), we derive them here for completeness. It is easily verified that $\mathcal{F}$ has the following representation: ${ }^{22}$

$$
\mathcal{F}\left(\bar{a}^{j} ; \sigma_{a}\right)=\frac{1}{\sigma_{a} \sqrt{2 \pi}} \int_{-\infty}^{\log \bar{a}^{j}} e^{x} e^{\frac{-\left(x+\frac{1}{2} \sigma_{a}^{2}\right)^{2}}{2 \sigma_{a}^{2}}} d x
$$

where $x=\log a$. Combining the exponential terms,

$$
\mathcal{F}\left(\bar{a}^{j} ; \sigma_{a}\right)=\frac{1}{\sigma_{a} \sqrt{2 \pi}} \int_{-\infty}^{\log \bar{a}^{j}} \exp \frac{-\left(x-\frac{1}{2} \sigma_{a}^{2}\right)^{2}}{2 \sigma_{a}^{2}} d x .
$$

${ }^{22}$ Note that $E a=1$ is imposed by specifying $E \log a=-\sigma_{a}^{2} / 2$. 
Now, make the change of variable,

$$
v \equiv \frac{x-\frac{1}{2} \sigma_{a}^{2}}{\sigma_{a}}
$$

so that

$$
d v=\frac{1}{\sigma_{a}} d x
$$

Substituting into the expression for $\mathcal{F}$ :

$$
\mathcal{F}\left(\bar{a}^{j} ; \sigma_{a}\right)=\frac{1}{\sqrt{2 \pi}} \int_{-\infty}^{\frac{\log \left(\bar{a}^{j}\right)+\frac{1}{2} \sigma_{a}^{2}}{\sigma_{a}}} \exp ^{\frac{-v^{2}}{2}} d v .
$$

This is just the standard normal cumulative distribution, evaluated at $\left(\log \left(\bar{a}^{j}\right)+\frac{1}{2} \sigma_{a}^{2}\right) / \sigma_{a}$. Differentiating $\mathcal{F}$, we obtain an expression for (B.44):

$$
\mathcal{F}_{t}^{j \prime}=\frac{1}{\bar{a}^{j} \sigma_{a} \sqrt{2 \pi}} \exp ^{-\frac{\left(\log \left(\bar{a}^{j}\right)+\frac{1}{2} \sigma_{a}^{2}\right)^{2}}{2 \sigma_{a}^{2}}} .
$$

The object on the right of the equality is just the normal density with variance $\sigma_{a}^{2}$ and mean $-\sigma_{a}^{2} / 2$, evaluated at $\log \left(\bar{a}^{j}\right)$ and divided by $\bar{a}^{j}$. From (4.6) we obtain:

$$
\mathcal{E}_{t}^{j \prime}=-\bar{a}_{t}^{j} \mathcal{F}_{t}^{j \prime}
$$

Differentiating (B.47),

$$
\mathcal{G}_{t}^{j \prime}=\frac{\mathcal{E}_{t}^{j \prime}\left(1-\mathcal{F}_{t}^{j}\right)+\mathcal{E}_{t}^{j} \mathcal{F}_{t}^{j \prime}}{\left[1-\mathcal{F}_{t}^{j}\right]^{2}}
$$

The surplus criterion governing the choice of $\bar{a}_{t}^{0}$ is (4.21). The first order necessary condition for an interior optimum is given by (4.22), which we reproduce here for convenience:

$$
s_{w} V_{t}^{0 \prime}+s_{e} \tilde{J}_{\bar{a}^{0}}\left(\tilde{W}_{t} ; \bar{a}_{t}^{0}\right)=\left[s_{w}\left(V_{t}^{0}-U_{t}\right)+s_{e} \tilde{J}\left(\tilde{W}_{t} ; \bar{a}_{t}^{0}\right)\right] \frac{\mathcal{F}_{t}^{0 \prime}}{1-\mathcal{F}_{t}^{0}},
$$

where we have made use of the fact that the wage paid to workers in the bargaining period is denoted $\tilde{W}_{t}$. After substituting from (B.45) and (B.50):

$$
\begin{aligned}
& s_{w}\left(\tilde{W}_{t} \frac{1-\tau_{t}^{y}}{1+\tau_{t}^{w}}-A_{L} \frac{\zeta_{t} \varsigma_{0, t}^{\sigma_{L}}}{v_{t}}\right) \varsigma_{0, t}^{\prime}+s_{e}\left[\left(W_{t} \mathcal{G}_{t}^{0}-\tilde{W}_{t}\right) \varsigma_{0, t}^{\prime}+W_{t} \mathcal{G}_{t}^{0 \prime} \varsigma_{0, t}\right]= \\
& {\left[s_{w}\left(V_{t}^{0}-U_{t}\right)+s_{e} \tilde{J}\left(\tilde{W}_{t} ; \bar{a}_{t}^{0}\right)\right] \frac{\mathcal{F}_{t}^{0 \prime}}{1-\mathcal{F}_{t}^{0}} .}
\end{aligned}
$$


In scaled terms this is

$$
\begin{aligned}
& s_{w}\left(w_{t} W_{t} \frac{1-\tau_{t}^{y}}{1+\tau_{t}^{w}}-A_{L} P_{t} z_{t}^{+} \frac{\zeta_{t} \varsigma_{0, t}^{\sigma_{L}}}{\psi_{z^{+}, t}}\right) \varsigma_{0, t}^{\prime}+s_{e}\left[\left(W_{t} \mathcal{G}_{t}^{0}-w_{t} W_{t}\right) \varsigma_{0, t}^{\prime}+W_{t} \mathcal{G}_{t}^{0 \prime} \varsigma_{0, t}\right]= \\
& {\left[s_{w}\left(P_{t} z_{t}^{+} V_{z^{+}, t}^{0}-U_{z^{+}, t} P_{t} z_{t}^{+}\right)+s_{e} \tilde{J}\left(\tilde{W}_{t} ; \bar{a}_{t}^{0}\right)\right] \frac{\mathcal{F}_{t}^{0 \prime}}{1-\mathcal{F}_{t}^{0}}} \\
& P_{t} z_{t}^{+} s_{w}\left(w_{t} \bar{w}_{t} \frac{1-\tau_{t}^{y}}{1+\tau_{t}^{w}}-A_{L} \frac{\zeta_{t} \varsigma_{0, t}^{\sigma_{L}}}{\psi_{z^{+}, t}}\right) \varsigma_{0, t}^{\prime}+P_{t} z_{t}^{+} \bar{w}_{t} s_{e}\left[\left(\mathcal{G}_{t}^{0}-w_{t}\right) \varsigma_{0, t}^{\prime}+\mathcal{G}_{t}^{0 \prime} \varsigma_{0, t}\right]= \\
& P_{t} z_{t}^{+}\left[s_{w}\left(V_{z^{+}, t}^{0}-U_{z^{+}, t}\right)+s_{e} \tilde{J}_{z^{+}, t}^{0}\right] \frac{\mathcal{F}_{t}^{0 \prime}}{1-\mathcal{F}_{t}^{0}}
\end{aligned}
$$

Dividing through by $P_{t} z_{t}^{+}$yields:

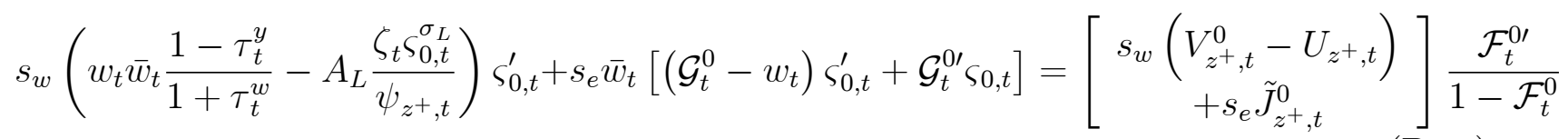

The Separation Decision of Agencies that Renegotiated in Previous Periods We now turn to the $\bar{a}_{t}^{j}$ decision, for $j=1, \ldots, N-1$. The representative agency that selects $\bar{a}_{t}^{j}$ is a member of the cohort of agencies that bargained $j$ periods in the past. We denote the present discounted value of profits of the representative agency in cohort $j$ by $F_{t}^{j}\left(\omega_{t-j}\right)$ :

$$
\begin{aligned}
\frac{F_{t}^{j}\left(l_{t}^{j}, \omega_{t-j}\right)}{l_{t}^{j}} \equiv & J_{t}^{j}\left(\omega_{t-j}\right)=\max _{\left\{\bar{a}_{t+i}^{j+i}, \tilde{v}_{t+i}^{j+i}\right\}_{i=0}^{N-j-1}}\left\{\left[\left(W_{t} \mathcal{G}_{t}^{j}-\Gamma_{t-j, j} \omega_{t-j}\right) \varsigma_{j, t}-P_{t} z_{t}^{+} \frac{\kappa}{\varphi}\left(\tilde{v}_{t}^{j}\right)^{\varphi}\right]\right. \\
& \times\left(1-\mathcal{F}_{t}^{j}\right) \\
& +\beta \frac{v_{t+1}}{v_{t}}\left[\left(W_{t+1} \mathcal{G}_{t+1}^{j+1}-\Gamma_{t-j, j+1} \omega_{t-j}\right) \varsigma_{j+1, t+1}-P_{t+1} z_{t+1}^{+} \frac{\kappa}{\varphi}\left(\tilde{v}_{t+1}^{j+1}\right)^{\varphi}\right] \\
& \times\left(1-\mathcal{F}_{t+1}^{j+1}\right)\left(\chi_{t}^{j}+\rho\right)\left(1-\mathcal{F}_{t}^{j}\right) \\
& +\ldots+ \\
& +\beta^{N-j} \frac{v_{t+N-j}}{v_{t}} J\left(\tilde{W}_{t+N-j}\right)\left(\chi_{t+N-1-j}^{N-1}+\rho\right)\left(1-\mathcal{F}_{t+N-j-1}^{N-1}\right) \cdots \\
& \left.\left(\chi_{t}^{j}+\rho\right)\left(1-\mathcal{F}_{t}^{j}\right)\right\} .
\end{aligned}
$$

Here, we exploit that $F_{t}^{j}\left(l_{t}^{j}, \omega_{t-j}\right)$ is proportional to $l_{t}^{j}$, as in the case $j=0$ considered in (4.12). In particular, $J_{t}^{j}\left(\omega_{t-j}\right)$ is not a function of $l_{t}^{j}$ and corresponds to the object in (B.49) with the time index, $t$, replaced by $t-j$. We can write $J_{t}^{j}\left(\omega_{t-j}\right)$ in the following form:

$$
J_{t}^{j}\left(\omega_{t-j}\right)=\tilde{J}_{t}^{j}\left(\omega_{t-j} ; \bar{a}_{t}^{j}\right)\left(1-\mathcal{F}_{t}^{j}\right)
$$


where

$$
\tilde{J}_{t}^{j}\left(\omega_{t-j} ; \bar{a}_{t}^{j}\right)=\left(W_{t} \mathcal{G}_{t}^{j}-\Gamma_{t-j, j} \omega_{t-j}\right) \varsigma_{j, t}-P_{t} z_{t}^{+} \frac{\kappa}{\varphi}\left(\tilde{v}_{t}^{j}\right)^{\varphi}+\beta \frac{v_{t+1}}{v_{t}} J_{t+1}^{j+1}\left(\omega_{t-j}\right)\left(\chi_{t}^{j}+\rho\right)
$$

from a generalization of (4.19) to $j=1 \ldots N-1$.

In this way, we obtain an expression for agency surplus for agencies that have not negotiated for $j$ periods which is symmetric to (4.20):

$$
F_{t}^{j}\left(\omega_{t-j}\right)=\tilde{J}_{t}^{j}\left(\omega_{t-j} ; \bar{a}_{t}^{j}\right)\left(1-\mathcal{F}_{t}^{j}\right) l_{t}^{j}
$$

Our expression for total surplus is the analog of (4.21):

$$
\left[s_{w}\left(V_{t}^{j}-U_{t}\right)+s_{e} \tilde{J}_{t}^{j}\left(\omega_{t-j} ; \bar{a}_{t}^{j}\right)\right]\left(1-\mathcal{F}_{t}^{j}\right) l_{t}^{j} .
$$

Differentiating,

$$
s_{w} V_{t}^{j \prime}+s_{e} \tilde{J}_{\bar{a}^{j}}\left(\omega_{t-j} ; \bar{a}_{t}^{j}\right)=\left[s_{w}\left(V_{t}^{j}-U_{t}\right)+s_{e} \tilde{J}_{t}^{j}\left(\omega_{t-j} ; \bar{a}_{t}^{j}\right)\right] \frac{\mathcal{F}_{t}^{j \prime}}{1-\mathcal{F}_{t}^{j}},
$$

which corresponds to (4.22). Here, $\tilde{J}_{\bar{a}^{j}}\left(\omega_{t-1} ; \bar{a}_{t}^{j}\right)$ is the analog of (B.50) with index 0 replaced by $j$. After substituting from the analogs for cohort $j$ of (B.45), (B.50):

$$
\begin{aligned}
& s_{w}\left(\Gamma_{t-j, j} \tilde{W}_{t-j} \frac{1-\tau_{t}^{y}}{1+\tau_{t}^{w}}-A_{L} \frac{\zeta_{t} \varsigma_{j, t}^{\sigma_{L}}}{v_{t}}\right) \varsigma_{j, t}^{\prime}+s_{e}\left[\left(W_{t} \mathcal{G}_{t}^{j}-\Gamma_{t-j, j} \tilde{W}_{t-j}\right) \varsigma_{j, t}^{\prime}+W_{t} \mathcal{G}_{t}^{j \prime} \varsigma_{j, t}\right]= \\
& {\left[s_{w}\left(V_{t}^{j}-U_{t}\right)+s_{e} \tilde{J}\left(\tilde{W}_{t-j} ; \bar{a}_{t}^{j}\right)\right] \frac{\mathcal{F}_{t}^{j \prime}}{1-\mathcal{F}_{t}^{j}} .}
\end{aligned}
$$

Scaling analogously to (B.55) and plugging in $\tilde{W}_{t-j}=w_{t-j} \bar{w}_{t-j} P_{t-j} z_{t-j}^{+}$and $\bar{w}_{t} z_{t}^{+} P_{t}=W_{t}$ we obtain:

$$
\begin{aligned}
& \left.s_{w}\left(G_{t-j, j} w_{t-j} \bar{w}_{t-j} \frac{1-\tau_{t}^{y}}{1+\tau_{t}^{w}}-A_{L} \frac{\zeta_{t} \varsigma_{j, t}^{\sigma_{L}}}{\psi_{z^{+}, t}}\right) \varsigma_{j, t}^{\prime}+s_{e}\left[\left(\bar{w}_{t} \mathcal{G}_{t}^{j}-G_{t-j, j} \bar{w}_{t-j} w_{t-j}\right) \varsigma_{j, t}^{\prime}+\bar{w}_{t} \mathcal{G}_{t}^{j \prime} \varsigma_{j, p}\right] .59\right) \\
& {\left[s_{w}\left(V_{z^{+}, t}^{j}-U_{z^{+}, t}\right)+s_{e} \tilde{J}_{z^{+}, t}^{j}\right] \frac{\mathcal{F}_{t}^{j \prime}}{1-\mathcal{F}_{t}^{j}}}
\end{aligned}
$$

Finally, we need an explicit expression for $\tilde{J}\left(\tilde{W}_{t} ; \bar{a}_{t}^{j}\right)$, or rather its scaled equivalent $\tilde{J}_{z^{+}, t}^{j}$. For this we use (B.49) to write out $J_{t+1}^{j+1}\left(\omega_{t}\right)$ for $j=1 \ldots N$ and plug into (4.19):

$$
\tilde{J}_{t}^{j}\left(\omega_{t-j} ; \bar{a}_{t}^{j}\right)=\left(W_{t} \mathcal{G}_{t}^{j}-\Gamma_{t-j, j} \omega_{t-j}\right) \varsigma_{j, t}-P_{t} z_{t}^{+} \frac{\kappa}{\varphi}\left(\tilde{v}_{t}^{j}\right)^{\varphi}+\beta \frac{v_{t+1}}{v_{t}} J_{t+1}^{j+1}\left(\omega_{t-1}\right)\left(\chi_{t}^{j}+\rho\right)
$$


Redisplaying (B.49) for convenience:

$$
\begin{aligned}
& J_{t+1}^{j+1}\left(\omega_{t}\right)=\max _{\left\{\bar{a}_{t+i}^{i} \tilde{v}_{t+i}^{i}\right\}_{i=j}^{N-1}}\left\{\left[\left(W_{t+1} \mathcal{G}_{t+1}^{j+1}-\Gamma_{t-j, j+1} \omega_{t-j}\right) \varsigma_{j+1, t+1}-P_{t+1} z_{t+1}^{+} \frac{\kappa}{\varphi}\left(\tilde{v}_{t+1}^{j+1}\right)^{\varphi}\right]\right. \\
& \times\left(1-\mathcal{F}_{t+1}^{j+1}\right) \\
& +\beta \frac{v_{t+2}}{v_{t+1}}\left[\left(W_{t+2} \mathcal{G}_{t+2}^{j+2}-\Gamma_{t-j, j+2} \omega_{t-j}\right) \varsigma_{j+2, t+2}-P_{t+2} z_{t+2}^{+} \frac{\kappa}{\varphi}\left(\tilde{v}_{t+2}^{j+2}\right)^{\varphi}\right] \\
& \times\left(1-\mathcal{F}_{t+2}^{j+2}\right)\left(\chi_{t+1}^{j+1}+\rho\right)\left(1-\mathcal{F}_{t+1}^{j+1}\right) \\
& +\ldots+ \\
& +\beta^{N-j} \frac{v_{t+N-j}}{v_{t+1}} J\left(\tilde{W}_{t+N-j}\right)\left(\chi_{t+N-j-1}^{N-1}+\rho\right)\left(1-\mathcal{F}_{t+N-j-1}^{N-1}\right) \cdots \\
& \left.\left(\chi_{t+1}^{j+1}+\rho\right)\left(1-\mathcal{F}_{t+1}^{j+1}\right)\right\},
\end{aligned}
$$

Accordingly:

$$
\begin{aligned}
\tilde{J}_{t}^{j}\left(\omega_{t-j} ; \bar{a}_{t}^{j}\right)= & \left(W_{t} \mathcal{G}_{t}^{j}-\Gamma_{t-j, j} \omega_{t-j}\right) \varsigma_{j, t}-P_{t} z_{t}^{+} \frac{\kappa}{\varphi}\left(\tilde{v}_{t}^{j}\right)^{\varphi}+\beta \frac{v_{t+1}}{v_{t}}\left(\chi_{t}^{j}+\rho\right)\{ \\
& {\left[\left(W_{t+1} \mathcal{G}_{t+1}^{j+1}-\Gamma_{t-j, j+1} \omega_{t-j}\right) \varsigma_{j+1, t+1}-P_{t+1} z_{t+1}^{+} \frac{\kappa}{\varphi}\left(\tilde{v}_{t+1}^{j+1}\right)^{\varphi}\right]\left(1-\mathcal{F}_{t+1}^{j+1}\right) } \\
& +\beta \frac{v_{t+2}}{v_{t+1}}\left[\left(W_{t+2} \mathcal{G}_{t+2}^{j+2}-\Gamma_{t-j, j+2} \omega_{t-j}\right) \varsigma_{j+2, t+2}-P_{t+2} z_{t+2}^{+} \frac{\kappa}{\varphi}\left(\tilde{v}_{t+2}^{j+2}\right)^{\varphi}\right] \\
& \times\left(1-\mathcal{F}_{t+2}^{j+2}\right)\left(\chi_{t+1}^{j+1}+\rho\right)\left(1-\mathcal{F}_{t+1}^{j+1}\right) \\
& +\ldots+ \\
& +\beta^{N-j} \frac{v_{t+N-j}}{v_{t+1}} J\left(\tilde{W}_{t+N-j}\right)\left(\chi_{t+N-j-1}^{N-1}+\rho\right)\left(1-\mathcal{F}_{t+N-j-1}^{N-1}\right) \cdots \\
& \left.\left(\chi_{t+1}^{j+1}+\rho\right)\left(1-\mathcal{F}_{t+1}^{j+1}\right)\right\}
\end{aligned}
$$


for $j=0, \ldots, N-1$. Plugging in for $\omega_{t-j}=\tilde{W}_{t-j}=w_{t-j} \bar{w}_{t-j} P_{t-j} z_{t-j}^{+}$and scaling obtains:

$$
\begin{aligned}
\tilde{J}_{z^{+}, t}^{j}\left(\tilde{W}_{t-j} ; \bar{a}_{t}^{j}\right) \equiv & \frac{\tilde{J}^{j}\left(\tilde{W}_{t} ; \bar{a}_{t}^{j}\right)}{P_{t} z_{t}^{+}}=\left(\bar{w}_{t} \mathcal{G}_{t}^{j}-G_{t-j, j} w_{t-j} \bar{w}_{t-j}\right) \varsigma_{j, t}-\frac{\kappa}{\varphi}\left(\tilde{v}_{t}^{j}\right)^{\varphi}+ \\
& \beta \frac{\psi_{z^{+}, t+1}}{\psi_{z^{+}, t}} \frac{P_{t} z_{t}^{+}}{P_{t+1} z_{t+1}^{+}}\left(\chi_{t}^{j}+\rho\right) \\
& \times\left\{\frac{P_{t+1} z_{t+1}^{+}}{P_{t} z_{t}^{+}}\left[\left(\bar{w}_{t+1} \mathcal{G}_{t+1}^{j+1}-G_{t-j, j+1} w_{t-j} \bar{w}_{t-j}\right) \varsigma_{j+1, t+1}-\frac{\kappa}{\varphi}\left(\tilde{v}_{t+1}^{j+1}\right)^{\varphi}\right]\left(1-\mathcal{F}_{t+1}^{j+1}\right)\right. \\
& +\beta \frac{\psi_{z^{+}, t+2}}{\psi_{z^{+}, t+1}} \frac{P_{t+1} z_{t+1}^{+}}{P_{t+2} z_{t+2}^{+}} \frac{P_{t+2} z_{t+2}^{+}}{P_{t} z_{t}^{+}}\left[\left(\bar{w}_{t+2} \mathcal{G}_{t+2}^{j+2}-G_{t-j, j+2} w_{t-j} \bar{w}_{t-j}\right) \varsigma_{j+2, t+2}\right] \\
& \left.\times\left(1-\mathcal{F}_{t+2}^{j+2}\right)\left(\chi_{t+1}^{j+1}+\rho\right)\left(1-\tilde{v}_{t+2}^{j+2}\right)^{\varphi}{ }_{t+1}^{j+1}\right) \\
& \left.+\ldots+\frac{P^{+}}{\varphi}\right] \\
& +\beta^{N-j} \frac{\psi_{z^{+}, t+N-j}}{\psi_{z^{+}, t+1}} \frac{P_{t+1} z_{t+1}^{+}}{P_{t+N-j} z_{t+N-j}^{+}} \frac{P_{t+N-j} z_{t+N-j}^{+}}{P_{t} z_{t}^{+}} J_{z^{+}, t+N-j} \\
& \left.\times\left(\chi_{t+N-j-1}^{N-1}+\rho\right)\left(1-\mathcal{F}_{t+N-j-1}^{N-1}\right) \cdots\left(\chi_{t+1}^{j+1}+\rho\right)\left(1-\mathcal{F}_{t+1}^{j+1}\right)\right\}
\end{aligned}
$$

which can be rewritten as

$$
\begin{aligned}
\tilde{J}_{z^{+}, t}^{j}\left(\tilde{W}_{t-j} ; \bar{a}_{t}^{j}\right)= & \left(\bar{w}_{t} \mathcal{G}_{t}^{j}-G_{t-j, j} w_{t-j} \bar{w}_{t-j}\right) \varsigma_{j, t}-\frac{\kappa}{\varphi}\left(\tilde{v}_{t}^{j}\right)^{\varphi}+\beta \frac{\psi_{z^{+}, t+1}}{\psi_{z^{+}, t}}\left(\chi_{t}^{j}+\rho\right) \\
& \times\left\{\left[\left(\bar{w}_{t+1} \mathcal{G}_{t+1}^{j+1}-G_{t-j, j+1} w_{t-j} \bar{w}_{t-j}\right) \varsigma_{j+1, t+1}-\frac{\kappa}{\varphi}\left(\tilde{v}_{t+1}^{j+1}\right)^{\varphi}\right]\left(1-\mathcal{F}_{t+1}^{j+1}\right)\right. \\
& +\beta \frac{\psi_{z^{+}, t+2}}{\psi_{z^{+}, t+1}}\left[\left(\bar{w}_{t+2} \mathcal{G}_{t+2}^{j+2}-G_{t-j, j+2} w_{t-j} \bar{w}_{t-j}\right) \varsigma_{j+2, t+2}-\frac{\kappa}{\varphi}\left(\tilde{v}_{t+2}^{j+2}\right)^{\varphi}\right] \\
& \times\left(1-\mathcal{F}_{t+2}^{j+2}\right)\left(\chi_{t+1}^{j+1}+\rho\right)\left(1-\mathcal{F}_{t+1}^{j+1}\right) \\
& +\ldots+ \\
& +\beta^{N-j} \frac{\psi_{z^{+}, t+N-j}}{\psi_{z^{+}, t+1}} J_{z^{+}, t+N-j}\left(\chi_{t+N-j-1}^{N-1}+\rho\right) \\
& \left.\times\left(1-\mathcal{F}_{t+N-j-1}^{N-1}\right) \cdots\left(\chi_{t+1}^{j+1}+\rho\right)\left(1-\mathcal{F}_{t+1}^{j+1}\right)\right\}
\end{aligned}
$$

Re-writing this in a way that makes use of $\Omega_{t}^{i}$ defined in (B.64) below:

$$
\begin{aligned}
\tilde{J}_{z^{+}, t}^{j}\left(\tilde{W}_{t-j} ; \bar{a}_{t}^{j}\right)= & \left(\bar{w}_{t} \mathcal{G}_{t}^{j}-G_{t-j, j} w_{t-j} \bar{w}_{t-j}\right) \varsigma_{j, t}-\frac{\kappa}{\varphi}\left(\tilde{v}_{t}^{j}\right)^{\varphi}+\beta \frac{\psi_{z^{+}, t+1}}{\psi_{z^{+}, t}} \frac{1}{\left(1-\mathcal{F}_{t}^{j}\right)} \quad(\mathrm{B} .61) \\
& \times\left\{\left[\left(\bar{w}_{t+1} \mathcal{G}_{t+1}^{j+1}-G_{t-j, j+1} w_{t-j} \bar{w}_{t-j}\right) \varsigma_{j+1, t+1}-\frac{\kappa}{\varphi}\left(\tilde{v}_{t+1}^{j+1}\right)^{\varphi}\right] \Omega_{t+1}^{j+1}\right. \\
& +\beta \frac{\psi_{z^{+}, t+2}}{\psi_{z^{+}, t+1}}\left[\left(\bar{w}_{t+2} \mathcal{G}_{t+2}^{j+2}-G_{t-j, j+2} w_{t-j} \bar{w}_{t-j}\right) \varsigma_{j+2, t+2}-\frac{\kappa}{\varphi}\left(\tilde{v}_{t+2}^{j+2}\right)^{\varphi}\right] \Omega_{t+2}^{j+2} \\
& +\ldots+ \\
& \left.+\beta^{N-j-1} \frac{\psi_{z^{+}, t+N-j}}{\psi_{z^{+}, t+1}} J_{z^{+}, t+N-j} \Omega_{t+N-j}^{N-j}\right\}
\end{aligned}
$$


for $j=0, \ldots, N-1$.

\section{B.4.4. Bargaining Problem}

The first order condition associated with the Nash bargaining problem is:

$$
\eta_{t} V_{w, t} J_{z^{+}, t}+\left(1-\eta_{t}\right)\left[V_{z^{+}, t}^{0}-U_{z^{+}, t}\right] J_{w, t}=0,
$$

after division by $z_{t}^{+} P_{t}$.

The following is an expression for $J_{t}$ evaluated at $\omega_{t}=\tilde{W}_{t}$, in terms of scaled variables:

$$
\begin{aligned}
J_{z^{+}, t}= & \sum_{j=0}^{N-1} \beta^{j} \frac{\psi_{z^{+}, t+j}}{\psi_{z^{+}, t}}\left[\left(\bar{w}_{t+j} \frac{\mathcal{E}_{t+j}^{j}}{1-\mathcal{F}_{t+j}^{j}}-G_{t, j} w_{t} \bar{w}_{t}\right) \varsigma_{j, t+j}-\frac{\kappa}{\varphi}\left(\tilde{v}_{t+j}^{j}\right)^{\varphi}\right] \Omega_{t+j}^{j} \\
& +\beta^{N} \frac{\psi_{z^{+}, t+N}}{\psi_{z^{+}, t}} J_{z^{+}, t+N} \frac{\Omega_{t+N}^{N}}{1-\mathcal{F}_{t+N}^{0}} .
\end{aligned}
$$

We also require the derivative of $J$ with respect to $\omega_{t}$, i.e. the marginal surplus of the employment agency with respect to the negotiated wage. By the envelope condition, we can ignore the impact of a change in $\omega_{t}$ on endogenous separations and vacancy decisions, and only be concerned with the direct impact of $\omega_{t}$ on $J$. Taking the derivative of (B.39):

$$
\begin{aligned}
J_{w, t}= & -\left(1-\mathcal{F}_{t}^{0}\right) \varsigma_{0, t} \\
& -\beta \frac{v_{t+1}}{v_{t}} \Gamma_{t, 1} \varsigma_{1, t+1}\left(\chi_{t}^{0}+\rho\right)\left(1-\mathcal{F}_{t+1}^{1}\right)\left(1-\mathcal{F}_{t}^{0}\right) \\
& -\beta^{2} \frac{v_{t+2}}{v_{t}} \Gamma_{t, 2} \varsigma_{2, t+2}\left(\chi_{t}^{0}+\rho\right)\left(\chi_{t+1}^{1}+\rho\right)\left(1-\mathcal{F}_{t+2}^{2}\right)\left[1-\mathcal{F}_{t+1}^{1}\right]\left[1-\mathcal{F}_{t}^{0}\right] \\
& -\ldots-\beta^{N-1} \frac{v_{t+N-1}}{v_{t}} \Gamma_{t, N-1} \varsigma_{N-1, t+N-1}\left(\chi_{t}^{0}+\rho\right)\left(\chi_{t+1}^{1}+\rho\right) \cdots\left(\chi_{t+1}^{N-2}+\rho\right) \times \\
& \left(1-\mathcal{F}_{t+N-1}^{N-1}\right) \cdots\left[1-\mathcal{F}_{t}^{0}\right] .
\end{aligned}
$$

Let,

$$
\Omega_{t+j}^{j}=\left\{\begin{array}{cc}
\left(1-\mathcal{F}_{t+j}^{j}\right) \prod_{l=0}^{j-1}\left(\chi_{t+l}^{l}+\rho\right)\left(1-\mathcal{F}_{t+l}^{l}\right) & j>0 \\
1-\mathcal{F}_{t}^{0} & j=0
\end{array} .\right.
$$

It is convenient to express this in recursive form:

$$
\begin{aligned}
\Omega_{t}^{0} & =1-\mathcal{F}_{t}^{0}, \Omega_{t+1}^{1}=\left(1-\mathcal{F}_{t+1}^{1}\right)\left(\chi_{t}^{0}+\rho\right) \overbrace{\left(1-\mathcal{F}_{t}^{0}\right)}^{\Omega_{t}^{0}}, \\
\Omega_{t+2}^{2} & =\left(1-\mathcal{F}_{t+2}^{2}\right)\left(\chi_{t+1}^{1}+\rho\right) \overbrace{\left(\chi_{t}^{0}+\rho\right)\left(1-\mathcal{F}_{t}^{0}\right)\left(1-\mathcal{F}_{t+1}^{1}\right)}^{\Omega_{t+1}^{1}}, \ldots
\end{aligned}
$$

so that

$$
\Omega_{t+j}^{j}=\left(1-\mathcal{F}_{t+j}^{j}\right)\left(\chi_{t+j-1}^{j-1}+\rho\right) \Omega_{t+j-1}^{j-1}
$$


for $j=1,2, \ldots$. It is convenient to define these objects at date $t$ as a function of variables dated $t$ and earlier for the purposes of implementing these equations in Dynare:

$$
\begin{aligned}
& \Omega_{t}^{0}=1-\mathcal{F}_{t}^{0}, \Omega_{t}^{1}=\left(1-\mathcal{F}_{t}^{1}\right)\left(\chi_{t-1}^{0}+\rho\right) \overbrace{\left(1-\mathcal{F}_{t-1}^{0}\right)}^{\Omega_{t-1}^{0}}, \\
& \Omega_{t}^{2}=\left(1-\mathcal{F}_{t}^{2}\right)\left(\chi_{t-1}^{1}+\rho\right) \overbrace{\left(\chi_{t-2}^{0}+\rho\right)\left(1-\mathcal{F}_{t-2}^{0}\right)\left(1-\mathcal{F}_{t-1}^{1}\right)}^{\Omega_{t-1}^{1}}
\end{aligned}
$$

so that

$$
\Omega_{t}^{j}=\left(1-\mathcal{F}_{t}^{j}\right)\left(\chi_{t-1}^{j-1}+\rho\right) \Omega_{t-1}^{j-1} .
$$

Then, in terms of scaled variables we obtain:

$$
J_{w, t}=-\sum_{j=0}^{N-1} \beta^{j} \frac{\psi_{z^{+}, t+j}}{\psi_{z^{+}, t}} G_{t, j} \Omega_{t+j}^{j} \varsigma_{j, t+j} .
$$

Scaling $V_{t}^{i}$ by $P_{t} z_{t}^{+}$, we obtain:

$$
\begin{aligned}
V_{z^{+}, t}^{i}= & G_{t-i, i} w_{t-i} \bar{w}_{t-i} \varsigma_{i, t} \frac{1-\tau_{t}^{y}}{1+\tau_{t}^{w}}-\zeta_{t}^{h} A_{L} \frac{\varsigma_{i, t}^{1+\sigma_{L}}}{\left(1+\sigma_{L}\right) \psi_{z^{+}, t}} \\
& +\beta E_{t} \frac{\psi_{z^{+}, t+1}}{\psi_{z^{+}, t}}\left[\rho\left(1-\mathcal{F}_{t+1}^{i+1}\right) V_{z^{+}, t+1}^{i+1}+\left(1-\rho+\rho \mathcal{F}_{t+1}^{i+1}\right) U_{z^{+}, t+1}\right]
\end{aligned}
$$

for $i=0,1, \ldots, N-1$, where

$$
\frac{V_{t}^{i}}{P_{t} z_{t}^{+}}=V_{z^{+}, t}^{i}, U_{z^{+}, t+1}=\frac{U_{t+1}}{P_{t+1} z_{t+1}^{+}}
$$

In our analysis of the Nash bargaining problem, we must have the derivative of $V_{t}^{0}$ with respect to the wage rate. To define this derivative, it is useful to have:

$$
\mathcal{M}_{t+j}=\left(1-\mathcal{F}_{t}^{0}\right) \cdots\left(1-\mathcal{F}_{t+j}^{j}\right)
$$

for $j=0, \ldots, N-1$. Then, the derivative of $V^{0}$, which we denote by $V_{w}^{0}\left(\omega_{t}\right)$, is:

$$
\begin{aligned}
V_{w}^{0}\left(\omega_{t}\right) & =E_{t} \sum_{j=0}^{N-1}(\beta \rho)^{j} \mathcal{M}_{t+j} \varsigma_{j, t+j} \frac{1-\tau_{t+j}^{y}}{1+\tau_{t+j}^{w}} \Gamma_{t, j} \frac{v_{t+j}}{v_{t}} \\
& =E_{t} \sum_{j=0}^{N-1}(\beta \rho)^{j} \mathcal{M}_{t+j} \varsigma_{j, t+j} \frac{1-\tau_{t+j}^{y}}{1+\tau_{t+j}^{w}} G_{t, j} \frac{\psi_{z^{+}, t+j}}{\psi_{z^{+}, t}} .
\end{aligned}
$$

Note that $\omega_{t}$ has no impact on the intensity of labor effort. This is determined by (B.36), independent of the wage rate paid to workers. 
Scaling (4.14),

$$
U_{z^{+}, t}=b^{u}\left(1-\tau_{t}^{y}\right)+\beta E_{t} \frac{\psi_{z^{+}, t+1}}{\psi_{z^{+}, t}}\left[f_{t} V_{z^{+}, t+1}^{x}+\left(1-f_{t}\right) U_{z^{+}, t+1}\right] .
$$

This value function applies to any unemployed worker, whether they got that way because they were unemployed in the previous period and did not find a job, or they arrived into unemployment because of an exogenous separation, or because they arrived because of an endogenous separation.

\section{B.4.5. Final equilibrium conditions}

Total job matches must also satisfy the following matching function:

$$
m_{t}=\sigma_{m}\left(1-L_{t}\right)^{\sigma} v_{t}^{1-\sigma}
$$

where

$$
L_{t}=\sum_{j=0}^{N-1}\left(1-\mathcal{F}_{t}^{j}\right) l_{t}^{j} .
$$

and $\sigma_{m}$ is the productivity of the matching technology.

In our environment, there is a distinction between effective hours and measured hours. Effective hours is the hours of each person, adjusted by their productivity, $a$. Recall that the average productivity of a worker in working in cohort $j$ (i.e., who has survived the endogenous

productivity cut) is $\mathcal{E}_{t}^{j} /\left(1-\mathcal{F}_{t}^{j}\right)$. The number of workers who survive the productivity cut in cohort $j$ is $\left(1-\mathcal{F}_{t}^{j}\right) l_{t}^{j}$, so that our measure of total effective hours is:

$$
H_{t}=\sum_{j=0}^{N-1} \varsigma_{j, t} \mathcal{E}_{t}^{j} l_{t}^{j},
$$

In contrast, total measured hours is:

$$
H_{t}^{\text {meas }}=\sum_{j=0}^{N-1} \varsigma_{j, t}\left(1-\mathcal{F}_{t}^{j}\right) l_{t}^{j} .
$$

The job finding rate is:

$$
f_{t}=\frac{m_{t}}{1-L_{t}}
$$

The probability of filling a vacancy is:

$$
Q_{t}=\frac{m_{t}}{v_{t}}
$$

Total vacancies $v_{t}$ are related to vacancies posted by the individual cohorts as follows:

$$
v_{t}=\frac{1}{Q_{t}^{\iota}} \sum_{j=0}^{N-1} \tilde{v}_{t}^{j}\left(1-\mathcal{F}_{t}^{j}\right) l_{t}^{j} .
$$

Note however, that this equation does not add a constraint to the model equilibrium. In fact, it can be derived from the equilibrium equations (B.74), (4.16) and (4.8). 


\section{B.4.6. Characterization of the Bargaining Set}

Implicitly, we assumed that the scaled wage,

$$
w_{t}^{i}=\frac{W_{t}^{i}}{z_{t}^{+} P_{t}}
$$

paid by an employment agency which has renegotiated most recently $i$ periods in the past is always inside the bargaining set, $\left[\underline{\mathrm{w}}_{t}^{i}, \bar{w}_{t}^{i}\right], i=0,1, \ldots, N-1$. Here, $\overline{\mathrm{w}}_{t}^{i}$ has the property that if $w_{t}^{i}>\bar{w}_{t}^{i}$ then the agency prefers not to employ the worker and $\underline{w}_{t}^{i}$ has the property that if $w_{t}^{i}<\underline{\mathrm{w}}_{t}^{i}$ then the worker prefers to be unemployed. We now describe our strategy for computing $\underline{\mathrm{w}}_{t}^{i}$ and $\overline{\mathrm{w}}_{t}^{i}$.

The lower bound, $\underline{\mathrm{w}}_{t}^{i}$, sets the surplus of a worker, $\left(1-\mathcal{F}_{t}^{i}\right)\left(V_{z^{+}, t}^{i}-U_{z^{+}, t}\right)$, in an agency in cohort $i$ to zero. By (B.66):

$$
\begin{aligned}
U_{z^{+}, t}= & \underline{\mathrm{w}}_{t}^{i} \varsigma_{i, t} \frac{1-\tau_{t}^{y}}{1+\tau_{t}^{w}}-\zeta_{t}^{h} A_{L} \frac{\varsigma_{i, t}^{1+\sigma_{L}}}{\left(1+\sigma_{L}\right) \psi_{z^{+}, t}} \\
& +\beta E_{t} \frac{\psi_{z^{+}, t+1}}{\psi_{z^{+}, t}}\left[\rho\left(1-\mathcal{F}_{t+1}^{i+1}\right) V_{z^{+}, t+1}^{i+1}+\left(1-\rho+\rho \mathcal{F}_{t+1}^{i+1}\right) U_{z^{+}, t+1}\right],
\end{aligned}
$$

for $\mathrm{i}=0, \ldots, \mathrm{N}-1$. In steady state, this is

$$
\underline{\mathrm{w}}^{i}=\frac{U_{z^{+}}+\zeta^{h} A_{L} \frac{\varsigma_{i}^{1+\sigma_{L}}}{\left(1+\sigma_{L}\right) \psi_{z^{+}}}-\beta\left[\rho\left(1-\mathcal{F}^{i+1}\right) V_{z^{+}}^{i+1}+\left(1-\rho+\rho \mathcal{F}^{i+1}\right) U_{z^{+}}\right]}{\varsigma_{i} \frac{1-\tau^{y}}{1+\tau^{w}}}
$$

where a variable without time subscript denotes its steady state value. We now consider the upper bound, $\bar{w}_{t}^{i}$, which sets the surplus $J_{z^{+}, t}$ of an agency in cohort $i$ to zero, $\mathrm{i}=0, \ldots, \mathrm{N}$ 1. From (B.63)

$$
\begin{aligned}
0= & \sum_{j=0}^{N-1-i} \beta^{j} \frac{\psi_{z^{+}, t+j}}{\psi_{z^{+}, t}}\left[\left(\bar{w}_{t+j} \frac{\mathcal{E}_{t+j}^{j}}{1-\mathcal{F}_{t+j}^{j}}-G_{t, j} \bar{w}_{t}^{i}\right) \varsigma_{j, t+j}-\frac{\kappa}{\varphi}\left(\tilde{v}_{t+j}^{j}\right)^{\varphi}\right] \Omega_{t+j}^{j} \\
& +\beta^{N-i} \frac{\psi_{z^{+}, t+N-i}}{\psi_{z^{+}, t}} J_{z^{+}, t+N-i} \frac{\Omega_{t+N-i}^{N-i}}{1-\mathcal{F}_{t+N-i}^{0}}
\end{aligned}
$$

for $\mathrm{i}=0, \ldots ., \mathrm{N}-1$. In steady state:

$$
\begin{aligned}
0= & \sum_{j=0}^{N-1-i} \beta^{j}\left[\left(\bar{w} \frac{\mathcal{E}^{j}}{1-\mathcal{F}^{j}}-G_{j} \bar{w}^{i}\right) \varsigma_{j}-\frac{\kappa}{\varphi}\left(\tilde{v}^{j}\right)^{\varphi}\right] \Omega^{j} \\
& +\beta^{N-i} J_{z^{+}} \frac{\Omega^{N-i}}{1-\mathcal{F}^{0}} .
\end{aligned}
$$

For the dynamic economy, the additional unknowns are the $2 N$ variables composed of $\underline{w}_{t}^{i}$ and $\bar{w}_{t}^{i}$ for $\mathrm{i}=0,1, \ldots, \mathrm{N}-1$. We have an equal number of equations to solve for them. 


\section{B.5. Summary of equilibrium conditions for Employment Frictions in the Base- line Model}

This subsection summarizes the equations of the labor market that define the equilibrium and how they are integrated with the baseline model. The equations include the $N$ efficiency conditions that determines hours worked, (B.36); the law of motion of the workforce in each cohort, (4.9); the first order conditions associated with the vacancy decision, (B.40), (B.43), $j=0, \ldots, N-1$; the derivative of the employment agency surplus with respect to the wage rate, (B.65); scaled agency surplus, (B.63); the value function of a worker, $V_{z^{+}, t}^{i}$, (B.66); the derivative of the worker value function with respect to the wage rate, (B.68); the growth adjustment term, $G_{t, j}$ (B.42); the scaled value function for unemployed workers, (B.69); first order condition associated with the Nash bargaining problem, (B.62); the (suitably modified) resource constraint, (4.23); the equations that characterize the productivity cutoff for job separations, (B.55) and (B.59); the equations that characterize $\tilde{J}_{z^{+}, t}^{j}$ (B.61); the value of finding a job, (4.15); the job finding rate, (B.73); the probability of filling a vacancy, (B.74); the matching function, (4.16); the wage updating equation for cohorts that do not optimize, (B.37); the equation determining total employment, (B.71); the equation determining $\Omega_{t+j}^{j}$, (B.64); the equation determining the hiring rate, $\chi_{t}^{i}$ (4.8); the equation determining the number of matches (the matching function), (B.70); the definition of total effective hours (B.72); the equations defining $\mathcal{M}_{t}^{j}$, (B.67); the equations defining $\mathcal{F}_{t}^{j}$, (B.8); the equations defining $\mathcal{E}_{t}^{i}$, (B.7); the equations defining $\mathcal{G}_{t}^{j \prime}$ (B.53); the equations defining $\mathcal{F}_{t}^{j \prime}$ (B.51)

The following additional endogenous variables are added to the list of endogenous variables in the baseline model:

$$
\begin{aligned}
& l_{t}^{j}, \mathcal{E}_{t}^{j}, \mathcal{F}_{t}^{j}, \varsigma_{j, t}, \mathcal{M}_{t}^{j}, \bar{a}_{t}^{j}, \tilde{v}_{t}^{j}, G_{t, j}, Q_{t}, \Omega_{t+j}^{j}, J_{w, t}, w_{t}, J_{z^{+}, t}, V_{z^{+}, t}^{j}, U_{z^{+}, t}, V_{w, t}^{0}, \\
& V_{z^{+}, t}^{x}, f_{t}, m_{t}, v_{t}, \chi_{t}^{j}, \tilde{\pi}_{w, t}, L_{t}, \mathcal{G}_{t}^{j \prime}, \mathcal{F}_{t}^{j \prime} \text { and } \tilde{J}_{z^{+}, t}^{j}
\end{aligned}
$$

We drop the equations from the baseline model that determines wages, eq. (B.30), (B.31), (B.32),(B.28) and (2.48).

\section{B.6. Summary of equilibrium conditions of the Full Model}

In this subsection, we integrate financial frictions and labor market frictions together into what we call the full model.

The equations which describe the dynamic behavior of the model are those of the baseline model discussed in section 2.8 plus those discussed in the financial frictions model specified in section 3.2.1 plus those discussed in the employment friction model presented in section B.5. Finally, the resource constraint needs to be adjusted to include monitoring as well as recruitment costs. Similarly measured GDP is adjusted to exclude both monitoring costs and recruitment costs (and, as in the baseline model, capital utilization costs). 